\title{
The Evolution and Ecology of Hygrochastic Capsule Dehiscence
}

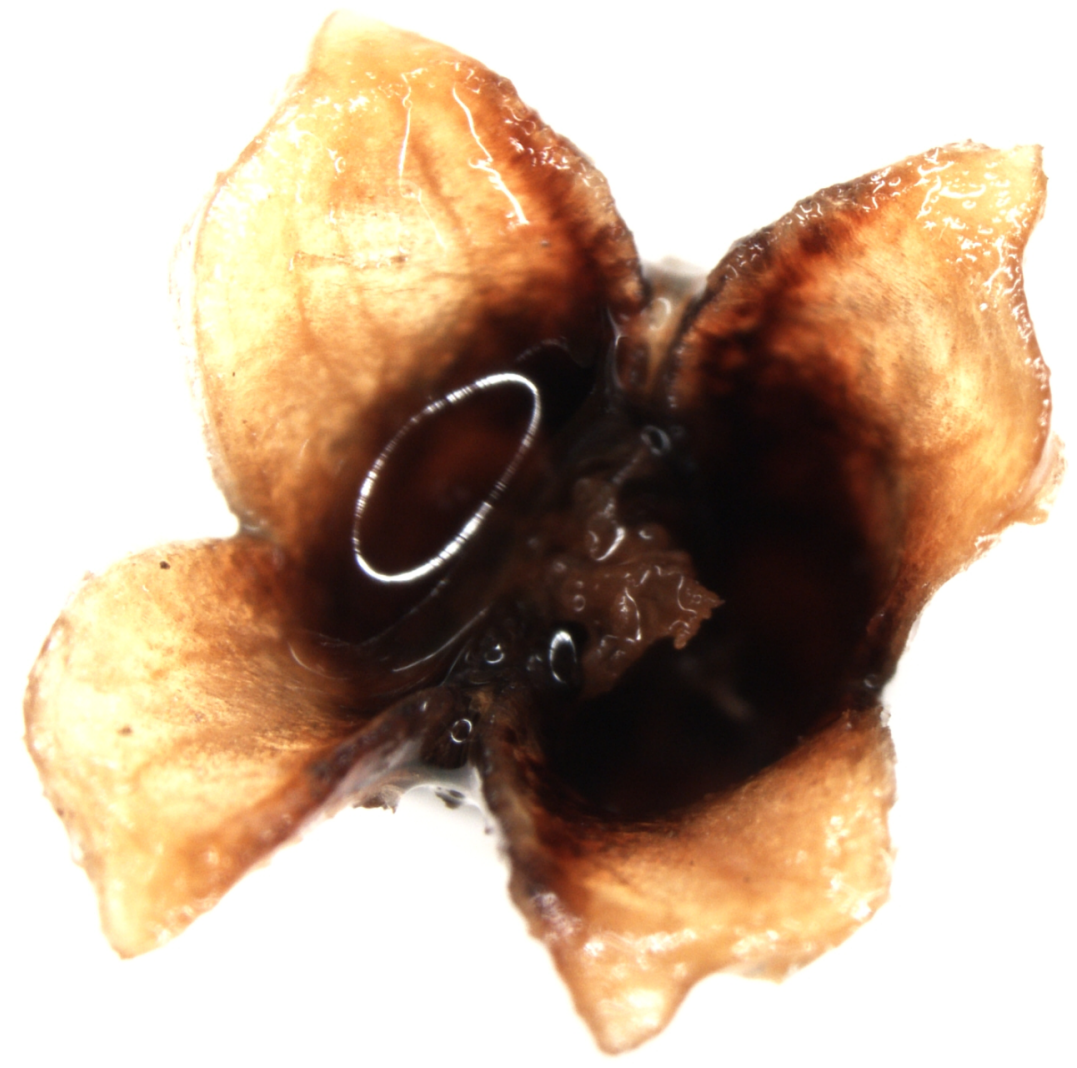

\section{Gesine Pufal}

A thesis submitted to Victoria University of Wellington in fulfilment of the requirements for the degree of Doctor of Philosophy in Ecology and Biodiversity

Victoria University of Wellington 2010 

This dissertation aims to explore hygrochasy in different genera of various habitats by investigating biomechanics, challenging accepted hypotheses and broadening the knowledge of the ecology and evolution of this dispersal mechanism. Hygrochasy, the dehiscence of capsules in response to moisture, is a specialized plant movement that facilitates primary dispersal by raindrops. This research enhances the understanding of this intriguing plant behaviour with a multidisciplinary approach outlined in the following paragraphs.

Hygrochastic New Zealand Veronica (Plantaginaceae) have been identified and investigated in regards to the anatomy and biomechanics of their opening mechanism and comparisons to related ripening dehiscent species have been drawn. Light microscopy has been used to analyse the capsule anatomy and function, while multivariate methods have been used to explore the data and associations with other characters. A swelling tissue in the septum, which absorbs water quickly and expands and a lignified resistance tissue have been found to cause the opening of hygrochastic capsules. This imbibition mechanism can be found in a number of hygrochastic genera in different habitats but the position of involved tissues due to capsule anatomy is unique for New Zealand Veronica. Morphological analysis revealed that hygrochasy in Veronica is most likely associated with solitary, erect, narrowly angustiseptate capsules on short peduncles of creeping subshrubs or cushions.

The hypothesis that hygrochasy in alpine Veronica is an adaptation to ensure short distance dispersal to safe sites is explored. Dispersal distances were measured in the field and in laboratory experiments and habitat patch size was measured for hygrochastic and related non-hygrochastic species. Habitat patches for alpine hygrochastic Veronica are small and distinctly different from surrounding habitat. They provide safe sites due to their microtopography and the presence of adult cushion plants. Hygrochastic capsules facilitate ombrohydrochory by raindrops, which is an antitelechoric strategy previously reported from desert plant species. For the first time directed short distance dispersal to safe sites could be demonstrated in alpine hygrochastic species. 
Additionally, environmental attributes for known locations of hygrochastic and related non-hygrochastic Veronica were obtained from LENZ IV in arcGIS. These have been used to identify the environmental amplitude for each species as well as variations in habitat. Non-hygrochastic species show a higher environmental amplitude and grow in a wider range and variety of habitats than hygrochastic species. Hygrochastic Veronica are specialists with a narrow ecological niche and are usually confined to small habitat patches in specific alpine habitats.

By combining both approaches I show that hygrochasy in alpine Veronica not only supports safe site strategies in seed dispersal but that hygrochastic Veronica are limited to special habitats requiring specific edaphic conditions. Short-distance dispersal also ensures the persistence of existing populations in these rare habitats.

Opening of some sessile New Zealand Colobanthus capsules during rain has been observed in the field and I carried out investigations regarding hygrochastic movements in this genus. Various staining and sectioning techniques for light microscopy have been carried out and scanning electron microscopy has been used to further analyse capsule anatomy. Statistical analysis similar to the investigation of Veronica capsules was employed. In contrast to other species with hygrochastic capsules, Colobanthus capsules are not lignified. Here, opening under wet conditions is a result of a combination of imbibition and cohesion mechanisms. Outer cells of the capsule have a thickened outer cell wall, which absorbs moisture, whereas the inner cells have thin cell walls and the cell lumen swells when water is absorbed. Interestingly, all Colobanthus species have the same capsule anatomy and are therefore capable of hygrochastic opening.

Earlier it was assumed that only Colobanthus species with sessile capsules might potentially be hygrochastic. In order to understand the relations between those species and other Colobanthus and to investigate whether this genus is monophyletic, I attempted to solve the phylogeny of this genus.

I used the nuclear marker ITS and the chloroplast markers rps16 and trnT-trnE to investigate the phylogeny with parsimony and Bayesian analyses. A number of outgroups in the family of Caryophyllaceae were used to test for monophyly of Colobanthus. Analyses of combined datasets show that the genus Colobanthus is monophyletic with Sagina as sister clade. Colobanthus forms a crown clade with no 
distinct differences between species. Results suggest a very recent speciation but further study with different markers or AFLPs is warranted, since the markers used in this study showed very little variation.

Hygrochasy has previously been reported and described to some extent in some North American Oenothera (Onagraceae) of subclade B, characterized by winged fruits. Here, I use the same methods employed by Poppendieck to extend the list of known hygrochastic Oenothera and I also describe xerochasy in one additional species. The position of the swelling tissue and resistance tissue is the same in all hygrochastic Oenothera, whereas the positions of these tissues are reversed in the xerochastic species. Hygrochastic movement was also observed in a ripening dehiscent species of subclade B, which is characterized by lanceoloid fruits. Here, hygrochasy occurs when the exocarp disintegrates and the endocarp expands after water absorption, similar to hygrochastic species of subclade B. However, due to the morphology of the capsule, the opening of the fruit does not resolve in a wide splash cup.

Hypotheses for hygrochastic capsules have mostly been developed for plants in arid regions. The most prevalent theories are that hygrochasy restricts dispersal in time by limiting dispersal events to rainfall events and therefore favourable germination conditions. Also, hygrochasy restricts seed dispersal to short distances, which increases the survival chance of seeds in the very local parental habitat, rather than surrounding harsh environments. However, hygrochasy occurs in a wide range of unrelated genera in a variety of habitats. Here, I investigate whether the widely accepted hypotheses for arid species also apply to hygrochastic Oenothera in North America.

Dispersal experiments, cluster analysis of morphological traits and the analysis of environmental and distribution data were used in this study and compared with similar data for hygrochastic Veronica in New Zealand and hygrochastic Aizoaceae in Southern Africa. Character evolution was also investigated using the latest published phylogenies of Oenothera and Veronica.

Results indicate that none of the hypotheses for hygrochasy applies to current day Oenothera. However, it appears that hygrochasy evolved only once in this genus and previous research implies that Oenothera have evolved as part of the Madro-Tertiary flora in the mid- to late Miocene. The Madro-Tertiary flora evolved in a dry, highly 
seasonal climate. Possessing hygrochastic capsules would be advantageous to restrict dispersal to rare rainfall events in the wet seasons.

It therefore appears that at least the temporal restriction hypothesis applies to Oenothera at the time of their evolution. Other, unknown factors might play a role in the persistence of this character. 


\section{ACKNOWLEDGEMENTS}

I would like to express my deepest gratitude to my supervisors Prof. Phil GarnockJones and Dr. Ken Ryan. Without their support and generosity this work would not have been possible. Phil, thank you forgetting me interested in my topic and for believing in me - without you I would have never come to Victoria University. And through your meticulous correction of endless drafts you might have finally taught me the difference between 'was' and 'has been'! Ken, without you the path to microscopy would have been a lot rockier!

I am very thankful for the financial support of the following organizations: New Zealand International Doctoral Research Scholarship, Faculty of Science and Victoria University, School of Biological Sciences at Victoria University, Wellington Botanical Society, Ecological Society of Australia, New Zealand Ecological Society, Royal Society of New Zealand (Hutton Fund). Their contribution had a major part in the success of my numerous fieldtrips and my labwork and also allowed me to present my work at a number of international conferences.

The Department of Conservation granted me the permits to collect samples in the field and I am very grateful for their support. I also conducted fieldwork on privately run ski fields, which graciously allowed me access to their land: Remarkables Skifield, Mount Dobson Skifield, Waiorau Snow Farm and Rainbow Skifield.

Fieldwork would also not have been possible without the help from my field assistants, who bravely conquered mountains with me across the South Island. Many thanks go to Monica Awasthy, Monique Crawford, Juliane Falke, Jessie Prebble and Katrin Schult. My parents also managed to get themselves 'employed' as field assistants during their short visit here and it still confuses reviewers, when I thank E. and G. Pufal for their help! 
Some of my work was only possible with the help of people here at Victoria University, Te Papa and overseas. I sincerely thank Kyra Krakos for not only supplying me with information about Oenothera, but also providing me with samples, which have been extremely important for my work. Pia Parolin gave me access to her raw data from one of her papers and I really appreciate this. Martin Timana originally planned to work on a phylogeny of Colobanthus but sadly never got the chance to do it. By giving me his manuscripts and also helping a lot with the organization of my South American fieldtrip, he gave me the opportunity to study this genus and I greatly appreciate his help. Carlos Lehnebach has been a good friend and a great help when it comes to statistics, especially of the multivariate kind! Jessie Prebble and Mei Lin Tay made sure I actually understood what I was doing in the lab and at the computer and were generally great helps with all things phylogenetic. Heidi Meudt was extremely helpful answering questions about molecular work and kindly read my draft on the phylogeny of Colobanthus. Her comments made a big difference for this chapter.

David Flynn and Richard Tilley from the physics lab allowed me to use their facilities and especially David was extremely helpful with all those microscopy problems.

Thanks to Barry Sneddon, who provided me with a number of samples for Colobanthus, helped me to identify plants and deal with all herbarium related issues. Stephen Hartley and KC Burns have been great in helping me figuring out methodology and statistics. Pete Ritchie is thanked for including me in his labgroup and giving me the opportunity to study phylogenetics. A great thank you goes to Lesley Millicich, who was great in all questions concerning the greenhouse and the odd chemical for staining plant tissue. Lastly, the plant club and TVG were great platforms to discuss ideas, practice talks and seek help with complicated stats - thank you all!

I am very thankful to the warm welcome that I received at SBS, which made it a great and relaxed place to study. The biggest thank you goes to Mary, Sandra and Patricia the women at the front line! 
I really appreciate the help of the Allan Herbarium at Landcare Research and the Herbarium at the Instituto Argentino de Investigaciones de las Zonas Áridas in Mendoza, Argentina, which provided plant samples that played a very important part in my research. The Allen Herbarium, the Auckland Herbarium and the herbarium at Te Papa also gave me access to their plant databases, for which I am extremely grateful.

A big thank-you goes to my friends in New Zealand who made my stay here that much more enjoyable and worthwhile. Thank you Monica, for getting me into birds, knitting and those nightly outings for "just one drink"! Elizabeth, Ilse, Jamie, Roz, Beaux, Barnaby, the Dixson family, Mairead, Jo, Roan, Peter, Mark, Jay, Mairead, Lisa, Bionda, Heidy, Kristina and everyone else, who's name I forgot to mention - I am glad I have met you at this end of the world and you provided all those wonderful distractions, when work was just a little bit too stressful! A big shout-out goes to Wellington Batucada, who were welcoming me from the beginning and are responsible for some of my highlights in Wellington.

I am extremely grateful to the Beverley clan who really made me feel like part of the family. Suzie, Simon and Dash, you have been the best flatmates I could ever wish for and the whole family has been great in welcoming me and making me feel like home.

My deepest gratitude goes to my friends at home, who had to put up with absence for such a long time but still kept in touch: Anne and Markus, Anke and Jana, you have been great friends and will always be, Wiebke, Netti and Erbse, who even made it all the way across the world to check on me (and New Zealand). My godson Matti, who was the best reason to keep visiting home - after all, it's a bit hard for him to get on a train to visit me!

My love goes to my family: my parents who have never questioned my decision to move across the world to pursue my dream and have always supported me. Nadine and Sabine, who are awesome sisters and cheer me up when I need it most. My grandparents, who to this day don't understand what I am doing but are still extremely proud of me. 


\section{TABLE OF CONTENTS}

Abstract _II

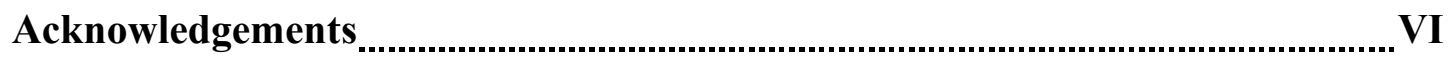

Table of Contents

Table of Figures

XIII

Glossary

Chapter One:General Introduction

1.1 Abstract $\quad 1$

1.2 Plant dispersal and evolution of dispersal strategies _ 2

1.2.1 DisPERSAL STRUCTURES _...................................... 3

1.2.2 DisPeRsal AGENTS AND CLASSES _...................... 4

1.2.3 DisPersal STRATEGIES $\quad 7$

1.3 Ombrohydrochory and splash cup dispersal _................. 10

1.4 Hygrochasy, hygrochastic capsule dehiscence and examples $\ldots$

1.5 Potential hygrochastic genera in New Zealand and North America 15

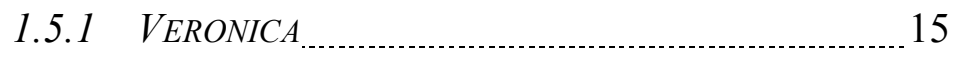

1.5.2 COLOBANTHUS _............................................... 17

1.5.3 OENOTHERA 19

1.6 The New Zealand alpine region _................................. 21

1.6.1 HISTORY _.................................................. 21

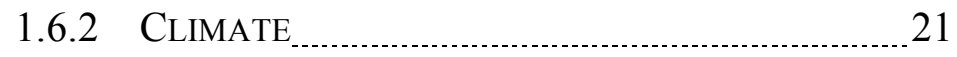

1.6.3 ALPINE ZONES _............................................... 22

1.7 Key questions, thesis outline and style $\quad 23$

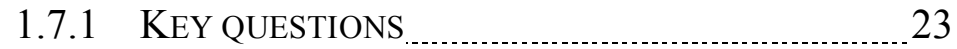

1.7.2 THESIS OUTLINE AND STYLE _........................... 24

1.8 References 26

Chapter Two: Hygrochastic Capsule Dehiscence in New Zealand Alpine Veronica (Plantaginaceae)

2.1 Abstract $\quad 33$ 
$2.2 \quad$ Introduction 34

2.3 Materials and methods 39

2.4 Results 43

2.5 Discussion $\ldots$

$2.6 \quad$ References 58

Chapter Three: $\quad$ The Influence of Hygrochastic Capsule Dehiscence on Seed Dispersal and Species Distribution of New Zealand Alpine Veronica (Plantaginaceae)

3.1 Overview 62

3.2 Hygrochastic Capsule Dehiscence supports

Safe Site Strategies in New Zealand Alpine

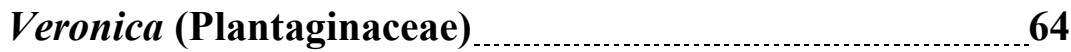

3.2.1 ABSTRACT 64

3.2.2 INTRODUCTION _............................................. 65

3.2.3 MATERIALS AND METHODS _............................ 69

3.2.4 RESULTS 74

3.2.5 DISCUSSION

3.2.6 REFERENCES _.............................................. 85

3.3 Do Hygrochastic Veronica inhabit Restricted Ecological

Niches? 88

3.3.1 ABSTRACT 88

3.3.2 INTRODUCTION

3.3.3 MATERIALS AND METHODS _........................ 93

3.3.4 RESULTS

3.3.5 DisCUSSION ................................................. 104

3.3.6 REFERENCES _..................................... 107

3.4 Summary and Conclusion 110

Chapter Four: $\quad$ An Investigation of Hygrochasy and Species Relationships in Colobanthus (Caryophyllaceae)

4.1 Overview 112

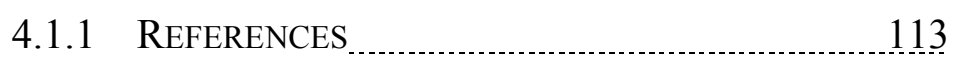

4.2 Hygrochastic Movement in Capsules of the Southern

Hemisphere Genus Colobanthus (Caryophyllaceae)_........114

4.2.1 ABSTRACT 114 
4.2.2 INTRODUCTION

4.2.3 MATERIALS AND METHODS .............................. 118

4.2.4 RESULTS 121

4.2.5 DiSCUSSION

4.2.6 REFERENCES 132

4.3 A Molecular Approach to the Phylogeny of the Southern Hemisphere Genus Colobanthus (Caryophyllaceae) ..........134

4.3.1 ABSTRACT 134

4.3.2 INTRODUCTION _........................................... 135

4.3.3 MATERIALS AND METHODS _........................... 139

4.3.4 RESULTS 150

4.3.5 DISCUSSION _............................................ 163

4.3.6 REFERENCES 168

4.4 Summary

Chapter Five: $\quad$ Capsule Dehiscence Types in Oenothera (Onagraceae)

5.1 Abstract 176

5.2 Introduction 177

5.3 Materials and methods 179

5.4 Results 180

5.4.1 OENOTHERA LINIFOLIA

(SECT. PENIOPHYLLUM) 181

5.4.2 OENOTHERA PERENNIS (SECT. KNEIFFIA) _........ 183

5.4.3 OENOTHERA SPECIOSA (SECT. HARTMANNIA) _.. 184

5.4.4 OENOTHERA FRUTICOSA (SECT. KNEIFFIA) 186

5.4.5 OENOTHERA PALLIDA (SECT. ANOGRA) _............ 187

5.4.6 OENOTHERA HOWARDII

(SECT. MEGAPTERIUM) 189

5.5 Discussion 191

5.6 References 193

Chapter Six: $\quad$ Are Hypotheses for Hygrochasy in Plants of Arid Regions also applicable for Unrelated Genera in Different Habitats?

6.1 Abstract 197

6.2 Introduction 198

6.3 Materials and methods $\quad 204$ 
6.3.1 DISPERSAL AND SEED RETENTION _.................. 204

6.3.2 PLANT MORPHOLOGY 206

6.3.3 HABITAT QUALITY, CLIMATE CONDITIONS AND SPECIES DISTRIBUTION _.................................... 207

6.3.4 SYSTEMATICS AND CHARACTER EVOLUTION 208

$6.4 \quad$ Results $\quad 210$

6.4.1 DISPERSAL AND SEED RETENTION _.................. 210

6.4.2 PLANT MORPHOLOGY 212

6.4.3 HABITAT QUALITY, CLIMATE CONDITIONS AND SPECIES DISTRIBUTION _................................ 214

6.4.4 SYSTEMATICS AND CHARACTER EVOLUTION 217

6.5 Discussion 221

6.5.1 DISPERSAL AND SEED RETENTION _ 221

6.5.2 PLANT MORPHOLOGY _.................................... 222

6.5.3 HABITAT QUALITY AND SPECIES DISTRIBUTION 224

6.5.4 SYSTEMATICS AND CHARACTER EVOLUTION _...225

6.6 Conclusion 228

6.7 References 229

Chapter Seven: $\quad$ Summary and Conclusion

7.1 Summary of key findings 233

7.2 Conclusion and future directions $\quad 237$

7.3 References 240

Appendix 241 


\section{TABLE OF FIGURES}

FIG. 1.1 Ecological dispersal classes based on dispersal agents adapted from Van der Pijl (1982), Van Oudtshoorn and Van Rooyen (1999) and Parolin (2006).

FIG 1.2 Dispersal strategies and associated dispersal classes adapted from Gutterman (1994), Van der Pijl (1982) and Poppendieck (1995).

FIG 2.1 Dry (A) and wet (B) capsule of Veronica densifolia.

FIG 2.3 Septum of Veronica densifolia (hygrochastic) and Veronica lanceolata (ripening dehiscent).

FIG 2.4 Scores for cell measurements of all species on the first two PCA axes.

FIG 2.5 Box-whisker plots of (A) Length of cells in the swelling tissue (STL), (B) width of cells in the swelling tissue (STW), (C) change of length of the swelling tissue after water absorption.

FIG 2.6 Hierarchical cluster analysis of Euclidean distances in a dissimilarity matrix of character states of 23 Veronica species.

FIG 3.1 Habitat patch with Veronica densifolia and $V$. thomsonii at Blue Lake, Garvie Mountains, New Zealand. 
FIG 3.2.2 Boxplots of dispersal distances for 5 hygrochastic Veronica and results for Mann-Whitney-U tests between species.

FIG 3.2.3 Histogram of the frequency distribution (A) and line graph of the density distribution (B) of seeds of $V$. densifolia, $V$. spathulata and $V$. thomsonii.

FIG 3.2.4 The seed shadow of $V$. densifolia in situ (A) and in vivo (B) and of $V$. thomsonii (C).

FIG 3.2.5 Habitat patch occupied by $V$. pulvinaris and $V$. cheesemanii on Mole Tops, Nelson Lakes National Park.

FIG 3.3.1 Coefficient of variation in five environmental variables of hygrochastic Veronica (blue) and non-hygrochastic Veronica (black) shown as box and whisker plots

FIG 3.3.2 Potentially suitable habitat for V. lyallii (grey) and $V$. thomsonii (black) and locations of $V$. thomsonii (yellow circles) and $V$. lyallii (red triangles) used in the analysis.

FIG 4.1 Wet open Colobanthus apetalus capsules at Blue Lake, Garvie Mountains.

FIG 4.2.1 Dry (A) and wet (B) capsules of Colobanthus strictus.

FIG 4.2.2 Principal Component Analysis of measurements in Colobanthus capsules.

FIG 4.2.3 Hierarchical Cluster Analysis of character states for nine Colobanthus species. 
FIG 4.2.4 SEM micrographs of Colobanthus capsules

FIG 4.2.5 SEM micrographs of Colobanthus capsules, continued.

FIG 4.3.1 $50 \%$ consensus tree of the ITS dataset of

Colobanthus sequences.

FIG 4.3.2 Splits graph network illustrating relationships among ITS sequences of Colobanthus.

FIG 4.3.3 $50 \%$ consensus tree of the combined chloroplast dataset of Colobanthus sequences.

FIG 4.3.4 Splits graph network illustrating relationships among chloroplast sequences of Colobanthus.

FIG 4.3.5 $50 \%$ consensus tree of the combined dataset (ITS, rps 16, trnT-E) of Colobanthus sequences.

FIG 4.3.6 Splits graph network illustrating relationships among the combined nuclear and chloroplast sequences of Colobanthus.

FIG 5.1 Micrograph of cross section through an Oneothera speciosa capsule.

FIG 5.2 Dry (A) and wet (B) capsule of $O$. linifolia.

FIG 5.3 micrographs cross-sections of Oenothera capsules, stained with Toluidine Blue.

FIG 5.4 Dry capsule (A) of Oenothera perennis and same capsule after wetting (B) exposing seeds and placental column. 
FIG 5.5 Dry capsule (A) of Oenothera speciosa and same capsule after wetting (B).

FIG 5.6 Dry capsule (A) of Oenothera fruticosa and same capsule after wetting (B)

FIG 5.7 Unripe, dry capsule (A) of Oenothera pallida with splits between valves visible and same capsule after wetting (B)

FIG 5.8 Micrographs of O. macrocarpa (A) and O. howardii (B) stained with Toluidine Blue.

FIG 6.1 Worldwide distribution of hygrochastic Veronica, Oenothera and Aizoaceae.

FIG 6.2 Dispersal distances of hygrochastic species.

FIG 6.3 Ward's cluster analysis of morphological characters in hygrochastic species.

FIG 6.4 Ward's hierarchical cluster analysis of precipitation, distribution and altitude in hygrochastic species.

FIG 6.5 Capsule dehiscence traced on an updated strict consensus tree of combined ITS, trnL-trnF and rps16 data, reproduced from Wagner et al. (2007).

FIG 6.6 Capsule dehiscence traced on a combined phylogeny (ITS and cpDNA) of Veronica sect. Hebe, reproduced from Albach and Meudt (2010). 


\section{GLOSSARY}

Definitions are adapted from Van der Pijl (1982) and Van Oudtshoorn and Van Rooyen (1999).

Amphicarpy : $\quad$ burying of a number of diaspores near the mother plant

Anemochory : dispersal by wind

Antitelechory : $\quad$ avoidance of long-distance dispersal by initial placement of diaspores or morphological characteristics

Atelechory : diaspores lack morphological characteristics promoting longdistance dispersal

Autochory: dispersal of diaspores by the plant itself

Basicarpy: formation of fruits immediately above ground level

Barochory: dispersal of the diaspore by weight alone

Baryspermy: $\quad$ same as barochory

Bradyspory: dispersal of diaspores from parent plant is delayed and spread over a significant time.

Bythisochory: diaspores are transported by water currents on the bottom of the water body, also includes non-floating seeds

Carpospermy: monospermy (one-seededness) without dispersal

Chiropterochory: dispersal by bats

Cohesion tissue: plant tissue capable of absorbing water in the lumen of its cells

Dehiscence: the splitting open along predetermined lines

Diaspore: the plant part to be dispersed

Diplochory: $\quad$ diaspores being dispersed by two different agents

Dissemination: discharge or liberation of seeds

Dysozoochory: $\quad$ process, whereby diaspores are destroyed (e.g. eaten), but some of the diaspores are dropped by accident and are therefore dispersed

Endocarp: $\quad$ the innermost layer of the pericarp of an angiosperm fruit

Endozoochory: dispersal of diaspores inside an animal

Epizoochory: diaspores carried accidentally outside the animal

Exocarp: the outermost layer of the pericarp of an angiosperm fruit 
Geocarpy:

Heterocarpy:

Heterodiaspory:

Hydroballochory:

Hydrochory:

Hygrochasy:

Ichthyochory:

Mammaliochory:

Mesocarp:

Mucilage:

Myrmecochory:

Myxospermy:

Nautohydrochory:

Ornithochory:

Ombrohydrochory:

Passive ballist:

Pericarp:

Polychory:

Rain-ballist:

Saurochory:

Stomatochory:

Synaptospermy:

Syncarpous:

Synzoochory: production of diaspores beneath the soil surface

production of two or more morphologically distinct diaspores by an individual plant

same as heterocarpy

rain ballism as dispersal mechanism (using the kinetic energy of the falling rain drops)

dispersal of diaspores by water

opening of the capsule in response to moisture and closing when drying out

dispersal of diaspores by fish

dispersal of diaspores by mammals

middle layer of the pericarp of an angiosperm fruit substance that swells in water to form slimy/sticky solution dispersal of diaspores by ants an anchorage mechanism, where mucilage is produced after wetting

diaspores capable of floating are dispersed by water currents on the water surface

dispersal of diaspores by birds

dispersal of diaspores by rain

action of an outside agent releases internal tension within dead tissue in the fruit and provides the energy for the action, propelling out the seeds

wall of a fruit, derived from the maturing ovary wall diaspores are dispersed by more than two agents plant in which falling raindrops provide energy to activate a lever mechanism by which diaspores are ejected from their conatiner

dispersal of diaspores by reptiles transport of diaspores in the mouth, diaspores are not swallowed keeping or bringing together many seeds until germination developed from an ovary with two or more carpels deliberate transport of diaspores externally by an animal 
Tachyspory: diaspores are released immediately after maturation

Telechory: long-distance dispersal of diaspores

Trypanocarpy: form of diaspore or its appendages favour burial in the soil upon contact

Trypanospermy: same as trypanocarpy

Vivipary: the germination of seeds within the fruit prior to abscission from the maternal plant

Xerochasy: $\quad$ opening of fruits in response to dry conditions and infolding when wet

Zoochory: $\quad$ dispersal of diaspores by animals 


\section{CHAPTER ONE}

\section{General Introduction}

\subsection{Abstract}

Plants are not able to move in the sense that most animals can. Often, their only means of establishing populations and colonizing new habitats is seed and spore dispersal, which together with pollination play important roles in gene flow. The variety of different dispersal strategies is astonishing. Some diaspores lack special adaptations and are moved in random dispersal events by various agents. Other dispersal units show adaptations, for example seeds with appendages to be carried by wind, fleshy fruits attracting specific animals to eat them and disperse the seeds and diaspores that are able to float and be transported by water. Plants also show adaptations that react to a specific cue or trigger and only then disperse their seeds, which usually restricts dispersal to a specific dispersal agent. One of these specific plant responses to a trigger is hygrochasy, the opening of a fruit in response to moisture. When rainfall occurs, hygrochastic capsules open, exposing seeds in a splash cup from where raindrops are able to splash the seeds out and disperse them over short distances.

Hygrochasy has mostly been reported for plants growing in arid habitats, where it ensures that seeds are dispersed only during favourable germination conditions. Until dispersal, seeds are protected within the capsule against extreme climatic conditions and seed predators. In recent decades, hygrochasy has been discovered in various taxa and different habitats, raising the question why this specific mechanism has evolved 
in various unrelated species and what advantages it poses in diverse environmental conditions. This work takes the opportunity to explore that question and to also investigate hygrochasy in detail in several plant groups.

This first chapter reviews different dispersal strategies in more detail, paying special attention to dispersal by water. The basic principles of hygrochasy are explained and taxa used in this study are introduced. The research hypothesis and related questions are presented, which will be addressed in the data chapters.

\subsection{Plant dispersal and evolution of dispersal strategies}

Plant dispersal is concerned with the ways and means used to reach sites where a new generation can establish (Van der Pijl, 1982). It is the key biological process responsible for the distribution of species in the world, may explain their presence and absence in different localities, changes the flora at different periods, and it is also a vital factor in the evolution of species, promoting gene flow in and between populations (Ridley, 1930; Van der Pij1, 1982; Webb, 1998). It also helps escape from specialist predators and pathogens supported by the parent, and prevents competition between parents and offspring (Fenner and Thompson, 2005), although some pathogens are seed-borne and rely on the host's seeding for their own dispersal (Gopalakrishnan and Valluvaparidasan, 2009; Sharma and Gour, 2009; Afzal et al., 2010). Plant dispersal is usually achieved by either spores, seeds, fruits or the entire plant, which leads to generative, recombinative dispersal (Van der Pijl, 1982). The next section takes a closer look at dispersal units, which can be immensely complex and variable, whereas the following sections give a brief overview of dispersal agents, classes and strategies and introduce the genera and habitats investigated in this study. 


\section{CHAPTER ONE}

\subsubsection{DISPERSAL STRUCTURES}

The dispersal unit or dispersal organ is referred to as diaspore (Sernander, 1927), which can be everything from spores or single seeds to the entire plant (e.g. tumbleweeds (Mehlman, 1993)). Here, I will pay special attention to the dispersal of seeds and fruits in Angiosperms. Fruit systems can be classified based on morphology (Levina, 1961; Van der Pijl, 1982), which includes literally hundreds of terms to describe fruits and is not always appropriate. Here, I will follow Bell (1991). Unlike the common belief, a fruit is not always edible, it is rather a term that is applied to a seed bearing structure. Simple fruits can either develop from single flowers, then representing either the single carpel (e.g. hazelnut) or a single compound ovary (e.g. melon - syncarpous fruit). Aggregate fruits can derive from one apocarpous flower, in which the carpels are not united (e.g. raspberry). Sometimes structures other than the gynoecium are involved in fruit formation, such as the receptacle, hypanthium or perianth members. Both Bell (1991) and Van der Pijl (1982) distinguish between fleshy, dry, dehiscent and indehiscent fruits; those classifications are largely based on morphology and dispersal type. For more information on different fruit types, see Bell (1991).

The fruit wall is the pericarp, which is made up of exo- or epicarp (outer layer), mesocarp and endocarp (inner layer) and is derived from the ovary wall. Depending on the type of fruit (e.g. drupe, berry or nut), either epicarp, mesocarp or endocarp can be changed dramatically. For example, in the peach, the skin of the fruit is the epicarp, the flesh the mesocarp and the stone the endocarp. Inside the stone the thin brown layer is the testa surrounding the embryo (Bell, 1991). 


\section{CHAPTER ONE}

\subsubsection{DisPERSAL AGENTS AND CLASSES}

The transport of the diaspore from the parent plant to a new location can happen via numerous agents, e.g. animals (zoochory) including birds (ornithochory), mammals (mammalochory) or reptiles (saurochory). Abiotic dispersal agents include wind (anemochory) and water (hydrochory) (Van der Pijl, 1982). A comprehensive overview is given in Fig. 1.1, but this list is by no means complete. Almost every category of dispersal class can be specified further and more often than not diaspores can be transported by more than one agent (polychory).

There is evidence that most zoochorous diaspores and their dispersal agents coevolved (Stapanian and Smith, 1978; Janzen, 1980; Stiles, 1980; Herrera and Jordano, 1981; Tombac, 1982; Wheelwright and Orians, 1982; Janzen, 1983; Rogers and Applegate, 1983; Howe and Westley, 1986; Midgley and Bond, 1991; Dean and Milton, 2003; Gove et al., 2007; Siepielski and Benkman, 2007; Lomascolo and Schaefer, 2010). Fruits with a bird-syndrome usually possess an attractive edible part with signalling colours, outer protection against premature eating, and inner protection of the seed against digestion (Oppel and Mack, 2010; Rumeu et al., 2009; Lomascolo and Schaefer, 2010) but some birds prove to be effective dispersers by caching seeds (Pons and Pausas, 2007). Frugivorous bats respond to exposed fruits that have a rancid odour and easily digestible juice (chiropterochory) (Van der Pijl, 1982). Anemochorous diaspores are usually structures where the surface area to weight ratio is greatly increased. Examples are dust-like seeds, light enough to be carried by wind and balloon fruits, winged or plumed diaspores (Van der Pijl, 1982). Despite various examples of specialisations there are numerous generalists among plant diaspores, which are not adapted to a specific transport agent. Wind and water dispersed species belong to that group as well as plants whose diaspores are dispersed 


\section{CHAPTER ONE}

externally, such as trample burrs and diaspores with other adhesive features (Van der Pijl, 1982). There are numerous examples of diaspores and their dispersal agents, some of which are astonishing. However, since it is such a wide field to cover I refer to the cited literature and textbooks for more in depth information. 
CHAPTER ONE

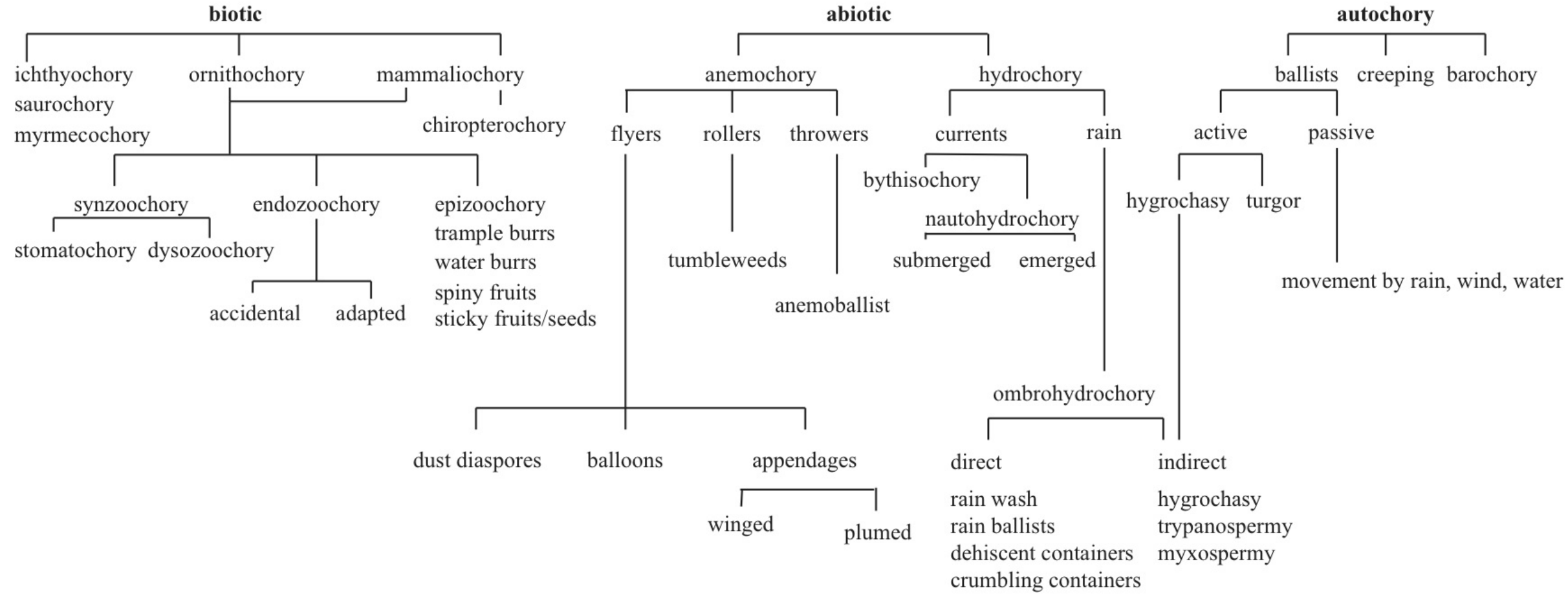

FIG. 1.1 Ecological dispersal classes based on dispersal agents adapted from Van der Pijl (1982), Van Oudtshoorn and Van Rooyen (1999) and Parolin (2006). See Glossary for definitions of dispersal classes. 


\section{CHAPTER ONE}

\subsubsection{DiSPERSAL STRATEGIES}

Long-distance dispersal (telechory) has been essential for colonizing habitats and distributing plant species, which has already been recognized by Darwin (1859). However, for a long time the importance of long-distance dispersal has been rarely studied, partly due to the fact that observing and documenting it is almost impossible (Cain et al., 2000). Cain et al. (2000) define long-distance as being over $100 \mathrm{~m}$, and it is stated that most seeds do not travel further than a few metres (Harper, 1977; Howe and Smallwood, 1982; Willson, 1993; Cain et al., 1998; Cheplick, 1998). However, those short distances cannot account for the re-colonization of areas following the retreat of glaciers or the colonization of remote islands (Cain et al., 2000). Longdistance dispersal can occur in various ways, which have been described by Darwin (1859), Van der Pijl (1982), Janzen (1984) and others in great detail. Well recorded are also extraordinary long-range dispersal events, such as the colonization of Krakatau (Ernst, 1934; Docters van Leeuwen, 1936), the dispersal of the coconut Cocos nucifera (Van der Pijl, 1982) and increasingly prevalent conclusion that the New Zealand flora is largely long distance dispersed (Raven, 1973; Pole, 1994; Macphail, 1997; Jordan, 2001; Sanmartin et al., 2007).

As important as long-distance dispersal is for most plant species, avoidance of dispersal (atelechory) also plays a significant role in deserts and semi-deserts (Ellner and Shmida, 1981; Van der Pij1, 1982; Gutterman, 1994; Fenner and Thompson, 2005). Especially for species with very specific ecological conditions or the mother plant being in a favourable niche surrounded by hostile conditions like arid zones or islands, long distance dispersal is rather disadvantageous (Fahn and Werker, 1972). Bolker \& Pacala (1999) developed models that suggested local dispersal of the 
majority of diaspores, which can retain the benefits of the parent's environment, combined with long-distance dispersal of a few diaspores as a successful strategy.

Gutterman (1994) describes the protection strategy of a large number of desert plant species, where ombrohydrochory is the main dispersal mechanism and the seeds are protected against seed predators until a rainfall event that facilitates dispersal and quick germination thereafter. Another suggested reason for atelechory is the limitation of suitable germination sites, which plays an important role in extreme habitats such as deserts (Ellner and Shmida, 1981), mangrove forests (Lee and Harmer, 1980; Elmquist and Cox, 1996) or alpine and arctic environments (Scherff et al., 1994; Elmquist and Cox, 1996). Here, the dispersal is limited to the already occupied (therefore suitable) site (Van der Pijl, 1982). There are different mechanisms that lead to atelechory, e.g. synaptospermy, hygrochasy, basicarpy and vivipary (Zohary, 1962) (see glossary for definition of terms).

A plant species might not be restricted to one dispersal agent alone. Sometimes two or more mechanisms are combined, which often happens incidentally (Van der Pijl, 1982). Diplochory or polychory has the advantage of possessing two aspects, which are important for the plant survival. One might be vital for the dispersal of the species, whereas the second agent may play an important role in the establishment of the seedling in a suitable habitat. Examples are the genera Avena, Erodium, and Stipa. Their diaspores are dispersed by wind but when they land in suitable habitats (loose soil), their hygroscopic boring action by alternation of wetting and drying fixes the seed in the soil (Zohary, 1937). Other, rather accidental polychorous events might occur when seeds that have been dispersed by wind are transported further by rainwash (Van der Pijl, 1982) or other anemochorous seeds might be carried underground 
by ants and germinate there (Ridley, 1930). An overview of dispersal strategies combined with dispersal classes is given in Fig. 1.2.

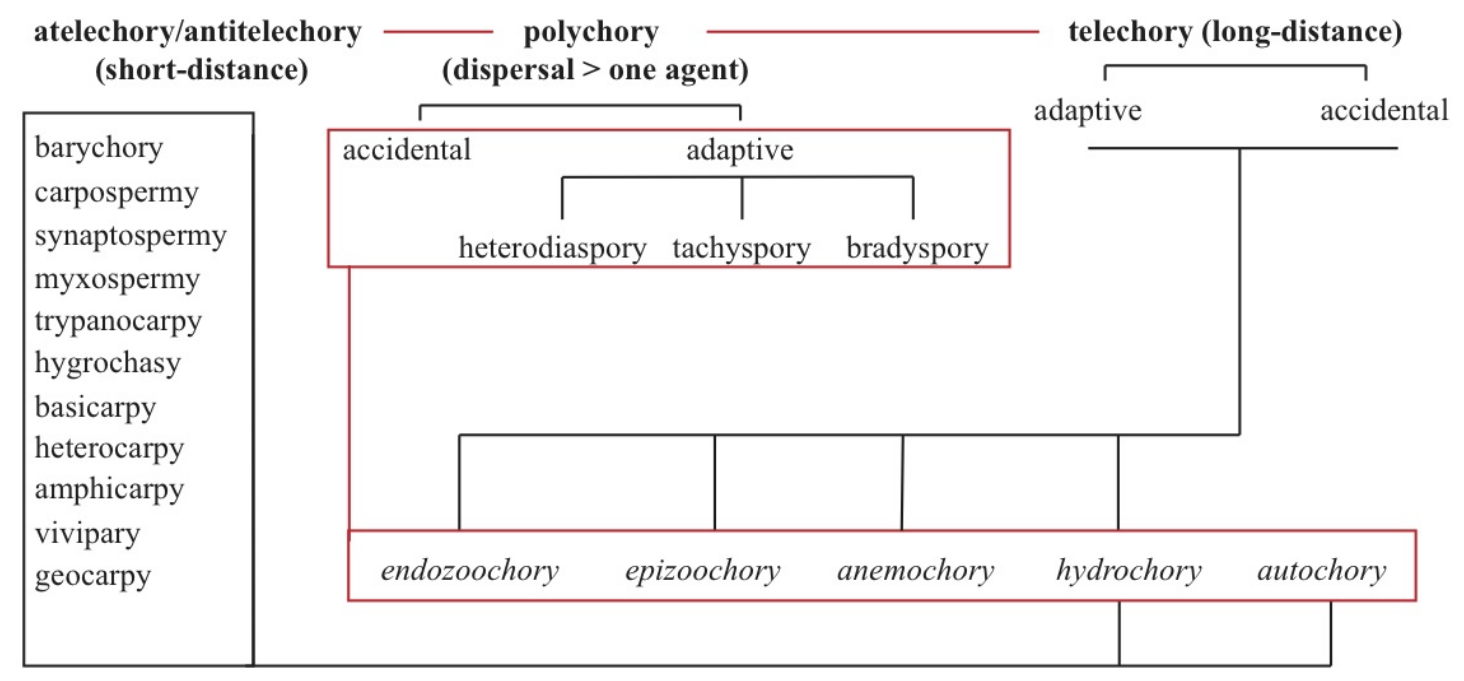

FIG 1.2 Dispersal strategies (BOLD) and associated dispersal classes (italic) adapted from Gutterman (1994), Van der Pijl (1982) and Poppendieck (1995). See the Glossary for definition of dispersal strategies and classes. The red lines indicated that every dispersal class and strategy can be part of polychory.

Dispersal is not only concerned with the transport of the diaspore to a suitable habitat; it is a process that is firstly prepared by the detachment or dehiscence of the diaspore, allowing travel by providing structural and physiological protective devices. Travel is then followed by settlement and germination (Van der Pij1, 1982). Often, the means of detachment and the dispersal strategy are closely linked, such as passive ballists dispersed by passing animals (Van der Pijl, 1982) or hygrochasy and ombrohydrochory (Van der Pijl, 1982; Gutterman, 1994). 


\section{CHAPTER ONE}

\subsection{Ombrohydrochory and splash cup dispersal}

Dispersal by water can be split into three categories: ombrohydrochory, nautohydrochory (or nautochory), and bythisochory. Both latter dispersal modes have water currents as transport agents, but nautohydrochory refers to diaspores capable of floating on the water surface, whereas bythisochory describes transport of diaspores on the bottom of the water body (Mueller-Schneider, 1983; Bonn and Poschlod, 1998).

Bythisochory and nautohydrochory lead to long-distance dispersal along waterways, often playing a role as secondary dispersal mechanism (dichory or polychory). Van der Pijl (1982) also includes ombrohydrochory as part of di- or polychory, combined with dispersal strategies such as anemochory or autochory, whereas Parolin (2006) states that ombrohydrochory is only part of dichory when it is paired with nautochory, as is the case in Caltha (Bonn and Poschlod, 1998). Ombrohydrochory (dispersal by water drops, which can activate a ballistic mechanism in the plant) can be split into further categories, where the diaspore could either be washed away from the mother plant (rain wash) or be dispersed by ballistic forces, when raindrops propel seeds out of the fruit (Brodie, 1951, 1955; Parolin, 2006).

As stated before, ombrohydrochory is considered to promote atelechory by restricting seed transport to raindrops as dispersal agents (Zohary and Fahn, 1941; Fahn and Werker, 1972; Van der Pijl, 1982; Van Oudtshoorn and Van Rooyen, 1999; Parolin, 2006) and it is the favoured dispersal strategy in very wet or very dry environments (Zohary and Fahn, 1941; Van Oudtshoorn and Van Rooyen, 1999). Also, plants growing along mountain torrents on rocks, where splash water could easily be caught, profit from being ombrohydrochorous (Nakanishi, 2002). They mostly possess splash cups, from which seeds get expelled by the ballistic forces of splash water. Nakanishi 
(2002) found that, although only considered to be of minor importance, splash cup dispersal appears to be far more common and widespread. It can be found in various genera across a wide range of habitats (even temperate regions), where plants grow in sparse vegetation. However, he considered dispersal by rain as disadvantageous in dense vegetation (Nakanishi, 1988). More evidence for ombrohydrochory in temperate regions has been given by Walck \& Hidayati (2007), who investigated the dispersal of two Oenothera (Onagraceae) species. They found that not only are hygrochastic capsules ombrohydrochoric (Oenothera triloba) but also that the xerochastic Oenothera macrocarpa is indirectly ombrohydrochoric by opening wider in dry conditions after rain.

Even in tropical rainforest, dispersal by rain is evident in some species. Bertolonia mosenii (Melastomataceae), a Neotropical rainforest herb, exhibits yet another mechanism operated by rain, the so-called "squirt-corner". When raindrops hit the capsule, they force seeds outwards to the angles of the triangular fruit, where they are released (Pizo and Morellato, 2002). Some species of the pan-tropical subfamily Acanthoideae (Acanthaceae) are also dispersed by rain (Witzum and Schulgasser, 1995).

\subsection{Hygrochasy, hygrochastic capsule dehiscence and examples}

When dealing with the dispersal of plants, most authors refer mainly to the morphology of the diaspore (Ridley, 1930; Van der Pijl, 1982). Those morphologies are the results of anatomical changes in the diaspore. Sometimes the whole mechanism of diaspore dispersal is based only on the ultrastructure of the cell walls in the dispersal unit (Fahn and Werker, 1972). Different dehiscence types in fruits may be an example of the profound effect of only slight anatomical changes. 
Dehiscence usually involves the splitting of a fruit along specific areas and can be caused by various chemical, anatomical and seasonal changes. It affects dry fruits that either developed from a single carpel, e.g. follicles and legumes, or syncarpous fruits, e.g. siliques and capsules (Fahn, 1990).

Hygrochastic capsule opening is defined as the dehiscence of a fruit in response to the presence of moisture (Van der Pijl, 1982). It most likely aids dispersal by rain (ombrohydrochory) (Van der Pijl, 1982; Parolin, 2001, 2006), but Fahn \& Werker (1972) consider it to be an autochorous function, which is triggered by an external agent, in this case, water. Parolin (2006) also clearly separates the different forms of hydrochory as being either telechorous (nautohygrochory and bythisochory) or atelechorous (ombrohydrochory).

Hygrochasy is also considered to be one of the most efficient mechanisms for ombrohydrochory since it restricts seed dispersal to rain events. It is especially advantageous for desert species, giving the seeds protection from predators, spreading the risk of dispersal and germination over a long period and depositing the seeds in a suitable location (Van Oudtshoorn and Van Rooyen, 1999). In contrast to dispersal by turgor mechanism, which is telechoric and involves living cells, hygrochastic mechanisms can be found for both telechoric and atelechoric dispersal strategies and action takes place in cell walls of dead cells (Fahn and Werker, 1972).

Hygrochastic capsule opening is predominantly based on the imbibition mechanism. The movement of fruit parts in this mechanism results from the action of walls of cells belonging to two antagonistic groups. With the loss or uptake of water a cell wall shrinks or expands, respectively, in a direction perpendicular to that of cellulose microfibrils. If the orientations of those microfibrils in different cells or the orientation of those cells vary, the direction of movement in response to moisture will 
be different. The movement of the cells and tissues involved is either bending or torsion (Fahn and Werker, 1972). The imbibition mechanism acts both in xerochastic and hygrochastic fruits as both dehiscence types react in response to the change of moisture.

Only a few authors have provided anatomical descriptions of hygrochastic and xerochastic fruits (Steinbrinck, 1883, 1888; Von Guttenberg, 1926; Straka, 1955; Roth, 1977), which Poppendieck (1995) summarized in his paper about hygrochastic capsules in Oenothera. In order to be classified as hygrochastic, two conditions must be met. Firstly, the swelling tissue must be composed of fibres whose volume increases in wet conditions at right angles to their longest dimension. Secondly, different tissues must act in an antagonistic fashion to be reversible - the fibres must be either arranged at cross-angles or a differentiation is given between prosenchymatic cells of a swelling tissue and lignified cells of a resistance tissue. There might be variations in the swelling capacity of the tissue, which depends on the wall thickness and its chemical components. Swelling capacity of cell walls usually increases from lignin over cellulose and hemicellulose to pectins (Poppendieck, 1995).

In his study of the hygrochastic capsules of Oenothera (evening primroses), Poppendieck (1995) found a sequence of increasing complexity among the fruits he investigated and he also proved the existence of the proposed resistance and swelling tissues in different species, e.g. Oenothera fruticosa subsp. glauca, O. triloba, O. acaulis and $O$. perennis. For example, O. triloba only needs a few raindrops to open the capsule. The swelling tissue is located in the septum, where its cell walls take up the water, add it to the micellar structure of the cellulose contained in the wall and increase the volume. Consequently, the free parts of the valves are forced outwards 
and uncover the seeds, which can then be splashed out by raindrops. The hygrochastic response of Oenothera triloba and its consequences for seed dispersal have also been investigated by Walck and Hidayati (2007), but with little regard to the capsule anatomy.

The most studied family in regard to hygrochastic capsule opening and its implications is the ice-plant family Aizoaceae. The majority of the almost 2000 species are hygrochastic with various degrees and specifications (Parolin, 2001). Different species show different seed expulsion mechanisms, depending on their morphological and anatomical details of the capsules. Varying degrees of seed retention and atelechory are achieved by an increasing closure of the inner parts of the capsule (Schwantes, 1952; Straka, 1955; Bittrich, 1986). Hartmann (1988) investigated the relation of the shape and size of closing bodies, covering membranes, and the expanding mechanism to the dispersal syndrome. Another manipulative study by Parolin (2001) showed that the complex structures of different Aizoaceae are responsible not only for an effective seed expulsion but also for the retention of seeds in the capsule. Here, the capsule acts as seed bank and attributes such as closing bodies, covering membranes, and/or funicles ensure the release of seeds only when sufficient rain has fallen; they may also allow the storage of some seeds for further rain events (Parolin, 2001).

Other hygrochastic plants can be found in many different Angiosperm orders but their hygrochastic mechanism is not always related to capsule dehiscence as is the case in the examples described above. One interesting example is Anastatica hierochuntica (Brassicaceae), a desert annual, whose whole dead skeleton possesses hygrochastic branches. In dry conditions they curl up, thus protecting the fruits. Seeds are released either after uncurling during dew or rainfall through raindrops or through repeated 
curling and uncurling (Hegazy et al., 2006). The mechanics of another hygrochastic mechanism is decribed by Witzum and Schulgasser (1995) on the example of Ruellia britonniana (Acanthaceae subf. Acanthoideae). Again, an active and a resistance layer with differently lignified cell walls are involved in the movement, which allows for different water absorption, resulting in tension between the layers. The tension is released explosively with a raindrop hitting the capsule and the seeds are expelled with a catapult action (Witzum and Schulgasser, 1995).

\subsection{Potential hygrochastic genera in New Zealand and North}

\section{America}

Traditionally the study of hygrochastic capsules has focussed on Aizoaceae in southern Africa, but in recent decades studies reporting hygrochasy in other families and places have been published. In my dissertation I wanted to extend understanding of the anatomy, function, evolution and ecology of hygrochastic plants by studying New Zealand alpine plants. During the study, an opportunity arose to include work on Oenothera in North America.

\subsubsection{VERONICA}

Veronica L., with approximately 450 species of various life forms, is the largest genus within the Plantaginaceae (Angiosperm Phylogeny Group, 1998, 2003), having been formerly placed in the Scrophulariaceae (Albach et al., 2004; Albach and Meudt, 2010). Species are distributed mainly in temperate regions of the northern hemisphere and in Australasia (Albach et al., 2004; Garnock-Jones et al., 2007) and occur in a wide range of habitats. The genus Veronica is divided into numerous sections and subsections (Juan et al., 1997b; Martinez-Ortega, 1999; Garnock-Jones et al., 2007; 
Munoz-Centeno et al., 2007) but in this study, I concentrate on 23 Southern Hemisphere Veronica species, mostly formerly treated as Parahebe W.R.B. Oliv. and Chionohebe B. Briggs et Ehrend., which are now included in Veronica sect. Hebe (Garnock-Jones et al., 2007). Species formerly treated under Parahebe and Chionohebe are now arranged in two informal groups (speedwell hebes and snow hebes) that do not have the same circumscription as the original genera (Albach and Meudt, 2010).

The generalised Veronica fruit is a capsule formed by two locules separated by a linear septum. All capsules have bilateral symmetry. The epicarp and mesocarp are usually thin, whereas the endocarp can be thickened and/or lignified (Juan et al., 1997a).

If 11 New Guinea species are included, the speedwell hebe group comprises ca. 24 species, which are subshrubs with decussate leaves and racemose inflorescences with numerous short-tubed flowers on long slender pedicels. The capsules, developed from two carpels, are only weakly laterally compressed with a quite broad septum and open both at the apex by septicidal (between the carpels) and loculicidal (along the dorsal bundle of each carpel) splits and may gape at the septum by a septicidal split (Garnock-Jones and Lloyd, 2004). However, the position of $V$. linifolia Hook.f., $V$. colostylis Garn.-Jones and $V$. cheesemanii Benth. within the group is still not entirely resolved and the placement of $V$. planopetiolata G.Simpson \& J.S.Thomson differs among markers (Albach and Meudt, 2010). The recently described $V$. jovellanoides Garn.-Jones \& de Lange (Davidson et al. , 2009) is most similar to the speedwell hebe group.

The snow hebes (Albach and Meudt, 2010; Taskova et al., 2010) include species formerly placed in Chionohebe and alpine Parahebe. They comprise four species of 
high alpine cushion plants and four species of alpine low subshrubs, both on DNA evidence (Albach and Meudt, 2010) and morphology (Garnock-Jones, 1993; Garnock-Jones and Lloyd, 2004; Garnock-Jones et al., 2007). These are found in alpine areas of the South Island of New Zealand, although one cushion plant extends to Tasmania and one subshrub to the Australian Alps (Meudt, 2008; Meudt and Bayly, 2008). Compared to other Australasian Veronica, snow hebes have a compact habit, rather symmetrical 5-(6-) merous calyces and corolla and the capsules are laterally compressed with a narrow septum (Meudt and Bayly, 2008). Similar to the speedwell hebes, the capsules of snow hebes also open septicidally and loculicidally, but without gaping at the septum. The flowers are mostly solitary and either sunk in the cushion or set on greatly reduced peduncles. One additional species, $V$. zygantha Garn.-Jones, shares some morphological features with snow hebes (Garnock-Jones and Lloyd, 2004) but a close relationship has not been demonstrated.

So far, the Australasian Veronica species have received little attention regarding their fruit anatomy and dispersal strategies, but a number of papers have been published on Mediterranean species (Juan et al., 1997a; Juan et al., 2000). They showed that the dehiscence type is closely related to the anatomical structures of the investigated capsules, with the compression of the capsules strongly correlating with the strength of the cohesion tissue.

\subsubsection{COLOBANTHUS}

The genus Colobanthus Bartl. (Caryophyllaceae subf. Alsinoideae) is restricted to the Southern Hemisphere, consisting of approximately 20 species. Thirteen (14) of those are indigenous to New Zealand; of those, all but two are endemic (Allan, 1961; Sneddon, 1999). The genus covers a wide spectrum of habitats, occurring in S.E. 
Australia, Tasmania, New Zealand, in the Kerguelen biological region as well as the Andes, Antarctic Peninsula and sub-Antarctic Islands across a wide range of latitudinal, longitudinal, and vertical gradients. Colobanthus quitensis is one of the only two higher plants present in Antarctica (Convey, 1996), the other being Deschampsia antarctica. The genus Colobanthus has not been monographed to date and very little is known about the phylogeny of the genus (Sneddon, 1999). Not many studies have been carried out about all Colobanthus species, but a strong research interest exists in C. quitensis, due to its wide range and Antarctic distribution (e.g. Corner, 1971; Edwards, 1972, 1974, 1975; Edwards and Smith, 1988; Convey, 1996; Gianoli et al., 2004).

The flowers of the New Zealand Colobanthus are hermaphrodite and solitary, with 4 5 sepals and no petals. There are as many stamens as sepals, alternating with them. The ovary is one-celled and there are as many carpels and styles as stamens. Capsules are herbaceous and ovoid and the opening takes place with as many teeth (valves) as sepals. The placenta is a free standing column and there is no septum. The plants are small, densely leafy, glabrous herbs with narrow, exstipulate leaves that are connate at the base. The most cushions have a strong taproot (Allan, 1961). Observations of opening of some Colobanthus capsules during rainfall (Bill Malcolm, pers. comm.) led to the assumption that those species might be hygrochastic. They are also similar to Veronica with respect to capsule position and splash cup forming, which adds to the possibility that alpine Colobanthus also exhibit hygrochasy, hence they were included in this study. 


\section{CHAPTER ONE}

\subsubsection{OENOTHERA}

The genus Oenothera L. (Onagraceae) consists of approximately 145 species native to South and North America (Wagner et al., 2007). Literally hundreds of papers have been published concerning Oenothera, its ecology and evolution. Some of the interest results from the tendency of Oenothera to form interesting chromosome rearrangements and led to the pioneering genetic work of de Vries and the origin of the term "mutation" (de Vries, 1905). I will therefore only give a very brief description of the genus and refer for further studies to the references mentioned therein.

The species range from being annual, biennial, and perennial herbaceous plants, which can vary in size from small sprawling herbs (O. acaulis in Chile) to plants up to $3 \mathrm{~m}$ tall (O. stubbei in Mexico). The range of habitats extends from coastal areas up to the timberline. The leaves form a basal rosette at ground level and spiral up the flowering stems; they can be dentate or deeply lobed. The common name Evening Primrose derives from the opening time of the flowers, which are mostly yellow, but white, purple, pink, or red flowers are also known. The number of petals is four and the stigma has four branches, forming a distinctive cross (Petersen and McKenny, 1968). The fruits of Oenothera are capsules with different dehiscence types, such as opening with ripening, xerochastic or hygrochastic opening in varying degrees. Capsule types vary greatly within Oenothera, the most prominent difference can be found between species of subclades A and B (Tobe et al., 1987; Wagner et al., 2007). Subclade A includes species with terete or linear capsules, whereas species in subclade B exhibit winged or angled capsules. The differentiation into these two subclades is also supported to some extent by molecular analysis (Levin et al., 2004). 


\section{CHAPTER ONE}

Oenothera appears to have diverged from Eremothera about $10 \mathrm{Ma}$ (Sytsma et al., 2004), which is consistent with an origin in the mid- to late Miocene by most literature (Raven and Axelrod, 1974; Raven and Raven, 1976; Raven and Axelrod, 1978; Raven, 1979; Wagner et al., 1985; Wagner, 2005).

Oenothera may have originated in Mexico and Central America, from where it spread north and southwards, colonizing temperate, arid and alpine habitats (Katinas et al., 2004; Wagner et al., 2007). Nowadays, various Oenothera species can be found across the world in temperate regions, including New Zealand, due to international travel and horticulture (Webb et al., 1988; Thompson, 1990; Sun et al., 1992; Dhaliwal and Sharma, 1995; Deng et al., 2001; Hosking et al., 2003; Mihulka et al., 2006; Gfutte et al., 2007; Lambdon et al., 2008). The revised classification of Onagraceae now also includes Gaura, Stenosiphon and Calylophus in Oenothera (Wagner et al., 2007). 


\section{CHAPTER ONE}

\subsection{The New Zealand alpine region}

Most of the studies concerned with hygrochastic capsules concentrate on plants in arid regions. However, in the last decades hygrochastic species were reported in species of other habitats in temperate regions. In my dissertation I investigate hygrochasy in alpine plant species native to New Zealand. Therefore it is essential to give an introduction to the New Zealand alpine region.

\subsubsection{HISTORY}

Most of the South Island of New Zealand is dominated by the Southern Alps, which run almost the entire length of the island, whereas alpine regions on the North Island are restricted to Mount Taranaki, the volcanic plateau and a few high peaks of the axial ranges. All mountains of New Zealand are geologically young and very dynamic and the present relief is very heterogenous, with rocks differing regionally. An important feature of the Southern Alps is the Alpine Fault, where the Australian and Pacific Plates are in collision, which resulted in the uplifting of the Southern Alps during the Pliocene (5-2 million years ago) and a lateral displacement of related rocks by $450 \mathrm{~km}$.

\subsubsection{Climate}

Since New Zealand is relatively small and located in the southern ocean its climate is oceanic although prevailing westerly winds combine with New Zealand mountains to impose a strong west-east gradient. The more exposed mountains receive more than $4000 \mathrm{~mm}$ precipitation annually with local records on the South Island of up to 12000 mm on the western slopes (McSaveney, 1978). However, areas in the rain shadow often record rainfall of only $1000-1500 \mathrm{~mm}$ annually (Mark, 1965; Mark and 
Rowley, 1976; McCracken, 1980). Air temperatures vary greatly between the seasons as well as between night and day (Mark and Dickinson, 1997). At high altitudes only a few days in summer are frost free and freeze-thaw cycles occur frequently but permafrost is not recorded in New Zealand. Wind is a recurrent feature of the New Zealand mountains, especially in the rain shadow region of the South Island, where westerly gales are common.

\subsubsection{ALPINE ZONES}

In New Zealand, the alpine zone starts with the low-alpine generally at about $1100 \mathrm{~m}$ in the south and at $1500 \mathrm{~m}$ on the North Island (Mark and Dickinson, 1997). The lowalpine zone is between 300 and $500 \mathrm{~m}$ in vertical extent and is characterized by tall grassland, dominated by the largely endemic genus Chionochloa. Bogs and mires of various types are a common feature and the plant cover comprises mostly cushion plants and low trailing subshrubs and herbs, carnivorous species, lichens, sedges, and rushes. A century of European pastoralism has clearly influenced species composition in some parts.

The high-alpine zone contains smaller grasses, forbs, and low shrubs. Four distinctive natural types can be found throughout New Zealand's high-alpine plant communities: fell-field, scree, cushion field, and snowbank. Each has very distinctive characteristics and associated vegetation (Enting and Molloy, 1982).

Fell-field can usually be found on relatively stable rocks and consists of sparsely vegetated communities. A distinction can be made between wet and dry fell-field, differing in species composition (Mark and Dickinson, 1997). Scree only occurs on steep greywacke mountains in the rain shadow region of the South Island. Plant species found on scree are usually endemic to this habitat, morphologically different 
from near relatives, and have a suite of common characteristics, such as fleshy glaucous leaves. Cushion fields are found in Central Otago, mostly on broad plateau summits. The vegetation is characterized by extreme dwarfism (Mark and Dickinson, 1997). Snowbanks occur only locally in the high alpine zone, where snow accumulates and persists well into summer. They also show very adapted vegetation, which differs greatly even locally (Mark and Dickinson, 1997). They are generally differentiated based on climate, topography and lithology. The permanent snow line forms the upper limit of the high alpine zone. It decreases with latitude from $2400 \mathrm{~m}$ on the central North Island to about $2000 \mathrm{~m}$ in the south.

\subsection{Key questions, thesis outline and style}

The key questions my thesis addresses are concerned with the morphology, anatomy and biomechanics of hygrochastic capsules and the application of traditional hypotheses developed for hygrochasy in arid areas to hygrochastic species in other habitats.

\subsubsection{KeY QUESTIONS}

- The first key question is concerned with the mechanism itself - how does it operate in the investigated species and what are the differences regarding capsule anatomy in different hygrochastic species and between hygrochastic species and their non-hygrochastic relatives?

- Secondly, how does hygrochasy effect dispersal in New Zealand alpine plants? As stated before, the main reason for desert plants to be hygrochastic is thought to be protection against seed predators and drought and optimal timing for germination, but those reasons might not be as important for New Zealand alpine 


\section{CHAPTER ONE}

hygrochastic species, where water is a continually available resource. I test the idea that hygrochasy in alpine species is foremost an aid in dispersal by rain ballistic forces and a strategy to inhibit long distance dispersal and quickly occupy a suitable germination site in a restricted area.

- Thirdly, what are the reasons for hygrochasy in plants of different habitats? Desert plants open rather slowly and only when a certain amount of rain has fallen, whereas New Zealand alpine plants open quickly and with a minimal amount of rain needed (desert plants: Parolin, 2001; Poppendieck, 1995; alpine plants: pers. comm. P.J. Garnock-Jones \& W.M. Malcolm, own observations). Hygrochastic species can also be either very limited in their distribution (Aizoaceae) or very widespread (Oenothera).

- Lastly, I propose that despite quite complex structural changes, hygrochasy might be quite labile in its evolution. Phylogenetic analysis can show how many times a feature has evolved and whether the change is reversible. It may also indicate suitable precursor conditions from which the feature arose.

\subsubsection{THESIS OUTLINE AND STYLE}

This thesis comprises five research chapters that are prepared in the style of research papers, which are either already in press, submitted or formatted for submission to peer reviewed journals. Chapter Three and Four are each split into two subchapters due to the close relation and complexity of the topics. Each chapter starts with an abstract, followed by introduction, materials and methods, results and discussion and references. Chapters with subchapters have an overview and a summary describing both subchapters. This style inevitably results in some repetition, especially in introductory sections and descriptions of plant species and some experiments. The 
advantage of this style is the production of separate studies whilst addressing the overall hypotheses and research questions. Figures, photographs, tables and appendix numbers are linked with chapter numbers. These separate studies explore hygrochasy in previously unknown habitats, investigate existing hypotheses for hygrochasy in arid regions and add significantly to the knowledge of the evolution of hygrochastic capsule dehiscence. To achieve this I have:

1. Investigated and described in detail hygrochasy in New Zealand Veronica, with the use of various microscopy techniques and multivariate analysis of anatomical and morphological traits (Chapter Two),

2. Explored traditional hypotheses that have been used to explain the evolution of hygrochasy in arid habitats with regard to New Zealand alpine Veronica by investigating dispersal distances, habitat sizes and ecological amplitudes (Chapter Three),

3. Investigated capsule opening in Colobanthus with methods similar to techniques used in Chapter Two. I also conducted research towards a molecular phylogeny of the genus Colobanthus, through sequencing of nuclear and chloroplast markers, with the intention of using it to study evolution of hygrochasy (Chapter Four)

4. Identified additional hygrochastic and xerochastic Oenothera species and described their opening mechanism (Chapter Five),

5. Used experimental data about dispersal distance, opening time and seed retention as well as environmental and distribution data of hygrochastic Veronica, Oenothera and Aizoaceae to study the application of traditional hypotheses to previously unknown species in various habitats. I also studied character evolution by using existing phylogenies of Veronica and Oenothera, (Chapter Six) and 
6. Summarized the results of the studies and included an outlook on future research for hygrochastic dispersal (Chapter Six).

\subsection{References}

AfZal, R., S. M. Mughal, M. Munir, K. Sultana, R. Qureshi, M. Arshad, AND M. K. LAGHARI. 2010. Mycoflora associated with seeds of different sunflower cultivars and its management. Pakistan Journal of Botany 42: 435-445.

Albach, D. C., AND H. M. MeudT. 2010. Phylogeny of Veronica in the Southern and Northern Hemispheres based on plastid, nuclear ribosomal and nuclear low-copy DNA. Molecular Phylogenetics and Evolution 54: 457-471.

Albach, D. C., M. M. Martinez-Otega, M. A. Fischer, AND M. W. Chase. 2004. A new classification of the tribe Veroniceae - problems and a possible solution. Taxon 53: 429-452.

ALlaN, H. H. 1961. Flora of New Zealand Volume 1 Indigenous Tracheophyta. Government Printer, Wellington, New Zealand.

ANgiosperm Phylogeny Group. 1998. An ordinal classification for the families of flowering plants. Annals of the Missouri Botanical Garden 85: 531-553. . 2003. An update of the Angiosperm Phylogeny Group classification for the orders and families of flowering plants: APG II. Botanical Journal of the Linnean Society 141: 399-436.

BeLL, A. D. 1991. Plant Form - an illustrated guide to flowering plant morphology. Oxford University Press, Oxford.

BITTRICH, V. 1986. Untersuchungen zu Merkmalsbestand, Gliederung und Abgrenzung der Unterfamilie Mesembryanthemoideae (Mesembryanthemaceae Fenzl.). Mitteilungen aus dem Institut fuer Allgemeine Botanik Hamburg 21: 5-116.

BOLKER, B. M., AND S. W. PACALA. 1999. Spatial moment equations for plant competition: understanding spatial strategies and the advantages of short dispersal. American Naturalist 153: 575-602.

BONN, S., AND P. PosCHLOD. 1998. Ausbreitungsbiologie der Pflanzen Mitteleuropas. UTB Wissenschaft, Quelle \& Meyer.

Brodie, H. J. 1951. The splash-cup dispersal mechanism in plants. Canadian Journal of Botany 29: 224-234. . 1955. Springboard dispersal operated by rain. Canadian Journal of Botany 33: 156.

CAIN, M. L., H. Damman, AND A. MuIR. 1998. Seed dispersal and the Holocene migration of woodland herbs. Ecological Monographs 68: 325-347.

CAin, M. L., B. G. Milligan, AND A. E. StRAND. 2000. Long-distance seed dispersal in plant populations. American Journal of Botany 87: 1217-1227.

CHEPLICK, G. P. 1998. Seed dispersal and seedling establishment in grass populations. In G. P. Cheplick [ed.], Population biology of grasses, 84-105. Cambridge University Press, Cambridge, UK.

CONVEY, P. 1996. Reproduction of Antarctic flowering plants. Antarctic Science 8: 127-134.

CORNER, R. W. M. 1971. Studies in Colobanthus quitensis (Kunth.) Bartl. and Deschampsia antarctica Desv.: IV. Distribution and reproductive performance in the Argentine islands. British Antarctic Survey Bulletin 26: 41-50.

DARWIN, C. 1859. The origin of species. John Murray, London, UK.

DAVIDSON, G. R., P. J. DE LANGE, AND P. GARNOCK-JONES. 2009. Two additional indigenous species of Veronica (Plantaginaceae): V. jovellanoides, a new and highly endangered species, and $V$. plebeia R.Br. New Zealand Journal of Botany 47: 271279. 
DEAN, W. R. J., AND S. J. MiLton. 2003. Did the flora match the fauna? Acocks and historical changes in Karoo biota. South African Journal of Botany 69: 68-78.

DENG, Y.-C., H.-M. HUA, J. LI, AND P. LAPINSKAS. 2001. Studies on the cultivation and uses of evening primrose (Oenothera spp.) in China. Economic Botany 55: 83-92.

DE VRIES, H. 1905. Species and varieties. Their origin by mutation.

Dhaliwal, D. S., AND M. Sharma. 1995. Oenothera affinis Camb. (Onagraceae): A new record for India from Himalaya. Rheedea 5: 151-153.

DOCTERS VAN LEEUWEN, W. M. 1936. Krakatau. Brill, Leiden, Netherlands.

EDWARDS, J. A. 1972. Studies in Colobanthus quitensis (Kunth.) Bartl. and Deschampsia antarctica Desv.: V. Distribution, ecology and vegetative performance on Signy Island. British Antarctic Survey Bulletin 28.

. 1974. Studies in Colobanthus quitensis (Kunth.) Bartl. and Deschampsia antarctica Desv.: VI. Reproductive performance on Signy Island. British Antarctic Survey Bulletin 39: 67-86.

. 1975. Studies in Colobanthus quitensis (Kunth.) Bartl. and Deschampsia antarctica Desv.: VII. Cyclic changes related to age in Colobanthus quitensis. British Antarctic Survey Bulletin 40: 1-6.

EDWARDS, J. A., AND R. I. L. SMITH. 1988. Photosyntheis and respiration of Colobanthus quitensis and Deschapsia antarctica from the maritime Antarctic. British Antarctic Survey Bulletin 81: 43-63.

ELLNER, S., AND A. SHMIDA. 1981. Why are adaptations for long-range seed dispersal rare in desert plants? Oecologia (Berlin) 51: 133-144.

ELMQUist, T., AND P. A. Cox. 1996. The evolution of vivipary in flowering plants. Oikos 77: 3-9.

ENTING, B., AND L. Molloy. 1982. The ancient islands - New Zealand's natural environments. Port Nicholson Press, Wellington, New Zealand.

ERNST, A. 1934. Das biologische Krakatau-Problem. Vierteljahresschrift der Naturforschenden Gesellschaft in Zurich 59.

FAHN, A. 1990. Plant anatomy, fourth edition. Pergamon Press, Oxford, UK.

FAHN, A., AND E. WERKER. 1972. Anatomical mechanisms of seed dispersal. In T. T. Kozlowski [ed.], Seed Biology. Academic Press, New York, USA.

FEnNer, M., AND K. THOMPSON. 2005. The ecology of seeds. Cambridge University Press, Cambridge.

GARnock-Jones, P., D. Albach, AND B. G. Briggs. 2007. Botanical names in Southern Hemisphere Veronica (Plantaginaceae): sect. Detzneria, sect. Hebe, and sect. Labiatoides. Taxon 56: 571-582.

GARNOCK-JONES, P. J. 1993. Phylogeny of the Hebe complex (Scrophulariaceae: Veroniceae). Australian Systematic Botany 6: 457-479.

GARNOCK-JONES, P. J., AND D. G. LLOYD. 2004. A taxonomic revision of Parahebe (Plantaginaceae) in New Zealand. New Zealand Journal of Botany 42: 181-232.

Gfutte, P., M. BReitfeld, AND H. D. HorBACH. 2007. Oenothera deflexa Gates - A evening primrose new for Bavaria. Berichte der Bayerischen Botanischen Gesellschaft zur Erforschung der Heimischen Flora 77: 201-203.

Gianoli, E., P. Inostroza, A. Zuniga-Feest, M. Reyes-Diaz, L. A. Cavieres, L. A. BRAVO, AND L. J. CORCUERA. 2004. Ecotypic differentiation in morphology and (old resistance in Populations of Colobanthus quitensis (Caryophyllaceae) from the Andes of central Chile and the maritime Antarctic. Arctic Antarctic and Alpine Research 36: 484-489.

GOPALAKRISHNAN, C., AND V. VALluVAPARIDASAN. 2009. Seed-borne microflora associated with rice seeds in Tamil Nadu, India. Crop Research (Hisar) 37: 207-209.

Gove, A. D., J. D. MAJER, AND R. R. DuNN. 2007. A keystone ant species promotes seed dispersal in a "diffuse" mutualism. Oecologia (Berlin) 153: 687-697.

GutTERMAN, Y. 1994. Strategies of seed dispersal and germination in plants inhabiting deserts. Botanical Review 60: 373-425.

HARPER, J. L. 1977. Population biology of plants. Academic Press, London, UK. 
Hartmann, H. E. K. 1988. Fruit types in Mesembryanthema. Beitraege zur Biologie der Pflanzen 63: 313-349.

Hegazy, A. K., H. N. BARAKAT, AND H. F. KABIEL. 2006. Anatomical significance of the hygrochastic movement in Anastatica hierochuntica. Annals of Botany 97: 47-55.

Herrera, C. M., AND P. JordanO. 1981. Prunus mahale and birds the high efficiency seed dispersal system of temperate fruiting tree. Ecological Monographs 51: 203-218.

Hosking, J. R., B. J. CONN, AND B. J. LEPSCHI. 2003. Plant species first recognised as naturalised for New South Wales over the period 2000-2001. Cunninghamia 8: 175187.

Howe, H. F., AND J. Smallwood. 1982. Ecology of seed dispersal. Annual Review of Ecology and Systematic 13: 201-228.

Howe, H. F., AND L. C. WeSTLEY. 1986. Ecology of pollination and seed dispersal. In Crawley, M. J. [ed.]. Plant Ecology. Xiii+496p. Blackwell Scientific Publications, Inc.: Palo Alto, California, USA; Oxford, England.

JANZEN, D. H. 1980. When is it coevolution? Evolution 34: 611-612. 1983. Dispersal of seeds by vertebrate guts. In Futuyama, D.J. and M. Slatkin [ed.]. Coevolution XI $+555 p$. Sinauer Associates Inc, Sunderland, Massachusetts.

1984. Dispersal of small seeds by big herbivores: foliage is the fruit. American Naturalist: 338-353.

JORDAN, G. J. 2001. An investigation of long-distance dispersal based on species native to both Tasmania and New Zealand. Australian Journal of Botany 49: 333-340.

JUAN, R., I. FERNANDEZ, AND J. PASTOR. 1997a. Scanning electron and light microscope study of the fruits and seeds of Chaenorrhinum from SE Spain. Lagascalia 20: 117128. 1997b. Morphological and anatomical studies on fruits of Veronica from south-west Spain. Botanical Journal of the Linnean Society 123: 157-171.

JUAN, R., J. PASTOR, AND I. FERNANDEZ. 2000. SEM and light microscope observations on fruit and seeds in Scrophulariaceae from Southwest Spain and their systematic significance. Annals of Botany (London) 86: 323-338.

KATINAS, L., J. CRISCI, W. L. WAGNeR, AND P. C. HoCH. 2004. Geographical diversification of tribes Epilobieae, Gongylocarpeae, and Onagreae (Onagraceae) in North America, based on parsimony analysis of endemicity and track compatibility analysis. Annals of the Missouri Botanical Garden 91: 159-185.

Lambdon, P. W., P. Pysek, C. Basnou, M. Hejda, M. Arianoutsou, F. Essl, V. Jarosik, J. Pergl, M. Winter, P. Anastasiu, P. Andriopoulos, I. Bazos, G. Brundu, L. Celesti-Grapow, P. Chassot, P. Delipetrou, M. Josefsson, S. Kark, S. Klotz, Y. KoKKoris, I. Kuehn, H. Marchante, I. Perglova, J. Pino, M. VILA, A. ZIKOS, D. ROY, AND P. E. HULME. 2008. Alien flora of Europe: species diversity, temporal trends, geographical patterns and research needs. Preslia (Prague) 80: 101-149.

LEE, J. A., AND R. HARMER. 1980. Vivipary, a reproductive strategy in response to environmental stress? Oikos 35: 254-265.

LEVINA, R. E. 1961. On the classification and nomenclature of fruits. Botanicheskii Zhurnal SSSR 46: 488-495.

LOMASCOLO, S. B., AND H. M. SCHAEFER. 2010. Signal convergence in fruits: a result of selection by frugivores? Journal of Evolutionary Biology 23: 614-624.

MacphaIL, M. K. 1997. Comment on M. Pole (1994): 'The New Zealand flora - entirely long-distance dispersal?' Journal of Biogeography 24: 113-117.

MARK, A. F. 1965. The environment and growth rate of narrow-leafed snow tussock, Chionochloa rigida, in Otago. New Zealand Journal of Botany 3: 73-103.

MARK, A. F., AND J. ROWLEY. 1976. Water yield of low-alpine snow tussock grassland in Central Otago. Journal of Hydrology (New Zealand) 15: 59-79.

MARK, A. F., AND K. J. M. Dickinson. 1997. New Zealand alpine ecosystems. In F. E. Wielgolaski [ed.], Polar and Alpine Tundra, 311-345. Elsevier, Amsterdams, Netherlands. 
Martinez-Ortega, M. M. 1999. Revision taxonomica de Veronica sect. Veronica L y V. sect. Veronicastrum W.D.J. Koch (Scrophulariaceae) en el Mediterraneo Occidental, University of Salamanca, Salamanca.

MCCRACKEN, I. J. 1980. Mountain climate in the Craigieburn Range, New Zealand. In U. Benecke and M. R. Davis [eds.], Mountain Environments and Subalpine Tree Growth, 41-59. N.Z. Forest Service, Wellington.

MCSAVENEY, M. J. 1978. The magnitude of erosion across the Southern Alps. Conference on Erosion Assessment and Control in New Zealand, Wellington: 7-24.

Mehlman, D. W. 1993. Tumblewood dispersal in Florida sandhill Baptisia (Fabaceae). Bulletin of the Torrey Botanical Club 120: 60-63.

MEudT, H. M. 2008. Taxonomic revision of Australasian snow hebes (Veronica, Plantaginaceae). Australian Systematic Botany 21: 387-421.

MeUdT, H. M., AND M. J. BAYLY. 2008. Phylogeographic patterns in the Australasian genus Chionohebe (Veronica s.l., Plantaginaceae) based on AFLP and chloroplast DNA sequences. Molecular Phylogenetics and Evolution 47: 319-338.

MidgleY, J. J., AND W. J. BoND. 1991. Ecological aspects of the rise of Angiosperms - a challenge to the reproductive superiority hypotheses. Biological Journal of the Linnean Society 44: 81-92.

MinulKa, S., P. PYSeK, J. Martinkova, AND V. JAROSIK. 2006. Invasiveness of Oenothera congeners alien to Europe: Jack of all trades, master of invasion? Perspectives in Plant Ecology Evolution and Systematics 8: 83-96.

MUELLER-SCHNEIDER, P. 1983. Verbreitungsbiologie (Diasporologie) der Bluetenpflanzen. Stiftung Ruebel, Zuerich.

Munoz-Centeno, L. M., L. Delgado-Sanchez, M. Santos-Vicente, AND M. M. MARTINEZ-ORTEGA. 2007. Taxonomy of Veronica L. subsect. Veronica (Plantaginaceae) in the western Mediterranean. Botanical Journal of the Linnean Society 155: 65-81.

NAKANISHI, H. 1988. Mechanical seed dispersal of herbaceous plants in southwestern Japan. Hikobia 10: 129-133. 2002. Splash seed dispersal by raindrops. Ecological Research 17: 663-671.

OPPEL, S., AND A. L. MACK. Bird assemblage and visitation pattern at fruiting Elmerrillia tsiampaca (Magnoliaceae) trees in Papua New Guinea. Biotropica 42: 229-235.

PAROLIN, P. 2001. Seed expulsion in fruits of Mesembryanthema (Aizoaceae): A mechanistic approach to study the effect of fruit morphological structures on seed dispersal. Flora (Jena) 196: 313-322.

2006. Ombrohydrochory: Rain-operated seed dispersal in plants - With special regard to jet-action dispersal in Aizoaceae. Flora (Jena) 201: 511-518.

PETERSEN, R. T., AND M. MCKENNY. 1968. A field guide to wildflowers of north eastern and north central North America. Houghton Mifflin Company, Boston, USA.

Pizo, M. A., AND L. P. C. Morellato. 2002. A new rain-operated seed dispersal mechanism in Bertolonia mosenii (Melastomataceae), a neotropical rainforest herb. American Journal of Botany 89: 169-171.

POLE, M. 1994. The New Zealand flora - entirely long-distance dispersal? Journal of Biogeography 21: 625-635.

PONS, J., AND J. G. PAUSAS. 2007. Acorn dispersal estimated by radio-tracking. Oecologia (Berlin) 153: 903-911.

POPPENDIECK, H.-H. 1995. Hygrochastic capsules in Oenothera (Onagraceae). Mitteilungen aus dem Institut fuer Allgemeine Botanik Hamburg 25: 99-115.

RAVEN, P. H. 1973. Evolution of subalpine and alpine plant groups in New Zealand. New Zealand Journal of Botany 11: 177-200.

. 1979. A survey of reproductive biology in Onagraecae. New Zealand Journal of Botany 17: 575-593.

RAVEN, P. H., AND D. I. AXElRoD. 1974. Angiosperm biogeography and past continental movements. Annals of the Missouri Botanical Garden 61: 539-673. 
RAVEN, P. H., AND T. E. RAVEN. 1976. The genus Epilobium (Onagraceae) in Australasia: a systematic and evolutionary study. New Zealand Department of Science and Industry Research Bulletin 216: 1-321.

RAVEN, P. H., AND D. I. AXELROD. 1978. Origin and relationships of the California flora. University of California Publications in Botany 72: 1-134.

RIDLEY, H. N. 1930. The dispersal of plants throughout the world. Reeve, Ashford.

Rogers, L. L., AND R. D. Applegate. 1983. Dispersal of fruit seeds by black bears. Journal of Mammalogy 64: 310-311.

ROTH, I. 1977. Fruits of Angiosperms, Handbuch der Pflanzenanatomie. Borntraeger Verlag, Berlin \& Stuttgart.

Rumeu, B., D. P. PADIlla, AND M. Nogales. 2009. The key role of a Ring Ouzel Turdus torquatus wintering population in seed dispersal of the endangered endemic Juniperus cedrus in an insular environment. Acta Ornithologica (Warsaw) 44: 199204.

SANMARTIN, I., L. WANNTORP, AND R. C. WINKWORTH. 2007. West wind rift revisited: testing for directional dispersal in the Southern Hemisphere using event-based tree fitting. Journal of Biogeography 34: 398-416.

SCHERFF, E.J., C. GALEN AND M.L. STANTON. 1994. Seed dispersal, seedling survival and habitat affinity in a snowbed plant: limits to the distribution of the snow buttercup, Ranunculus adoneus. Oikos 69: 405-413

SCHWANTES, G. 1952. Die Fruechte der Mesembryanthemaceen. Mitteilungen des Botanischen Museums der Universitaet Zuerich ser. Botanik 39: 1-38.

SERNANDER, R. 1927. Zur Morphologie und Biologie der Diasporen, Uppsala.

SHARMA, P., AND H. N. GOUR. 2009. Location of seed-borne mycoflora in pea (Pisum sativum L.) and efficacy of fungicides on germination and seedling vigour. Journal of Mycology and Plant Pathology 39: 90-93.

SiEPIELSKI, A. M., AND C. W. BENKMAN. 2007. Convergent patterns in the selection mosaic for two north American bird-dispersed pines. Ecological Monographs 77: 203-220.

SNEDDON, B. V. 1999. The taxonomy and breeding system of Colobanthus squarrosus (Caryophyllaceae). New Zealand Journal of Botany 37: 195-204.

StAPANIAN, M. A., AND C. C. SMITH. 1978. A model for seed scatter hoarding co=evolution of fox squirrels and black walnuts. Ecology (Washington D C) 59: 884-896.

STEINBRINCK, C. 1883. Ueber einige Fruchtgehaeuse, die ihre Samen infolge von Benetzung freilegen. Berichte der Deutschen Botanischen Gesellschaft 1: 339-347. 1888. Ueber die Abhaengigkeit der Richtung hygroskopischer Spannkraefte von der Zellwandstruktur. Berichte der Deutschen Botanischen Gesellschaft 6: 385-389, Tafel XIX.

STILES, E. W. 1980. Patterns of fruit presentation and seed dispersal in bird disseminated wood plants in the eastern USA deciduous forest. American Naturalist 116: 670-688.

STRAKA, H. 1955. Anatomische und entwicklungsgeschichtliche Untersuchungen an Fruechten parapsermer Mesembryanthemen. Nova Acta Leopoldine 118: 127-190.

Sun, B. Y., C. H. KIM, AND T. J. KIM. 1992. Naturalized weeds and new location of plants to Korean flora. Korean Journal of Plant Taxonomy 22: 235-240.

Sytsma, K. J., A. Litt, M. L. ZiJhra, J. C. Pires, M. Nepokroeff, E. Conti, J. Walker, AND P. G. WILSON. 2004. Clades, clocks, and continents: Historical and biogeographical analysis of Myrtaceae, Vochysiaceae, and relatives in the southern hemisphere. International Journal of Plant Sciences 165 (4 suppl.): S85-S105.

Taskova, R. M., Kokubun, T. AND Ryan, K.G. 2010. Phenylethanoid and Iridoid Glycosides in the New Zealand Snow Hebes. Chemical and Pharmaceutical Bulletin (Tokyo) 58: 703-711

THOMPSON, J. 1990. Onagraceae, Bureau of Flora and Fauna, Canberra. Flora of Australia, Vol. 18. Podostemaceae to Combretaceae. Xvi+349p. Australian Government Publishing Service: Canberra, Australian Capital Territory, Australia.

Thulin, M. 1987. A new species of Xylocalyx (Scrophulariaceae) from Somalia. Nordic Journal of Botany 7: 267-269. 


\section{CHAPTER ONE}

ToBe, H., W. L. WAGNER, AND H.-C. ChIN. 1987. A systematic and evolutionary study of Oenothera (Onagraceae): Seed coat anatomy. Botanical Gazette 148: 235-257.

TOMBAC, D. F. 1982. Dispersal of whitebark pine Pinus albicaulis seed by Clarks nutcracker Nucifraga columbiana - a mutualism hypothesis. Journal of Animal Ecology 51: 451468.

VAN DER PIJL, L. 1982. Principles of dispersal in higher plants. Springer-Verlag, Berlin, Germany.

VAN OUdTShOORn, R. K., AND M. W. VAN ROOYEn. 1999. Dispersal biology of desert plants. Springer-Verlag, Berlin, Germany.

VON GUtTEnBERG, H. 1926. Die Bewegungsgewebe, Handbuch Pflanzenanatomie. Borntraeger Verlag, Berlin \& Stuttgart.

WAGNeR, W. L. 2005. Systematics of Oenothera sections Contortae, Eremia, and Ravenia (Onagraceae). Systematic Botany 30: 332-356.

WAgner, W. L., R. Stockhouse, AND W. M. KLein. 1985. A systematic and evolutionary study of the Oenothera caespitosa species complex (Onagraceae). Monographs in Systematic Botany from the Missouri Botanical Garden 12: 1-103.

Wagner, W. L., P. C. Hoch, AND P. H. RAVEN. 2007. Revised Classification of the Onagraceae. Systematic Botany Monographs 83: 1-240.

WALCK, J. L., AND S. N. HiDAYATI. 2007. Ombrohydrochory and its relationship to seed dispersal and germination strategies in two temperate North American Oenothera species (Onagraceae). International Journal of Plant Sciences 168: 1279-1290.

Webb, C.J., W.R. Sykes AND P.J. Garnock-Jones. 1988. Flora of New Zealand Volume: Naturalised Pteridophytes, Gymnosperms, Dicotyledons. Government Printer, Wellington, New Zealand

WeBB, C. J. 1998. The selection of pollen and seed dispersal in plants. Plant Species Biology 13: 57-67.

WheElwright, N. T., AND G. H. ORIANS. 1982. Seed dispersal by animals - contrasts with pollen dispersal, problems of terminology, and constraints on coevolution. American Naturalist 119: 402-413.

WILLSON, M. F. 1993. Dispersal mode, seed shadows, and colonization patterns. Vegetatio 107/108: 261-280.

Witzum, A., AND K. SChUlgasser. 1995. The mechanics of seed expulsion in Acanthaceae. Journal of Theoretical Biology 176: 531-542.

ZOHARY, M. 1937. Die verbreitungsoekologischen Verhaeltnisse der Pflanzen Palaestinas. Beiheft zum Botanischen Zentralblatt A 56: 1-155. . 1962. Plant life of Palestine. Reinhold Press, London, UK.

ZOHARY, M., AND A. FAHN. 1941. Anatomical-carpological observations in some hygrochastic plants of the oriental flora. Palestinian Journal of Botany: 125-135. 


\section{CHAPTER TWO}

\section{Hygrochastic Capsule Dehiscence in New Zealand Alpine}

\section{Veronica (Plantaginaceae)}

This chapter is published in the American Journal of Botany under the title

"Hygrochastic capsule dehiscence in New Zealand alpine Veronica (Plantaginaceae)" by Pufal, G., K.G. Ryan and P. Garnock-Jones. The co-authors' role was restricted to supervision and advice and P. Garnock-Jones designed the drawings in Fig 2.2.

G. Pufal collected all data, carried out the analysis and wrote the manuscript.
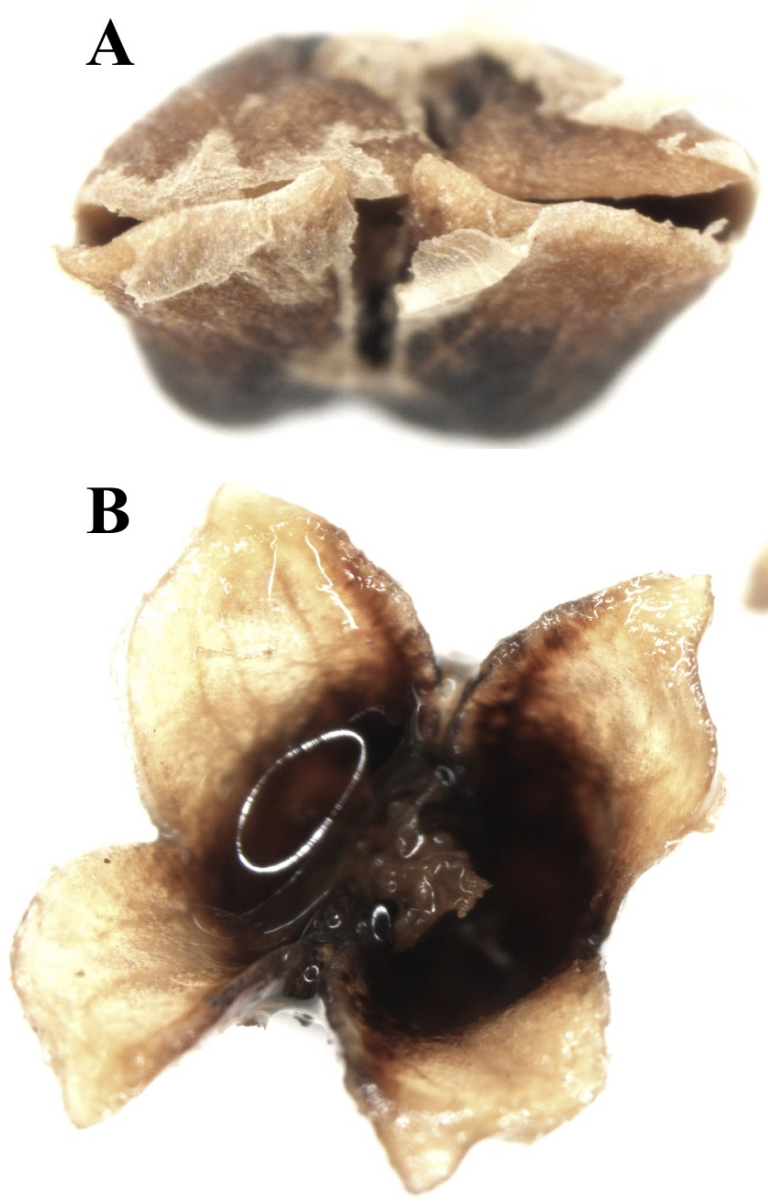

FIG 2.1 Dry (A) and wet (B) capsule of Veronica densifolia. 
CHAPTER TWO

\subsection{Abstract}

- Premise of the study: Plant movement is more widespread than often recognized, involving different organs and mechanisms. Hygrochasy (opening in response to moisture) is a capsule opening movement that is widely believed to be predominantly a feature of plants of desert and arid zones, where it may protect against seed predators and harsh climatic conditions and restrict dispersal to favourable germination times and sites. However, recently it has been reported from a wider range of environments. Here we describe hygrochasy for the first time for plants of alpine habitats.

- Methods: Capsules of 23 species of New Zealand Veronica were collected and we used light microscopy to investigate the anatomy and biomechanics responsible for the opening mechanism. Additionally, we collected morphological data to identify common traits of hygrochastic species.

- Key results: Hygrochastic capsule dehiscence was found in ten alpine Veronica species. The opening mechanism is based on an antagonistic reaction between a non-lignified swelling tissue and a lignified resistance tissue. In Veronica, hygrochasy is associated with erect, narrowly angustiseptate capsules on short peduncles of creeping subshrubs or cushion plants.

- Conclusion: Hygrochasy is a common dehiscence type in New Zealand alpine Veronica and for the first time this mechanism is described in detail for plants in alpine habitats. We propose that hygrochasy provides an effective seed dispersal mechanism in solitary capsules embedded in cushion plants and may restrict dispersal within habitat patches.

Keywords: alpine, cushion plants, hygrochasy, New Zealand Alps, rain dispersal, Veronica 


\subsection{Introduction}

The inability of plants to move is one of the fundamental differences between them and animals, yet many animals (e.g. corals, sponges) are sessile and in some way plant-like, while many plants can move at least some of their organs. Plants lack nerves, yet are able to detect environmental changes and although they have no muscles they can sometimes move in response. Biologists have been fascinated for centuries by plant movement (Darwin, 1865; Darwin and Darwin, 1880; Edwards and Moles, 2009) and people generally are attracted to plant movements in carnivorous plants (e.g. Dionaeae) or flowers that open suddenly (e.g. Oenothera). Plants achieve movement either by differential growth or by differential changes in volume of cells and tissues, sometimes through the actions of cells that are already dead. Movements in plants provide interesting questions for plant anatomy (Parolin 2001, 2006), ecology (Gutterman, 1990; Pufal \& Garnock-Jones, in press), evolution, and developmental biology. The three main types of movement in plants are (1) circumnutation, a movement associated with growth (Karban, 2008), (2) tropism, a dictated movement in response to stimuli (light, gravity or contact) and (3) nasticism, a movement independent of the direction of the stimulus (Darwin and Darwin, 1880; Karban, 2008). Circumnutation usually takes place in the growing tips of roots and stems, whereas tropism and nasticism function on a larger scale, such as leaves or entire plants.

Even though movements occur in plants, the vast majority of plants are sessile and have to utilize other means to venture into new areas. For a sessile organism, dispersal plays a crucial role in colonizing new habitats, promoting gene flow and extending species distribution. A large number of plant species rely on agents such as animals, wind or water (Van der Pij1, 1982) for successful dispersal and their diaspores (seed 
dispersal unit (Fahn and Werker, 1972)) may be highly adapted to their specific dispersal modes. However, autochorous plants are able to disperse their seeds without the aid of external agents, possessing autonomous mechanisms that facilitate dispersal (Fahn and Werker, 1972). Here, movement can be achieved by either change in turgor pressure (e.g. capsules of Impatiens parviflora), an imbibition mechanism or cohesion mechanism (Fahn and Werker, 1972); all of them operated by changes in water content and pressure either in the cell lumen (turgor and cohesion mechanism) or cell walls (imbibition mechanism).

Hygrochasy is defined as the opening of a structure in reaction to moisture. The opposite of the process; opening when dry and infolding when wet, is referred to as xerochasy (Fahn and Werker, 1972). Different organs on a plant may be involved in hygrochastic movement, for example parts of the inflorescence (Fahn and Werker, 1972; Gutterman, 1990, 1994; Gutterman and Ginott, 1994), the fruit (Garside and Lockyer, 1930; Ellner and Shmida, 1981; Van der Pij1, 1982; Ihlenfeldt, 1983; Thulin, 1987; Gutterman, 1994; Poppendieck, 1995; Nakanishi, 2002; Parolin, 2006) or even the entire plant (Hegazy et al., 2006). In this paper, we are concerned only with species that possess hygrochastic capsular fruits.

In general, hygrochasy is based on an imbibition mechanism, which involves only the walls of dead cells (Fahn and Werker, 1972). The shrinking and swelling in this mechanism is based on an antagonistic action of cell walls of two contrasting cell types. Enlarged cell walls shrink with water loss and expand with its uptake, in a direction perpendicular to the orientation of cellulose microfibrils. Commonly, increases in cell size in the swelling tissue are converted into bending or torsion by the presence of an attached lignified non-swelling resistance tissue (Fahn and Werker, 1972). Variations in the expanding capacity of the swelling tissue depend on the cell 
wall thickness and its chemical components (Poppendieck, 1995). However, size, location, arrangement and cell properties can also vary greatly between genera or even between related species (Garside and Lockyer, 1930; Poppendieck, 1995) and influence the extent, duration and speed of the capsule opening.

Hygrochastic dehiscence has generally been associated with plants of arid environments (Steinbrinck, 1883; Zohary and Fahn, 1941; Van Oudtshoorn and Van Rooyen, 1999). The best-known example is the Aizoaceae in southern Africa, where 98\% of the highly diverse family exhibit hygrochastic capsules (Parolin, 2006). Hygrochastic species also occur in other arid regions of the world, belonging to a variety of genera and families (Ellner and Shmida, 1981; Thulin, 1987; Gutterman, 1994; Poppendieck, 1995; Van Oudtshoorn and Van Rooyen, 1999). It is widely recognized that hygrochastic capsule opening is positively linked to delay and restriction of dispersal (Fahn and Werker, 1972; Ellner and Shmida, 1981; Van der Pijl, 1982; Ihlenfeldt, 1983; Parolin, 2006). Thus, hygrochasy not only aids seed dispersal by rain, but also limits it to periods of adequate rainfall. This ensures favourable germination conditions (sufficient moisture) following dispersal. Furthermore, the seeds are splashed out of the capsules by falling raindrops and only travel a short distance, thus restricting dispersal to safe sites. The closed woody capsules additionally protect seeds against predators and harsh climatic conditions during dry periods in extreme habitats such as deserts and may even function after the parent plant is dead (Steinbrinck, 1883; Ellner and Shmida, 1981; Ihlenfeldt, 1983). In recent years, hygrochastic capsules have also been reported in plants from other habitats, such as wetlands (Van der Pijl, 1982; Parolin, 2006), vegetation along water torrents (Nakanishi, 2002), and in low vegetation in temperate regions (Nakanishi, 
2002; Walck and Hidayati, 2007), where wind as the dispersal agent is not readily available but rain and/or drops falling from higher vegetation are frequent.

These studies show that hygrochasy might be more widespread than previously assumed but little to no attention has been paid to the anatomical background and the biomechanics behind the mechanism. However, functioning of hygrochastic capsules in some Aizoaceae (Garside and Lockyer, 1930; Parolin, 2001) and Oenothera (Poppendieck, 1995) is well understood and clearly shows the difference in capsule reaction to water depending on tissue arrangement.

Hygrochasy has been reported in a number of cushion-forming species of New Zealand Veronica L. (Garnock-Jones, 1993; Garnock-Jones and Lloyd, 2004, as Parahebe and Chionohebe), but details about the biomechanics and hypotheses for the occurrence of hygrochasy in those species have not been investigated. Most hygrochastic species are found in high alpine areas of the Southern Alps on the South Island, but one species is present in high alpine areas on the volcanic plateau on the North Island. For a description of New Zealand alpine environments, see Wardle (1991).

Veronica is the largest genus within the Plantaginaceae (Angiosperm Phylogeny Group, 2003) with approximately 450 species (Albach et al., 2004; Albach and Meudt, 2010) of various life forms. Species are distributed mainly in temperate regions of the northern hemisphere and in Australasia (Albach et al., 2004; GarnockJones et al., 2007) and occur in a wide range of habitats. In this work, we concentrate on 23 Southern Hemisphere Veronica species, mostly formerly treated as Parahebe W.R.B. Oliv. and Chionohebe B. Briggs et Ehrend., which are now included in Veronica sect. Hebe (Garnock-Jones et al., 2007). Both Parahebe and Chionohebe are 
now arranged in two groups, informally named speedwell hebes and snow hebes, respectively (Albach and Meudt, 2010).

Together with potentially 11 New Guinea species, the speedwell hebe group comprises ca. 24 species, which are subshrubs with decussate leaves and racemose inflorescences with numerous short-tubed flowers on long slender pedicels. The capsules, developed from two carpels, are only weakly laterally compressed with a quite broad septum and open both at the apex by septicidal (between the carpels) and loculicidal (along the dorsal bundle of each carpel) splits and gape at the septum by a septicidal split (Garnock-Jones and Lloyd, 2004). However, the position of $V$. linifolia Hook. f., V. colostylis Garn.-Jones and V. cheesemanii Benth. within the group is still not entirely resolved and the placement of $V$. planopetiolata G. Simpson \& J.S. Thomson differs among markers (Albach and Meudt, 2010). The recently described $V$. jovellanoides Garn.-Jones \& de Lange (Davidson et al., 2009) is most similar to the speedwell hebe group. The snow hebes (Albach and Meudt, 2010) include species formerly placed in Chionohebe and alpine Parahebe. They comprise four species of high alpine cushion plants and four species of alpine low subshrubs, both on DNA evidence (Albach and Meudt, 2010) and morphology (Garnock-Jones, 1993; Garnock-Jones and Lloyd, 2004; Garnock-Jones et al., 2007). These are found in alpine areas of the South Island of New Zealand, although one cushion plant extends to Tasmania and one subshrub to the Australian Alps (Meudt, 2008). Compared to other Australasian Veronica, snow hebes have a compact habit, 5-(6-)merous calyces and corolla and the capsules are laterally compressed with a narrow septum (Meudt and Bayly, 2008). Similar to the speedwell hebes, the capsules of snow hebes also open septicidally and loculicidally, but without gaping at the septum. The flowers are solitary and either sunk in the cushion or set on greatly reduced peduncles. One 
additional species, $V$. zygantha Garn.-Jones, shares some morphological features with snow hebes (Garnock-Jones and Lloyd, 2004) but a close relationship has not been demonstrated.

So far, the Australasian Veronica species have received little attention regarding their fruit anatomy and dispersal strategies, but a number of papers have been published on Mediterranean species (Juan et al., 1997; Juan et al., 2000). They showed that the dehiscence type is closely related to the anatomical structures of the capsules, with the compression of the capsules strongly correlating with the strength of the cohesion tissue, which is the tissue influencing movement within the capsule (Fahn and Werker, 1972).

We document which species of New Zealand Veronica possess hygrochastic capsules and describe the anatomy and biomechanics of hygrochastic capsule dehiscence in Veronica for the first time. We also introduce hypotheses to explain the investment of alpine plants in hygrochastic opening.

\subsection{Materials and Methods}

Fresh samples of 11 Veronica species were collected in various field sites in New Zealand. Dried capsule samples from a further six species were obtained from the Allan Herbarium at Landcare Research Center in Lincoln, New Zealand (CHR). Annotated voucher specimens of the collected samples are held in the herbarium at Victoria University of Wellington (WELTU) (Appendix 1).

To detect hygrochasy, dry capsules were immersed in water for about 10 min and their reaction was observed. If they opened, they were classified as hygrochastic. In addition, cryostat sections (see below) were exposed to water and observed under a microscope. If there was dramatic swelling of cells they were also classified as 
hygrochastic. Capsules that were already open and did not change in response to water, were classified as 'ripening dehiscent' (e.g., capsules open with the ripening process and stay open). Capsules that were closed and remained closed were classified based on previous observations by Garnock-Jones and Lloyd (1994) and/or cryostat analysis.

To investigate the anatomy of the capsules, transverse sections of the capsules of all species were made using a range of embedding and sectioning methods.

For frozen sections (cryostat sections), dried capsule material was placed in a $-80^{\circ} \mathrm{C}$ freezer for several days and then transferred to a cryostat (Leica CM 3050S). Here, the capsules were embedded in Jung tissue freezing medium and cut with carbon knives, resulting in sections between 5 and $35 \mu \mathrm{m}$ thick. The advantage of cryostat sections is that the plant tissue is not infiltrated by any medium or stain, therefore preserving a natural state of the material. These sections were used to observe and measure the reaction of cells to water by inserting water under the cover slip and measuring changes in cell size and shape after water absorption. If tissue expanded after water absorption, it was classified as swelling tissue (ST) and the species was considered hygrochastic. Since cryostat sections were relatively thick, it was difficult to distinguish individual cells, and the changes occurring during water uptake were therefore measured as percentage change for the tissue. Ten measurements per species were made, when possible from different capsules. Following these trials, histochemistry was investigated in cryostat sections. Phloroglucinol and hydrochloric acid were used as a sensitive stain for lignin. Unfortunately the use of highly concentrated hydrochloric acid destroyed the samples within a few minutes (Gurr, 1953). In younger samples, Safranin and Light Green were used to stain for lignified substances and cellulose (Gurr, 1963). 
Capsules were also embedded in epoxy resin, which allowed for much thinner sections (ultratome sections). Following a dehydration alcohol series, the samples were placed in $100 \%$ absolute alcohol and propylene oxide for $30 \mathrm{~min}$ each, left overnight in 50:50 propylene oxide : resin and then transferred to $100 \%$ resin for at least three to four hours. They were then arranged in resin-filled moulds and dried overnight. Sections $(2-4 \mu \mathrm{m})$ were cut with glass knives in a Leica Ultracut $\mathrm{E}$ ultratome and stained with Toluidine Blue. These sections were used to measure cell size and cell wall thickness in ten samples per species, when possible from different capsule samples. The following cell measurements were made both in the septum, where the swelling tissue (ST) is located and on cells in the valve tissue, where the resistance tissue (RT) is located in hygrochastic Veronica: length of cells in the ST (STL), wall thickness of cells in the ST (STCW), the percentage change of the length of the ST after water absorption (change), width of cells in the ST (STW), diameter of cells in the RT (RTDIA), and wall thickness of cells in the RT (RTCW). A description of the origin and number of capsules per species used for the microscopical investigation can be found in Appendix 1.

Measurements from ultratome sections were used in a Principal Components Analysis (PCA) in order to find anatomical traits associated with dehiscence type. In the PCA ordination, two clusters were retrieved. One cluster contained species that were classified hygrochastic based on the water test on whole capsules and on the water absorption test in cryostat sections. The other cluster contained 'ripening dehiscent' species, identified by the water test. All measurements were compared between hygrochastic and 'ripening dehiscent' species using Shapiro-Wilks test to test for normality and subsequently Wilcoxon Rank test to test for significant differences between the groups. 
In order to identify common characters in hygrochastic species and to use these to predict hygrochasy in species without capsule material, a hierarchical cluster analysis was performed. Usually, hierarchical cluster analysis is used to show which samples are most similar to each other and subsequently group them in the same cluster. The similarity is based on Euclidean distances from every sample to every other sample in an $\mathrm{m}$-dimensional space defined by the $\mathrm{m}$ variables (quantitative dissimilarity matrix) (Crawley, 2007). Here, we use cluster analysis slightly differently. Our aim was to identify characters that hygrochastic species have in common. Based on observations of positively identified hygrochastic species we chose life form, capsule position, number of inflorescences, capsule compression and capsule orientation as characters which are important for the dispersal by raindrops. A morphological dataset for a total of 23 Veronica was compiled with data from field observations, the Allan Herbarium database, herbarium material and literature (Garnock-Jones and Lloyd, 2004; Meudt, 2008; Davidson et al., 2009). This dataset includes 17 species for which capsule samples were available (Appendix 1) as well as six additional Veronica species to include all Veronica of the snow hebe and speedwell hebe groups. The traits were scored as character states and a hierarchical cluster analysis using Euclidean distances was performed. If hygrochastic species clustered together and 'ripening dehiscent' species were in a different cluster the chosen morphological characters can serve as likely indicators for hygrochasy. Statistical analyses were carried out using $R$ ( R Development Core Team, 2005). 
CHAPTER TWO

\subsection{Results}

Six Veronica species had capsules that opened when submerged in water and closed again when they dried and were therefore classified as hygrochastic. Seven species had capsules that remained open in the water and were classified as 'ripening dehiscent'. Capsule samples of four species remained closed, these were classified as hygrochastic based on water absorption in cryostat section. These observations are summarized in Table 2.1. The classifications of Garnock-Jones and Lloyd (1994) are also given in the table, where it is apparent that $V$. colostylis and $V$. lilliputiana do not match our classification.

Table 2.1 Classification of Veronica with different experimental treatments.

Note: Statistical analysis is based on the classification after the investigation of cryostat sections. For these, an expansion of tissue after water absorption was used to identify hygrochastic and 'ripening dehiscent' species. The classifications from Garnock-Jones and Lloyd (1994) are included for comparison.

\begin{tabular}{|c|c|c|c|}
\hline & cryostat sections & water test & $\begin{array}{l}\text { Garnock-Jones and } \\
\text { Lloyd (1994) }\end{array}$ \\
\hline V. catarractae & 'ripening dehiscent' & 'ripening dehiscent' & xerochastic \\
\hline$V$. cheesemanii & hygrochastic & hygrochastic & hygrochastic \\
\hline$V$. ciliolata & hygrochastic & - & - \\
\hline V. colostylis & hygrochastic & - & xerochastic \\
\hline V. decora & 'ripening dehiscent' & 'ripening dehiscent' & xerochastic \\
\hline$V$. densifolia & hygrochastic & hygrochastic & - \\
\hline$V$. hookeriana & 'ripening dehiscent' & 'ripening dehiscent' & xerochastic \\
\hline V. lanceolata & 'ripening dehiscent' & 'ripening dehiscent' & xerochastic \\
\hline V. lilliputiana & hygrochastic & - & xerochastic \\
\hline V. lyallii & 'ripening dehiscent' & 'ripening dehiscent' & xerochastic \\
\hline V. melanocaulon & 'ripening dehiscent' & 'ripening dehiscent' & xerochastic \\
\hline$V$. planopetiolata & hygrochastic & hygrochastic & hygrochastic \\
\hline V. pulvinaris & hygrochastic & hygrochastic & - \\
\hline$V$. senex & 'ripening dehiscent' & 'ripening dehiscent' & xerochastic \\
\hline V. spathulata & hygrochastic & hygrochastic & hygrochastic \\
\hline V. thomsonii & hygrochastic & hygrochastic & - \\
\hline V. trifida & hygrochastic & - & hygrochastic \\
\hline
\end{tabular}


Cryostat sections were used to test the reaction of cells to water absorption. After water was injected under the cover slip, tissue at the septum of ten species expanded noticeably, whereas in the septum of the remaining seven species a distinct expansion was not observed. The tissue showing expansion was identified as swelling tissue (ST) and all ten species expressing swelling were classified as hygrochastic. When transverse ultratome sections were analysed, the ST could be identified in hygrochastic species as possessing distinctly different cells. Using sections from three orthogonal planes, the shape of the cells was determined. The ST was located in the septum of the capsule and consisted of one cell layer. It comprised elongated cylindrical cells with thick cell walls. These were aligned so that the longest cell dimension was orthogonal to the outer edge of the tissue (Fig. 2.2 A). 


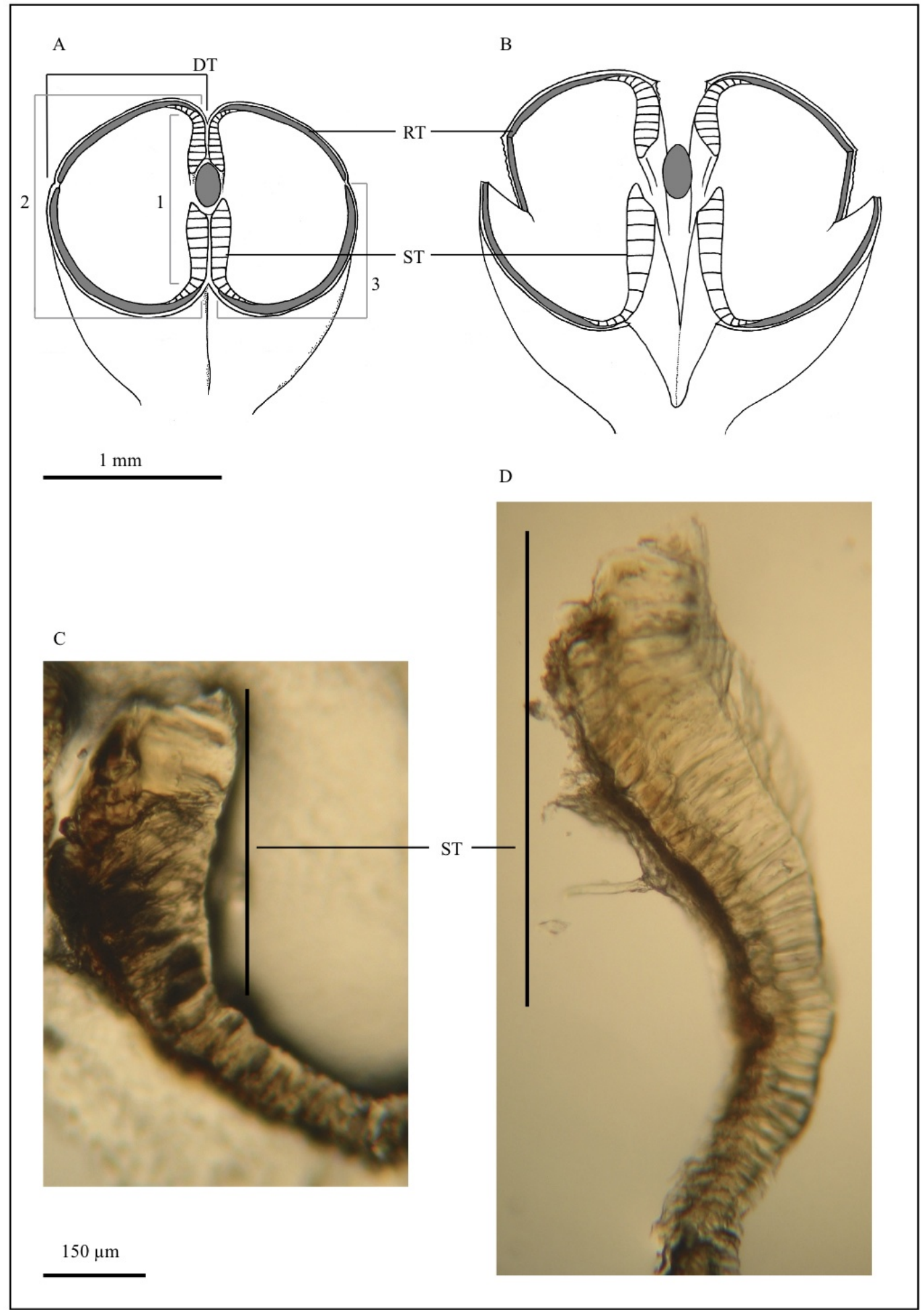

FIG 2.2 Differences in the swelling tissue (ST) between dry and wet capsules.

(A) Diagram of a transverse section of a dry (closed) hygrochastic Veronica capsule, (B) Diagram of a transverse section of a wet (open) hygrochastic Veronica capsule, (C) micrograph (16x) of an unstained septum of Veronica spathulata (dry), (D) micrograph (16x) of an unstained septum of Veronica spathulata (wet), Resistance tissue (RT) in the diagrams is shown in grey, swelling tissue (ST) in the diagram is shown in striped, the dehiscence tissue (DT) is indicated by black lines. The grey lines show the septum (1), a locule (2) and the valve of a locule (3). 
The RT was present throughout the valves of each carpel and two, sometimes three cell layers thick. RT cells were spherical and generally smaller than the cylindrical cells of the ST. Phloroglucinol staining of cryostat sections revealed that lignin was only present in walls of cells in the RT and was absent in the ST (Fig. 2.3). In contrast, 'ripening dehiscent' Veronica showed spherical cells with thick cell walls in the valves as well as in the septum, with all cell walls being completely lignified (similar to RT in hygrochastic species) (Fig. 2.3). Throughout the capsule the cells appeared in layers of two to three cells.

Veronica densifolia

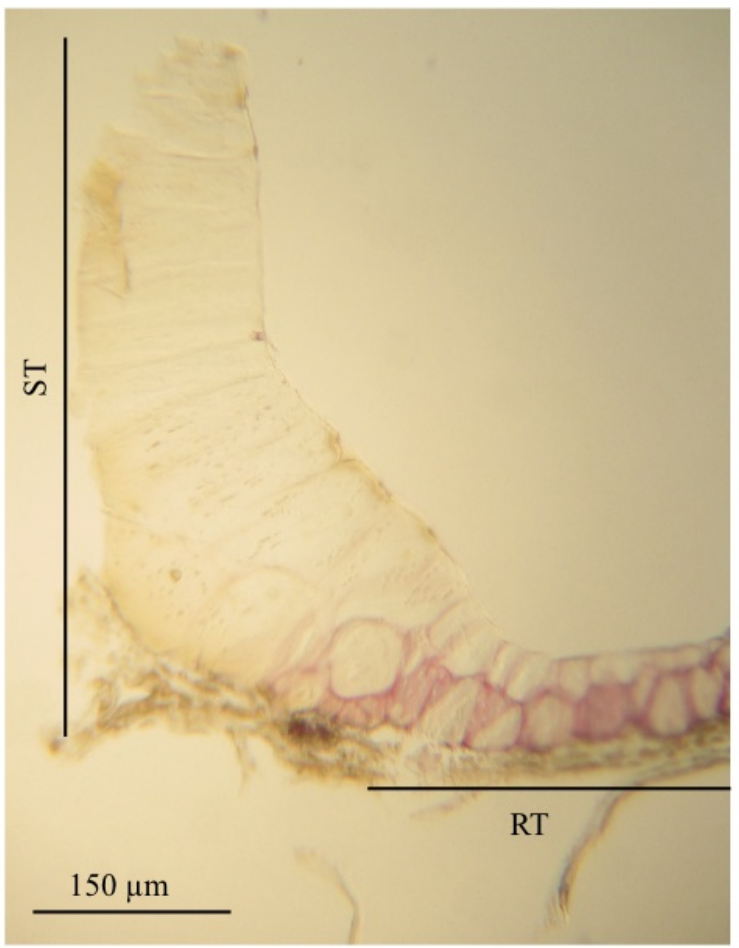

Veronica lanceolata

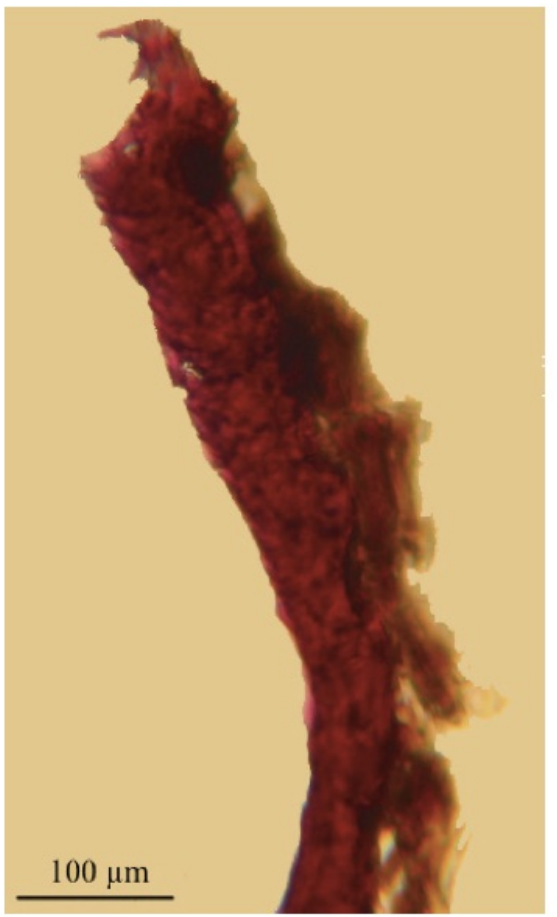

FIG 2.3 Septum of Veronica densifolia (hygrochastic) and Veronica lanceolata ('ripening dehiscent'). Magnification 16x, Phloroglucinol was used to stain for lignin (red). Section were made using a cryostat, with the $V$. densifolia sample being $12 \mu \mathrm{m}$ and $V$. lanceolata 25 $\mu \mathrm{m}$ thick. The location of the swelling tissue (ST) and resistance tissue (RT) are indicated in Veronica densifolia. 
Principal Components Analysis (PCA) of cell measurements and change after water absorption was run to determine which of the measurements were the most important in distinguishing between hygrochastic and 'ripening dehiscent' species (Table 2.2). Measurements for each species are given in Appendix 2.2. The first three components of the PCA accounted for $83.5 \%$ of the variation among the samples.

Table 2.2 Principal Component Analysis (PCA). Loadings were based on measurements made from ultratome sections of 'ripening dehiscent' species and hygrochastic species, identified based on anatomy.

STL - length of cells in swelling tissue (ST); STCW - thickness of cell walls in ST; change percentage change of the length of ST after water absorption; STW - width of cells in the ST; RTDIA - diameter of cells in the resistance tissue (RT); RTCW - thickness of cell walls in the RT.

\begin{tabular}{||lllllll||}
\hline & Comp. 1 & Comp. 2 & Comp. 3 & Comp. 4 & Comp. 5 & Comp. 6 \\
\hline eigenvalues & 2.103 & 1.632 & 1.273 & 0.496 & 0.315 & 0.182 \\
$\begin{array}{l}\text { St. dev } \\
\begin{array}{l}\text { Proportion } \\
\text { of variance }\end{array}\end{array}$ & 1.450 & 1.277 & 1.128 & 0.704 & 0.561 & 0.427 \\
$\begin{array}{l}\text { Cumulative } \\
\text { proportion }\end{array}$ & 0.350 & 0.272 & 0.212 & 0.083 & 0.052 & 0.030 \\
\hline & & 0.622 & 0.835 & 0.917 & 0.970 & 1.000 \\
\hline STL & 0.606 & -0.259 & & -0.162 & -0.176 & 0.712 \\
STCW & 0.586 & & -0.356 & -0.110 & -0.349 & -0.629 \\
Change & 0.378 & -0.459 & 0.388 & 0.311 & 0.581 & -0.250 \\
STW & 0.196 & 0.467 & -0.580 & 0.240 & 0.569 & 0.161 \\
RTDIA & 0.237 & 0.509 & 0.429 & 0.617 & -0.341 & \\
RTCW & 0.228 & 0.496 & 0.447 & -0.653 & 0.266 & \\
\hline
\end{tabular}

The variables STL, STCW and change were associated with Axis 1 and STW, RTDIA and RTCW with Axis 2 and are shown in Fig. 2.4. 'ripening dehiscent' and hygrochastic species split into two distinct groups roughly along the first axis. In the PCA (Fig. 2.4, clear oval) the four species that did not open in the water test, but were classified hygrochastic based on cryostat section analysis, fell within the hygrochastic 
cluster. However, some measurements for $V$. lilliputiana Stearn lay between the groups.

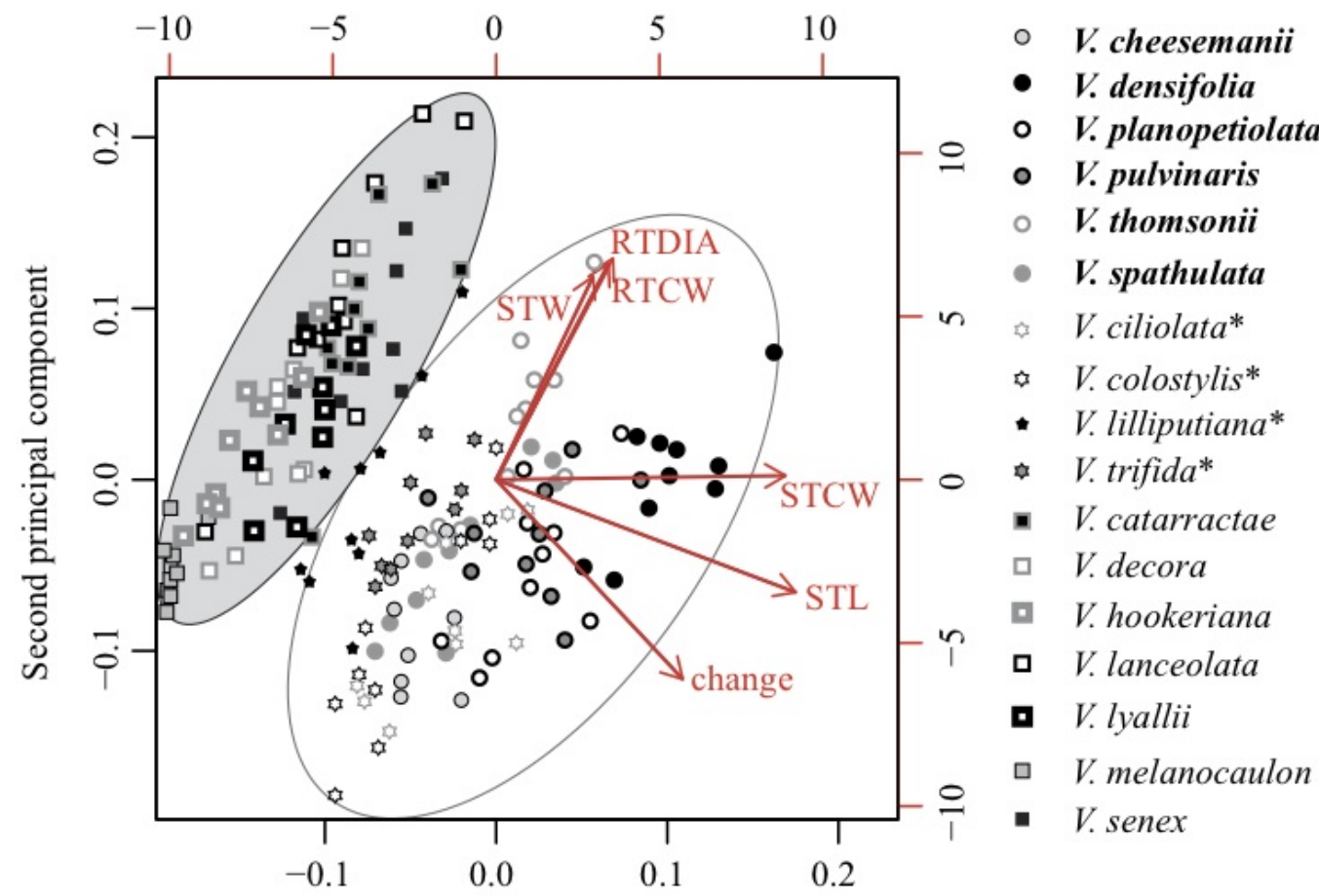

First principal component

FIG 2.4 Scores for all species on the first two PCA axes. Vector directions/lengths represent eigenvectors of measurements (loadings) for each axis.

Circle symbols and bold font represent known hygrochastic species; star symbols and stars behind the name indicate hygrochastic species inferred from anatomy; square symbols are 'ripening dehiscent' species. The grey shaded oval indicates the group 'ripening dehiscent' species, the clear oval indicates the group hygrochastic species.

STL - length of cells in swelling tissue (ST); STCW - thickness of cell walls in ST; change percentage change of the length of ST after water absorption; STW - width of cells in the ST; RTDIA - diameter of cells in the resistance tissue (RT); RTCW - thickness of cell walls in the RT. 
To investigate the difference between 'ripening dehiscent' and hygrochastic species further, the three influential variables in the first component (STL, STCW and change) were compared separately between both groups ('ripening dehiscent' and hygrochastic) (Fig. 2.5).

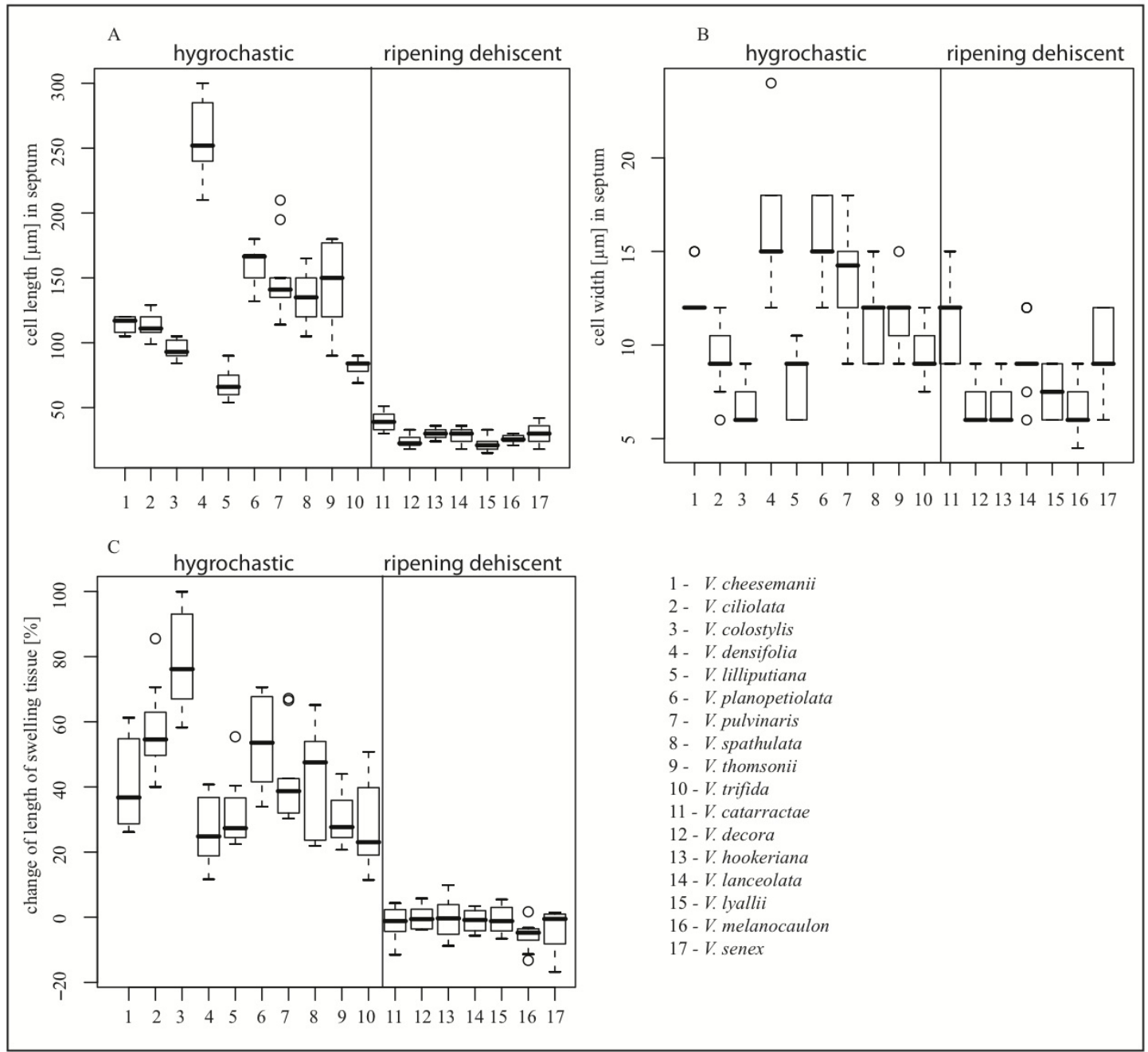

FIG 2.5 Box-whisker plots of (A) Length of cells in the septum (STL), (B) width of cells in the septum (STW), (C) change of length of the swelling tissue after water absorption. Hygrochastic species as identified by anatomy based on the PCA (1-10) and 'ripening dehiscent' species (11-17) are separated by a vertical line. 
A Wilcoxon Rank test showed that hygrochastic species possess significantly longer cells (A) with thicker cell walls in the swelling tissue (B), which expand significantly in length $(\mathrm{C})$ compared to 'ripening dehiscent' capsules, when water is absorbed (Table 2.3, Fig. 2.5). The width of cells in the swelling tissue (STW) is significantly different (Table 2.3) between both groups as well but is associated with the second principal component.

Table 2.3 Wilcoxon rank test between hygrochastic and 'ripening dehiscent' Veronica species. See Table 2.2 for abbreviations.

\begin{tabular}{|l|l|l|}
\hline \hline Measurement & W & P-value \\
\hline STL & 7000 & $<0.001^{* * *}$ \\
\hline STCW & 5485 & $<0.001^{* * *}$ \\
\hline change & 7000 & $<0.001^{* * *}$ \\
\hline STW & 2643 & $0.006^{* *}$ \\
\hline RTDIA & 3682.5 & 0.559 \\
\hline RTCW & 3379.5 & 0.688 \\
\hline \hline
\end{tabular}

In younger fruits of all species, a dehiscence tissue (DT) was found between the carpels along the septum, the carpel midribs and between the valves of each locule (Fig.2.2 A), comprising small round cells with thin cellulose cell walls (stained green with Light Green). The DT is formed as an outer cell layer of the endocarp. Those cells disintegrate with ripening; leaving a small split both at the septicidal and loculicidal end of the capsule. In older fruits that had previously been opened, the DT was usually absent or only visible as ripped cells still attached to the valves.

Based on opening experiments and observation of water absorption in cryostat slides, all hygrochastic Veronica capsules have been found to function in the same way, only differing in size of the swelling tissue cells and the degree of swelling tissue increase after water absorption. When a ripe hygrochastic capsule is exposed to water, the cell walls of the elongated cylindrical cells in the swelling tissue rapidly take up moisture 
resulting in an increase in diameter of the cylindrical cells (Fig. 2.2 C and D). This leads to an extension of the height and length of the septum, but not its thickness (Fig. 2.2 B). Due to the expansion of the septum the split resulting from the previously disintegrated DT widens and at the same time the valves are pushed towards the loculicidal splits. This opening widens and the four valves move outward, forming a splash cup. When the capsule dries again, the swelling recedes and the valves return to their previous position. Since the DT has been destroyed small splits remain at both the septicidal and loculicidal end.

In 'ripening dehiscent' Veronica, the capsules open with the ripening of the fruit, and the DT disintegrates. The lignified cells in the septum and valves most likely shrink in all planes on drying and a pore-like gap is formed at the capsule apex as the locule walls pull apart. This gap is big enough to release seeds when shaken in the wind. Additionally in the speedwell hebes (e.g. Veronica catarractae G.Forst.), the septum is pulled apart slightly and is open in the mature fruit. This appears to be reversible (xerochastic movement) in at least some species of New Zealand Veronica.

Table 2.4 Characters and character states of New Zealand Veronica species.

Note: Information adapted from own observations, Allan (1961); Mark and Adams (1995); Garnock-Jones and Lloyd (2004); Meudt (2008), Davidson et al. (2009).

\begin{tabular}{|l|l|l|}
\hline \hline \multicolumn{2}{|l|}{ Character } & Character state and codes \\
\hline 1 & Life form & $\begin{array}{l}\text { Cushion (1), creeping subshrub (2), creeping herb } \\
(3), \text { subshrub (4) }\end{array}$ \\
\hline 2 & Number of inflorescences & Solitary $(1),<4(2),<8(3),>8(4)$ \\
\hline 3 & Position of capsule & Sessile (1), peduncle $<2 \mathrm{~cm}(2)$, peduncle $>2 \mathrm{~cm}(3)$ \\
\hline 4 & Orientation of capsule & Erect (1), facing down (2), both (3) \\
\hline 5 & Capsule compression & $\begin{array}{l}\text { Narrowly angustiseptate }(1), \text { broadly angustiseptate } \\
(2)\end{array}$ \\
\hline
\end{tabular}

To identify common traits for hygrochastic Veronica, morphological characters of 23 species were given character states and are presented in Table 2.4. A cluster analysis 
of these was performed to group species based on Euclidean distances between the character states in a dissimilarity matrix. (Fig. 2.6).

Based on the chosen characters the species were split into two distinct groups. With the exception of $V$. colostylis Garn.-Jones, all hygrochastic species were grouped in one cluster. The cluster analysis also incorporated species for which capsule material was not available ( $V$. linifolia, $V$. zygantha, $V$. spectabilis (Garn.-Jones) Garn.-Jones, $V$. chionohebe Garn.-Jones, V. birleyi N.B. Br., V. jovellanoides).

Of these, $V$. chionohebe, $V$. zygantha, $V$. spectabilis, $V$. birleyi and $V$. jovellanoides fell into the hygrochastic group based on their morphological characters. The second group comprised all 'ripening dehiscent' species.

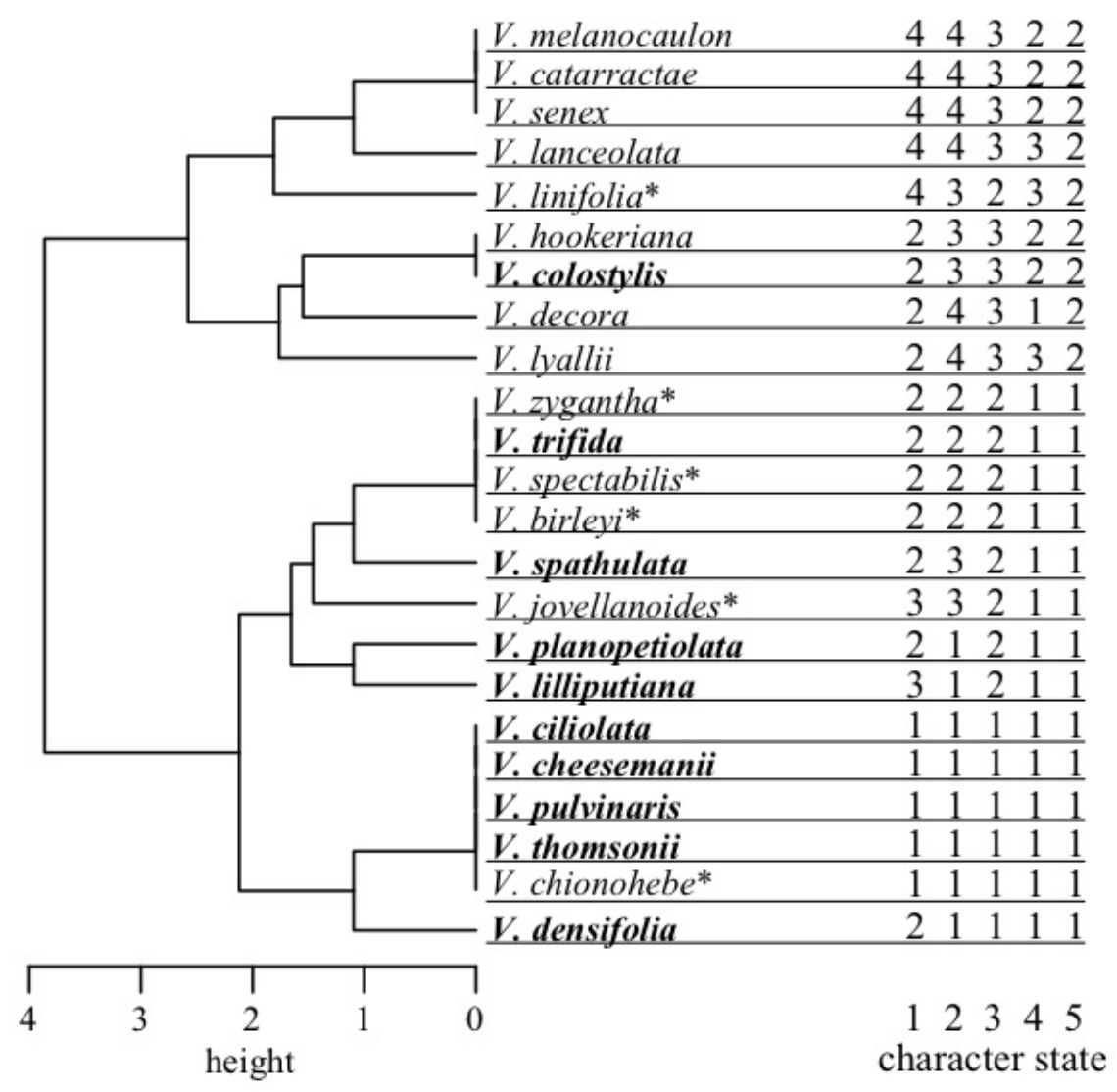

FIG 2.6 Hierarchical cluster analysis of Euclidean distances in a dissimilarity matrix of character states of 23 Veronica species. Known hygrochastic species (based on water experiments, anatomical analysis and Garnock-Jones and Lloyd (1994)) are shown in BOLD, species without capsule material are marked with *. 
CHAPTER TWO

\subsection{Discussion}

Plants, often considered sessile and motionless, are able to move either some of their parts or achieve movements through the dispersal of their diaspores (Darwin, 1865; Darwin and Darwin, 1880; Edwards and Moles, 2009; Van der Pij1, 1982). When differential growth of living tissues is the source of movement, such movements are irreversible, except by further growth of an opposing tissue, which then results in an overall enlargement of the organ. Reversible movement can be achieved by differential enlargement of living cells or tissues, e.g., in the reversible opening of stomata and closing and opening of fly traps in Dionaea, or in dead tissues, e.g., in hygrochastic capsules. Here we have shown that in some New Zealand species of Veronica, reversible hygrochastic dehiscence of capsules is achieved by differential swelling of thick-walled non-lignified cells of the septum, opposed by a resistance tissue in the lignified cells of the capsule walls.

Based on our observations we have been able to considerably update the number of hygrochastic species in New Zealand. Previously, Garnock-Jones and Lloyd (1994) had reported $V$. cheesemanii, $V$. spathulata Benth. (speedwell hebes), $V$. birleyi, $V$. spectabilis, V. trifida Petrie, V. zygantha (snow hebes) and $V$. planopetiolata as hygrochastic. We are now also able to add $V$. colostylis and $V$. lilliputiana (both in speedwell hebes) and confirm that all snow hebes (Meudt and Bayly, 2008) are also hygrochastic. Our morphological analysis also supports hygrochasy in the newly discovered $V$. jovellanoides (Davidson et al., 2009).

All hygrochastic species, apart from Veronica lilliputiana (restricted to lowland to montane lakesides), $V$. colostylis (mostly subalpine but extends to lower and higher altitudes) and $V$. jovellanoides (only found at one side in a lowland forest) were found exclusively in the alpine zone of New Zealand. Veronica spathulata Benth. and $V$. 
jovellanoides are the only hygrochastic Veronica found in the North Island of New Zealand.

Although analysis of capsule sections of $V$. colostylis provides clear evidence that it is hygrochastic, the cluster analysis showed that it does not possess all the morphological characters that are associated in other hygrochastic Veronica. This might explain why it was assumed to be xerochastic previously (Garnock-Jones and Lloyd, 2004). Its sister species V. linifolia (Garnock-Jones and Lloyd, 1994) has ripening dehiscence. $V$. lilliputiana has not been reported as hygrochastic before but the distinct expansion of the ST after water absorption in cryostat sections as well as measurements of cells in the ST in ultratome sections are good evidence for hygrochasy in this species. However, some of the data points within the PCA are closer to the cluster of 'ripening dehiscent' species, but this is probably due to the smaller cell size in the small capsule. The cluster analysis also grouped $V$. lilliputiana with hygrochastic species.

Although we did not have capsule material to test hygrochastic opening or to investigate capsule anatomy in $V$. chionohebe, $V$. jovellanoides, $V$. birleyi, $V$. spectabilis and $V$. zygantha in this study, the hierarchical cluster analysis suggests that they are highly likely to show it. Garnock-Jones and Lloyd (2004) described the last three as hygrochastic and opening after wetting was also observed in $V$. jovellanoides (Davidson et al., 2009). According to the cluster analysis, erect narrowly angustiseptate capsules, a short peduncle and solitary and/or few-flowered inflorescences, as seen in all these species seem to be characters associated with hygrochasy in Veronica. Juan et al. $(1997,2000)$ found that the compression of the capsule is strongly related to the cohesion tissue. According to Fahn and Werker (1972) a cohesion mechanism is based on the water content of the cell lumen, the 
change of which also results in tissue movement. We assume that the cohesion tissue described by Juan et al. (1997) might in fact be swelling tissue, since its description is similar to that of swelling tissue in hygrochastic Veronica and our preliminary studies indicate that $V$. arvensis is hygrochastic as well. It appears that the traits associated with hygrochasy in New Zealand Veronica are a syndrome of the functionally related hygrochastic species. Narrowly angustiseptate capsules only occur in hygrochastic species regardless of their position in the phylogeny (Albach and Meudt, 2010) and cushion plants can be found both in the speedwell hebe and snow hebe clade (Albach and Meudt, 2010).

Although the snow hebe and speedwell hebe clades both contain species with hygrochastic capsules, no studies have demonstrated a sister relationship for them (Garnock-Jones, 1993; Wagstaff and Garnock-Jones, 2000; Wagstaff et al., 2002; Albach and Meudt, 2010). Further, although all snow hebes have hygrochastic capsules, only a few speedwell hebes are hygrochastic and these species do not form a subclade or a basal grade within that group. The snow hebe and speedwell hebe clades diverge from adjacent nodes on the stem leading to the crown hebe clade (Albach and Meudt, 2010). It is thus unclear whether hygrochasy in New Zealand Veronica has evolved once and been lost at least once or has evolved independently in two or more lineages. The possible hybrid origin of morphologically anomalous species in the speedwell hebe clade, such as the tetraploid $V$. spathulata, has not been investigated in detail. The presence of hygrochastic dehiscence in other groups of Veronica, e.g. V. arvensis (subg. Chamaedrys) suggests the character is labile in the genus but further study is needed to confirm this.

The biomechanics of hygrochastic capsule opening in Veronica is based on a simple swelling tissue. The direction of the swelling is governed by the arrangement of 
swelling and resistance tissue. Our findings correspond with earlier studies of hygrochastic movements and are based on the same general principles (Fahn and Werker, 1972; Poppendieck, 1995). However, in contrast to previously studied hygrochastic species from arid areas (Poppendieck, 1995; Parolin, 2001), the capsules of the different hygrochastic Veronica are all similar, exhibit a much simpler mechanism and open in relatively short time (unpublished data). For example, hygrochastic Oenothera species show different structural complexity, which, depending on position of the swelling and resistance tissue influences the speed of the opening and closing of the capsules (Poppendieck, 1995). Furthermore, Aizoaceae in southern Africa exhibit a range of hygrochastic fruits, from simple fruits (e.g. in Mesembryanthemum) to very complex dispersal units (e.g. in Ruschia). The more complex systems have features such as closing bodies, funicles, valve wings, membranous locule lids, seed pockets and expanding keels, which mainly ensure the retention of some seeds in the capsule, and the release of seeds only after a certain amount of rain (Van Oudtshoorn and Van Rooyen, 1999; Parolin, 2001). At the same time, these features allow the seeds to be dispersed over greater distances compared to the more simple fruits (Parolin, 2006).

The development of structures that retain seeds or only release a certain number of seeds over time appears to be an evolutionary response to the harsh environment where those hygrochastic species are found (Van Oudtshoorn and Van Rooyen, 1999). The seeds are stored on the plant until release and are therefore protected against seed predators, drought and unfavourable germination conditions.

However, it has also been proposed that restriction in space might be another advantage of being dispersed by raindrops. The distance seeds can travel with raindrops is very limited, even if fruit structures enable jet dispersal, which increases 
dispersal distance (Parolin, 2006). The guarantee of short-distance dispersal enables the seedling to establish in close proximity to the parent plant. Although this carries a risk of parent-offspring competition, chances are considerably higher that the seed will germinate in a suitable habitat rather than a more distant hostile environment where mortality of seeds is exceptionally high (Steinbrinck, 1883; Zohary, 1962; Ellner and Shmida, 1981; Ihlenfeldt, 1983).

Dispersal restriction in time plays a major role in desert plants but it does not seem to apply for New Zealand alpine plants, for wet germination conditions are available throughout the season (Wardle, 1991) and capsules open quickly after only a small amount of rain. Due to the position of hygrochastic capsules on the plant (mostly embedded in the cushion), wind-mediated dispersal is not available to them and raindrops seem to be the most effective dispersal agents. The capsules face upwards and once they are open and form a splash cup the seeds are exposed to rain and falling drops splash the seeds out.

Space restrictions could be a likely explanation for the evolution of hygrochasy in some alpine plants of New Zealand. The majority of them occupy patchy habitats, which are usually restricted in size and altitude (Mark and Adams, 1995). Dispersal in space is limited for species with simple hygrochastic capsules but the restriction in time is not very pronounced (Van Rooyen et al., 1990) and the simplicity of hygrochastic capsules of alpine Veronica might play an important role in restricting dispersal to their specific habitats. In limited patchy habitats, restricted dispersal is likely to be selected, providing an explanation for the evolution of hygrochastic rather than 'ripening dehiscent' species (Pufal and Garnock-Jones, in press). By keeping the seeds in the closed capsule and only exposing them during rainfall events, accidental dispersal by other means such as wind gusts or animals is not available for 
hygrochastic capsules and short-distance dispersal with the aid of raindrops highly probable. On the other hand, 'ripening dehiscent' capsules disperse the seeds independently of weather conditions. Since they are facing down and are open, seeds are easily dropped or shaken out by slight movements. The seeds are then exposed to the environment and can be blown away by wind at any time, which results in unpredictable dispersal distances. Tests of these hypotheses are presented in Pufal and Garnock-Jones (in press).

Our results suggest that hygrochasy in Veronica is more common than previously thought. Van der Pijl (1982) proposed that Veronica species in marshy habitats are hygrochastic as well but Juan et al. (1997) did not find evidence for hygrochasy in their study of Mediterranean Veronica. Our preliminary observations indicate that Veronica javanica and Veronica arvensis also possess hygrochastic capsules. Both species are invasive in New Zealand. Especially for alpine Veronica in New Zealand, hygrochasy can play a crucial role in plant dispersal but has so far been overlooked (Thorsen et al., 2009). But as Thorsen et al. (2009) emphasized, further research is necessary to close gaps in the knowledge of dispersal systems in New Zealand.

\subsection{References}

Albach, D. C., M. M. Martinez-Ortega, AND M. W. Chase. 2004. Veronica: Parallel morphological evolution and phylogeography in the Mediterranean. Plant Systematics and Evolution 246: 177-194.

Albach, D. C., M. M. Martinez-Otega, M. A. Fischer, AND M. W. Chase. 2004. A new classification of the tribe Veroniceae - problems and a possible solution. Taxon 53: 429-452.

AlbaCH, D. C., AND H. M. MeudT 2010. Phylogeny of Veronica in the Southern and Northern Hemispheres based on plastid, nuclear ribosomal and nuclear low-copy DNA. Molecular Phylogenetics and Evolution 54: 457-471.

ANgiosperm Phylogeny Group. 2003. An update of the Angiosperm Phylogeny Group classification for the orders and families of flowering plants: APG II. Botanical Journal of the Linnean Society 141: 399-436.

CRAWLeY, M.J. 2007. The R Book. John Wiley \& Sons, Ltd., Chichester, England.

DARWIN, C. 1865. On the movements and habits of climbing plants. Journal of the Linnean Society of London (Botany) 9: 1-118. 
DARWIN, C., AND F. DARWIN. 1880. The power of movement in plants. J. Murray, London.

DAVIDSON, G.R., P.J. DE LANGE AND P.J. GARNOCK-JONES. 2009. Two additional indigenous species of Veronica (Plantaginaceae): $V$. jovellanoides, a new and highly endangered species, and V. plebeia R.Br. New Zealand Journal of Botany 47: 271279

EDWARDS, W., AND A. T. Moles. 2009. Re-contemplate an entangled bank: The Power of Movements in Plants revisited. Botanical Journal of the Linnean Society 160: 111118.

ELLNER, S., AND A. SHMIDA. 1981. Why are adaptations for long-range seed dispersal rare in desert plants? . Oecologia (Berlin) 51: 133-144.

FAHN, A., AND E. WERKER. 1972. Anatomical mechanisms of seed dispersal. In T. T. Kozlowski [ed.], Seed Biology, 152-221. Academic Press, New York, USA.

GARnock-JoneS, P., D. AlBACH, AND B. G. BRIGGS. 2007. Botanical names in Southern Hemisphere Veronica (Plantaginaceae): sect. Detzneria, sect. Hebe, and sect. Labiatoides. Taxon 56: 571-582.

GARNOCK-JONES, P. J. 1993. Phylogeny of the Hebe complex (Scrophulariaceae: Veroniceae). Australian Systematic Botany 6: 457-479.

GARnOCK-Jones, P. J., AND D. G. LlOYD. 2004. A taxonomic revision of Parahebe (Plantaginaceae) in New Zealand. New Zealand Journal of Botany 42: 181-232.

GARSIDE, S., AND S. LOCKYER. 1930. Seed dispersal from the hygroscopic fruits of Mesembryanthemum carpanthea (Mesembryanthemum) pomeridiana, N. E. Br. Annals of Botany 44: 639-U636.

GURR, G. 1953. A practical manual of medical and biological staining techniques. Leonard Hill Limited, London, UK. . 1963. Biological staining methods, London.

GUTTERMAN, Y. 1990. Seed dispersal by rain (ombrohydrochory) in some of the flowering desert plants in the deserts of Israel and the Sinai Peninsula. Mitteilungen aus dem Institut fuer Allgemeine Botanik Hamburg 22b: 841-852.

. 1994. Strategies of seed dispersal and germination in plants inhabiting deserts Botanical Review 60: 373-425.

GutTerman, Y., AND S. GinOTT. 1994. Long-term protected 'seed bank' in dry inflorescences of Asteriscus pygmaeus achene dispersal mechanism and germination. Annals of Botany 97: 47-55.

Hegazy, A. K., H. N. BARAKAT, AND H. F. KABIEL. 2006. Anatomical significance of the hygrochastic movement in Anastatica hierochuntica. Annals of Botany 97: 47-55.

IHLENFELDT, H.-D. 1983. Dispersal of Mesembryanthemaceae in arid habitats. Sonderbaende des Naturwissenschaftlichen Vereins Hamburg 7: 381-390.

JuAn, R., I. Fernandez, AND J. PASTOR. 1997. Scanning electron and light microscope study of the fruits and seeds of Chaenorrhinum from SE Spain. Lagascalia 20: 117128.

JUAN, R., J. PASTOR, AND I. FERNANDEZ. 2000. SEM and light microscope observations on fruit and seeds in Scrophulariaceae from Southwest Spain and their systematic significance. Annals of Botany (London) 86: 323-338.

KARBAN, R. 2008. Plant behaviour and communication. Ecology Letters 11: 727-739.

MARK, A. F., AND N. M. ADAMS. 1995. New Zealand alpine plants fully revised. Godwit Publishing, Auckland, New Zealand.

MEudT, H. M. 2008. Taxonomic revision of Australasian snow hebes (Veronica, Plantaginaceae). Australian Systematic Botany 21: 387-421.

MEUDT, H. M., AND M. J. BAYLY. 2008. Phylogeographic patterns in the Australasian genus Chionohebe (Veronica s.l., Plantaginaceae) based on AFLP and chloroplast DNA sequences. Molecular Phylogenetics and Evolution 47: 319-338.

NAKANISHI, H. 2002. Splash seed dispersal by raindrops. Ecological Research 17: 663-671.

PAROLIN, P. 2001. Seed expulsion in fruits of Mesembryanthema (Aizoaceae): A mechanistic approach to study the effect of fruit morphological structures on seed dispersal. Flora (Jena) 196: 313-322. 
. 2006. Ombrohydrochory: Rain-operated seed dispersal in plants - With special regard to jet-action dispersal in Aizoaceae. Flora (Jena) 201: 511-518.

POPPENDIECK, H.-H. 1995. Hygrochastic capsules in Oenothera (Onagraceae). Mitteilungen aus dem Institut fuer Allgemeine Botanik Hamburg 25: 99-115.

PUFAL, G. AND P. GARNOCK-JONES. 2010. Hygrochastic capsule dehiscence supports safe site strategies in New Zealand alpine Veronica (plantaginaceae). Annals of Botany: in press.

R Development Core Team. 2005. R: A language and environment for statistical computing. R Foundation for statistical computing, Vienna, Austria.

STEINBRINCK, C. 1883. Ueber einige Fruchtgehaeuse, die ihre Samen infolge von Benetzung freilegen. Berichte der Deutschen Botanischen Gesellschaft 1: 339-347.

THORSEN, M.J., DiCKINSON, K.J.M. AND P.J. SEDDON 2009. Seed dispersal systems in the New Zealand flora. Perspectives in Plant Ecology, Evolution and Systematics doi:10.1016/j.ppees.2009.06.001

ThulIN, M. 1987. A new species of Xylocalyx (Scrophulariaceae) from Somalia. Nordic Journal of Botany 7: 267-269.

VAN DER PIJL, L. 1982. Principles of dispersal in higher plants. Springer-Verlag, Berlin, Germany.

VAN OUdTSHOORn, R. K., AND M. W. VAN ROOYEN. 1999. Dispersal biology of desert plants. Springer-Verlag, Berlin, Germany.

VAn RoOyen, M. W., G. K. Theron, AND N. GrobbelaAR. 1990. Life form and dispersal spectra of the flora of Namaqualand, South Africa Journal of Arid Environments 19: 133-146.

WALCK, J. L., AND S. N. HidAYATI. 2007. Ombrohydrochory and its relationship to seed dispersal and germination strategies in two temperate North American Oenothera species (Onagraceae). International Journal of Plant Sciences 168: 1279-1290.

WARDLE, P. 1991. Vegetation of New Zealand. Cambridge University Press, London, UK.

ZOHARY, M. 1962. Plant life of Palestine. Reinhold Press, London, UK.

ZOHARY, M., AND A. FAHN. 1941. Anatomical-carpological observations in some hygrochastic plants of the oriental flora. Palestinian Journal of Botany: 125-135. 


\section{CHAPTER THREE}

\section{The Influence of Hygrochastic Capsule Dehiscence on Seed}

\section{Dispersal and Species Distribution of New Zealand Alpine}

\section{Veronica}

Chapter 3.2 is published in Annals of Botany with the title "Hygrochastic capsule dehiscence supports safe site strategies in New Zealand alpine Veronica (Plantaginaceae)" by G. Pufal and P. Garnock-Jones. The co-authors' role was restricted to supervision and advice.

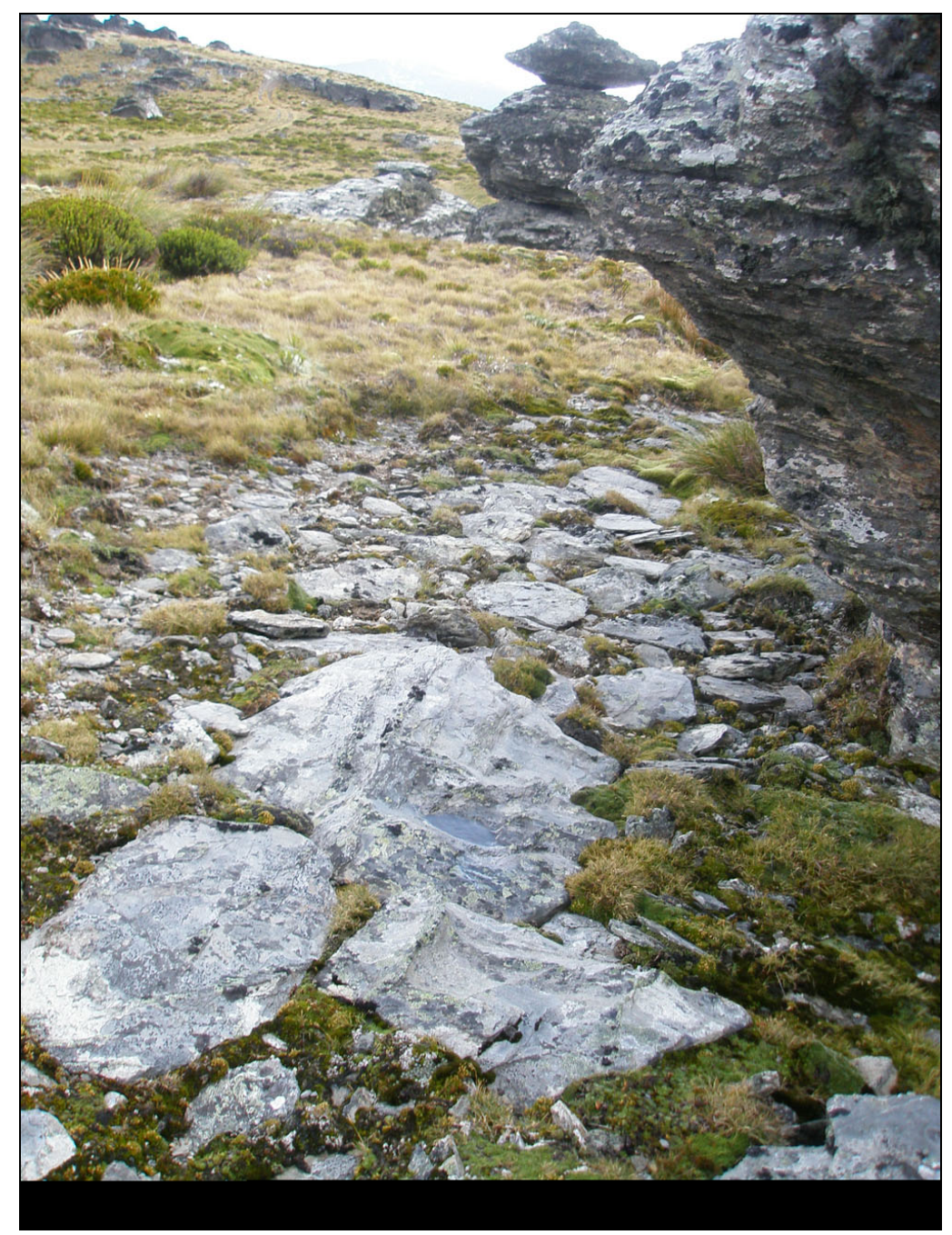

FIG 3.1 Habitat patch with Veronica densifolia and $V$. thomsonii at Blue Lake, Garvie Mountains, New Zealand. 


\section{Chapter 3.1}

\section{Overview}

Chapter 3.1 presents two linked research projects on the association between hygrochastic capsule dehiscence and restricted habitat patches.

In Chapter Two, hygrochasy was described in detail in several New Zealand Veronica. The majority of those species occur exclusively in high alpine areas predominantly on scree, in rock crevices or sparsely vegetated cushion fields. Hygrochastic capsule dehiscence is usually associated with plants of arid regions, which likewise grow in harsh environments and are patchily distributed. Hypotheses that were developed for desert species state that hygrochasy is a means of restricting dispersal in time (bradyspory) and space (atelechory). The risks associated with dispersal and germination are spread over several rainfall events and raindrops as dispersal agents ensure that seeds are only transported over a short distance, increasing the chance of germinating in the favourable parental habitat. Being atelechoric is an advantage if hygrochastic species are adapted to very specific edaphic conditions that can only be found in restricted areas.

In Chapter 3.2 (Hygrochastic capsule dehiscence supports safe site strategies in New Zealand alpine Veronica (Plantaginaceae)) I investigate the influence of dispersal distance on directed dispersal of seeds to safe sites within small habitat patches. Measurements of dispersal distances of several hygrochastic alpine Veronica were analysed in the laboratory and field observations of one species were made as well. Habitat patch size was estimated and compared between several hygrochastic and non-hygrochastic species. I hypothesize that hygrochasy in alpine Veronica in New Zealand serves as a spatial restriction of seed dispersal within a small suitable habitat 
patch with available safe sites in a heterogenous environment. This part of the chapter is published in Annals of Botany.

In Chapter 3.3 the environmental amplitude of hygrochastic Veronica in comparison with related non-hygrochastic species was tested in order to gain knowledge about the width of the ecological niche of hygrochastic Veronica. The multivariate analysis is based on environmental variables extracted from LENZ IV, a Landcare Research database used in arcMap. The coordinates used in arcMap are from locations chosen from three different herbarium databases. The aim of this chapter is to establish if hygrochastic species in alpine habitats are specialists and have small environmental niches compared to their non-hygrochastic relatives. I also discuss if LENZ and the use of herbarium records is an appropriate tool to assess ecological niche breadth. 


\section{Chapter 3.2}

\section{Hygrochastic Capsule Dehiscence supports Safe Site Strategies in New Zealand Alpine Veronica (Plantaginaceae)}

\subsubsection{ABSTRACT}

- Background and Aims Hygrochasy is a capsule opening mechanism predominantly associated with plants in arid habitats, where it facilitates spatially and temporally restricted dispersal. Recently, hygrochastic capsules were described in detail for the first time in alpine Veronica in New Zealand. The aim of the present study was to investigate whether hygrochastic capsules are an adaptation of alpine Veronica to achieve directed dispersal to safe sites. We expect that by limiting dispersal to rainfall events, distances travelled by seeds are short and confine them to small habitat patches where both seedlings and adults have a greater chance of survival.

- Methods Dispersal distances of five hygrochastic Veronica were measured under laboratory and field conditions and the seed shadow was analysed. Habitat patch size of hygrochastic Veronica and related non-hygrochastic species were estimated and compared.

- $\quad$ Key results Dispersal distances achieved by dispersal with raindrops did not exceed one metre but weather conditions could influence the even distribution of seeds around the parent plant. Compared to related Veronica species, hygrochastic Veronica mostly grow in small, restricted habitat patches surrounded by distinctly different habitats. These habitat patches provide safe sites for seeds due to their microtopography and occurrence of adult cushion plants. Non-hygrochastic Veronica 
can be predominantly found in large habitats without clearly defined borders and can be spread over long distances along rivers.

- Conclusions The results suggest that hygrochasy is a very effective mechanism of restricting seed dispersal to rainfall events and ensuring short-distance dispersal within a small habitat patch. It appears that it is an adaptation for directed dispersal to safe sites that only exist within the parent habitat.

Key words: dispersal, habitat patch, hygrochasy, New Zealand Alps, ombrohydrochory, safe sites, Veronica

\subsubsection{INTRODUCTION}

Plant dispersal is one of the most important stages in a plant's life cycle as it fulfils the role of colonizing new habitats, influences density and distribution of species and plays an important role in gene transfer for a usually stationary organism (Webb, 1998). A great variety of processes and strategies are involved in a plant's dispersal, which are usually linked to the morphology of the dispersal unit (Ellner and Shmida, 1981; Higgins et al., 2003; Hughes et al., 2006), i.e. the morphology of the dispersal unit defines the dispersal syndrome. These morphological dispersal syndromes (MDS) can be referred to as standard means of dispersal (Higgins et al., 2003) or classical dispersal syndromes, such as anemochory, zoochory, etc. One rather uncommon MDS is hygrochasy, a specific ballistic response by which dry, closed, woody capsules open under the influence of moisture, e.g. rain, and expose the seeds in a splash cup (Van der Pijl, 1982). Raindrops that fall into open capsules splash droplets out, taking the seeds with them over a short distance that is related to the size of the raindrop (Nakanishi, 2002). This occurs directly when seeds are freely exposed and indirectly 
when additional structures in the capsules transfer the raindrop's energy (Ihlenfeldt, 1983; Parolin, 2001). This latter dispersal strategy is known as ombrohydrochory, where both seed release and seed dispersal are triggered by rain (Van Oudtshoorn and Van Rooyen, 1999).

Hygrochasy is most famously associated with the Aizoaceae, with more than $98 \%$ of the species exhibiting hygrochastic capsules. It is also described as a characteristic of other plant species in arid regions such as Southern Africa, the Israeli desert or North America (Zohary and Fahn, 1941; Ihlenfeldt, 1983; Gutterman, 1994; Poppendieck, 1995; Parolin, 2001, 2006) and Somalia (Thulin, 1987). Less commonly, hygrochasy has been reported sporadically from plant species of other habitats, such as temperate meadows (Walck and Hidayati, 2007) or along streams (Nakanishi, 2002).

Hygrochastic capsules were also reported in several New Zealand Veronica in alpine habitats (Garnock-Jones, 1993; Garnock-Jones and Lloyd, 2004 as Parahebe and Chionohebe; G. Pufal, VUW, Wellington, New Zealand, unpubl. res.). The mechanism can be found in plants of the speedwell hebe and snow hebe groups (for phylogeny and groups see Albach and Meudt, 2010), which are characterized by either cushion or subshrub morphology and solitary, sessile capsules (Pufal et al., 2010).

New Zealand Veronica have evolved rapidly in the last 9 million years, which can partly be attributed to the variety of habitats present in the mountain regions, where the species most likely originated (Wagstaff et al., 2002). Most hygrochastic Veronica are found exclusively in the high alpine areas of the New Zealand Alps (exceptions in Pufal et al., 2010) There are four distinct plant community types in the high-alpine zone, which can be localized and heterogenous in distribution (Enting and Molloy, 1982). Fell-field habitats can usually be found on relatively stable rocks and consist of 
sparsely vegetated communities. A distinction can be made between wet and dry fellfield, differing in species composition (Mark and Dickinson, 1997). Scree habitats only occur on steep greywacke mountains in the rain shadow region of the South Island. Plant species found on scree are usually endemic to this habitat, being morphologically different from near relatives, and having a suite of common characteristics, such as fleshy glaucous leaves. Cushion fields are found in Central Otago, mostly on broad plateau summits. The vegetation is characterized by extreme dwarfism (Mark and Dickinson, 1997). Snowbanks occur only locally in the high alpine zone, where snow accumulates and persists well into summer. They also show very adapted vegetation, which differs greatly even locally. For more information on the New Zealand alpine zone refer to Mark and Dickinson (1997).

There are several hypotheses why plants evolved hygrochastic capsules; most of these stem from the investigation of species in arid regions. Gutterman (1994) argues that the seeds are protected in the capsule against drought and seed predators, both of which cause seed mortality in deserts. Capsules open only after sufficient rain has fallen and dispersal is therefore restricted in time to adequate rainfall events. The seeds are then dispersed and are able to germinate quickly in the now wet and favourable environment. Other authors also favour temporal restriction as the prevalent hypothesis for the evolution of hygrochastic dehiscence (Ellner and Shmida, 1981; Parolin 2001, 2006; Walck and Hidayati, 2007).

Van Rooyen (1990) classifies hygrochasy as an antitelechoric dispersal strategy, where dispersal is not only restricted in time but also space. According to Murbeck (1919, 1920) and Zohary (1937, 1962), desert species might have developed hygrochastic capsules as an adaptation to the harsh conditions of their environment with high seed mortality and germination success only in rare favourable sites. With 
an antitelechoric dispersal strategy the chances of the seeds landing and germinating in a suitable habitat are greatly increased. Especially in southern Africa, the plants are highly adapted to their specific habitat conditions. These can often only be found in small patches, which occur in a highly heterogenous environment of different habitat types (Eccles et al., 1999). The work of Ihlenfeldt (1983), Poppendieck (1995) and Parolin (2006) supports this hypothesis. However, most reports are anecdotal and few investigations have been made regarding dispersal distances in hygrochastic plants (but see Parolin (2001) and Nakanishi (2002)).

For the first time this study aims to apply the traditional hypotheses for hygrochasy in arid regions to hygrochastic species in alpine New Zealand. In alpine areas, reproducing with seeds is a high-risk strategy (Urbanska and Schultz, 1986; Koerner, 1999; Zoller and Lenzin, 2004). The seeds are subjected to numerous threats such as freezing temperatures, unsuitable germination conditions, formation of needle ice or insufficient soil conditions. Safe sites, with favourable conditions for seedlings, such as soil micro-topography, moisture, light conditions or temperature are highly advantageous in successful germination (Harper, 1977). Shelter from adult plants or seedlings dispersed in groups to form mutually sheltering clumps can also create safe sites (Zoller and Lenzin, 2004, 2006).

We propose that hygrochastic capsules of New Zealand alpine Veronica enforce short distance dispersal, which greatly increases the chance of the seed to land in a safe site within the parental habitat. We tested this by (1) measuring dispersal distances of several hygrochastic Veronica under laboratory and natural conditions, and (2) by comparing habitat patch sizes of hygrochastic Veronica with their non-hygrochastic relatives. 


\subsubsection{MATERIALS AND METHODS}

\subsubsection{Dispersal distance}

Veronica cheesemanii, $V$. densifolia, $V$. thomsonii, $V$. spathulata and $V$. planopetiolata were used in this experiment. All five species have been confirmed as hygrochastic by their anatomy, morphology and behaviour, with $V$. cheesemanii and $V$. thomsonii representing cushion plants, whereas $V$. densifolia, $V$. spathulata and $V$. planopetiolata are creeping subshrubs (Pufal et al., 2010).

The fruiting period of alpine Veronica is relatively short and varies greatly between locations (pers. obs.). We assumed that seeds were dispersed as soon as the capsule was ripe and rainfall occurred. In order to collect capsules of hygrochastic species still containing seeds, ten individuals of $V$. thomsonii and $V$. densifolia were covered with inverted plastic petri dishes to prevent rain from dispersing seeds. These were lined with shade cloth to limit sun damage, since the plastic of the petri dishes could potentially intensify the sunlight. The petri dishes were high enough that the plants were not harmed and air could move freely. This was done in spring, shortly after pollination and when plants were displaying unripe fruits.

In autumn, intact capsules from covered plants were collected and used in situ as follows. Capsules were mounted $2 \mathrm{~cm}$ above ground facing up (similar to their height in vivo $)$ and were placed in the middle of a white sheet $(2.5 \times 2.5 \mathrm{~m})$. Water was dropped from a height of $175 \mathrm{~cm}$, simulating rain (Parolin 2001). For a subset of the species the point pattern of expelled seeds on the sheet was noted in Cartesian coordinates (Cousens et al., 2008) and their distance from the capsule measured. Capsules of $V$. cheesemanii, $V$. planopetiolata and $V$. spathulata, which were found still containing seeds either in the field or in herbarium samples, were also included in this experiment. Additionally, this experiment was carried out in vivo, i.e. the same 
set-up was used outside in natural rain for a capsule of $V$. densifolia. However, due to the difficulties in terrain and under harsh weather conditions, the in vivo experiments were abandoned for other species.

The measured dispersal distances were used to create dispersal curves to show the frequency distribution of distances and densities. Here, distances of all seeds were used, even if seeds dispersed in clumps of two or more. Seed shadows were created by using the Cartesian coordinates. If several seeds were dispersed with one raindrop, they were only assigned one set of coordinates but their distance measurements were counted individually. The centroid was calculated to capture direction of dispersal. Descriptive statistics and comparisons between species were carried out using $R$ ( $R$ Development Core Team, 2005).

\subsubsection{Habitat patches}

Here, we define habitat patch as the area occupied by the respective investigated species, which is clearly different from the surrounding area. Two different methods were used to assess patch size and occupancy. These are outlined below as Method 1 and Method 2.

Method 1:

Patch size was measured in 13 locations for four hygrochastic species ( $V$. densifolia, V. cheesemanii, V. pulvinaris, V. thomsonii) (Appendix 3.2.1). Patches where hygrochastic species could be found were mostly very different from the surrounding vegetation and easy to distinguish. The overall size of the patch was estimated using two perpendicular distances through the patch where the species was found and then calculating the area as an ellipse (Fig. 3.2.1). Following Green (1983) we view the patch as safe site since all individuals of the given species could be found inside the 
patch, showing this habitat to be suitable for the species and surrounding area likely to be unsuitable. For comparison, patch size was also measured for five locations of nonhygrochastic species, using the same method (Appendix 3.2.1). Here, the habitat occupied by the respective species was not always easily distinguishable from the surrounding habitat. If the habitat patch was bigger than $100 \mathrm{~m}$ in length, we used 100 $\mathrm{m}$ as cut-off point and thus our estimates might be too small. Hygrochastic and nonhygrochastic species were compared using Mann-Whitney-U tests.

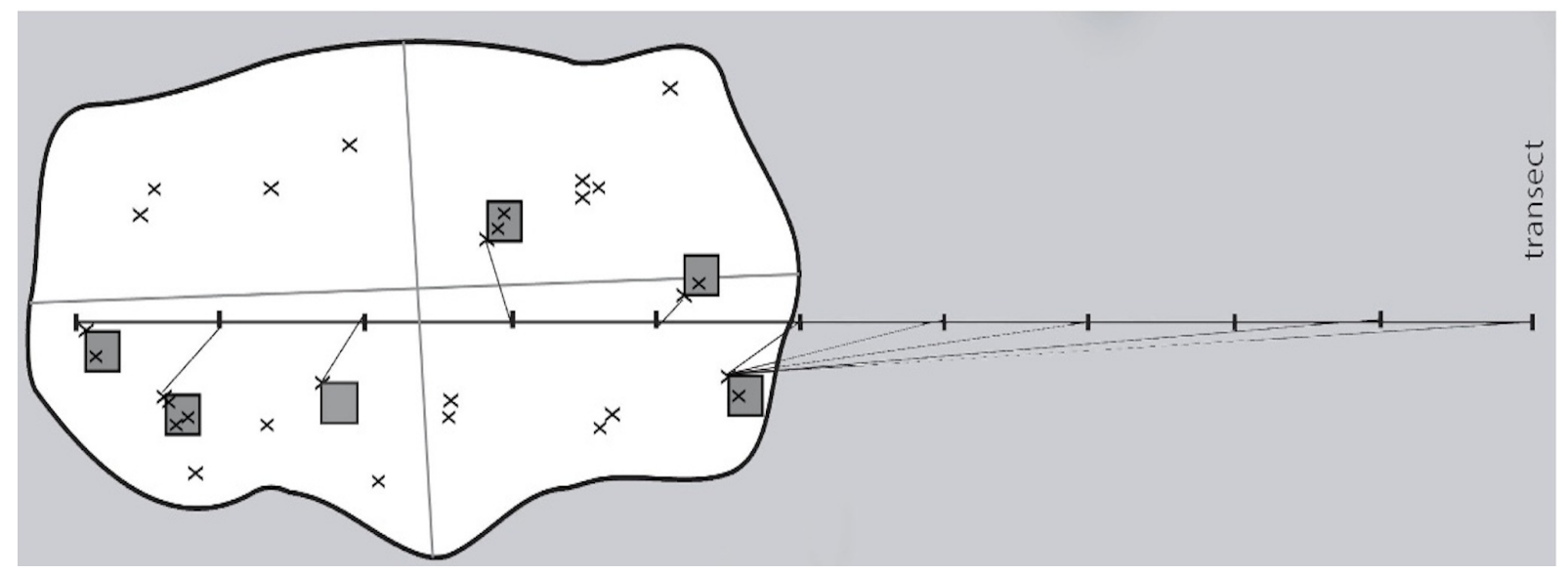

FIG 3.2.1 The sample design for habitat measurement. Distances from fixed points along a $100 \mathrm{~m}$ transect (starting at the first individual in the habitat patch) to nearest individuals ( $\mathrm{x}$ ) within a habitat (white area) were measured. Individuals within a $1 \mathrm{~m}^{2}$ (grey square) were counted and the habitat patch size was estimated using two perpendicular measurements (grey lines) from the borders of the habitat patch to the surrounding habitat (grey area). Note that this drawing is not scaled.

\section{Method 2:}

Especially for non-hygrochastic species with large habitat patches, the estimation of patch size area might bias results, therefore we used a different approach to assess patch site and occupancy. Once a patch containing the respective species was identified, a $100 \mathrm{~m}$ transect was aligned with the long axis of the population, starting at one outermost individual. Beginning with $0 \mathrm{~m}$ and ending with $100 \mathrm{~m}, 11$ points 
were fixed along the transect in $10 \mathrm{~m}$ steps and the distance from each point to the nearest plant individual was measured (Fig. 3.2.1). The first point at $0 \mathrm{~m}$ was excluded, since it was the starting point of the transect and therefore 0 . This method was used at all locations for both hygrochastic and non-hygrochastic species. Mean distances from transect points to nearest individuals for each population were compared between hygrochastic and non-hygrochastic species using Mann-WhitneyU tests. From the mean distances we can determine those populations that occupy a small habitat patch. When transect points lie outside a habitat patch, the measurements to plant individuals lead back into the habitat patch, resulting in bigger mean distances between transect points and individuals (Fig. 3.2.1).

To ensure that large mean distances did not result from large populations with single, randomly dispersed individuals, quadrats $\left(1 \mathrm{~m}^{2}\right)$ were laid out parallel to the transect and individuals within it were counted (Fig. 3.2.1). Nearest individuals to a transect point were used as corner point, resulting in a maximum of 11 quadrats per transect. If habitats were smaller than the transect, a smaller number of quadrats were used, since each quadrat was only counted once.

Densities within the quadrats were compared between hygrochastic and nonhygrochastic species using Mann-Whitney-U tests. Statistical analysis was carried out using R (R Development Core Team, 2005).

In five locations of hygrochastic species, nearest neighbour measurements were carried out to identify the dispersal pattern (Appendix 3.2.1). We used the t-square index (Ludwig and Reynolds, 1988) for ten random points per location. They were chosen by throwing a marker with closed eyes in different directions from the estimated middle of the population. From this marker, the distance to the nearest individual was measured $\left(\mathrm{x}_{\mathrm{i}}\right)$ and from this individual the distance to the nearest 
neighbour was measured as well $\left(\mathrm{y}_{\mathrm{i}}\right)$. The index of spatial pattern $(\mathrm{C})$ was calculated to find out if the distribution of individuals was random $(\mathrm{C}=0.5)$, uniform $(\mathrm{C}<<0.5)$ or clumped ( $\mathrm{C}>>0.5$ ), using Ludwig and Reynolds (1988) formula. To test for significance, $\mathrm{z}$ was calculated and compared with $\mathrm{p}$ from a probability table for standard normal distribution $(\mathrm{z}=1.96$ at $\mathrm{p}=0.05)$. 


\subsubsection{RESULTS}

\subsubsection{Dispersal distance}

In the dispersal distance experiments, seeds were not analysed per capsule but per respective species. Since Veronica densifolia and $V$. thomsonii were purposely prepared in the field for seed collection, they retained most of their seeds and have therefore higher seed numbers than $V$. cheesemanii, $V$. spathulata and $V$. planopetiolata (Table 3.2.1). The furthest dispersal event recorded was for $V$. densifolia, whereas $V$. cheesemanii shows the lowest dispersal distance. Combined, all species disperse their seeds exclusively over a short distance (Table 3.2.1).

Table 3.2.1 Descriptive statistics for dispersal distances [cm] of seeds from 5 hygrochastic Veronica species.

\begin{tabular}{|lllllll||}
\hline Species & $\#$ & $\min$ & $\max$ & med & mean & sd \\
\hline$V$. densifolia in situ & 208 & 0.3 & 110.5 & 11.85 & 12.63 & 9.15 \\
$V$. thomsonii & 55 & 0.5 & 38.7 & 8 & 10.01 & 8.79 \\
$V$. cheesemanii & 9 & 1 & 12 & 6 & 5.54 & 3.39 \\
$V$. spathulata & 63 & 0.3 & 54.9 & 5.9 & 10.69 & 13.54 \\
$V$. planopetiolata & 8 & 1 & 23 & 19.5 & 15.81 & 7.59 \\
total & 342 & 0.3 & 110.5 & 8.95 & 13.57 & 14.52 \\
\hline$V$. densifolia in vivo & 14 & 3.5 & 55.2 & 35 & 32.16 & 16.44 \\
\hline \hline
\end{tabular}

A Kruskal-Wallis test showed significant differences in dispersal distances among the hygrochastic species (chi-squared $=15.34, \mathrm{p}=0.005$ ) and subsequently, MannWhitney-U tests were conducted between all species. $V$. densifolia and $V$. planopetiolata dispersed their seeds significantly further than the other species (Fig. 3.2.2). 


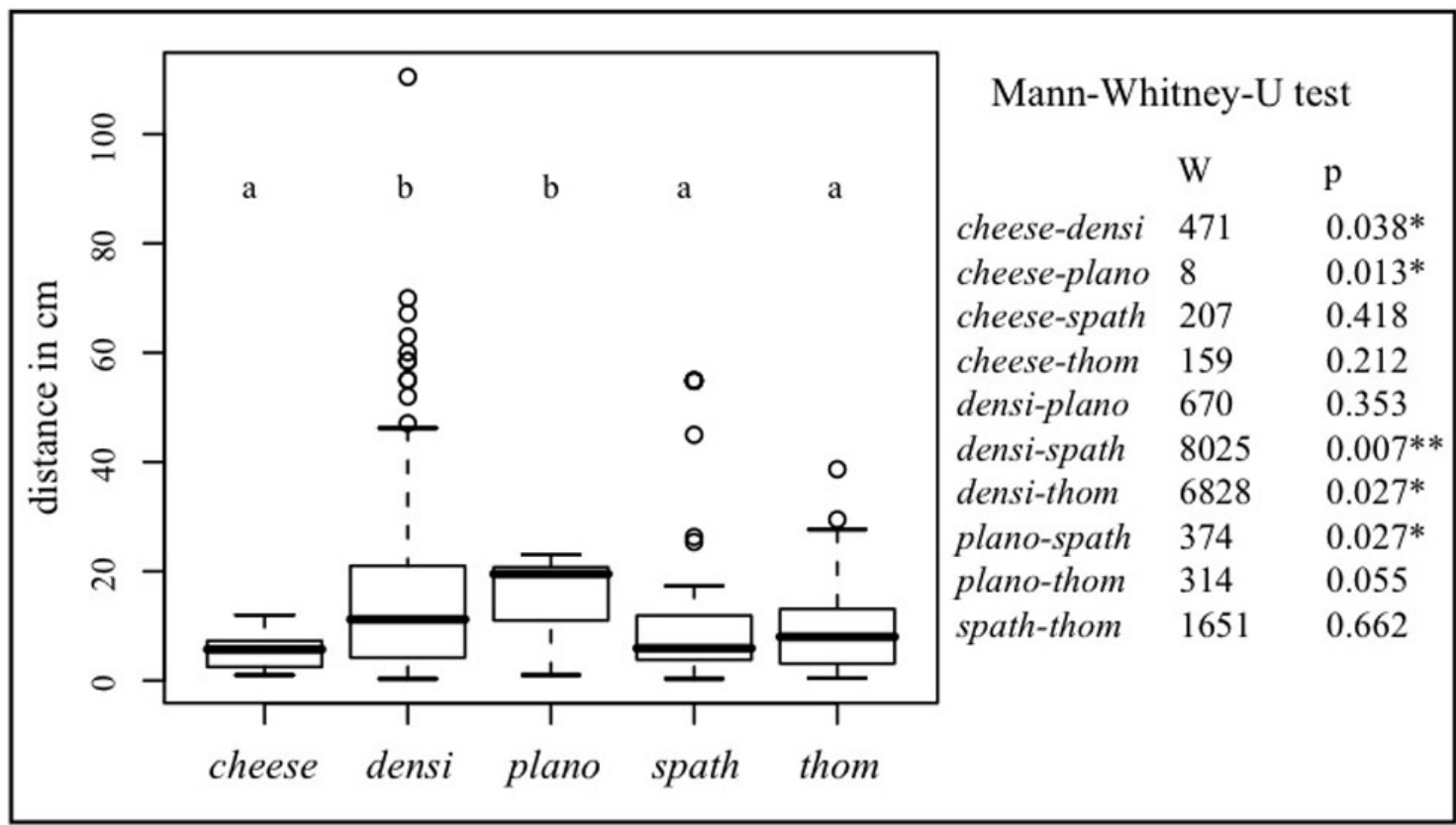

FIG 3.2.2 Boxplots of dispersal distances for 5 hygrochastic Veronica and results for MannWhitney-U tests between species. Significantly different species are marked with "a" and "b" in the figure. $(V$. cheesemanii $=$ cheese, $V$. densifolia $=$ densi, $V$. planopetiolata $=$ plano, $V$. spathulata $=$ spath, $V$. thomsonii $=$ thom)

One capsule of $V$. densifolia was used in an outdoor experiment under rain conditions ( $V$. densifolia in vivo), which resulted in the dispersal of 14 seeds. Under those conditions, $V$. densifolia dispersed significantly further than under laboratory conditions (Mann-Whitney-U: W = 382, p < 0.0001).

Frequency distribution and density distribution curves were created for $V$. densifolia, V. thomsonii and V. spathulata (Fig. 3.3.3). The histogram of the frequency distribution shows that all three species disperse more than $50 \%$ of their total seeds less than $10 \mathrm{~cm}$ from the source. All three species follow a Weibull function with a short tail. 
V. densifolia

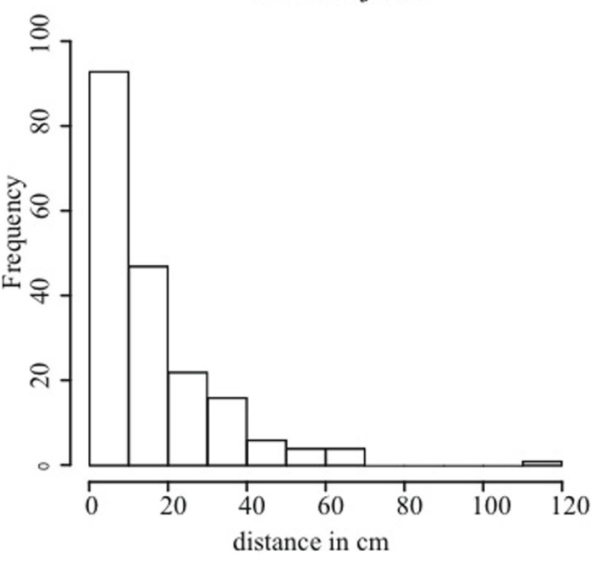

V. spathulata

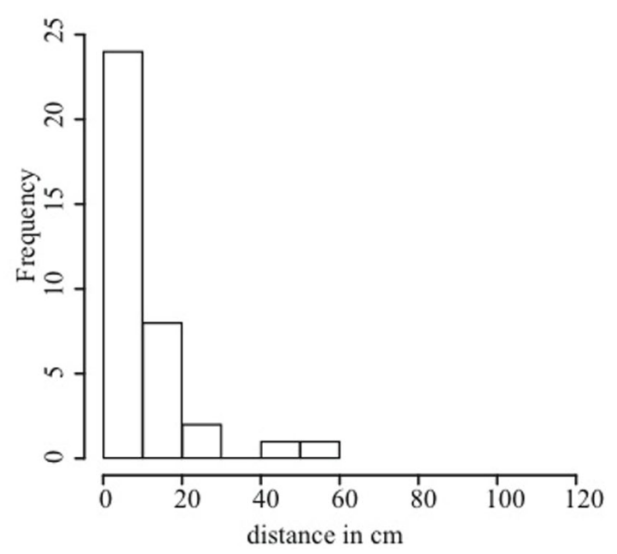

V. thomsonii

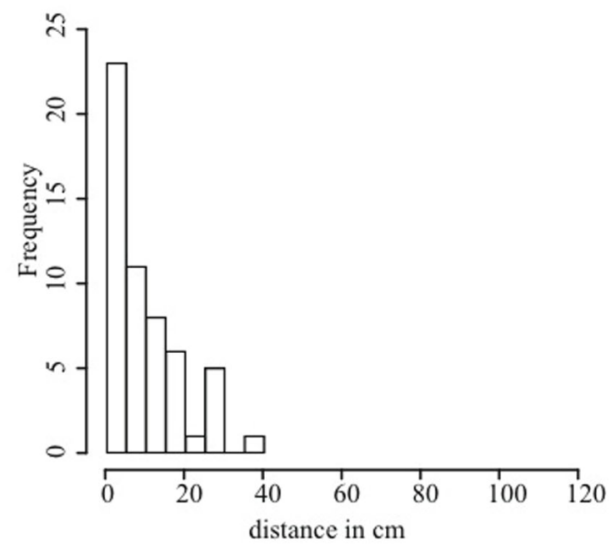

V. densifolia

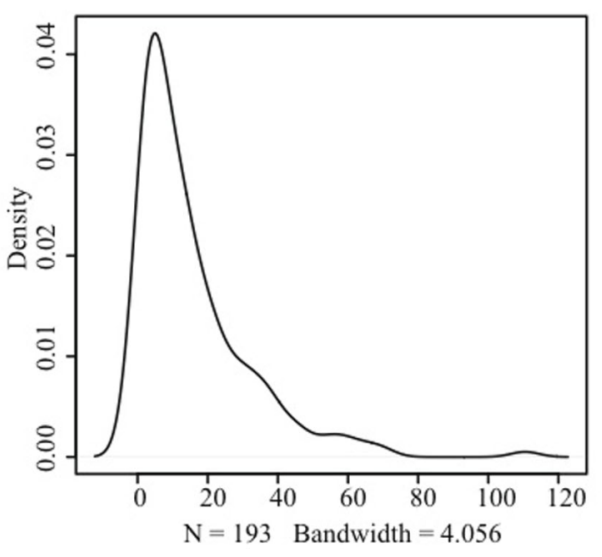

V. spathulata

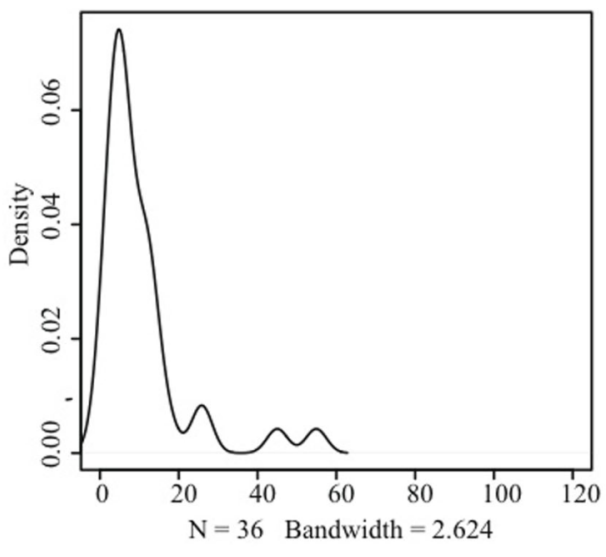

V. thomsonii

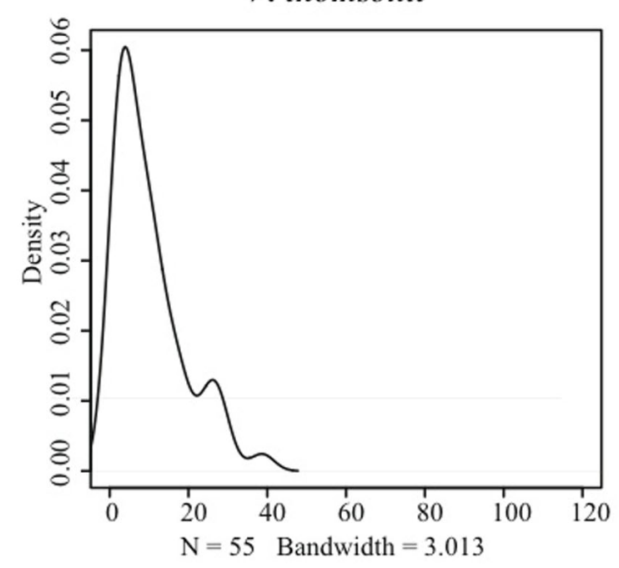

FIG 3.2.3 Histogram of the frequency distribution (A) and line graph of the density distribution (B) of seeds of $V$. densifolia, V. spathulata and $V$. thomsonii. The height of each histogram column represents the number of seeds found within a range of distances (for $V$. densifolia and $V$. spathulata $10 \mathrm{~cm}$ per column, $V$. thomsonii $5 \mathrm{~cm}$ per column). 
Cartesian coordinates from $V$. densifolia and $V$. thomsonii were used to visualize the seed shadow, showing again dispersal distances but also the directions in which seeds were dispersed as well as the $25 \%, 50 \%$ and $75 \%$ quartiles as circles around the source (Fig. 3.2.4). The net movement of the seeds away from the source can be measured by the position and distance of the centroid (mean of Cartesian coordinates).

The centroids of $V$. thomsonii and $V$. densifolia in vitro are $0.81 \mathrm{~cm}$ and $1.91 \mathrm{~cm}$ away from the source, respectively, whereas the centroid of $V$. densifolia from the outdoor experiment is $32.41 \mathrm{~cm}$ away from the source and located in the first quarter (Fig. 3.2.4). 


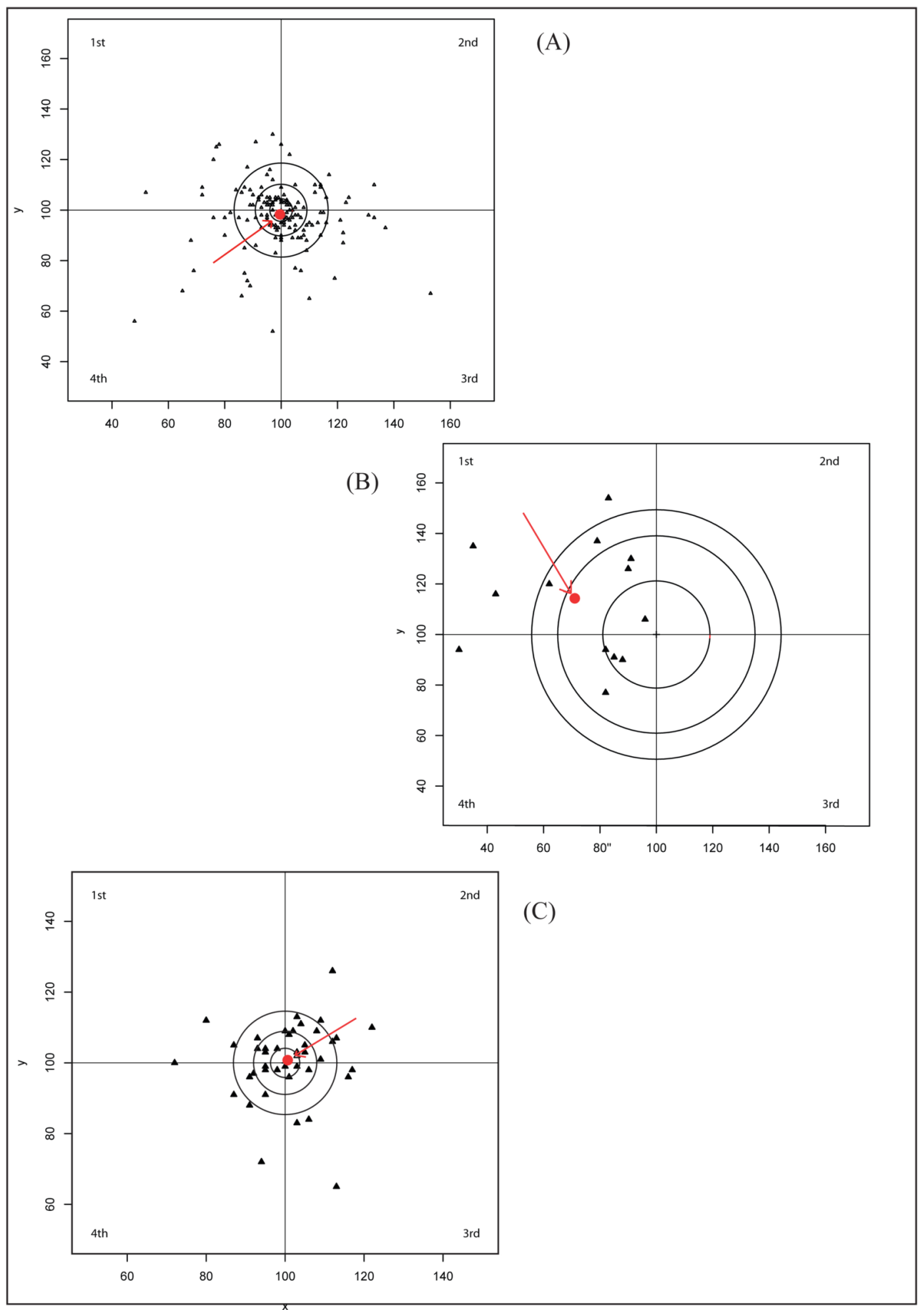

FIG 3.2.4 The seed shadow of $V$. densifolia in situ (A) and in vivo (B) and of $V$. thomsonii (C). The seed source is located at $\mathrm{x}=100, \mathrm{y}=100$, seed locations are triangles and the centroid is a red circle, pointed out by a red arrow. The area around the source was split into four quarters. Concentric circles show the $25 \%, 50 \%$ and $75 \%$ quartiles of dispersal distances from the source. Note that $\mathrm{C}$ is scaled differently from $\mathrm{A}$ and $\mathrm{B}$. 


\subsubsection{Habitat patches}

The habitat patches of hygrochastic species used in this study were between $40 \mathrm{~m}^{2}$ and $750 \mathrm{~m}^{2}$ in area, whereas patches of non-hygrochastic species were significantly larger (Mann-Whitney-U: $\mathrm{W}=11, \mathrm{p}=0.038$ ) between $270 \mathrm{~m}^{2}$ and $3920 \mathrm{~m}^{2}$ (Table 3.2.2). In hygrochastic species, no individuals of the respective species were found outside the habitat patch, but habitats at Arthur's Pass Village, Kea Point, Otira Valley and Fox Glacier were bigger than the $100 \mathrm{~m}$ cut-off distance for the patch size. Individuals outside the measured area were not taken into account.

Table 3.2.2 Locations and sizes of habitat patches (area) for hygrochastic species (BOLD) and non-hygrochastic species (detailed location vouchers in appendix 1), mean distance between transect point and random individuals as well as mean number of individuals per quadrat (\#).

\begin{tabular}{|c|c|c|c|c|}
\hline species & location & habitat & transect & quadrat \\
\hline & & area & distance & $\#$ \\
\hline V. cheesemanii & Mt Robert Skifield & 314.16 & 21.5 & 1.8 \\
\hline V. cheesemanii & Mt Robert Ridgetrack & 746.13 & 2.68 & 3.8 \\
\hline V. cheesemanii & Mole Tops scree & 39.27 & 50.01 & 2.5 \\
\hline V. cheesemanii & Mole Tops & 530.14 & 27.28 & 1.2 \\
\hline$V$. densifolia & Waiorau Snow Farm & 628.32 & 2.18 & 2 \\
\hline$V$. densifolia & Coronet Peak & 39.27 & 39.87 & 3.5 \\
\hline$V$. densifolia & Remarkables Skifield & 196.35 & 23.34 & 6.4 \\
\hline V.pulvinaris & Mt Robert Skifield & 471.24 & 23.33 & 7 \\
\hline V.pulvinaris & Mole Tops & 39.27 & 45.06 & 2.5 \\
\hline V.pulvinaris & Mt Robert Ridgetrack & 157.08 & 23.58 & 4.4 \\
\hline V.thomsonii & Remarkables Skifield & 219.91 & 24.47 & 2.5 \\
\hline V.thomsonii & Remarkables Skifield & 471.24 & 6.09 & 2 \\
\hline$V$. thomsonii & Remarkables track & 58.90 & 50.4 & 3.5 \\
\hline$V$. decora & Arthurs Pass village & 1570.80 & 0.43 & 5.8 \\
\hline$V$. decora & Kea Point, Mount Cook Village & 3926.99 & 0.13 & 16 \\
\hline V. lyallii & Klondyke corner Arthurs pass & 274.89 & 9.02 & 7.8 \\
\hline V. lyallii & Otira valley & 392.70 & 2.37 & 5.5 \\
\hline V. lyallii & Fox Glacier walking track & 2356.19 & 1.4 & 6.3 \\
\hline
\end{tabular}


When comparing mean distances from points on the $100 \mathrm{~m}$ transect to the nearest individual, hygrochastic species showed significantly longer distances than nonhygrochastic species (Mann-Whitney-U: $\mathrm{W}=5510.5, \mathrm{p}<0.0001$ ). Comparing the number of individuals within quadrats in each location, non-hygrochastic species had significantly more individuals per square (Mann-Whitney-U: $\mathrm{W}=798, \mathrm{p}<0.0001$ ). All squares contained on average more than one individual, which excludes the possibility that large measured distances are due to the occurrence of single widespread individuals.

The t-square index revealed that individuals showed a clumped distribution in all tested sites (Table 3.2.3) except for $V$. cheesemanii at Mt Patriarch, where $\mathrm{z}$ is not significant.

Table 3.2.3 The t-square index of nearest neighbour measurements of hygrochastic Veronica. For detailed location description see Appendix 3.2.1. Significance is indicated with *.

\begin{tabular}{||llll||}
\hline species & location & $\mathrm{C}$ & $\mathrm{z}$ \\
\hline V. cheesemanii & Mt. Patriarch & 0.535 & 0.385 \\
V. cheesemanii & Mt Robert Skifield & 0.824 & $3.546^{* * *}$ \\
V. densifolia & Remarkables Skifield & 0.858 & $3.926^{* * *}$ \\
$V$. densifolia & Blue Lake & 0.875 & $4.104^{* * *}$ \\
V. pulvinaris & Mt Robert Skifield & 0.734 & $2.561^{*}$ \\
\hline
\end{tabular}

\subsubsection{DISCUSSION}

In this study we tested whether hygrochastic capsules in New Zealand alpine Veronica restrict seed dispersal to small safe sites. We were able to confirm in laboratory tests that seeds from hygrochastic capsules only disperse over a short distance. Falling raindrops transport seeds for short distances depending on the raindrop's size (Nakanishi, 2002). In dry weather the capsules stay closed, therefore raindrops become the only available primary dispersal agent. Hygrochastic species 
can be found in scree, on rocky surfaces or gravel (Mark and Adams, 1995; GarnockJones and Lloyd, 2004; Meudt, 2008). These habitats show a microtopography of small cracks, crevices (rocky surfaces) or small gaps and depressions between stones (scree and gravel), which can trap seeds very easily. Therefore, secondary dispersal is highly unlikely and the dispersal distances achieved with raindrops are probably the absolute dispersal distances. The growth form of hygrochastic Veronica also complies with findings by Van Rooyen (1990). She states that most hygrochastic plants in Namaqualand, South Africa are chamaephytes or hemicryptophytes with antitelechory as the prominent dispersal strategy and simple capsules restrict dispersal spatially as opposed to temporally in more complex capsules. Hygrochastic alpine Veronica in New Zealand are hemicryptophytes with simple capsules and our data support antitelechory as the primary dispersal strategy.

Although there were differences among species regarding dispersal distance, all distances achieved were less than one metre. The probability density function is a Weibull function with a short tail. In the laboratory the majority of seeds landed very close to the parent plant and dispersed evenly around the source. However, results of an outdoor study of $V$. densifolia indicate that dispersal can become directional depending on the direction of wind and rain. These data suggest that under natural conditions seeds are not dispersed directly next to the parent plant (as was seen under laboratory conditions), preventing possible parent-offspring competition. Nevertheless, the maximum dispersal distance did not increase under natural conditions, confirming exclusive short-distance dispersal as seen in the laboratory studies. 
We established that hygrochastic alpine Veronica disperse following an antitelechoric strategy as an adaptation to habitats that are small in area and surrounded by stressful environments with harsh conditions for seedling survival. The surrounding area is often strikingly different, densely vegetated and has a very different species composition (Fig 3.2.5).

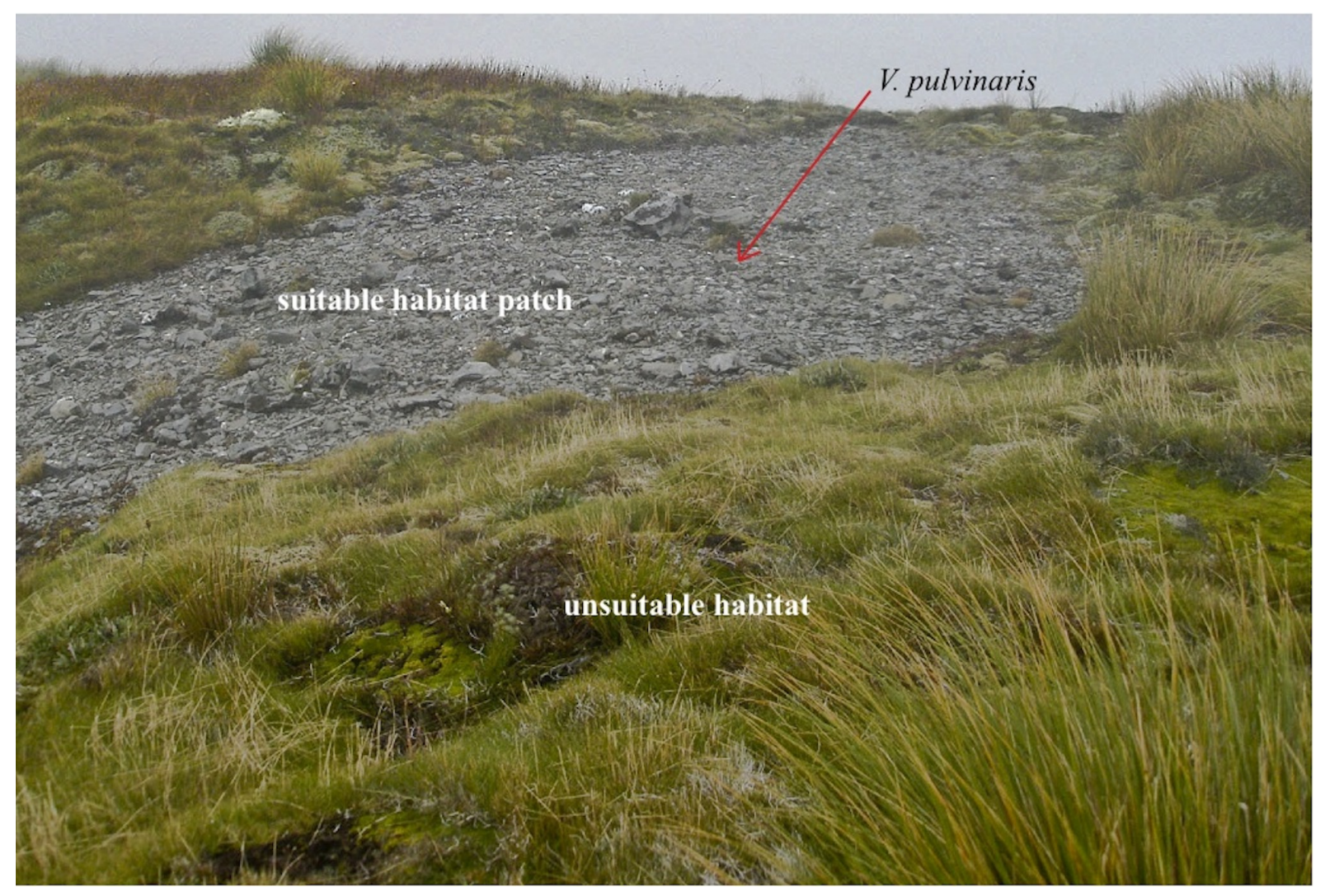

FIG 3.2.5 Habitat patch occupied by $V$. pulvinaris and $V$. cheesemanii on Mole Tops (see Appendix 3.2.1 for location details). One $V$. pulvinaris individual is pointed out with a red arrow, individuals of $V$. cheesemanii are too small and of a grey colour and therefore hard to see.

Our measurements of patch sizes show that they are indeed very restricted, compared to habitat sizes of related non-hygrochastic species. Comparing the distance that can be travelled by seeds dispersed from one plant with the available habitat patch, hygrochasy seems to be a very effective dispersal strategy because it limits seeds to 
the suitable site over many generations, sustaining the existing population in that patch. Although most alpine plants are dispersed over a short distance only by wind (Spence, 1990) hygrochastic species have the advantage of avoiding multiple chance dispersal events in very windy conditions by restricting the dispersal to a few rainfall events and protecting the seeds in a closed capsule before dispersal.

There seem to be several reasons why the habitat patches are especially suitable for the species we investigated. Adult individuals seem to be able to survive only within the patch. The complete absence of adult individuals from habitats outside the patch strongly suggests that even occasional dispersal events are most likely not successful. However, we did not investigate the seed bank in adjacent habitats and we also have no evidence that seedlings are unable to survive in habitats other than their parent habitat. We assume that the habitat patch of the extant population has suitable conditions both for seedlings and adults.

Additionally, microsites for seedling establishment seem to be confined to the habitat patch in which adult individuals were found, which by itself is small as well. Dispersal curves with a short tail have been shown to be the most efficacious in this scenario (Geritz et al., 1984). The habitat patches in which the hygrochastic study species are found are usually small, mostly bare and covered in small rocks or scree (pers. obs.). Plants found in those patches are either cushions of the same or another species. The edaphic conditions provide a suitable microtopography for seedlings, providing shelter and reducing the risk of interspecific competition due to the low vegetation density (Chambers et al., 1991; Jumpponen et al., 1999), whereas the adult cushion plants provide sheltered microsites, which support successful recruitment (Zoller and Lenzin, 2004). Choler et al. (2001) found that the effect of neighbours in high altitude environments is facilitation rather than competition. Zoller and Lenzin 
(2004) also defined the "incorporating safe site strategy", by which seeds germinating near the border of an adult cushion are included, resulting in a large cushion in a short time. Alpine Veronica seem to follow that strategy, which is shown by short dispersal distances in our experiment along with our observations that cushions grow directly next to each other in the field. It has also been shown that dispersal in groups of seeds has a positive effect on recruitment due to the sheltering influence of other seedlings (Carlson and Callaghan, 1991; Moen, 1993; Callaway et al., 2002; Zoller and Lenzin, 2004, 2006). In fact, seeds of hygrochastic Veronica often disperse in clumps of two to eight seeds (unpubl. data) and the t-square index showed a clumped distribution of the plants.

Even though hygrochasy restricts the seed dispersal of alpine Veronica to small habitat patches, these plants can be found across mountain ranges in New Zealand, albeit confined to certain areas. However, two species have dispersed from New Zealand to Australia (V. ciliolata and V. densifolia, see Meudt, 2008). This is most likely due to chance secondary dispersal, since rare long distance dispersal is more often not related to the primary dispersal (Higgins et al., 2003). In case of hygrochastic Veronica the cause of chance long-distance dispersal might be exceptionally strong winds during rainfall events, which might carry the lightweight seeds further. We also discovered that seeds of $V$. densifolia develop mucilage when wet, which might adhere to feet and feathers of birds, as is the case in arctic and alpine Bartsia (Molau, 1990). This might also explain the dispersal across the Tasman Sea. But again we need to stress that long distance dispersal events are probably very rare, which is reflected in the generally narrower distributions of hygrochastic species of Veronica compared to their non-hygrochastic relatives across New Zealand (see maps in Garnock-Jones and Lloyd, 2004; Meudt, 2008). 
By comparing habitat patch size and effective dispersal distances of hygrochastic and non-hygrochastic species of Veronica, we have shown for the first time that hygrochastic capsules and rain-dispersed seeds of alpine cushion plants can effectively restrict dispersal to safe sites. Our work supports the directed dispersal hypothesis (Howe and Smallwood, 1982), according to which the dispersal agents transport the seeds to non-random places that provide suitable conditions for establishment and growth. Habitat patches in which hygrochastic Veronica can be found provide safe microsites for seedlings not only with adequate microtopography but also with existing adult cushion plants as incorporating safe sites. This work is in accordance with hypotheses developed for hygrochastic plants in arid regions but until now was never actually investigated in hygrochastic taxa of any habitat type.

\subsubsection{REFERENCES}

AlBACH D.C. AND H.M. MeUdT . 2010. Phylogeny of Veronica in the Southern and Northern Hemispheres based on plastid, nuclear ribosomal and nuclear low-copy DNA. Molecular Phylogenetics and Evolution 54: 457-471.

CAllaway R.M., R.W. BroOKeR, P. CHOler, ET AL. 2002. Positive interactions among alpine plants increase with stress. Nature 417: 844-848.

CARLSON B.A. AND T.V. CALlaghan. 1991. Positive plant interactions in tundra vegetation and the importance of shelter. Journal of Ecology 79: 973-983.

CHAMBERS J.C., J.A. MACMAHON AND J.H. HAEFNER. 1991. Seed entrapment in alpine ecosystems: effects of soil particle size and diaspore morphology. Ecology 72: 16681677.

ChOler P, R. Michalet AND R.M. CALlaway. 2001. Facilitation and competition on gradients in alpine plant communities. Ecology 82: 3295-3308.

Cousens R., C. DYTHAM AND R. LAW. 2008. Dispersal in plants a population perspective. Oxford: Oxford University Press.

ECCLES N.S., K.J. ESLER AND R.M. COWLING. 1999. Spatial analysis in Namaqualand desert plant communities: evidence for general positive interactions. Plant Ecology 142: 71-85.

ELLNER S. AND A. SHMIDA. 1981. Why are adaptations for long-range seed dispersal rare in desert plants? Oecologia (Berlin) 51: 133-144.

ENTING B. AND B. MOLLOY. 1982. The ancient islands - New Zealand's natural environments. Wellington: Port Nicholson Press.

GARNOCK-JONES P.J. 1993. Phylogeny of the Hebe complex (Scrophulariaceae: Veroniceae). Australian Systematic Botany 6: 457-479.

GARNOCK-JONES P.J. AND D.G. LLOYD. 2004. A taxonomic revision of Parahebe

(Plantaginaceae) in New Zealand. New Zealand Journal of Botany 42: 181-232. 
GERITZ S.A.H., T.J. DE JONG AND P.G.L. KLINKHAMER. 1984. The efficacy of dispersal in relation to safe site area and seed production. Oecologia (Berlin) 62: 219-221.

GREEN D.S. 1983. The efficacy of dispersal in relation to safe site density. Oecologia (Berlin) 56: 356-358.

GUTTERMAN Y. 1994. Strategies of seed dispersal and germination in plants inhabiting deserts. Botanical Review 60: 373-425.

HARPER J.L. 1977. Population Biology of Plants. Academic Press, London.

Higgins S.I., R. NATHAN AND M.L. CAIN. 2003. Are long-distance dispersal events in plants usually caused by nonstandard means of dispersal? Ecology 84: 1945-1956.

Howe H.F. AND J. SMALLWOOD. 1982. Ecology of seed dispersal. Annual Review of Ecology and Systematics 13: 201-228.

Hughes K.A., K. Scherer, T. Svenoe, P. Rettberg, G. Horneck, P. Convey. 2006. Tundra plants protect the soil surface from UV. Soil Biology \& Biochemistry 38: 1488-1490.

IHLENFELDT H.-D. 1983. Dispersal of Mesembryanthemaceae in arid habitats. Sonderbaende des Naturwissenschaftlichen Vereins Hamburg 7: 381-390.

Jumpronen A., H. VAere, K.G. MATtSOn, R. OHtOnen, J.M. TRAPPe. 1999. Characterization of 'safe sites' for pioneers in primary succession on recently deglaciated terrain. Journal of Ecology 87: 98-105.

KOERNER C. 1999. Alpine plant life - Functional plant ecology of high mountain ecosystems. Springer Verlag, Berlin.

LUDWIG J.A. AND J.F. REYNOLDS. 1988. Statistical Ecology: a primer of methods and computing. Wiley Press, New York.

MARK A.F. AND N.M. ADAMS. 1995. New Zealand alpine plants fully revised. Godwit Publishing, Auckland, New Zealand.

MARK A.F. AND K.J.M. DiCKINSON. 1997. New Zealand alpine ecosystems. In: Wielgolaski F.E. [ed.] Polar and Alpine Tundra. Elsevier, Amsterdams, Netherlands 3: 311-345.

MEUDT H.M. 2008. Taxonomic revision of Australasian snow hebes (Veronica, Plantaginaceae). Australian Systematic Botany 21:387-421.

MoEN J. 1993. Positive versus negative interactions in a high alpine blockfield: germination of Oxyria digyna seeds in a Ranunculus digitalis community. Arctic and Alpine Research 25: 201-206.

Molau U. 1990. The genus Bartsia (Scrophulariaceae-Rhinanthoidae). Opera Botanica 102: 1-99.

MURBECK S.V. 1919. Beitraege zur Biologie der Wuestenpflanzen: Vorkommen und bedeutung von Schleimabsonderungen aus Samenhuellen. Lunds Univ Arsskr N F Adv 2 15: 1-36.

MuRBECK S.V. 1920. Beitraege zur Biologie der Wuestenpflanzen: die Synaptospermie. Lunds Univ Arsskr N F Avd 2 17: 1-52.

NAKANISHI H. 2002. Splash seed dispersal by raindrops. Ecological Research 17: 663-671.

PAROLIN P. 2001. Seed expulsion in fruits of Mesembryanthema (Aizoaceae): A mechanistic approach to study the effect of fruit morphological structures on seed dispersal. Flora (Jena) 196: 313-322.

PAROLIN P. 2006. Ombrohydrochory: Rain-operated seed dispersal in plants - With special regard to jet-action dispersal in Aizoaceae. Flora (Jena) 201: 511-518.

PUfAL, G., K.G. RYAN AND P. GARNOCK-JONES. 2010. Hygrochastic capsule dehiscence in New Zealand alpine Veronica (Plantaginaceae). American Journal of Botany 97: 1413-1423

POPPENDIECK, H.-H. 1995. Hygrochastic capsules in Oenothera (Onagraceae). Mitteilungen aus dem Institut fuer Allgemeine Botanik Hamburg 25: 99-115

R DEVELOPMENT CORE TEAM. 2005. R: A language and environment for statistical computing. R Foundation for statistical computing. Vienna, Austria

SPENCE J.R. 1990. Seed rain in grassland, herbfield, snowbank, and fellfield in the alpine zone, Craigieburn Range, South Island, New Zealand. New Zealand Journal of Botany 28: 439-450. 
Thulin M. 1987. A new species of Xylocalyx (Scrophulariaceae) from Somalia. Nordic Journal of Botany 7: 267-269.

URBANSKA K.M. AND M. SCHULTZ. 1986. Reproduction by seed in alpine plants and revegetation research above timberline. Botanica Helvetica 96: 43-60.

VAN DER PIJL L. 1982. Principles of dispersal in higher plants. Springer Verlag, Berlin, Germany.

VAN OUDTSHOORN R.K. AND M.W. VAN ROOYEN. 1999. Dispersal biology of desert plants. Springer Verlag, Berlin, Germany.

VAN ROOYEN M.W. 1990. Life form and dispersal spectra of the flora of Namaqualand, South Africa. Journal of Arid Environments 19: 133-145.

WAgSTAFF S.J., M.J. BAYLY, P. GARNOCK-JONES, D. AlBACH. 2002. Classification, origin, and diversification of the New Zealand Hebes (Scrophulariaceae). Annals of the Missouri Botanical Garden 89: 38-63.

WALCK J.L. AND S.N. HIDAYATI. 2007. Ombrohydrochory and its relationship to seed dispersal and germination strategies in two temperate North American Oenothera species (Onagraceae). International Journal of Plant Sciences 168: 1279-1290.

WeBB C.J. 1998. The selection of pollen and seed dispersal in plants. Plant Species Biology 13: 57-67.

ZOHARY M. 1937. Die verbreitungsoekologischen Verhaeltnisse der Pflanzen Palaestinas. Beiheft zum Botanischen Zentralblatt A 56: 1-155.

ZOHARY M. 1962. Plant life of Palestine. London, UK: Reinhold Press.

ZOHARY M. AND A. FAHN. 1941. Anatomical-carpological observations in some hygrochastic plants of the oriental flora. Palestinian Journal of Botany 2: 125-135.

ZOLLER H. AND H. LENZIN. 2004. Survival and recruitment favored by safe site-strategy the case of the high alpine, non-clonal cushions of Eritrichium nanum (Boraginaceae). Flora 199: 398-408.

ZOLLER H. AND H. LENZIN. 2006. Composed cushions and coexistence with neighbouring species promoting the persistence of Eritrichium nanum in high alpine vegetation. Botanica Helvetica 116: 31-40. 


\section{Chapter 3.3}

\section{Do Hygrochastic Veronica inhabit Restricted Ecological Niches?}

\subsubsection{ABSTRACT}

In the Aizoaceae more than $98 \%$ of species possess hygrochastic capsules, making this family the most widely known example of hygrochasy in arid environments. Another striking phenomenon is the distribution of most taxa; the areas single species or even entire genera inhabit are very small; they sometimes only cover a few square kilometres. One can interpret this as a high degree of ecological specialization, with species existing in very narrow ecological niches. The dispersal strategy of restricting dispersal to raindrops as dispersal agents and therefore limiting the seed transport close to the parent plant might explain the distribution pattern in Aizoaceae.

Hygrochastic Veronica are mostly found in high alpine areas of New Zealand, where they seem to be restricted to small habitat patches with specific characteristics. The aim of this study is to investigate whether hygrochastic Veronica have a narrow ecological niche compared to closely related non-hygrochastic species. The environmental amplitudes of hygrochastic and non-hygrochastic species are compared using data from Land Environments of New Zealand (LENZ IV) based on locations extracted from three herbarium databases.

There is convincing evidence that the ecological niche for hygrochastic Veronica is narrower in some environmental variables than for non-hygrochastic relatives, by definition making the hygrochastic species specialists.

This work strongly supports the hypothesis that hygrochasy spatially restricts seed dispersal for plants with little variation in their environmental niches and small habitat patches. The use of GIS based data for small habitats is discussed.

Keywords: ecological niche, GIS, hygrochasy, LENZ IV, specialists, range, Veronica 


\subsubsection{INTRODUCTION}

In his investigation of Aizoaceae (as Mesembryanthemaceae, see Bittrich and Hartmann (1988) for taxonomic details) Ihlenfeldt (1983) stressed that most hygrochastic species only occur in very small areas and sometimes even entire genera might be confined to only a few square kilometres (Ihlenfeldt, 1978). He interpreted this as a high degree of ecological specialization, i.e. these species are only able to compete in a very narrow ecological niche.

The succulent Karoo Biome is a region in southern Africa with a remarkably high level of endemism, which has led to its recognition as one of 25 global biodiversity hotspots (Myers et al., 2000). The majority of Aizoaceae are found there (HiltonTaylor, 1994; Cowling et al., 1998); this family comprises mostly hygrochastic species. Possible explanations for the level of endemism are smallscale habitat heterogeneity (Juergens, 1986), climatic fluctuations in recent geological time frames (Midgley et al., 2000), peculiar substrates (Cowling and Hilton-Taylor, 1997) and incredibly fast speciation amongst the Aizoaceae (Ihlenfeldt, 1994; Klak et al., 2004). Another arid region in southern Africa with high endemism is the "Sperrgebiet"; most endemics are Aizoaceae with canopy seed storage and short-range dispersal, i.e. hygrochastic species. Most of the habitat patches in these areas are small and mosaiclike distributed and the plants are highly adapted to their specific habitat conditions (Eccles et al., 1999). Again, hygrochastic species in this area can be described as specialists with a narrow ecological niche.

The niche concept is essential in ecology. The "concluding remarks" by Hutchinson (1957) were probably the most important contribution to the concept. Hutchinson (1957) describes the ecological niche as an n-dimensional hypervolume where the axes represent environmental variables, i.e. resources. Along each of the axes a 
population or species can display a wider or narrower tolerance. Specialization and generalization can then be defined with reference to certain axes, i.e. environmental variables (Futuyama and Moreno, 1988). Ecological specialization can be defined as a restricted ecological niche width of a given species (Futuyama and Moreno, 1988).

Another important aspect of the niche concept is the distinction between realized and fundamental (i.e. potential) niche (Hutchinson, 1957). The realized niche represents the niche that is actually occupied by a species or population whereas the fundamental niche is the niche where the species can potentially be found because it fulfils all requirements the species has of its niche space. However, the concept of the fundamental and realized niche is often only applied to the physical space a species occupies since other factors such as food resources or competition are hard to measure as axes in the niche space (Colwell and Rangel, 2009).

In general, the quantitative measuring of niche width can be difficult (Colwell and Futuyama, 1971; Feinsinger et al., 1981) and more often than not literature resorts to non-quantitative contrasts between specialists and generalists.

Estimating a niche based on presence data can be cheap and effective (Soberon and Peterson, 2005; Pearson et al., 2007; Soberon, 2007) and one way of gauging niche width. However, this approach might also be regarded as merely describing the characteristics of an environment that species may occupy for several reasons (Kearney, 2006).

In Chapter 3.2 I explored the hypothesis that hygrochasy is an adaptation of alpine Veronica to direct dispersal to safe sites within a small habitat patch. This study was carried out on the basis that a similar hypothesis was developed for hygrochastic species in arid areas (predominantly Aizoaceae) (Ihlenfeldt, 1983). From now on I will refer to this hypothesis as 'spatial restriction hypothesis'. However, this 
hypothesis is extended for desert species as it also states that most of them have a very small ecological niche and that hygrochasy is a strategy that supports the maintenance of populations in small areas that represent the ecological niche (Ihlenfeldt, 1983).

There are some astounding similarities between hygrochastic Aizoaceae and hygrochastic Veronica in New Zealand. The areas where both taxa can be found show a high degree of heterogeneity (Mark and Dickinson, 1997; Eccles et al., 1999) and most of the Veronica species are localized or are endemic to a small region (although $V$. ciliolata and $V$. densifolia show dispersal across the Tasman Sea, but they occupy small regions in both Australia and new Zealand (Meudt, 2008)). Lastly, there is evidence for recent speciation in both the Aizoaecae (Klak et al., 2004) and Veronica (Wagstaff et al., 2002; Albach and Meudt, 2010). It seems therefore plausible that both aspects of the spatial restriction hypothesis apply to hygrochastic Veronica in alpine New Zealand.

This study attempts to identify the breadth of the ecological niche of hygrochastic Veronica and compare it to related non-hygrochastic species. I predicted that alpine hygrochastic Veronica are specialists that occupy only specific habitats, which are restricted to certain areas. I tested this by comparing them to their non-hygrochastic relatives to see if they show a small ecological amplitude. If so, hygrochasy might be a dispersal strategy that restricts dispersal to sites within the specific habitats.

The question remains whether the localized extent of hygrochastic Veronica is a result of restricted short-distance dispersal or whether the restricted dispersal ability of those species results from their specialized habitats. To answer this question the use of the fundamental niche gives valuable information, i.e. is the distribution of hygrochastic Veronica limited by their fundamental niches or their dispersal ability? 
Presence-only data from herbarium or museum records is increasingly being used for predictive species distribution modelling (Elith et al., 2006; Elith and Leathwick, 2007; Miller et al., 2007; Loarie et al., 2008; Loiselle et al., 2008) and might therefore also be a valuable tool in comparing the distribution of study species in this work. The Land Environments of New Zealand database IV (LENZ IV) is an environmental classification of New Zealand with numerical data layers that describe multiple aspects of the country's climate, landforms and soils and it also uses a computerised classification procedure, which can identify similar environments (Leathwick et al., 2002). The variables that were used in the data layers were selected using results from an extended study of relationships between forest patterns and environments, including plot data, climate estimates from long-term meteorological station data and soil data from the New Zealand Land Resource Inventory. LENZ level IV has the highest standard of classification detail and contains 500 environments nationally.

For this study, environmental data contained in LENZ IV are used as measurements for the niche width, based on location points from the herbarium databases as presence data. This chapter will also be used as a platform to discuss the use of LENZ as a tool to measure ecological niche width of specialist species. 


\subsubsection{MATERIAL AND METHODS}

In this study we investigate Veronica species from the informal speedwell hebe and snow hebe groups (for phylogeny and groups see Albach and Meudt, 2010). Of these, 15 have been identified as being hygrochastic (Pufal et al., 2010) whereas 8 are classified as 'ripening dehiscent' (here referred to as non-hygrochastic).

Databases comprising 22 Veronica species were obtained from New Zealand's three large herbaria WELT, AK and CHR (for herbarium acronyms see Thiers [continuously updated]). Double entries, unidentified specimen and specimen without location information were not considered and were omitted from future analysis. For each species in the combined database, the number of entries was counted and compared between the groups hygrochastic and non-hygrochastic using a MannWhitney-U test. The data were subsequently used to analyse environmental conditions and identify the ecological amplitude of species at those locations.

All databases were searched for entries with accurate coordinates (degrees, minutes, seconds) to find exact sites. Specimens with insufficient coordinates but with very specific location descriptions (e.g. $20 \mathrm{~m}$ south of trig, Mount Arthur) were also included and Google Earth 5.1 (http://earth.google.com) has been used to find correct coordinates.

For the analysis of environmental parameters and population locations, species with 20 or more accurate locations were included. Species for which we could not find this number of locations were omitted and for species with more than 20 locations a random set of 20 was chosen for analysis. The coordinates of each location were used in arcMap 9.3 (ESRI, 1999-2008) to obtain environmental characters from the Land Environment of New Zealand database (LENZ). LENZ level IV is the layer with the finest scale ( $25 \mathrm{~m} \times 25 \mathrm{~m})$ and the most accurate environmental description including 
data for 16 environmental variables (Table 3.3.1). Locations were mapped and the range between the locations that were furthest apart was measured in a rough N-S orientation.

Table 3.3.1 List of variables obtained from the environmental layer IV of the LENZ database. The asterisk indicates constant variables excluded from analysis.

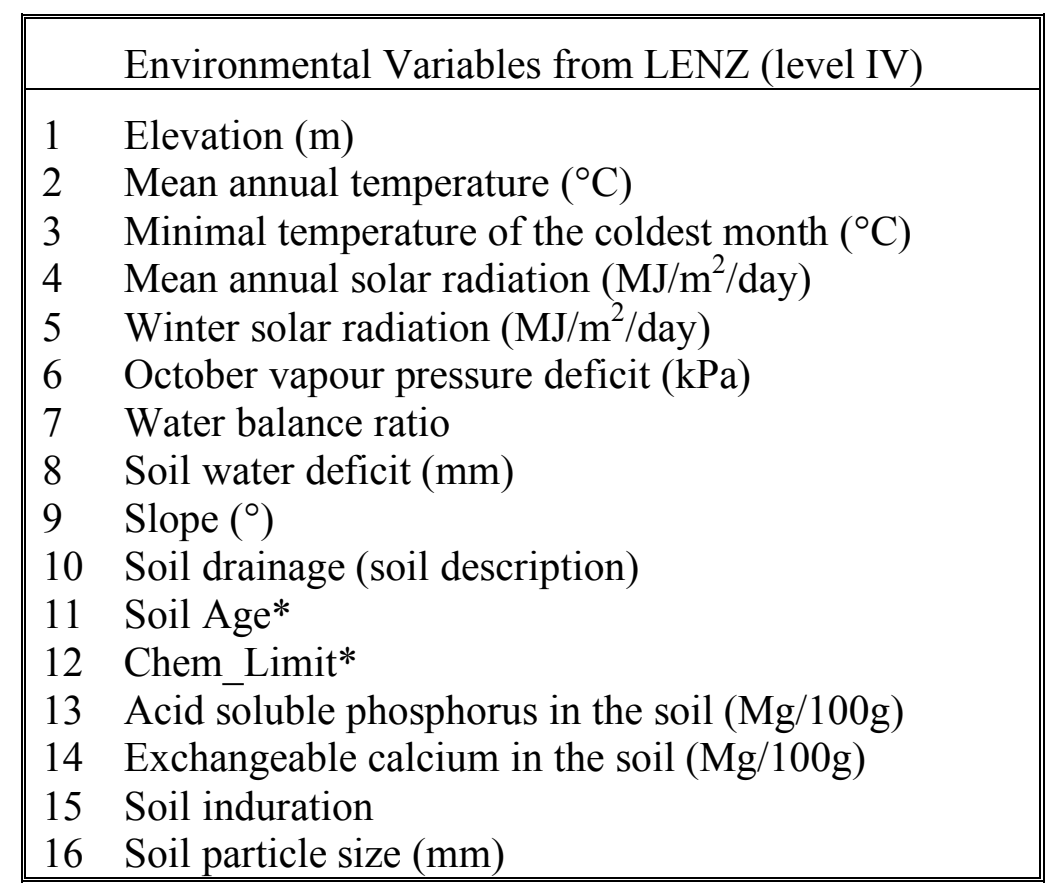

In LENZ IV, the specific combination of environmental variables for every selected point on a map is given a specific value number, i.e. each value number within LENZ IV stands for a specific habitat type. The number of values for the 20 locations for each species were counted and compared between the groups. If species within a group had more value numbers for the same number of locations it means that they occur in more different habitat types. Using LENZ IV, the total available potential habitat for each species was calculated and compared with the total area of New Zealand as well as between hygrochastic and non-hygrochastic groups.

For each species, the Coefficient of Variation (CV) of every environmental parameter among locations was calculated $(\mathrm{CV}=\mathrm{sd} /$ mean $)$ and general linear models were 
conducted on these with dispersal group used as fixed factor to find significant differences between the groups.

Statistical analysis was conducted in SPSS 16.0 and R (SPSS Inc., 1989-2007; R Development Core Team, 2005).

\subsubsection{RESULTS}

The combined herbarium databases showed no significant differences between hygrochastic and non-hygrochastic species for the number of locations per species (Mann-Whitney-U test; $\mathrm{W}=84.5, \mathrm{p}=0.056$ ) (Table 3.3.2).

Table 3.3.2 number of locations per species in a combined database from WELT, AUK, CHR. BOLD species were used in further statistical analysis.

\begin{tabular}{||llll||}
\hline Hygrochastic species & locations & Non-hygrochastic species & locations \\
\hline V. birleyi & 24 & V. catarractae & 41 \\
V. cheesemanii & 43 & V. decora & 89 \\
V. chionohebe & 9 & V. hookeriana & 102 \\
V. ciliolata & 57 & V. lanceolata & 276 \\
V. colostylis & 36 & V. linifolia & 83 \\
V. densifolia & 70 & V. lyallii & 288 \\
V. lilliputiana & 28 & V. melanocaulon & 32 \\
V.planopetiolata & 8 & V. senex & 8 \\
V.pulvinaris & 109 & & \\
V. spathulata & 36 & & \\
V. spectabilis & 1 & & \\
V. thomsonii & 54 & & \\
V. trifida & 17 & & \\
V.zygantha & 13 & & \\
\hline
\end{tabular}

Accurate locations appropriate for the use in arc GIS were found in six hygrochastic species and six non-hygrochastic species (Table 3.3.2). These were divided into two dehiscence groups (hygrochastic and non-hygrochastic), which were used in all following statistical analysis. 
Each location in each species has a certain set of environmental variables assigned by arcGIS and is given a value number. The more value numbers are listed for a species, the more habitat types the species can be found in.

When comparing value numbers between hygrochastic and non-hygrochastic groups, hygrochastic species showed significantly fewer values compared to non-hygrochastic species (Mann-Whitney-U test; $\left.\mathrm{W}=2.5 ; \mathrm{p}=0.016^{*}\right)($ Table 3.3.3). It is evident that all hygrochastic species included occur exclusively at high altitudes, whereas the nonhygrochastic species were found over a wide range of elevations, from lowland to high alpine areas (Table 3.3.3). Since hygrochastic Veronica have a lower number of different habitats, the variation in some environmental variables might thus be restricted. General linear models were therefore conducted on the Coefficient of Variation, which was calculated from the means and standard deviation in Table 3.3.3. 
Table 3.3.3 Environmental variables for 12 Veronica species extracted from LENZ IV. Given are mean with standard error, minimum, maximum and standard deviation. At the end of the table, the number of different values (habitat type) for each species is given. Hygrochastic species are shown in BOLD.

\begin{tabular}{|c|c|c|c|c|c|c|c|c|c|c|c|c|}
\hline \multirow[t]{2}{*}{ Species } & \multicolumn{4}{|l|}{ Elevation (m) } & \multicolumn{4}{|c|}{ Mean annual temperature $\left({ }^{\circ} \mathrm{C}\right)$} & \multicolumn{4}{|c|}{$\begin{array}{l}\text { Minimal temperature of the coldest } \\
\text { month }\left({ }^{\circ} \mathrm{C}\right)\end{array}$} \\
\hline & mean \pm se & $\min$ & $\max$ & $\mathrm{sd}$ & mean & $\min$ & $\max$ & $\mathrm{sd}$ & mean & Min & $\max$ & sd \\
\hline V. cheesemanii & $1438.3 \pm 45.97$ & 1041 & 1836 & 205.56 & $4.97 \pm 0.25$ & 2.8 & 7.2 & 1.1 & $-3.78 \pm 0.2$ & -4.6 & -2 & 0.91 \\
\hline V. ciliolata & $1247.35 \pm 41.5$ & 1037 & 1768 & 185.58 & $4.96 \pm 0.17$ & 3.2 & 6.3 & 0.76 & $-2.68 \pm 0.21$ & -4.3 & -1.6 & 0.93 \\
\hline$V$. densifolia & $1344.25 \pm 33.6$ & 962 & 1674 & 150.25 & $4.44 \pm 0.18$ & 3.1 & 6.6 & 0.79 & $-3.98 \pm 0.12$ & -4.3 & -2.5 & 0.55 \\
\hline$V \cdot p u l v i n a r i s$ & $1523.45 \pm 45.7$ & 1208 & 1836 & 204.37 & $4.38 \pm 0.23$ & 2.8 & 6.1 & 1.04 & $-4.1 \pm 0.11$ & -4.6 & -2.9 & 0.51 \\
\hline V. spathulata & $1518.1 \pm 74.82$ & 1028 & 1827 & 334.61 & $5.25 \pm 0.41$ & 3.6 & 8.1 & 1.84 & $-1.65 \pm 0.23$ & -2.5 & 0.1 & 1.02 \\
\hline V.thomsonii & $1467.75 \pm 37.9$ & 1347 & 1836 & 169.51 & $3.94 \pm 0.13$ & 2.8 & 4.3 & 0.58 & $-4.24 \pm 0.04$ & -4.6 & -3.8 & 0.2 \\
\hline V. catarractae & $424.85 \pm 59.79$ & 95 & 1290 & 267.4 & $8.19 \pm 0.27$ & 4.5 & 10.2 & 1.22 & $0.5 \pm 0.21$ & -2.6 & 1.7 & 0.96 \\
\hline$V$. decora & $904.45 \pm 77.09$ & 292 & 1387 & 344.75 & $7.33 \pm 0.4$ & 4.2 & 10.5 & 1.8 & $-2.28 \pm 0.25$ & -3.8 & 0.3 & 1.1 \\
\hline V. hookeriana & $1154.3 \pm 63.05$ & 867 & 1827 & 281.97 & $7.44 \pm 0.4$ & 3.6 & 9.1 & 1.78 & $-0.06 \pm 0.33$ & -2.5 & 2.1 & 1.48 \\
\hline V. lanceolata & $423.9 \pm 77.29$ & 34 & 1330 & 345.65 & $11.32 \pm 0.42$ & 6.1 & 14 & 1.87 & $2.7 \pm 0.38$ & -1.4 & 5.9 & 1.7 \\
\hline$V$. linifolia & $993.8 \pm 81.09$ & 292 & 1828 & 362.66 & $6.89 \pm 0.42$ & 2.8 & 10.5 & 1.86 & $-2.3 \pm 0.29$ & -4.5 & 0.3 & 1.29 \\
\hline V. lyallii & $812.25 \pm 87.73$ & 159 & 1508 & 392.35 & $7.82 \pm 0.44$ & 4.6 & 11.8 & 1.96 & $-1.46 \pm 0.36$ & -4.5 & 1.7 & 1.6 \\
\hline V. cheesemanii & $14.1 \pm 0.12$ & 12.9 & 14.7 & 0.52 & $4.63 \pm 0.05$ & 4 & 5.1 & 0.24 & $0.19 \pm 0.01$ & 0.11 & 0.27 & 0.05 \\
\hline$V$. ciliolata & $12.62 \pm 0.13$ & 11.9 & 13.7 & 0.6 & $3.61 \pm 0.12$ & 3 & 4.5 & 0.53 & $0.1 \pm 0.02$ & 0 & 0.24 & 0.08 \\
\hline$V$. densifolia & $13.2 \pm 0.01$ & 13.1 & 13.3 & 0.05 & $3.69 \pm 0.02$ & 3.6 & 3.9 & 0.1 & $0.23 \pm 0.01$ & 0.08 & 0.29 & 0.04 \\
\hline$V \cdot$ pulvinaris & $13.66 \pm 0.1$ & 12.9 & 14.7 & 0.43 & $4.5 \pm 0.07$ & 3.6 & 5.1 & 0.32 & $0.2 \pm 0.02$ & 0.02 & 0.33 & 0.07 \\
\hline V. spathulata & $14.13 \pm 0.04$ & 14 & 14.5 & 0.19 & $5.04 \pm 0.02$ & 5 & 5.2 & 0.08 & $0.15 \pm 0.02$ & 0.07 & 0.32 & 0.1 \\
\hline$V$. thomsonii & $13.28 \pm 0.04$ & 13.2 & 13.8 & 0.18 & $3.79 \pm 0.07$ & 3.6 & 4.7 & 0.32 & $0.21 \pm 0.01$ & 0.08 & 0.25 & 0.06 \\
\hline V. catarractae & $12.2 \pm 0.05$ & 11.8 & 12.7 & 0.23 & $3.15 \pm 0.05$ & 2.8 & 3.8 & 0.21 & $0.15 \pm 0.02$ & 0 & 0.27 & 0.07 \\
\hline V. decora & $13.76 \pm 0.1$ & 128 & 14.5 & 0.46 & $4.36 \pm 0.09$ & 3.6 & 4.8 & 0.4 & $0.31 \pm 0.03$ & 0.11 & 0.46 & 0.11 \\
\hline
\end{tabular}




\begin{tabular}{|c|c|c|c|c|c|c|c|c|c|c|c|c|}
\hline V. hookeriana & $14.33 \pm 0.07$ & 13.9 & 14.8 & 0.31 & $5.26 \pm 0.11$ & 4.6 & 6.1 & 0.47 & $0.22 \pm 0.02$ & 0.07 & 0.32 & 0.07 \\
\hline$V$. lanceolata & $14.47 \pm 0.08$ & 137 & 15 & 0.35 & $5.15 \pm 0.11$ & 4.6 & 6.2 & 0.49 & $0.32 \pm 0.01$ & 0.18 & 0.48 & 0.06 \\
\hline V. linifolia & $13.5 \pm 0.16$ & 11.9 & 14.7 & 0.71 & $4.17 \pm 0.1$ & 3 & 4.8 & 0.45 & $0.23 \pm 0.03$ & 0.02 & 0.45 & 0.13 \\
\hline V. lyallii & $13.65 \pm 0.2$ & 12 & 15.3 & 0.88 & $4.2 \pm 0.11$ & 3.1 & 4.8 & 0.51 & $0.25 \pm 0.03$ & 0.02 & 0.44 & 0.12 \\
\hline \multicolumn{5}{|c|}{ Water balance ratio } & \multicolumn{4}{|c|}{ Soil water deficit $(\mathrm{mm})$} & \multicolumn{4}{|l|}{ Slope $\left(^{\circ}\right)$} \\
\hline V. cheesemanii & $8.16 \pm 0.61$ & 4.6 & 15.7 & 2.73 & $0.02 \pm 0.01$ & 0 & 0.13 & 0.04 & $29.31 \pm 0.42$ & 27.3 & 35.2 & 1.86 \\
\hline V. ciliolata & $13.3 \pm 1.15$ & 4.5 & 19.9 & 5.16 & $0.001 \pm 0.001$ & 0 & 0.01 & 0.002 & $31.01 \pm 1.24$ & 13.2 & 42.9 & 5.56 \\
\hline$V \cdot p u l v i n a r i s$ & $9.31 \pm 1.04$ & 4.4 & 22.8 & 4.67 & $0.09 \pm 0.04$ & 0 & 0.63 & 0.2 & $28.19 \pm 1.18$ & 7.3 & 35.1 & 5.27 \\
\hline V. spathulata & $7.51 \pm 0.46$ & 4.1 & 9.3 & 2.07 & $0.11 \pm 0.05$ & 0 & 0.56 & 0.23 & $18.43 \pm 1.37$ & 9.5 & 24.4 & 6.11 \\
\hline V.thomsonii & $5.75 \pm 0.49$ & 4.4 & 10.4 & 2.21 & $0.12 \pm 0.03$ & 0 & 0.25 & 0.12 & $15.87 \pm 2.18$ & 7.3 & 29.9 & 9.74 \\
\hline V. catarractae & $11.69 \pm 0.85$ & 5.9 & 19.8 & 3.81 & $0.001 \pm 0.001$ & 0 & 0.02 & 0.004 & $22.47 \pm 2.67$ & 1.8 & 42.9 & 11.96 \\
\hline$V$. decora & $5.05 \pm 0.49$ & 1.6 & 9 & 2.2 & $19.12 \pm 8.4$ & 0 & 141.57 & 37.59 & $16.66 \pm 2.54$ & 0 & 31.3 & 11.36 \\
\hline V. hookeriana & $6.05 \pm 0.34$ & 4.1 & 9.3 & 1.51 & $0.23 \pm 0.08$ & 0 & 0.79 & 0.34 & $19.17 \pm 1.58$ & 5.7 & 27.8 & 7.06 \\
\hline$V$. linifolia & $9.4 \pm 1.3$ & 1.7 & 22.8 & 5.81 & $16.55 \pm 9.68$ & 0 & 175.53 & 43.3 & $24.65 \pm 2.25$ & 0 & 35.1 & 10.06 \\
\hline \multirow[t]{2}{*}{ V. lyallii } & $8.28 \pm 1.08$ & 3.1 & 19.9 & 4.84 & $7.07 \pm 4.31$ & 0 & 75.39 & 19.27 & $23.03 \pm 2.28$ & 0 & 33.6 & 10.21 \\
\hline & \multicolumn{4}{|c|}{ Soil drainage (soil description) } & \multicolumn{4}{|c|}{$\begin{array}{l}\text { Acid soluble phosphorus in the soil } \\
(\mathrm{Mg} / 100 \mathrm{~g})\end{array}$} & \multicolumn{4}{|c|}{$\begin{array}{l}\text { Exchangeable calcium in the soil } \\
(\mathrm{Mg} / 100 \mathrm{~g})\end{array}$} \\
\hline V. cheesemanii & $3.78 \pm 0.19$ & 3 & 5 & 0.85 & $2.79 \pm 0.13$ & 1.1 & 3 & 0.58 & $1.22 \pm 0.1$ & 1 & 2.5 & 0.46 \\
\hline$V$. ciliolata & $4.52 \pm 0.14$ & 3 & 5 & 0.63 & $2.37 \pm 0.21$ & 1 & 3.7 & 0.92 & $1.33 \pm 0.07$ & 1 & 1.9 & 0.33 \\
\hline V. densifolia & $3.9 \pm 0.21$ & 3 & 5 & 0.93 & $3 \pm 0$ & 3 & 3 & 0 & $1.71 \pm 0.08$ & 1 & 2 & 0.35 \\
\hline$V \cdot p u l v i n a r i s$ & $3.8 \pm 0.22$ & 3 & 5 & 0.98 & $2.98 \pm 0.01$ & 2.9 & 3 & 0.04 & $1.06 \pm 0.05$ & 1 & 2 & 0.23 \\
\hline V. spathulata & $4.85 \pm 0.03$ & 4.7 & 5 & 0.15 & $3.06 \pm 0.24$ & 1 & 3.8 & 1.09 & $1.39 \pm 0.05$ & 1 & 1.6 & 0.24 \\
\hline V.thomsonii & $4.06 \pm 0.22$ & 3 & 5 & 0.99 & $2.99 \pm 0.01$ & 2.9 & 3 & 0.03 & $1.72 \pm 0.08$ & 1 & 2 & 0.35 \\
\hline V. catarractae & $3.74 \pm 0.2$ & 2.7 & 5 & 0.92 & $1.31 \pm 0.16$ & 1 & 3.8 & 0.73 & $1.11 \pm 0.06$ & 1 & 1.9 & 0.28 \\
\hline V. decora & $4.24 \pm 0.34$ & 0 & 5 & 1.53 & $2.96 \pm 0.25$ & 0 & 4 & 1.11 & $1.21 \pm 0.13$ & 0 & 2 & 0.56 \\
\hline
\end{tabular}


CHAPTER THREE

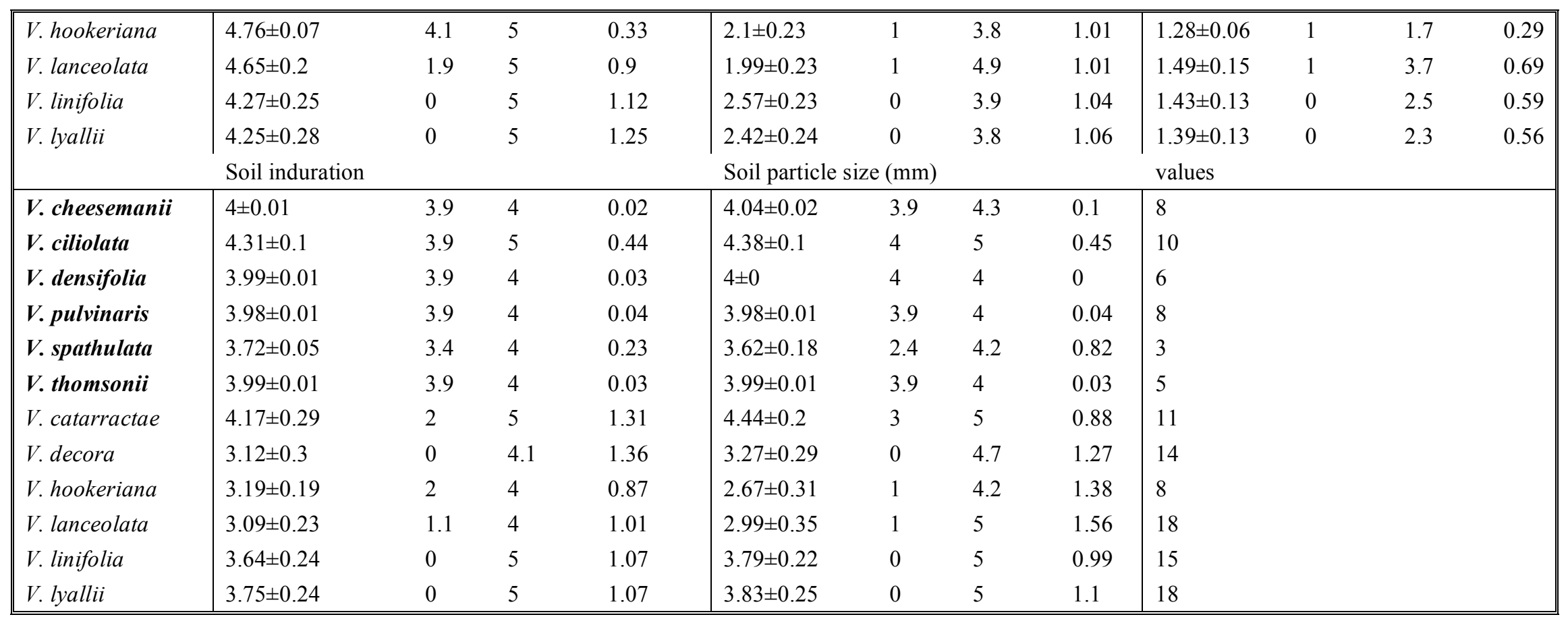


Significant differences were found in five environmental variables (Table 3.3.4).

Variation in the topographic variable elevation as well as in the soil fertility variables soluble phosphorus, soil induration, exchangeable calcium and particle size is significantly greater in non-hygrochastic species than it is for hygrochastic species (Fig. 3.3.1). Climatic variables and other soil layers were not significantly different in their variation between groups.

Table 3.3.4 General Linear Model (GLM) comparison between CV of environmental variables of hygrochastic and non-hygrochastic species. Significance is indicated by asterix $\left(\mathrm{p}<0.05^{*}, \mathrm{p}<0.005^{* *}, \mathrm{p}<0.0005^{* * *}\right)$.

\begin{tabular}{|c|c|c|c|c|}
\hline & df & $\mathrm{F}$ & $\mathrm{R}^{2}$ & $\mathrm{p}$ \\
\hline Elevation (m) & 1 & 14.778 & 0.556 & $0.003 * *$ \\
\hline Mean annual temperature $\left({ }^{\circ} \mathrm{C}\right)$ & 1 & 0.035 & -0.096 & 0.855 \\
\hline Minimal temperature of the coldest month $\left({ }^{\circ} \mathrm{C}\right)$ & 1 & 0.844 & -0.014 & 0.380 \\
\hline Mean annual solar radiation $\left(\mathrm{MJ} / \mathrm{m}^{2} /\right.$ day $)$ & 1 & 1.128 & 0.012 & 0.313 \\
\hline Winter solar radiation $\left(\mathrm{MJ} / \mathrm{m}^{2} /\right.$ day $)$ & 1 & 1.992 & 0.083 & 0.188 \\
\hline October vapour pressure deficit $(\mathrm{kPa})$ & 1 & 0.039 & -0.096 & 0.848 \\
\hline Water balance ratio & 1 & 0.336 & -0.064 & 0.575 \\
\hline Soil water deficit (mm) & 1 & 0.132 & -0.086 & 0.724 \\
\hline Soil drainage (soil description) & 1 & 0.832 & -0.015 & 0.383 \\
\hline Slope $\left(^{\circ}\right)$ & 1 & 2.759 & 0.138 & 0.128 \\
\hline Acid soluble phosphorus in the soil $(\mathrm{Mg} / 100 \mathrm{~g})$ & 1 & 14.465 & 0.55 & $0.003 * *$ \\
\hline Exchangeable calcium in the soil $(\mathrm{Mg} / 100 \mathrm{~g})$ & 1 & 6.24 & 0.323 & $0.032 *$ \\
\hline Soil induration & 1 & 93.522 & 0.894 & $0.000 * * *$ \\
\hline Soil particle size (mm) & 1 & 20.072 & 0.634 & $0.001 * *$ \\
\hline
\end{tabular}




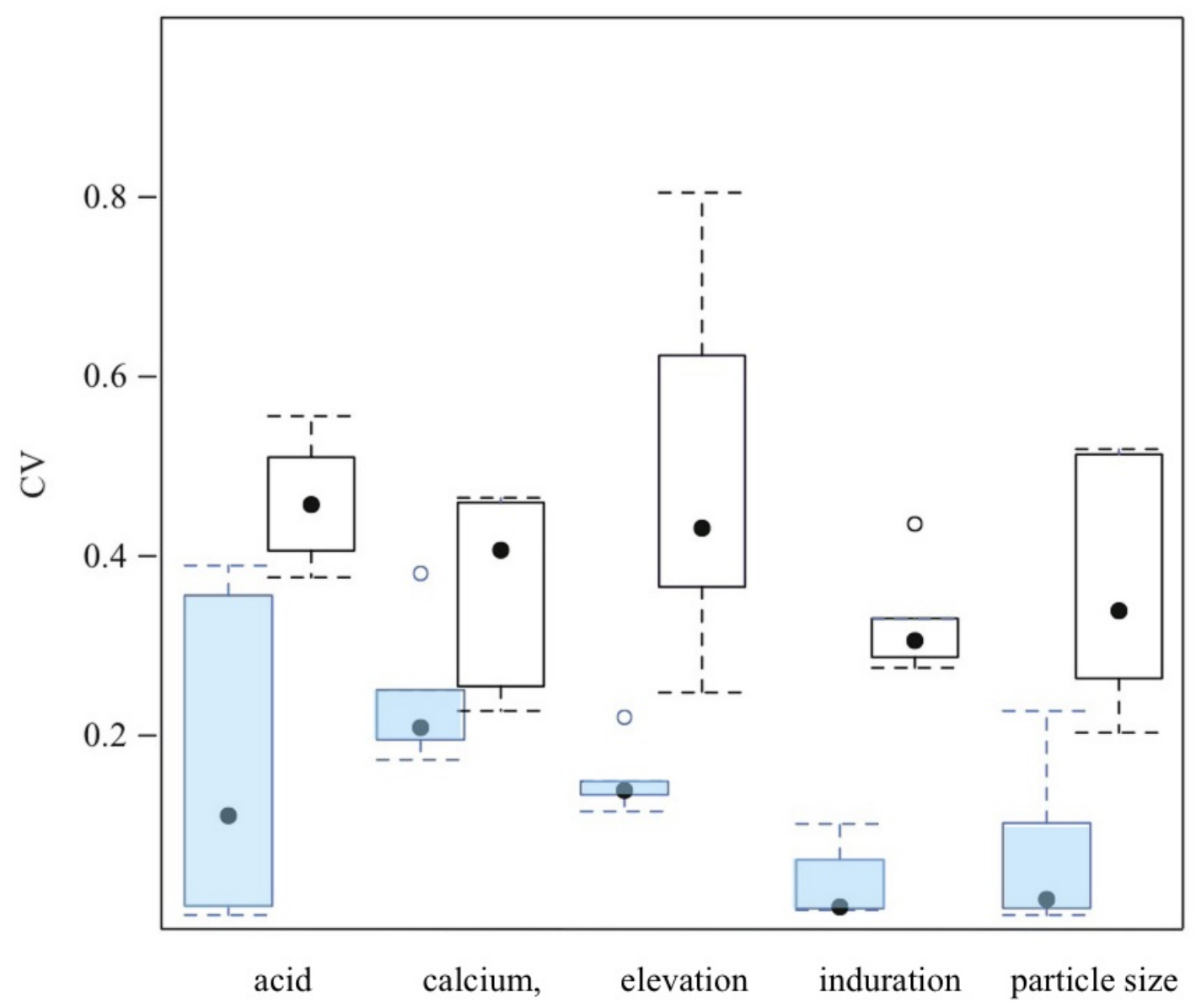

FIG. 3.3.1 Coefficient of variation in five environmental variables of hygrochastic Veronica (blue) and non-hygrochastic Veronica (black) shown as box and whisker plots. Dark circles indicate the median of the $\mathrm{CV}$.

An advantage of LENZ IV is that the New Zealand wide area of each habitat type is given as well. Values associated with one species were classified as potential available habitats and the area was calculated for each species. Potential available habitats for all species only cover a small percentage of New Zealand (Table 3.3.5). Non-hygrochastic species occur in a wider range of habitat types and the area of suitable habitats for occupation is larger than for hygrochastic species, albeit not significantly (MWU: $\mathrm{W}=30, \mathrm{p}=0.06$ ). When comparing the rough $\mathrm{N}-\mathrm{S}$ range of 20 locations per species (Table 3.3.5), no significant difference was found between both dehiscence groups (Mann-Whitney-U test; $\mathrm{W}=27.5, \mathrm{p}=0.15$ ). 
Table 3.3.5 Potential suitable habitats for 12 Veronica species as inferred from values from LENZ IV. Also given is the rough N-S range inferred from 20 locations per species.

\begin{tabular}{|llll|}
\hline species & Area in ha & \% of NZ area & N-S range in $\mathrm{km}$ \\
\hline V. cheesemanii & 739719 & 2.82 & 240 \\
V. ciliolata & 1332458 & 5.08 & 520 \\
V. densifolia & 737841 & 2.81 & 210 \\
V. pulvinaris & 1067606 & 4.07 & 510 \\
V. spathulata & 163616 & 0.62 & 90 \\
V. thomsonii & 586154 & 2.24 & 220 \\
$V$. catarractae & 926536 & 3.53 & 210 \\
$V$. decora & 1906326 & 7.27 & 590 \\
$V$. hookeriana & 627046 & 2.39 & 290 \\
$V$. lanceolata & 2665700 & 10.16 & 490 \\
$V$. linifolia & 2206221 & 8.41 & 660 \\
$V$. lyallii & 2970458 & 11.33 & 660 \\
\hline
\end{tabular}

An example of potentially suitable habitat based on LENZ IV values and the distribution of 20 locations per species is given in Fig. 3.3.2, which depicts the South Island of New Zealand and localities for $V$. thomsonii and $V$. lyallii. Similar maps can be drawn for all other investigated species but will not be shown here. Actual distribution maps for the species used in this study can be found in Garnock-Jones and Lloyd (2004) and Meudt and Bayly (2008). Although the map presented here is based on a small dataset (20 locations) it presents the overall distribution of the species well (compare to Meudt and Bayly, 2008). 


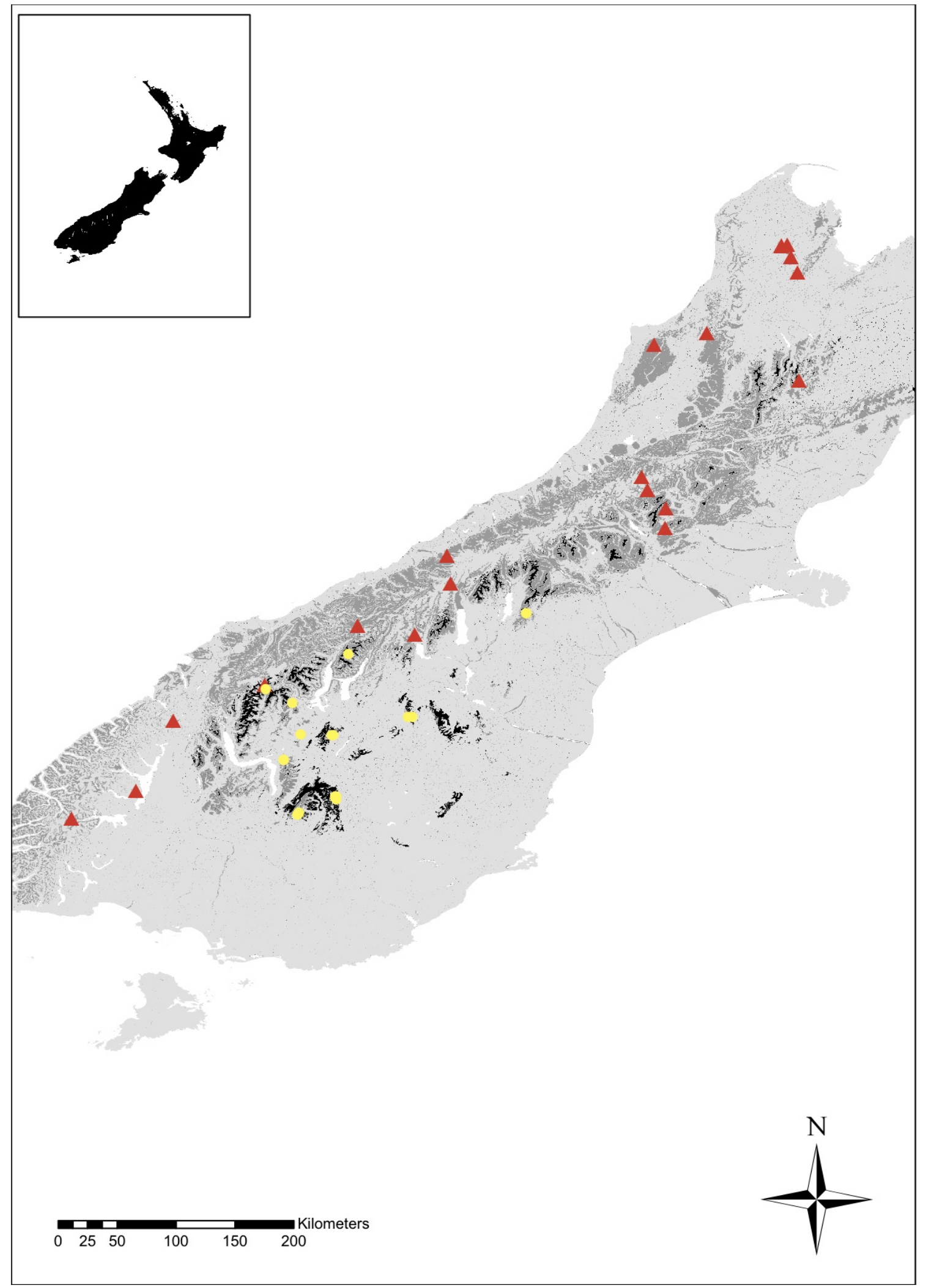

FIG 3.3.2 Potentially suitable habitat for $V$. lyallii (grey) and $V$. thomsonii (black) and locations of $V$. thomsonii (yellow circles) and $V$. lyallii (red triangles) used in the analysis. Shown is the South Island in the main map and New Zealand in the inset. 


\subsubsection{DISCUSSION}

Results show that non-hygrochastic species use a significantly higher number of different habitats compared to the number of habitats utilized by hygrochastic species. The analysis of environmental layers in LENZ IV showed highly significant differences in the variation of five variables associated with altitude and soil fertility among hygrochastic and non-hygrochastic species. In general, hygrochastic species occur in a restricted high altitudinal belt on strongly indurated gravel substrates with low fertility, whereas non-hygrochastic Veronica can be found at varying altitudes and with more widely varying environmental variables. According to Hutchinson (1957) we can view the five significantly different variables as axes in a fivedimensional hypervolume, where the hypervolume represents the ecological space. The occurrences of the species within the ecological space essentially represent its niche (Calenge and Basille, 2008). By showing a wide tolerance for these variables, non-hygrochastic species occur in a larger niche, whereas hygrochastic species exhibit a narrow tolerance in a small niche, making them effectively specialists (Futuyama and Moreno, 1988) with a small fundamental niche.

My findings are similar to those proposed by Ihlenfeldt (1983) for Aizoaceae in South Africa but with the added support of GIS-based analyses. Like hygrochastic desert species, alpine Veronica are restricted to certain habitat types (Ihlenfeldt, 1983; Desmet and Cowling, 1999). By investigating the distribution of suitable habitat it is evident that not all available sites are occupied (Fig. 3.3.2). Here, the available or potentially suitable sites represent the fundamental niche, whereas the range of the species is equal to the realized niche. This local distribution pattern is most likely due to the short distance dispersal in hygrochastic species (Pufal and Garnock-Jones, 2010). Since suitable sites are located on mountaintops, dispersal to these can only 
happen by secondary chance dispersal, e.g. strong winds or storms, since valleys provide an efficient barrier for continuous seed dispersal (McGlone et al., 2001). The limited distribution of hygrochastic Veronica is therefore not necessarily a result of the limited distribution of their niche but rather the result of their dispersal ability. Nevertheless, compared to other species and to all available habitat in New Zealand, the fundamental niche of hygrochastic Veronica is restricted in size.

The width of the ecological niche regarding 16 environmental variables for New Zealand Veronica was identified by using LENZ IV. Based on the narrow amplitude of five variables for hygrochastic species, the occurrence of those species in specific habitats is evident. However, there are several reasons why this result needs to be treated with caution.

From the available 22 Veronica species (see Pufal et al., 2010 for details on phylogeny) I was able to use six hygrochastic and six non-hygrochastic species with enough localities. Although this is only a subset of the original species pool, these examples nevertheless provide a good average - hygrochastic species from both North and South Island are included as well as both cushion and subshrub growth form. Non-hygrochastic species are also from both islands and represent the general sub-shrub growth form.

Herbarium databases are increasingly being used as presence only data to model species distribution (Elith et al., 2006; Elith and Leathwick, 2007; Miller et al., 2007; Loarie et al., 2008; Loiselle et al., 2008; Riordan and Rundel, 2009). However, datasets used in those studies were usually much larger than data available for this study. Another limiting factor was the accuracy of locations, which in turn limited the number of localities used in the statistical analysis. Instead of choosing as many locations as possible for each species, I decided to use 20 per species to provide 
balanced sampling (Dytham, 2005). This sampling strategy might have influenced the results by not including certain habitat types or over-emphasizing others. However, especially for the low numbers of hygrochastic species in the databases, this sampling effort is reasonable.

Although the LENZ IV dataset is the most accurate system available with $25 \times 25 \mathrm{~m}$ squares, it is still rather coarse for my purposes. Most habitat patches for hygrochastic Veronica are smaller than the grid provided by LENZ (Chapter 3.2) and much higher spatial resolution is needed in alpine areas due to rugged topography. LENZ also poses a source of circularity since some parameters are based on the interpolation of remote vegetation mapping (Leathwick et al., 2002).

The LENZ database uses climatic layers and soil layers, which are based on different sources. The climatic variables are used directly or indirectly from mathematical surfaces that use information about the climate, elevation and location from a large number of meteorological stations across New Zealand (Leathwick et al., 2002). The soil layers are derived largely from the New Zealand Land Resource Inventory (NZLRI) and the New Zealand Soils database. Information from NZLRI is based on soil maps, whereas the information from the New Zealand Soils database comes from soil samples from close to 1500 locations throughout New Zealand. The soil layers in LENZ are especially prone to error, largely due to 1) variation in the map scale, 2) variation in the size of units mapped in the NZLRI database, where the lowest resolution occurs in montane areas; 3) older NZLRI mapping lacks substantial topographic details, 4) the quality of data sources varies greatly and 5) the sample points used by the New Zealand Soils database are unevenly distributed across the country (Leathwick et al., 2002). 
Overall, the use of herbarium data in combination with LENZ IV seems an appropriate tool to identify ecological niches for plant species in New Zealand, but errors due to sample size and accuracy can easily occur.

In the introduction I highlighted that this work is used to explore whether the spatial restriction hypothesis is as important for hygrochastic Veronica as it is for hygrochastic Aizoaceae in South African desert regions. In particular, this study focussed on the argument that most hygrochastic desert species have a narrow ecological niche and are specialists in their habitat (Ihlenfeldt, 1983; Eccles et al., 1999). This work supports the spatial restriction hypothesis by providing good evidence that hygrochastic Veronica have restricted ecological niches compared to related non-hygrochastic species and are specialists in alpine habitats. Furthermore, the localized extent of hygrochastic Veronica is most likely the result of restricted short-distance dispersal through hygrochasy rather than the availablility of fundamental niche space. The spatial restriction hypothesis was previously only associated with species in arid areas but this study provides some indication that this holds true for species in alpine areas as well.

\subsubsection{REFERENCES}

AlBaCh, D. C., AND H. M. MeudT. 2010. Phylogeny of Veronica in the Southern and Northern Hemispheres based on plastid, nuclear ribosomal and nuclear low-copy DNA. Molecular Phylogenetics and Evolution 54: 457-471.

BitTRICH, V., AND H. E. K. HARTMANN. 1988. The Aizoaceae - a new approach. Botanical Journal of the Linnean Society 97: 239-254.

CALENGE, C., AND M. BASILlE. 2008. A general framework for the statistical exploration of the ecological niche. Journal of Theoretical Biology 252: 674-685.

COLWELL, R. K., AND D. J. FUTUYAMA. 1971. On the measurement of niche breadth and overlap. Ecology 52: 567-576.

COLWELL, R.K. AND T.F. RANGEL. 2009. Hutchinson's duality: The once and future niche. Proceedings of the National Academy of Sciences 106, suupl. 2: 19651-19658

CowLING, R. M. et al. 1998. Extraordinarily high regional-scale plant diversity in southern African arid lands: subcontinental and global comparisons. Diversity and Distributions 4: 27-36. 
COWling, R. M., AND C. Hilton-TAYLOR. 1997. Phytogeography, flora and endemism. In R. M. Cowling, D. M. Richardson, and S. M. Pierce [eds.], Vegetation of southern Africa, 43-61. Cambridge University Press, Cambridge.

DESMET, P. G., AND R. M. CowLING. 1999. Biodiversity, habitat and range-size aspects of a flora from a winter-rainfall desert in north-western Namaqualand, South Africa. Plant Ecology 142: 23-33.

Dytham, C. 2005. Choosing and using statistics - A biologist's guide. Blackwell Publishing.

ECCLES, N. S., K. J. ESLER, AND R. M. COWLING. 1999. Spatial analysis in Namaqualand desert plant communities: evidence for general positive interactions. Plant Ecology 142: 71-85.

ELITH, J., AND J. LEATHWICK. 2007. Predicting species distribution from museum and herbarium records using multiresponse models fitted with multivariate adaptive regression splines. Diversity and Distributions 13: 265-275.

Elith, J., C. H. Graham, R. P. Anderson, M. Dudik, S. Ferrier, A. Guisan, R. J. Hijmans, F. Huettmann, J. Leathwick, A. Lehmann, J. Li, L. G. LohmanN, B. A. Loiselle, G. MANiON, C. Moritz, M. NAKAMURA, Y. NAKAZAWA, J. M. Overton, A. T. Peterson, S. J. Phillips, K. Richardson, R. SCACHETtiPereira, R. E. SChapire, J. SOBERon, S. Williams, M. S. WisZ, AND N. E. ZIMMERMANN. 2006. Novel methods improve prediction of species' distribution from occurence data. Ecography 29: 129-151.

ESRI. 1999-2008. arcMap.

FEINSINGER, P., E. E. SPEARS, AND R. W. POOLE. 1981. A simple measure of niche breadth. Ecology 62: 27-32.

FUTUYAMA, D. J., AND G. MORENO. 1988. The evolution of ecological specialisation. Annual Review of Ecology and Systematic 19: 207-233.

HILTON-TAYLOR, C. 1994. Karoo-Namib region: Kaokoveld. In S. D. Davis, V. H. Heywood, and A. C. Hamilton [eds.], Centres of plant diversity: a guide and strategy for their conservation, 201-203. IUCN Publ. Unit.

HUTCHINSON, G. E. 1957. Concluding remarks. Cold Spring Harbour Symposium of Quantitative Biology, Cold Spring Harbour, 22: 415-427.

IHLENFELDT, H.-D. 1978. Morphologie und Taxonomie der Gattung Oophytum N. E. BR. (Mesembryanthemaceae) Botanische Jahrbuecher 99: 303-328. . 1983. Dispersal of Mesembryanthemaceae in arid habitats. Sonderbaende des Naturwissenschaftlichen Vereins Hamburg 7: 381-390. 1994. Diversification in an arid world - the Mesembryanthemaceae. Annual Review of Ecology and Systematic 25: 521-546.

JUERGENS, N. 1986. Untersuchungen zur oekologie sukkulenter Pflanzen des suedlichen Afrikas. Mitteilungen aus dem Institut fuer Allgemeine Botanik Hamburg 21: 139365 .

KEARNEY, M. 2006. Habitat, environment and niche: what are we modeling. Oikos 115: 186191.

KLAK, C., G. REEVES, AND T. HEDDERSON. 2004. Unmatched tempo of evolution in southern African semi-desert ice-plants. Nature 427: 63-65.

Leathwick, J., F. Morgan, G. Wilson, D. Rutledge, M. McLeod, AND K. Johnston. 2002. Land Environments of New Zealand: A technical guide. Ministry for the Environment.

Loarie, S. R., B. E. Carter, K. Hayhoe, S. Mcmahon, R. Moe, C. A. Knight, AND D. D. ACKERLEY. 2008. Clmate change and the future of California's endemic flora. PloS ONE 3.

Loiselle, B. A., P. M. Jorgensen, T. Consiglio, I. Jimenez, J. G. Blake, L. G. LOHMANN, AND O. M. MONTIEL. 2008. Predicting species distribution from herbarium collections: does climate bias in collection sampling influence model outcomes? Journal of Biogeography 35: 105-116. 
MARK, A. F., AND K. J. M. DiCKINSON. 1997. New Zealand alpine ecosystems. In F. E. Wielgolaski [ed.], Polar and Alpine Tundra, 311-345. Elsevier, Amsterdams, Netherlands.

MCGlone, M. S., R. P. DunCAn, AND P. B. HeEnAn. 2001. Endemism, species selection and the origin and distribution of the vascular plant flora of New Zealand. Journal of Biogeography 28: 199-216.

MeudT, H. M. 2008. Taxonomic revision of Australasian snow hebes (Veronica, Plantaginaceae). Australian Systematic Botany 21: 387-421.

Midgley, G. F. et al. 2000. Have Pleistocene climatic cycles influenced species richness patterns in the greater Cape Mediterranean Region? Journal of Mediterranean Ecology 2: 137-144.

Miller, B. P., N. J. ENRIGHT, AND B. B. LAMONT. 2007. Record error and range contraction, real and imagined, in the restricted shrub Banksia hookeriana in southwestern Australia. Diversity and Distributions 13: 406-417.

MYERS, N. et al.. 2000. Biodiversity hotspots for conservation priorities. Nature 403: 853858.

Pearson, R. G., C. J. Raxworthy, M. NaKamura, AND A. T. Peterson. 2007. Predicting species distributions from small numbers of occurence records: a test case using cryptic geckos in Madagaskar. Journal of Biogeography: 102-117.

PUFAL, G., K.G. RYAN AND P. GARNOCK-JONES. 2010. Hygrochastic capsule dehiscence in New Zealand alpine Veronica (Plantaginaceae). American Journal of Botany 97: 1413-1423

PUFAL AND P. GARNOCK-JONES. 2010. Hygrochastic capsule dehiscence supports safe site strategies in New Zealand alpine Veronica (Plantaginaceae). Annals of Botany 106: 405-412

R Development CoRe TEAM. 2005. R: A language and environment for statistical computing. R Foundation for statistical computing, Vienna, Austria.

RIORDAN, E. C., AND P. W. RUNDEL. 2009. Modelling the distribution of a threatened habitat: the California sage shrub. Journal of Biogeography 36: 2176-2188.

SOBERON, J. 2007. Grinellian and Eltonian niches and geographic distribution of species. Ecology Letters 10: 1115-1123.

SOBERON, J., AND A. T. PETERSON. 2005. Interpretation of models of fundamental ecological niches and species' distribution areas. Biodiversity Informatics 2: 1-10.

SPSS INC., S. 1989-2007. SPSS.

THIERS, B. [continuously updated]. Index Herbariorum: A global directory of public herbaria and associated staff. New York Botanical Garden's Virtual Herbarium. http://sweetgum.nybg.org/ih/

WAgstafF, S. J., M. J. BAYLY, P. GARnOCK-JONES, AND D. AlbaCh. 2002. Classification, origin, and diversification of the New Zealand Hebes (Scrophulariaceae). Annals of the Missouri Botanical Garden 89: 38-63. 


\section{Chapter 3.4}

\section{Summary and Conclusion}

Chapter Three is presented as an in depth analysis of the role of hygrochastic dehiscence in the seed dispersal and plant distribution of hygrochastic Veronica in New Zealand. I explored the spatial restriction hypothesis, which relates this dispersal strategy to atelechory, directed dispersal, safe site strategies and habitat specialization. In the species presented here, hygrochasy confines seed transport to raindrops as sole dispersal agents, resulting in a very short dispersal distance. I found convincing evidence that this dispersal strategy directs dispersal to safe sites for seeds within the parental habitat, which is otherwise surrounded by a heterogeneous environment. The analysis of herbarium records of both hygrochastic and non-hygrochastic Veronica supports the hypothesis that hygrochastic Veronica are specialists with a small ecological niche and being hygrochastic supports the persistence of populations in high alpine habitats. Short-distance dispersal within small suitable habitat patches results in the survival of more offspring because seeds germinate in a favourable habitat.

However, the selection of locations from herbarium databases and the use of LENZ IV are open to criticism, because they might not provide accurate small-scale information. Nevertheless, field observations support the analysis of herbarium databases with LENZ IV; the species I investigated in this study are confined to certain habitats, e.g. gravel substrates of a certain size and low vegetation cover.

Overall, this work strongly supports the spatial restriction hypothesis that has so far only been applied to hygrochastic species in arid regions. In New Zealand alpine Veronica, ombrohydrochory with hygrochasy appears to be an adaptation to ensure short distance dispersal to safe sites for species with a narrow ecological niche. 


\section{CHAPTER FOUR}

An Investigation of Hygrochasy and Species Relationships in

\section{Colobanthus (Caryophyllaceae)}

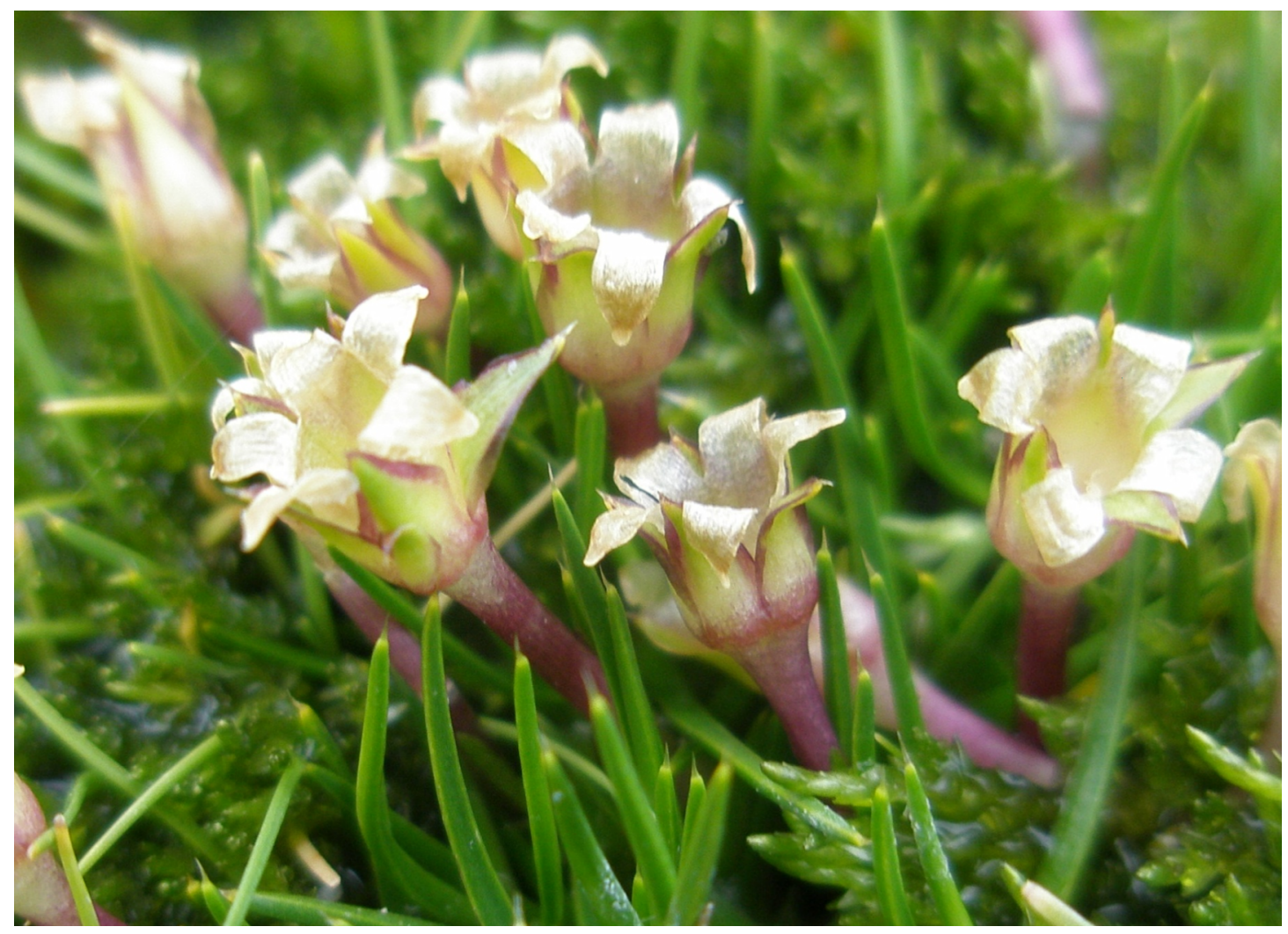

FIG 4.1 Wet open Colobanthus apetalus capsules at Blue Lake, Garvie Mountains. 


\section{Chapter 4.1}

\section{Overview}

In this dissertation I was able to show that hygrochasy, which is predominantly associated with plants in arid regions, also occurs in New Zealand Veronica, mostly in alpine areas. A common syndrome for alpine hygrochastic species is apparent in the investigated species; hygrochasy seems to be associated with low subshrub or cushion plants and solitary, sessile capsules.

Additional studies (see Chapter Three) also show that hygrochasy in alpine Veronica is of advantage for plants in small, specialized habitats and it fascilitates shortdsitance dispersal to safe sites within the parent habitat. These findings raise the question, whether other alpine species in New Zealand might be hygrochastic as well. A large number of New Zealand alpine species has a cushion or low, creeping life form and capsule fruits can be found in a number of species (Mark and Adams, 1995). Often, these species are found at high altitudes on scree or in fellfield, where it is of advantage to disperse seeds only over a short distance to avoid seedling germination in densely vegetated tussock fields.

One alpine genus, which has potentially hygrochastic capsules, is Colobanthus (Caryophyllaceae). Opening of capsules has been observed in some individuals (B.V. Sneddon, pers. comm.; P. Garnock-Jones and W.M. Malcolm, pers. comm.) and further research is warranted to investigate all New Zealand species regarding their dehiscence mechanism. Colobanthus is a strictly southern hemispheric genus and consists of approximately 20 species across temperate regions in the Southern Hemisphere. So far, very little is known about the taxonomy and species relationships within the genus. When investigating the capsule dehiscence in the majority of Colobanthus, an understanding of the species relationships and lineages would be of 
great advantage to infer whether hygrochasy evolved once within the genus or is a labile character associated with occurrence in alpine habitats.

In Chapter 4.2 I investigate capsule anatomy in ten Colobanthus species implementing methods successfully used for the investigation of hygrochasy in Veronica (Pufal et al., 2010). I used additional species for scanning electron microscopy and analysis of morphological characteristics. I hypothesize that cushion species with sessile capsules are hygrochastic, since they correspond to the syndrome discovered for hygrochastic New Zealand Veronica. However, the arrangement of tissues is likely to differ due to genus-specific capsule anatomy. In this Chapter I plan to identify capsule dehiscence mechanisms in all available species.

Chapter 4.3 represents a molecular approach to solve the phylogeny of Colobanthus. Taxonomic treatments based on morphology are treated with care, especially in the Caryophyllaceae (Harbaugh et al., 2010) and species identification based on morphology is extremely difficult in Colobanthus. One nuclear marker (ITS) and two chloroplast markers (rps16 and trnE-trnTr) are used to study the phylogeny of New Zealand and South American species. The resulting phylogeny can then be used to map hygrochasy as character and trace its evolution within the genus.

\subsubsection{REFERENCES}

Harbaugh, D.T., M. NePOKRoefF, R.K. RABeler, J. MCNeill, E.A. ZimMer, W.L. WARREN. 2010. A new lineage-based tribal classification of the family Caryophyllaceae. International Journal of Plant Sciences. 171 (2): 185-198

MARK A.F. AND N.M. ADAMS. 1995. New Zealand alpine plants fully revised. Godwit Publishing, Auckland, New Zealand.

PUfAL, G., K.G. RYAN AND P. GARNOCK-JONES. 2010. Hygrochastic capsule dehiscence in New Zealand alpine Veronica (Plantaginaceae). American Journal of Botany 97: $1413-1423$ 


\section{Chapter 4.2}

\section{Hygrochastic Movement in Capsules of the Southern Hemisphere Genus Colobanthus (Caryophyllaceae)}

\subsubsection{ABSTRACT}

Hygrochasy is a capsule opening mechanism that responds to moisture and is increasingly being found in a diverse range of plants and habitats. In general, it is based on an antagonistic movement, where a swelling tissue absorbs water and expands while the direction of the movement is controlled by an unmoving resistance tissue. Following recent work on hygrochastic capsules in New Zealand alpine Veronica, observations of capsule movement in some New Zealand Colobanthus also suggested hygrochastic capsules in this genus. I investigated 15 species with regards to their capsule opening mechanism. Based on techniques used for hygrochastic Veronica, I employed various light microscopy techniques, staining procedures and SEM micrographs to identify capsule anatomy and cell arrangement. Morphological traits and additional information on capsule structures were used in multivariate analysis to explore relations between species based on dispersal strategy.

In contrast with other genera with hygrochastic capsules, no resistance tissue was found in Colobanthus and none of the cells were lignified. However, the outer cell layer of capsules showed thickened cell walls capable of swelling. In contrast to woody hygrochastic capsules, which work with an imbibition mechanism, hygrochasy in Colobanthus is based on a combination of imbibition and cohesion mechanism within the capsule. Results suggest that all species in this genus are capable of hygrochastic movement. 
Keywords: cohesion mechanism; Colobanthus, hygrochasy, imbibition mechanism, microscopy, New Zealand, southern hemisphere

\subsubsection{INTRODUCTION}

Recently, Thorsen et al. (2009) published a comprehensive study on the seed dispersal systems in the New Zealand Flora. They attempted to assign dispersal mechanisms to the entire flora, based on literature and observations but also acknowledge the lack of data for a number of species. Especially in species with inconspicuous fruits, dispersal strategies were assigned with uncertainty if literature data could not be supported by observations.

Two of the groups Thorsen et al. (2009) listed as uncertain are Veronica (as Parahebe and Chionohebe, for phylogeny and nomenclature see Albach and Meudt, 2010 and Garnock-Jones et al., 2007). The authors assume that the primary dispersal agent is wind and secondary dispersal could be carried out by water.

Some of these species have been previously characterised as being either hygrochastic or xerochastic (Garnock-Jones, 1993; Garnock-Jones and Lloyd, 2004) but until now the hygrochastic movement and its implications for primary dispersal by rain have not been studied in more detail (but see Pufal et al., 2010 and Pufal and Garnock-Jones, 2010). The common morphological traits associated with hygrochasy in Veronica were a cushion or subshrub growth form with solitary sessile capsules that stayed closed until wetted. When they are wetted in rainfall events, they open to form a splash cup and seeds are subsequently dispersed by falling raindrops. The mechanism is based on an antagonistic movement between a swelling tissue and a resistance tissue, where the swelling tissue absorbs water in its cell walls and stretches, whereas the resistance tissue is lignified and not capable of moving (Fahn and Werker, 1972). 
Dispersal by raindrops alone results in short-distance dispersal, mostly not further than one meter. This atelechoric strategy is most likely an adaptation to ensure directed dispersal within a small suitable habitat patch with available safe sites for seedlings (Pufal and Garnock-Jones, 2010). Most hygrochastic Veronica (for exceptions see Pufal et al., 2010) occur exclusively in high alpine areas, where they can be found in small habitat patches of cushion field, fellfield or in snowbank vegetation. An atelechoric dispersal strategy seems favourable in a restricted alpine habitat (Chapter Three) and the idea arose that hygrochasy might well exist in other plants in alpine habitats with similar growth forms and sessile capsule fruits. Potential candidate genera other than Veronica are Colobanthus, Donatia and Dracophyllum. Incidentally, opening under wet conditions was observed in some New Zealand Colobanthus species (B.V. Sneddon, pers. comm.; P. Garnock-Jones and W.M. Malcolm, pers. comm.) (Fig. 4.2.1).

Colobanthus (Caryophyllaceae subfamily Alsinoideae) is a southern hemispheric genus with approximately 20 species found in South America, Kerguelen Islands, Falkland Islands, South Georgia, Antarctica, Australia, Tasmania and New Zealand. The diversity centre is New Zealand with 13 species, ten of them in alpine habitats and all but two of them endemic (Allan, 1961). To this date the genus has not been monographed and the phylogeny remains unresolved.

Colobanthus is a small perennial plant characterized by a cushion or tufted life form with inconspicuous apetalous flowers that are either sessile or on short pedicels. The fruits are small papery capsules with either four or five valves. When open, the capsules resemble splash cups. 


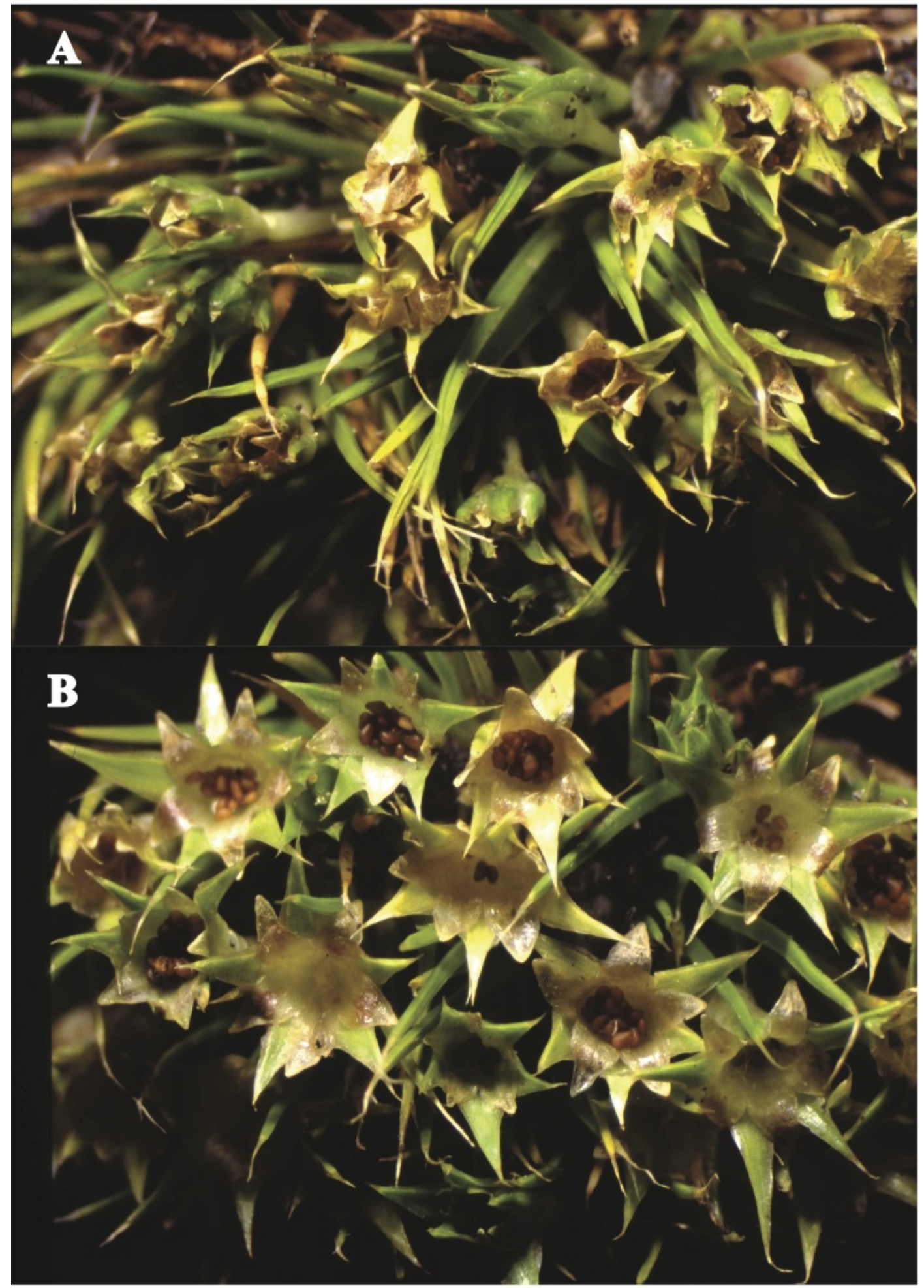

FIG 4.2.1 Dry (A) and wet (B) capsules of Colobanthus strictus. Photographs by W.M. Malcolm. 
Comparatively little research has been carried out on Colobanthus. Most focus lies on C. quitensis, which is one of the two only flowering plants in Antarctica and therefore interesting in regards to cold resistance and photosynthesis (Ruhland and Day, 2001; Gianoli et al., 2004; Bravo and Griffith, 2005; Piotrowicz-Cieslak et al., 2005; Bravo et al., 2007; Sierra-Almeida et al., 2007; Gielwanowska et al., 2008; Zuniga-Feest et al., 2009). Subantarctic species received some attention due to their location (Van der Putten et al., 2010) and the seed ecology of Colobanthus kerguelensis has been investigated to some extent (Hennion and Walton, 1997). However, New Zealand species are underrepresented in the literature (but see Sneddon, 1999).

The aim of this study is to investigate the dispersal mechanism of New Zealand Colobanthus species to broaden the knowledge of New Zealand seed dispersal systems. Special attention is paid to the anatomy and morphology of Colobanthus capsules with regards to their opening mechanism since opening under wet conditions had been reported. I attempt to find the underlying biomechanics of the hygrochastic movement in Colobanthus and draw parallels to alpine Veronica. Methods that have been proved to be appropriate for Veronica in Pufal et al. (2010) (light microscopy, different staining techniques) were applied here as well, but in addition scanning electron microscopy was carried out. Additional to the anatomical data, morphological data were also integrated in a hierarchical cluster analysis to attempt the identification of groupings related to the dehiscence mechanism in the genus.

\subsubsection{METHODS}

Dried capsule samples were obtained from the Allan Herbarium at Landcare Research Centre in Lincoln, New Zealand (CHR) and additional fresh samples were collected at various field sites on South Island, New Zealand (see Appendix 4.2.1 for location 
details and voucher numbers). To detect hygrochasy, dry capsules were submerged in water and their reaction was observed. If an opening movement of capsules could be observed, they were classified as hygrochastic. If no movement was observed, they were not classified until further anatomical studies were carried out.

For anatomical studies, capsules were embedded in epoxy resin, which allowed for very thin ultratome sections. Following a dehydration alcohol series, the samples were placed in $100 \%$ absolute ethanol and propylene oxide for 30 min each, left overnight in 50:50 propylene oxide : resin and then transferred to $100 \%$ resin for at least three to four hours. They were then arranged in resin-filled moulds and dried overnight. Sections $(2-4 \mu \mathrm{m})$ were cut with glass knives in a Leica Ultracut E ultratome and stained with Toluidine Blue. However, most Colobanthus specimen proved to be too brittle for this method and only a few samples could be used for measurements. Therefore additional sections were made using paraffin embedded samples following a modified protocol of Jensen (1962). Samples were dehydrated in an alcohol series from water to $100 \%$ ethanol in 5 steps, each step lasting about one hour. Tissue was then placed in a 50:50 mix of xylene : 100\% ethanol for 1.5 hours. Samples were then transferred to $100 \%$ xylene for 2 hours. A small glass jar partly filled with paraffin was topped up with $100 \%$ xylene including the tissue sample (resulting in approximately 50:50 of paraffin : xylene) and placed in an oven at $60^{\circ} \mathrm{C}$ for 6 hours for infiltration. The paraffin was tipped out, leaving the sample in the jar and the jar was then topped up with another change of paraffin and placed in the oven for four hours. A third change was made and after four hours the sample was mounted in fresh paraffin on a wooden block.

A rotary microtome was used to make sections of $12-15 \mu \mathrm{m}$ thickness. Sections were made in two orthogonal planes (cross-sections and longitudinal sections). The 
paraffin infiltration was reversed by washing the sections in $100 \%$ xylene and then reversing the ethanol series to the desired ethanol concentration. Sections were stained with Ruthenium Red for pectinous substances (Gurr, 1953) and hydrocholic acid and Phloroglucinol for lignified substances (Gurr, 1953). The following measurements were made on the cells in the capsule wall in ultratome sections and paraffin sections: length, width and cell wall thickness of cells in the inner layers of the capsule (random cells), length, width and cell wall thickness at the outer edge of the outer cell layer of the capsule. The thickness of the capsule wall was also measured. The measurements were used in a Principal Component Analysis (PCA) in order to find anatomical traits associated with dehiscence type. All measurements were compared between the species using Kruskal Wallis tests and subsequent Mann-Whitney-U tests were used to identify significant differences between the species.

Cross sections of single valves made by hand were used to observe change in valve width after water absorption. The valve pieces were placed on glass slides and measured with a moticam (Motic Images Plus 2.0) at 6.3x magnification under a Zeiss microscope before and after water was applied. The change was recorded in percentages.

Scanning electron microscopy was used to collect additional information about capsule anatomy and tissue arrangement. Samples were prepared by mounting dry capsules and capsule cuttings on carbonfoil and coating them with gold (12 nm thick) using a sputter coater (Poleron SC500). Those samples were then carbon coated and viewed with a JEOL JSM-5300LV scanning microscope.

The morphological characters measured for all Colobanthus species were based on the Veronica treatment in Chapter Two. In addition, the number of valves and the relationship between valves and sepals were also coded as character states (Table 
4.2.1). All character states were used in a hierarchical cluster analysis to identify characters separating hygrochastic from non-hygrochastic species. The cophenetic correlation coefficient was calculated to determine how well the dendrogram represents the Euclidean distance matrix. Statistical analyses were carried out using R (R Development Core Team, 2005).

Table 4.2.1 Characters and character states for morphological traits of Colobanthus species.

\begin{tabular}{|lll|}
\hline \multicolumn{2}{ll|}{ Character } & Character states and codes \\
\hline 1 & life form & cushion (1), tufted (2), flat rosette (3) \\
2 & number of inflorescences & solitary (1), $-4(2)$ \\
3 & position of capsule & sessile $(1)$, peduncle $<2 \mathrm{~cm}(2)$, peduncle $>2 \mathrm{~cm}(3)$ \\
4 & orientation of capsule & erect $(1)$, facing down $(2)$, both (3) \\
5 & number of valves & 4 valves (1), 5 valves (2), both (3) \\
6 & valves vs. sepals & valves shorter (1), valves longer (2), same or both (3) \\
\hline
\end{tabular}

\subsubsection{RESULTS}

Nine Colobanthus species were used in the main part of this study, eight from New Zealand and one South American species (C. subulatus). Additional species were used for scanning electron microscopy. Obvious opening in water was observed in $C$. buchananii, C. canaliculatus, C. muelleri and C. wallii and these species were classified as hygrochastic. Capsules of C. affinis, C. acicularis and C. apetalus remained closed and only little change could be observed in capsules of C. subulatus and C. strictus, which showed splits in the capsule before wetting. These species were not classified regarding their opening mechanism.

All Colobanthus capsules show the same structure, only differing slightly in size, number of valves and length of valves. The capsules are made up of either four or five valves and a free - standing placental column with no septum. There are nor dorsal 
bundles in the valves, but weakly developed veins are present. Once seeds break off the funicles they lie unordered in the capsule cavity.

Sections showed that all species had more or less irregularly shaped rhomboidal cells and the cell walls of the cells on the outer side of the capsule were significantly thicker than cell walls of other cells in the capsule (Mann-Whitney-U test: p-values for all species $<0.002)$. Staining with Ruthenium Red showed that all cell walls contained pectinous substances but no lignin was detected in any of the capsules when staining with $\mathrm{HCl}$ and Phloroglucinol.

Measurements of cell traits and of valve change with water absorption were used in a PCA to reveal grouping amongst the species and to ascertain if some variables were more influential than others. The first three components of the PCA explain $66 \%$ of the variation and all variables are influential in the first three components. When displaying the first two components graphically, no grouping can be observed amongst the species (Table 4.2.2; Fig. 4.2.2). However, samples from the same species tend to group together due to their similar cell size.

A noticeable increase in valve size after water absorption occurred in all tested species (for raw data, see Appendix 4.2.2). However, compared to hygrochastic Veronica (Pufal et al., 2010), the change is significantly smaller (Mann-Whitney-U test: $\mathrm{W}=1661, \mathrm{p}<0.0001)$. 
Table 4.2.2 Eigenvalues and loadings for PCA. Change of valve size after water absorption (change), capsule wall thickness (wall thickness), the length (length in), width (width in) and cell wall thickness (cell wall in) of cells in the inner layers of the capsule as well as length (length out), width (width out) and cell wall thickness (cell wall out) of the outer cell layer of the capsule.

\begin{tabular}{|lllllllll||}
\hline \hline Components & 1 & 2 & 3 & 4 & 5 & 6 & 7 & 8 \\
\hline Eigenvalues & 2.744 & 1.432 & 1.12 & 0.976 & 0.751 & 0.471 & 0.294 & 0.212 \\
St. dev. & 1.657 & 1.197 & 1.058 & 0.988 & 0.867 & 0.686 & 0.542 & 0.461 \\
$\begin{array}{l}\text { Proportion } \\
\text { variance }\end{array}$ & 0.343 & 0.179 & 0.14 & 0.122 & 0.094 & 0.059 & 0.037 & 0.027 \\
$\begin{array}{l}\text { Cumulative } \\
\text { proportion }\end{array}$ & 0.343 & 0.522 & 0.662 & 0.784 & 0.878 & 0.937 & 0.973 & 1 \\
\hline loadings & & & & & & & & \\
\hline Length in & -0.39 & -0.328 & -0.393 & & 0.126 & 0.677 & -0.189 & -0.274 \\
Width in & -0.301 & -0.418 & -0.116 & 0.376 & 0.573 & -0.404 & 0.26 & 0.143 \\
Cell wall in & -0.38 & & -0.357 & -0.543 & -0.279 & -0.201 & 0.558 & \\
Length out & -0.465 & -0.236 & 0.18 & -0.168 & -0.274 & -0.436 & -0.631 & \\
Width out & -0.402 & 0.312 & 0.482 & 0.232 & & & 0.286 & -0.609 \\
Cell wall out & -0.464 & 0.348 & 0.263 & & 0.115 & 0.302 & & 0.698 \\
Wall thickness & & 0.619 & -0.399 & -0.161 & 0.495 & -0.218 & -0.319 & -0.19 \\
Change & -0.132 & 0.24 & -0.46 & 0.675 & -0.494 & & & \\
\hline
\end{tabular}




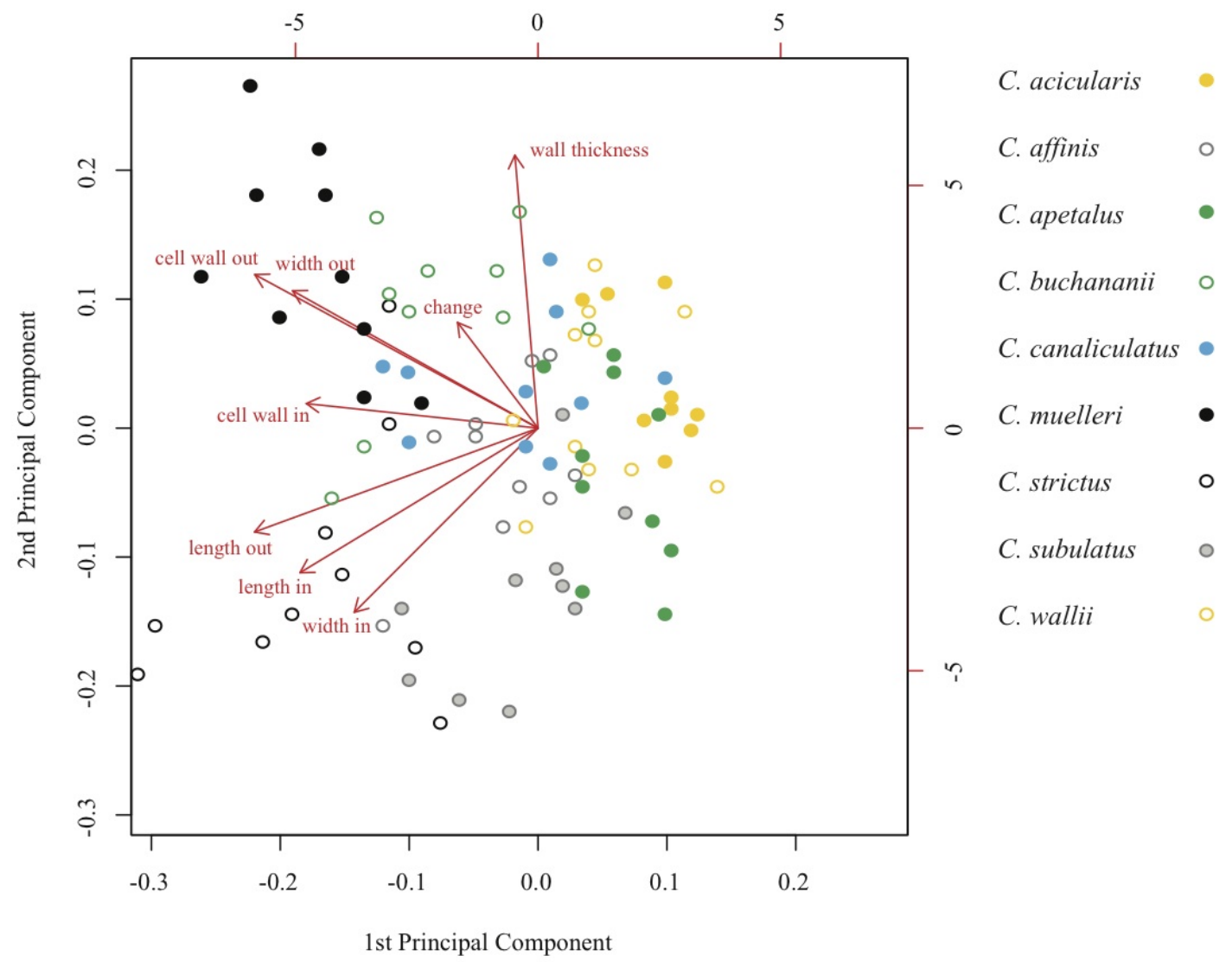

FIG. 4.2.2 Principal Component Analysis of measurements in Colobanthus capsules. Red arrows represent the eigenvalues of the change of valve size after water absorption (change), capsule wall thickness (wall thickness), the length (length in), width (width in) and cell wall thickness (cell wall in) of cells in the inner layers of the capsule as well as length (length out), width (width out) and cell wall thickness (cell wall out) of the outer cell layer of the capsule.

When comparing each measured variable between species in a Kruskal Wallis test and subsequent Mann-Whitney-U tests, differences were significant but not consistent between variables (Appendix 4.2.3).

Morphological characters were coded as character states and used in a hierarchical cluster analysis. Characters that were identified as common characters for hygrochastic Veronica (Chapter Two), such as solitary capsules and short pedicels, were equally present in all investigated Colobanthus species (Fig. 4.2.3). 
Clustering into groups is very well supported with a cophenetic value of 0.904 . Species split into clusters because of the different life forms; therefore three distinct groups can be found (cushion species - I, tufted species - II and C. muelleri - III, which forms a rosette).

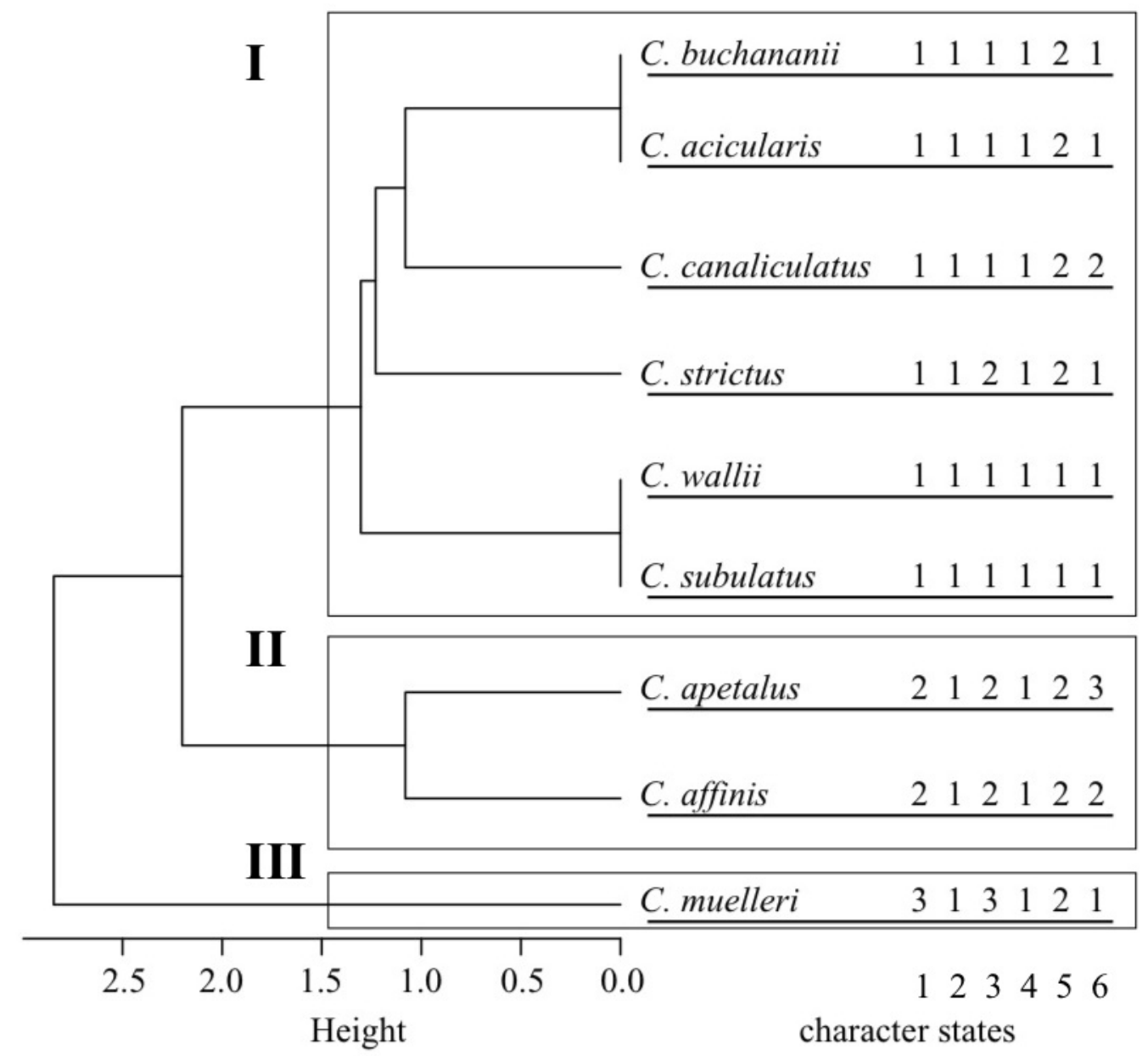

FIG. 4.2.3 Hierarchical Cluster Analysis of character states for nine Colobanthus species. Coding for character states can be found in Table 4.2.1. Cluster I includes cushion species, cluster II tufted species and C. muelleri forming a rosette stands separately (III).

For SEM micrographs a total of 13 species was used (see Appendix 4.2.1 for location details and voucher specimen) to capture the capsule morphology of as many species as possible. All Colobanthus capsules have a ridged surface on the outside of the capsule (Fig. 4.2.4 and Fig. 4.2.5) but vary in pattern and depth of ridges. Thickened 
valve apices are also present in all species and are shown in some micrographs (Fig.4.2.4 B and F, Fig. 4.2.5 B, D, E, G). Again, all investigated species appeared to be similar, except for capsule shape and occasional number of valves (Fig. 4.2.4 and Fig. 4.2.5).

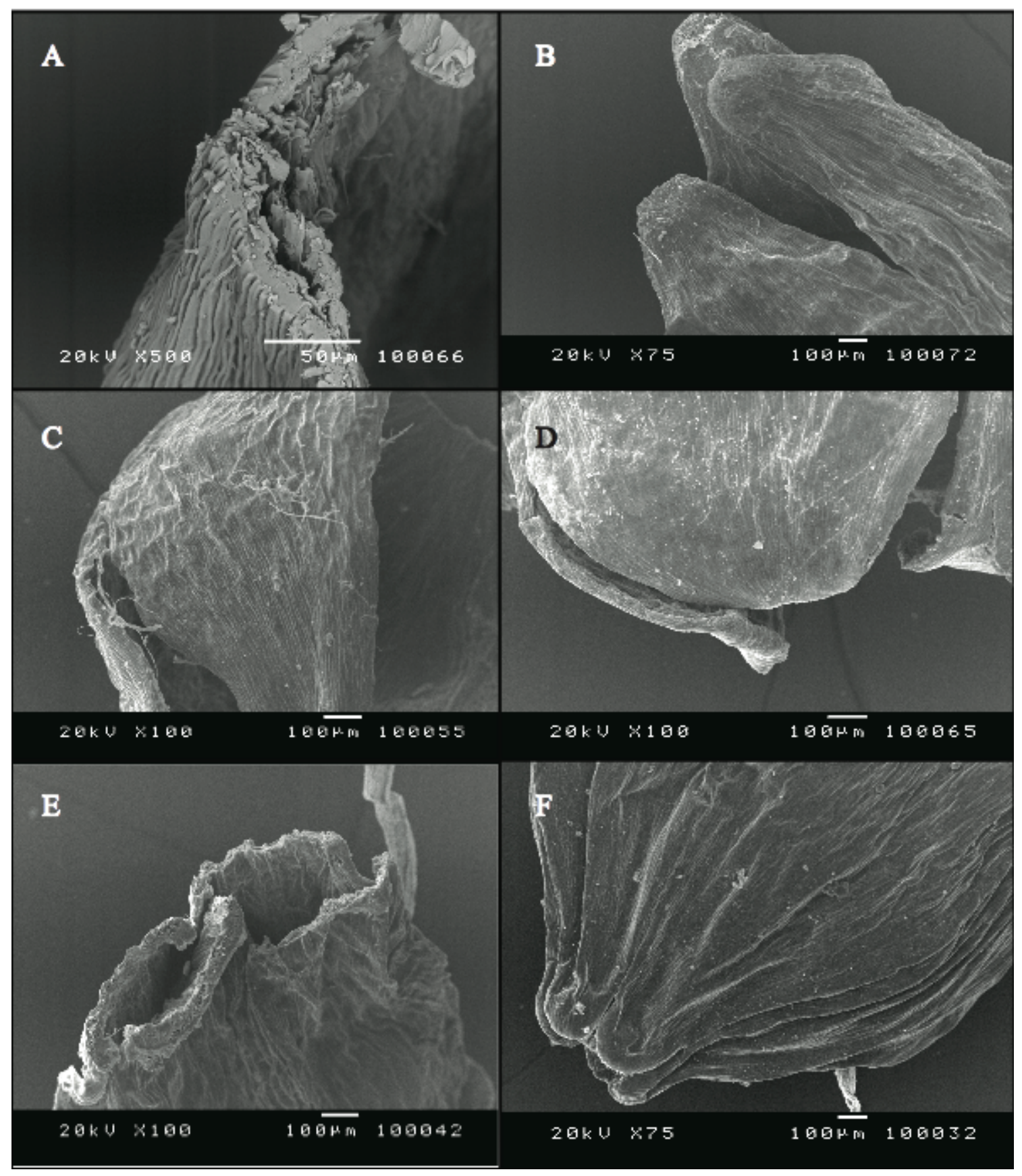

FIG. 4.2.4 SEM micrographs of Colobanthus capsules. (A) C. buchananii cut valve, (B) $C$. apetalus valve apices, (C) C. strictus valve, (D) C. wallii valve, (E) C. canaliculatus cut capsule apex, (F) C. masoniae closed capsule apex. 


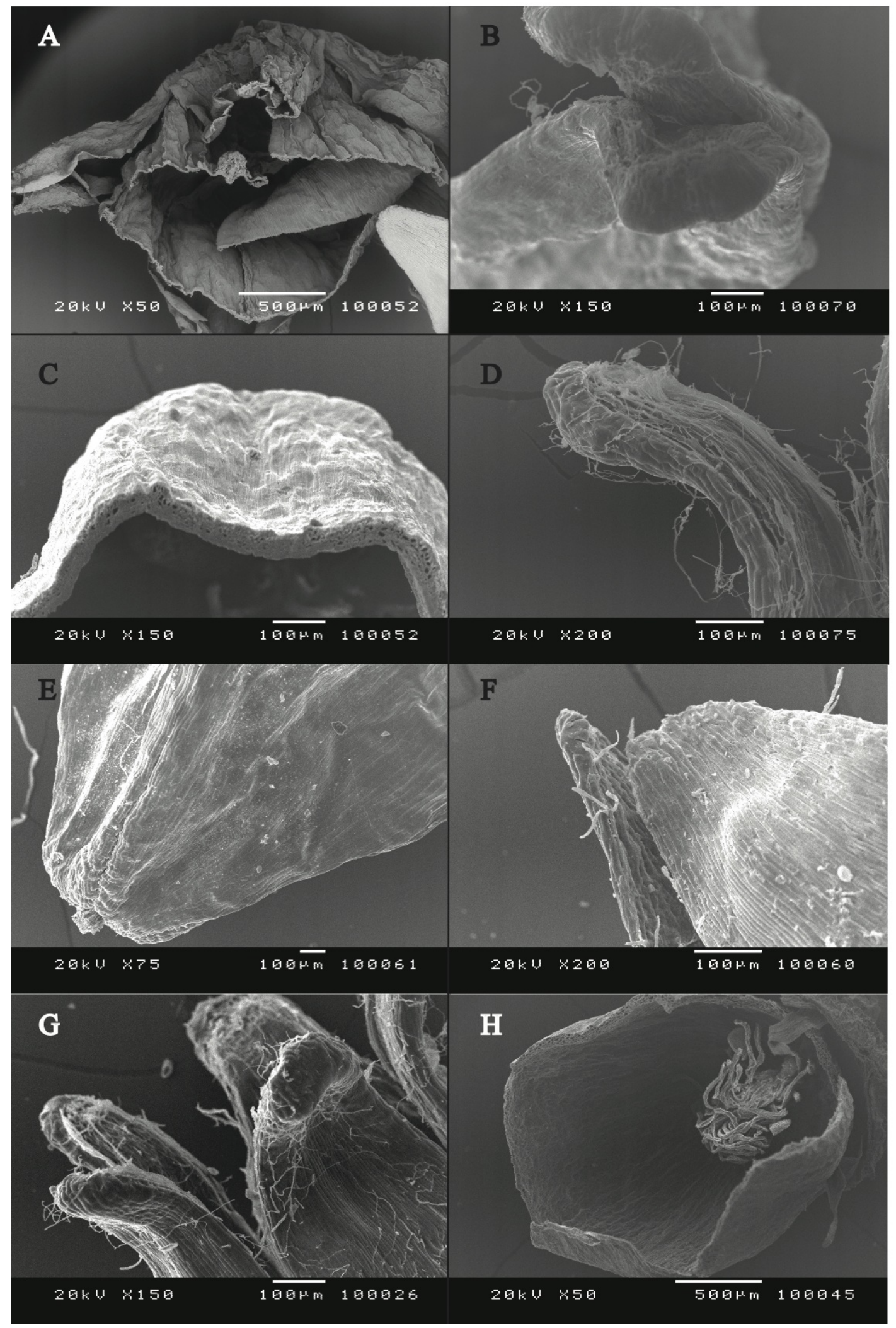

FIG. 4.2.5 SEM micrographs of Colobanthus capsules. (A) C. muelleri cut capsule top, (B) C. acicularis valve apex, (C) C. brevisepalus cross-cut capsule, (D) C. buchananii valve apex, (E) C. kerguelensis closed capsule apex, (F) C. lycopodioides cut valve, (G) C. monticola valve apices, (H) C. quitensis cut capsule with placenta. 


\subsubsection{DisCUSSION}

In this study, the main aim was to test the association between hygrochastic capsules, cushion or mat habit and sessile fruits observed in alpine Veronica, by close examination of a phylogenetically independent genus. A secondary aim was to add information on the poorly studied genus Colobanthus to the study by Thorsen et al. (2009). The focus of this study was to investigate capsule dehiscence in Colobanthus species on the basis that opening of capsules was observed in wet conditions. Submerging capsules in water resulted in the capsule opening of some species. However, detailed analysis of capsule sections, and size change in valve pieces revealed that all investigated species are capable of opening to some degree. The capsules that remained closed during submersion in water were unripe and the valves still completely attached to each other.

Contrary to 'classic' hygrochastic capsules, where a swelling tissue and a resistance tissue are present to direct the swelling movement (Steinbrinck, 1883; Garside and Lockyer, 1930; Fahn and Werker, 1972; Poppendieck, 1995; Pufal et al., 2010), no resistance tissue could be located in the studied Colobanthus species. All cells seem to be capable of some swelling, the outer cells more so since their pectinous cell walls are overly thickened and hence probably able to absorb more water than inner cells, which have much thinner cell walls. The PCA did not reveal any grouping based on cell measurements and changes after water absorption, which implies that dehiscence in all investigated species is similar. SEM pictures showed the ribbed outside of capsules and the partly folded and crumbled structure of some valves. After observing capsules during wetting, analysing cross sections and longitudinal section of valves as well as studying SEM micrographs I propose the hygrochastic movement of Colobanthus capsules works as follows: 
Upon wetting, the pectinous and lignin-free cell walls of cells in the valves absorb water quickly and start to swell. This swelling causes the cells to stretch in all directions to their maximum as they have been irregularly shaped and somewhat shrunk before. Cells on the outside of the capsule have thickened cell walls capable of absorbing substantial amounts of water. The cells line up in a ribbed pattern, directing the swelling to stretch the entire capsule. Within a few minutes the valves open out in a star shape and seeds are exposed in a splash cup to falling raindrops (Fig. 4.2.1).

Part of the movement is an imbibition mechanism, which is based on antagonistic actions (Fahn and Werker, 1972). In most hygrochastic capsules, a swelling and a resistance tissue are involved but imbibition can also function when cell walls of the same cell act as antagonistic groups (Fahn, 1967; Fahn and Werker, 1972). When a cell wall imbibes water, it usually swells in a direction perpendicular to that of cellulose microfibrils. Therefore, if the angles of microfibrils within cell walls varies, their reaction towards moisture will be different. The outer cells of Colobanthus capsules show a significant thickening of their outer cell wall compared to the cell wall on the inside of the cells. Here, the thickened cell wall acts as swelling tissue, whereas the inner cell walls of the outer cells act as resistance tissue.

Fahn and Werker (1972) also describe the cohesion mechanism as another movement acting in dead cells, but here the cell lumen is involved. Cell walls of cells involved in this mechanism are usually thin and the cells wrinkle with water loss. When saturated with water, this tissue can expand considerably. Inner cells of Colobanthus capsules have thin cell walls and appear wrinkled and irregular when dry, which also leaves the capsule tissue somewhat crumpled when viewed under the microscope or in SEM (Fig. 4.2.3 and 4.2.4). After water absorption, the cells have a regular rhomboid shape and capsules stretch. 
Results strongly suggest that the hygrochastic dehiscence of all investigated Colobanthus species is most likely based on a combination of imbibition and cohesion mechanisms. The concurrence of imbibition and cohesion mechanisms was observed in a number of plants, where it causes short-distance dispersal (Steinbrinck and Schinz, 1908; Zohary and Fahn, 1941; Hegazy et al., 2006). However, so far it has never been observed within the same fruit.

Unfortunately I was not able to use all known Colobanthus species in this study and of the species I investigated only some of them were used in all analyses. I did not include any Australian species since I was not able to procure any specimens. Colobanthus capsules are extremely fragile and brittle and prove to be quite a challenge in different embedding techniques. This is the reason why some species could not be used in the anatomical analysis, because their capsules did not deliver good enough sections. However, both New Zealand and South American species uniformly show hygrochastic dehiscence to some extent, which leads me to the assumption that Australian species are highly likely to be hygrochastic as well.

This study extends the list of hygrochastic genera in New Zealand and also includes a coastal species as opposed to exclusively montane species. In contrast to Thorsen et al. (2009) who assumed that Colobanthus seeds might be wind dispersed, hygrochasy implies dispersal by raindrops, since fruits expose the seeds in a splash cup. The tufted Colobanthus species grow along rivers and streams, which provide splash water as a reliable dispersal agent (Nakanishi, 2002). For the coastal species C. muelleri, splash water from the surf is also a highly likely dispersal agent. However, some fruits are slightly open even when dry, which certainly exposes seeds to wind. Whether this exposure is sufficient for dispersal remains to be investigated. 
This study demonstrates that small plants with inconspicuous fruits can reveal a relatively uncommon phenomenon on closer inspection. Usually fruits with no apparent adaptation for dispersal are labelled as generalists (Fahn and Werker, 1972; Van der Pijl, 1982) but Colobanthus is clearly hygrochastic and most likely disperses by raindrops and subsequent rainwash (ombrohydrochory).

My findings are a further indication that hygrochasy might be a more common dispersal strategy in alpine plants, which was not known before. Alpine habitats are restricted and I showed previously that hygrochasy is an adequate dispersal strategy to maintain populations in those habitats (Chapter Three).

Further examination of dehiscence and associated dispersal mechanism in alpine plants is warranted, not only in New Zealand but in other alpine regions as well. 


\subsubsection{REFERENCES}

Albach, D. C., AND H. M. MeudT. 2010. Phylogeny of Veronica in the Southern and Northern Hemispheres based on plastid, nuclear ribosomal and nuclear low-copy DNA. Molecular Phylogenetics and Evolution 54: 457-471.

Allan, H. H. 1961. Flora of New Zealand Volume 1 Indigenous Tracheophyta. Government Printer, Wellington, New Zealand.

BRAVO, L. A., AND M. GRIFFITH. 2005. Characterization of antifreeze activity in Antarctic plants. Journal of Experimental Botany 56: 1189-1196.

Bravo, L. A., F. A. SaAvedra-Mella, F. Vera, A. Guerra, L. A. Cavieres, A. G. IVANOV, N. P. A. HUNER, AND L. J. CORCUERA. 2007. Effect of cold acclimation on the photosynthetic performance of two ecotypes of Colobanthus quitensis (Kunth) Bartl. Journal of Experimental Botany 58: 3581-3590.

FAHN, A. 1967. Plant anatomy. Pergamon, Oxford.

FAHN, A., AND E. WERKER. 1972. Anatomical mechanisms of seed dispersal. In T. T. Kozlowski [ed.], Seed Biology. Academic Press, New York, USA.

GARNOCK-JONES, P. J. 1993. Phylogeny of the Hebe complex (Scrophulariaceae: Veroniceae). Australian Systematic Botany 6: 457-479.

GARNOCK-JONES, P. J., AND D. G. LLOYD. 2004. A taxonomic revision of Parahebe (Plantaginaceae) in New Zealand. New Zealand Journal of Botany 42: 181-232.

GARnOCK-Jones, P., D. AlbaCh AND B.G. BRIGGS. 2007. Botanical names in Southern Hemisphere Veronica (Plantaginaceae); sect. Detzneria, sect. Hebe, and sect. Labiatoides. Taxon 56: 571-582

GARSIDE, S., AND S. LOCKYER. 1930. Seed dispersal from the hygroscopic fruits of Mesembryanthemum carpanthea (Mesembryanthemum) pomeridiana, N. E. Br. Annals of Botany 44: 639-U636.

Gianoli, E., P. Inostroza, A. Zuniga-Feest, M. Reyes-Diaz, L. A. Cavieres, L. A. BRAVO, AND L. J. CORCUERA. 2004. Ecotypic differentiation in morphology and cold resistance in Populations of Colobanthus quitensis (Caryophyllaceae) from the Andes of central Chile and the maritime Antarctic. Arctic Antarctic and Alpine Research 36: 484-489.

Gielwanowska, I., A. BOCHENEK, AND P. LORO. 2008. Anatomical responses of Colobanthus quitensis (Kunth) Bartl. and Deschampsia antarctica Desv. to abiotic stress factors. Ecological Questions 9: 45-56.

GURR, E. 1953. A practical manual of medical and biological staining techniques. Leonard Hill Limited, London.

Hegazy, A. K., H. N. BARAKAT, AND H. F. KABIEL. 2006. Anatomical significance of the hygrochastic movement in Anastatica hierochuntica. Annals of Botany 97: 47-55.

Hennion, F., AND D. W. H. WALTON. 1997. Seed germination of endemic species from Kerguelen phytogeographic zone. Polar Biology 17: 180-187.

JENSEN, W. A. 1962. Botanical Histochemistry - principles and practice. W.H. Freeman and Company, San Fransisco, USA.

NAKANISHI, H. 2002. Splash seed dispersal by raindrops. Ecological Research 17: 663-671.

Piotrowicz-Cieslak, A. I., I. Gielwanowska, A. BocheneK, P. Loro, AND R. J. GORECKI. 2005. Carbohydrates in Colobanthus quitensis and Deschampsia antarctica. Acta Societatis Botanicorum Poloniae 74: 209-217.

POPPENDIECK, H.-H. 1995. Hygrochastic capsules in Oenothera (Onagraceae). Mitteilungen aus dem Institut fuer Allgemeine Botanik Hamburg 25: 99-115.

PUFAL, G., K.G. RYAN AND P. GARNOCK-JONES. 2010. Hygrochastic capsule dehiscence in New Zealand alpine Veronica (Plantaginaceae). American Journal of Botany 97: 1413-1423

PUFAL AND P. GARNOCK-JONES. 2010. Hygrochastic capsule dehiscence supports safe site strategies in New Zealand alpine Veronica (Plantaginaceae). Annals of Botany 106: $405-412$ 
R Development Core Team, R. D. C. 2005. R: A language and environment for statistical computing. R Foundation for statistical computing, Vienna, Austria.

RuHLAND, C. T., AND T. A. DAY. 2001. Size and longevity of seed banks in Antarctica and the influence of ultraviolet-B radiation on survivorship, growth and pigment concentrations of Colobanthus quitensis seedlings. Environmental and Experimental Botany 45: 143-154.

Sierra-Almeida, A., M. A. Casanova-Katny, L. A. Bravo, L. J. Corcuera, AND L. A. CAVIERES. 2007. Photosynthetic responses to temperature and light of Antarctic and Andean populations of Colobanthus quitensis (Caryophyllaceae). Revista Chilena de Historia Natural 80: 335-343.

Sneddon, B. V. 1999. The taxonomy and breeding system of Colobanthus squarrosus (Caryophyllaceae). New Zealand Journal of Botany 37: 195-204.

STEINBRINCK, C. 1883. Ueber einige Fruchtgehaeuse, die ihre Samen infolge von Benetzung freilegen. Berichte der Deutschen Botanischen Gesellschaft 1: 339-347.

SteINBRINCK, C., AND H. SCHINZ. 1908. Ueber die anatomische Ursache der hygrochastischen bewegungen der sog. Jerichorosen usw. Flora 98: 471-500.

Thorsen, M. J., K. J. M. Dickinson, AND P. J. SEDDON. 2009. Seed dispersal systems in the New Zealand flora. Perspectives in Plant Ecology, Evolution and Systematics 11: 285-309.

VAN DER PIJL, L. 1982. Principles of dispersal in higher plants. Springer-Verlag, Berlin, Germany.

Van der Putten, N., C. Verbruggen, R. Ochyra, E. Verleyen, AND Y. Frenot. 2010. Subantarctic flowering plants: pre-glacial survivors or post-glacial immigrants? Journal of Biogeography 37: 582-592.

ZOHARY, M., AND A. FAHN. 1941. Anatomical-carpological observations in some hygrochastic plants of the oriental flora. Palestinian Journal of Botany: 125-135.

Zuniga-Feest, A., L. Bascunan-Godoy, M. Reyes-Diaz, L. A. Bravo, AND L. J. CORCUERA. 2009. Is survival after ice encasement related with sugar distribution in organs of the Antarctic plants Deschampsia antarctica Desv. (Poaceae) and Colobanthus quitensis (Kunth) Bartl. (Caryophyllaceae)? Polar Biology 32: 583-591. 


\section{Chapter 4.3}

\section{A Molecular Approach to the Phylogeny of the Southern Hemisphere Genus Colobanthus (Caryophyllaceae)}

\subsubsection{ABSTRACT}

Colobanthus (Caryophyllaceae) is a genus of approximately 20 species occurring in Australasia, South America, Antarctica and various subantarctic islands. The plants are small perennials with a cushion or caespitose growth form and inconspicuous flowers. Although a number of genera in the Caryophyllaceae have received intense phylogenetic treatment, Colobanthus has so far been overlooked and relationships within the genus as well as species delimitation are unclear. The aim of this study is to investigate whether Colobanthus is a monophyletic genus, how New Zealand and South American species relate to each other and whether species with different growth forms belong to different lineages. To resolve the phylogeny of Colobanthus and to answer the research questions, a molecular approach was taken, since morphological characters used to identify species are few, vary within species and are likely to be homoplastic. After running primer assays on 13 primer pairs, ITS, rps 16 and $\operatorname{trn} \mathrm{T}-\operatorname{trn} \mathrm{E}$ were chosen as markers in this study. Parsimony and Bayesian analyses of nrDNA (ITS) and cpDNA (rps16 and trnT-trnE) sequence data from New Zealand, South American and subantarctic species were used to build phylogenetic trees of Colobanthus and its near and distant relatives within the Caryophyllacae. All sequences tested in this study have single base mutations and show generally very little variation within Colobanthus, resulting in a largely unresolved crown clade for the genus. It appears from this lack of resolution that species delimitation is still problematic and no distinct sequence differences between species with different 
growth forms or from different continents could be found. However, monophyly of Colobanthus within Caryophyllaceae received moderate support with Sagina as sister clade. The low resolution for the three markers is suspected to be an indicator for very recent speciation following long distance dispersal events. Additional molecular methods such as AFLPs or microsatellites together with analysis of morphological characteristics are recommended to resolve the problematic phylogeny of this genus.

Keywords: Colobanthus, phylogeny, recent speciation, Southern Hemisphere, ITS, rps 16, trn T-trnE

\subsubsection{INTRODUCTION}

The family Caryophyllaceae Juss. includes around 3000 species in 88 genera (Rabeler and Hartmann, 2005). Although cosmopolitan, the main distribution of the family is in the Holarctic, with centres of diversity in the Mediterranean and Southwest Asia (Bittrich, 1993). The relationships within the family have been difficult to understand and numerous studies have been undertaken to solve the problematic phylogeny (Harbaugh et al., 2010; Oxelman et al., 2000; Oxelman et al., 2002; Smissen et al., 2002; Scheen et al., 2004; Popp et al., 2005; Applequist et al., 2006; Fior et al., 2006; Sakai et al., 2006; Fior and Karis, 2007; Frajman and Oxelman, 2007; Kool et al., 2007). Many of the genera are not well defined morphologically (Bittrich, 1993) and monophyletic groups are hard to identify due to the difficulties in determining phylogenetically useful characters. Therefore the use of molecular phylogenetic data is essential to understand the relationships within the family (Smissen et al., 2002; Fior et al., 2006; Fior and Karis, 2007). To date, most phylogenetic studies have concentrated on the relationships between families within the Caryophyllales (Rettig 
et al., 1992; Downie and Palmer, 1994; Downie et al., 1997; Cuenoud et al., 2002) and a number of studies on genera in the Caryophyllaceae have been completed (Bacchetta et al., 2010 ; Harbaugh et al., 2010 ; Oxelman et al., 2002; Smissen and Garnock-Jones, 2002; Smissen et al., 2003; Popp et al., 2005; Minuto et al., 2006; Sakai et al., 2006; Sosa et al., 2006; Tzvelev, 2006; Fior and Karis, 2007; Frajman and Oxelman, 2007; Kool et al., 2007; Adams et al., 2008; Schaeferhoff et al., 2009). These studies have shown that none of the three traditional subfamilies (Alsinoideae, Caryophylloideae and Paronychioideae) is monophyletic (Smissen et al., 2002; Fior et al., 2006). A new study by Harbaugh et al. (2010) proposes to abandon the classification of subfamilies, since they are not natural groups. They recommend recognition of at least eleven tribes, which are based on well-supported lineages. However, further study of diverse genera within the family is necessary to increase the understanding of the relationships within the newly proposed tribes.

The southern hemisphere Colobanthus is a genus traditionally placed in the subfamily Alsinoideae (Bittrich, 1993) but according to the new classification belongs to the tribe Sagineae (Harbaugh et al., 2010). The genus comprises ca. 20 species that are distributed across the southern temperate region. The centre of diversity is in New Zealand, with 14 indigenous species, eight of these endemic (Sneddon, 1999). Australia has five species: of these, Colobanthus pulvinatus is endemic, C. nivicola is endemic to the mainland and C. curtisiae to Tasmania (Gilfedder and Kirkpatrick, 1996). Three species are found on the different subantarctic islands, of these $C$. muscoides and C. hookeri only occur in the subantarctic region, while C. apetalus is more widespread. Colobanthus kerguelensis is endemic to the South Indian Ocean province, which includes Kerguelen Island, Heard Island, Crozet Island and the Marion and Prince Edward Islands (Van der Putten et al., 2010). In the South America 
region C. quitensis (syn. C. crassifolius) is the species with the widest distribution, ranging from Mexico, northern South America, along the Andes to Tierra del Fuego, the Falkland Islands, South Georgia Island and the Scotia Basin. The other South American species is C. subulatus, which occurs in southern South America, Falkland Islands and South Georgia. Variants of this species have also been described as $C$. lycopodioides (Moore, 1983).

Plants are perennial herbs with an often caespitose or cushion habit, usually with a strong taproot. The solitary flowers are hermaphrodite and inconspicuous and are either sessile or borne on short pedicels (Allan, 1961; Moore, 1983). Petals are absent and capsules dehisce by as many valves as there are sepals.

In Chapter 4.2 I investigated capsule dehiscence in Colobanthus under the premise that species with sessile capsules are hygrochastic. At the onset of the study I expected only New Zealand alpine species to be hygrochastic and coastal species as well as South American species to be 'ripening dehiscent'. So far, no studies had been published regarding the phylogeny of Colobanthus but to answer questions about the relatedness of suspected hygrochastic and 'ripening dehiscent' species and also to trace character evolution a phylogeny was warranted and work on it commenced simultaneously with the analysis of Chapter 4.2 .

Results from Chapter 4.2 indicate that all Colobanthus species are hygrochastic but the more general need for a resolved phylogeny has not diminished. It could now be used to investigate how closely related the species are, since they all have the same specialized opening mechanism. Questions about the monophyly of the genus, the relationships between South American and New Zealand species as well as species delimitation are still unanswered. Additionally, a total of five species names have been proposed for South American Colobanthus species but it is strongly suspected 
that these only describe two species (Moore, 1983). A molecular phylogeny can be used to address those issues.

As with most genera within the former subfamily Alsinoideae (Endress, 1996; Hufford, 1996), morphological traits are very similar within Colobanthus and species identification remains difficult (B. Sneddon, pers. comm.). In the Flora of New Zealand (Allan, 1961), habit, flowers, sepals and leaf lengths are predominantly used to identify the species and group them into two informal groups but even here, the differences are usually minute and can often be misinterpreted. The phylogeny should therefore be examined by use of molecular characters.

In this study, a combination of nuclear markers and chloroplast markers is chosen to construct the phylogeny. The nuclear DNA (nrDNA) is independent from the chloroplast DNA (cpDNA) and they are differently inherited. Chloroplast DNA is generally maternally inherited and may therefore be able to show genetic relatedness better than nrDNA, which is inherited from both parents and undergoes recombination (Mort et al., 2007). Another advantage of using both nrDNA and cpDNA is the detection of hybridisation, which can be a reason for conflicting signals from the different genomes (Lockhart et al., 2001; Albach and Chase, 2004; Smissen et al., 2005). If no conflict between markers can be detected, datasets can be concatenated to result in a longer sequence. These can then be used to build more robust trees and improve the power of analysis (Cummings et al., 1995).

Internal transcribed spacer regions (ITS) have previously been successfully used in phylogenetic studies in many angiosperm families, including the Caryophyllaceae (Baldwin et al., 1995). Recently, ITS sequences were used to investigate the origin for Scleranthus (Caryophyllaceae) (Smissen et al., 2003), which is in the sister tribe (Scleranthae) to Saginae (Harbaugh et al.). ITS was also successfully used in studies 
of Moehringia (Fior and Karis, 2007), Cardia (Sosa et al., 2006), Silene (Popp et al., 2005) and Gymnocarpos (Oxelman et al., 2002). The chloroplast rps16 intron is another marker that has been used in phylogenies of genera within the Caryophyllaceae (Oxelman et al., 2002; Kool et al., 2007). Lastly, the chloroplast $\operatorname{trn} \mathrm{T}-\operatorname{trn} \mathrm{E}$ region was also chosen as a result of successful primer assays. This region has been developed for phylogenetic studies in Poaceae (Doyle et al., 1992) but was also successfully implemented in the Gesnerioideaa (Zimmer et al., 2002) and in a Plantago study (Tay, 2008).

\subsubsection{MATERIALS AND METHODS}

\subsubsection{Study group}

Fresh samples were collected at various sites on the South Island (New Zealand) and in Patagonia (Chile) and leaf samples were stored in silica gel. Table 4.3.1 shows all sample species and their origin. For common species several individuals from different locations were collected. In New Zealand, two undescribed species $(C$. 'marble' and C. 'ultramafic', B. Sneddon, pers. comm.) were also included in the analysis. Herbarium samples were obtained from CHR, WELTU and MERL (Thiers, [continuously updated]). Furthermore, samples from three species were taken from live collections at the greenhouse at Victoria University of Wellington and used fresh. This sampling resulted in sequences from $100 \%$ of New Zealand species and $100 \%$ of South American species. Samples of South American species include individuals referable to four of the five accepted names (excluding C. cherlerioides). Unfortunately Colobanthus kerguelensis and Australian species could not be included since fresh samples could not be obtained and herbarium samples did not yield sufficient DNA samples. 
Sagina apetala was selected as sister group (Harbaugh et al., 2010). Sequences from Bufonia tenuifolia, B. paniculata, Geocarpon minimum, Minuartia rossii, Schiedea viscosa, Scleranthus biflorus and Stellaria media (Harbaugh et al., 2010; Smissen et al., 2002) were obtained from GenBank as more distant outgroups to test for the monophyly of Colobanthus (Table 4.3.1). For the trnT-E region, no further outgroup sequences were available. 
Table 4.3.1 Collection details, herbarium voucher numbers and GenBank accession numbers for species included in this study. Collectors: MNC - M.N. Correa; PGJ - Phil Garnock-Jones; OM - O. Magens; GP - Gesine Pufal; BS - Barry Sneddon.

\begin{tabular}{|c|c|c|c|c|c|c|c|c|}
\hline $\begin{array}{l}\text { Names used in } \\
\text { analysis }\end{array}$ & Species & Location & collector & ITS & rps16 & $\begin{array}{l}\operatorname{trn} E- \\
T\end{array}$ & $\begin{array}{l}\text { Herbarium } \\
\text { voucher }\end{array}$ & $\begin{array}{l}\text { GenBank } \\
\text { accession }\end{array}$ \\
\hline aci_si_seal & C. acicularis & Sealey Range, Aoraki National Park, NZ & GP (2008) & 1 & 1 & 1 & WELTU20254 & \multirow{25}{*}{ AY286511.1 } \\
\hline aci_si_blue & C. acicularis & Blue Lake, Garvie Mountains, Central Otago, NZ & GP (2009) & 1 & & 1 & WELTU20255 & \\
\hline aci_si ${ }^{-}$ & C. acicularis & & GP (2008) & 1 & 1 & 1 & WELTU20275 & \\
\hline affi_si_arth & C. affinis & Mt. Arthur, Kahurangi National Park, NZ & GP (2008) & 2 & 1 & 1 & WELTU20256 & \\
\hline ape_si_blue & C. apetalus & Blue Lake, Garvie Mounatins, Central Otago, NZ & GP (2009) & 1 & 1 & 1 & WELTU20257 & \\
\hline ape_2519 & C. apetalus & $\begin{array}{l}\text { Garvie Mts, route from Blue Lake to Lake Laura, } \\
\text { Otago, NZ }\end{array}$ & PGJ 2005) & 1 & 1 & & PGJ2519 & \\
\hline ape_green & C. apetalus & Greenhouse, VUW, NZ & $\mathrm{BS}$ & 1 & 1 & 1 & & \\
\hline C_brevisepalus & C. brevisepalus & & & 1 & & & & \\
\hline buch_si_dob & C. buchananii & Mount Dobson Skifield, Canterbury, NZ & GP & 3 & 3 & 1 & WELTU20248 & \\
\hline buch_si_blue & C. buchananii & Blue Lake, Garvie Mountains, Central Otago, NZ & GP (2009) & 1 & 1 & 1 & WELTU20258 & \\
\hline buch_si_red & C. buchananii & Red Peak, Mt Aspiring National Park, NZ & GP (2009) & 3 & 3 & 1 & WELTU20259 & \\
\hline buch_2507 & C. buchananii & $\begin{array}{l}\text { Garvie Mts, route from Blue Lake to Lake Laura, } \\
\text { Otago, NZ }\end{array}$ & PGJ (2005) & 1 & 1 & & PGJ2507 & \\
\hline buch_2533 & C. buchananii & Garvie Mts, ridge east of Blue Lake, Otago, NZ & PGJ (2005) & 1 & 1 & & PGJ2533 & \\
\hline canal_si_green & C. canaliculatus & Greenhouse, VUW, NZ & $\mathrm{BS}$ & 1 & 2 & 2 & & \\
\hline canal_si_kakapo & C. canaliculatus & Kakapo Peak, Kahurangi National Park, NZ & GP (2009) & 1 & 1 & 1 & WELTU20260 & \\
\hline hook_sub_2484 & C. hookeri & Campbell Island, west shoulder of Mt Lyall, NZ & PGJ (2004) & 1 & 1 & & PGJ2484 & \\
\hline marble_si_arth & C. 'marble' & Mt Arthur, Kahurangi National Park, NZ & GP (2008) & 1 & 1 & & WELTU20261 & \\
\hline mas_si_kakapo & C. masoniae & Kakapo Peak, Kahurangi National Park, NZ & GP (2009) & 2 & 2 & 1 & WELTU20250 & \\
\hline mont_si_muel1 & C. monticola & Sealey Range, Aoraki National Park, NZ & GP (2008) & 2 & 2 & & WELTU20262 & \\
\hline muell_si_green & C. muelleri & Greenhouse, VUW, NZ & $\mathrm{BS}$ & 1 & 1 & 1 & & \\
\hline muell_si_cape & C. muelleri & Cape Foulwind, Westcoast, NZ & GP (2007) & 1 & 1 & & WELTU20263 & \\
\hline C_muscoides & C. muscoides & & & & 1 & & & \\
\hline squarr_si_sun & C. squarrosus & Sunshine Ridge, Kahurangi National Park, NZ & GP (2007) & 1 & 1 & 1 & WELTU20264 & \\
\hline stric_SI_blue & C. strictus & Blue Lake, Garvie Mountains, Central Otago, NZ & GP (2009) & 3 & 3 & & WELTU20265 & \\
\hline strict_si_patr & C. strictus & Mt Patriarch, Richmond Forest Park, Nelson, NZ & GP (2008) & 1 & 1 & & WELTU20266 & \\
\hline
\end{tabular}




\begin{tabular}{|c|c|c|c|c|c|c|c|c|}
\hline strict_si_port & C. strictus & Port Hills, Canterbury, NZ & PGJ & 1 & 1 & & & \\
\hline strict_si_robert & C. strictus & Mt. Robert, Nelson Lakes National Park, NZ & GP (2009) & 1 & 1 & 1 & WELTU20267 & \\
\hline strict_si_arth & C. strictus & Mt. Arthur, Kahurangi National Park, NZ & GP (2008) & 1 & 2 & 1 & WELTU20252 & \\
\hline ultra_si_asbest & C. 'ultramafic' & Asbestos Mine, Kahurangi National Park, NZ & GP (2009) & 2 & 2 & 1 & WELTU20268 & \\
\hline wall_si_arth & C. wallii & Mt. Arthur, Kahurangi National Park, NZ & GP (2008) & 2 & 2 & 1 & WELTU20253 & \\
\hline sealey & Colobanthus sp. & Sealey range, Aoraki National Park, NZ & GP (2008) & 3 & 3 & 2 & WELTU20269 & \\
\hline redpeak1 & Colobanthus sp. & Red Peak, Mt Aspiring National Park, NZ & GP (2009) & 1 & 1 & & WELTU20270 & \\
\hline blackbirch1 & Colobanthus sp. & Blackbirch Creek, Aoraki National Park, NZ & PGJ & 1 & 1 & & & \\
\hline crassi_sa_tierra & C. crassifolius & Tierra del Fuego, Argentina & OM (1956) & 1 & & & WELTU20273 & \\
\hline lyco_sa_laguna & C. lycopodioides & Laguna Cabeza de Mar, Patagonia, Chile & GP (2008) & 1 & 1 & & WELTU20271 & \\
\hline lyco_sa_morro & C. lycopodioides & Morro Chico, Patagonia, Chile & GP (2008) & 2 & 1 & & WELTU20249 & \\
\hline quit_sa_lake & C. quitensis & Lake close to Pali Aike, Patagonia, Chile & GP (2008) & 3 & 1 & 1 & WELTU20272 & \\
\hline quit_SA_punta & C. quitensis & Punta Arenas, Patagonia, Chile & GP (2008) & 2 & 2 & & WELTU20251 & \\
\hline sub_sa & C. subulatus & San Gregorio, Patagonia, Chile & GP (2008) & 1 & 1 & & WELTU20274 & \\
\hline sub_sa_28026 & C. subulatus & Guer Aike, Cordillera, Argentina & $\begin{array}{l}\text { MNC } \\
(1978)\end{array}$ & 1 & 1 & & MERL28026 & \\
\hline sape_2556_PGJ & Sagina apetalus & Cass Railway Station, Canterbury, NZ & PGJ & 1 & 1 & & PGJ2556 & \\
\hline Sape_21 & Sagina apetalus & & PGJ & 1 & 1 & 1 & & \\
\hline $\begin{array}{l}\text { Bufonia_- } \\
\text { paniculata }\end{array}$ & Bufonia paniculata & & & & 1 & & & FJ404897 \\
\hline $\begin{array}{l}\text { Bufonia } \\
\text { tenuifolia }\end{array}$ & Bufonia tenuifolia & & & 1 & & & & AY936238.1 \\
\hline $\begin{array}{l}\text { Geocarpon } \\
\text { minimum }\end{array}$ & $\begin{array}{l}\text { Geocarpon } \\
\text { minimum }\end{array}$ & & & 1 & 1 & & & $\begin{array}{l}\text { AY517648.1 } \\
\text { FJ404906.1 }\end{array}$ \\
\hline Minuartia_rossii & Minuartia rossii & & & 1 & 1 & & & $\begin{array}{l}\text { AY517649.1 } \\
\text { FJ404921.1 }\end{array}$ \\
\hline Schiedea_viscosa & Schiedea viscosa & & & 1 & 1 & & & $\begin{array}{l}\text { AY517655.1 } \\
\text { FJ404942.1 }\end{array}$ \\
\hline $\begin{array}{l}\text { Scleranthus_ } \\
\text { biflorus }\end{array}$ & Scleranthus biflorus & & & & 1 & & & FJ404944.1 \\
\hline Stellaria_media & Stellaria media & & & 1 & 1 & & & $\begin{array}{l}\text { AY0.5472.1 } \\
\text { FJ404953.1 }\end{array}$ \\
\hline
\end{tabular}




\subsubsection{Primer assays and genetic markers}

A number of both nuclear and organellar DNA markers have been successfully used in building phylogenies of plant species based on molecular characters. The majority of studies on genera in the Caryophyllaceae in the last decade used universal markers such as ITS, matK or rps 16 but additional primers already available to me were tested in this study as well (Table 4.3.2).

Primer assays were run on several pairs of primers to test their usefulness for the genus Colobanthus (Table 4.3.2) These were usually run on a subset of species from New Zealand and South America and when clear single bands could be viewed in the agarose gel after amplification, sequencing was carried out for some species.

DNA extractions were performed following a modified cetyltrimethylammonium bromide (CTAB) protocol by Doyle and Doyle (1990), after tissue was finely ground with a pestle and mortar.

PCR amplification was performed with the Eppendorf Mastercycler ep gradient S (Hamburg, Germany). Samples used contained the following: $15.60 \mu 1 \mathrm{H}_{2} \mathrm{O}, 2.5 \mu 1$ 10x ThermoPol reaction buffer $\left(10 \mathrm{mM} \mathrm{KCl}, 10 \mathrm{mM}\left(\mathrm{NH}_{4}\right) 2 \mathrm{SO}_{4}, 20 \mathrm{mM}\right.$ Tris- $\mathrm{HCl}$ (pH 8.8), 2 mM MgSO $4,0.1 \%$ Triton X-100) (New England BioLabs), $1 \mu$ l each BSA and dNTPs (250 $\mu \mathrm{mol}), 1 \mu \mathrm{l}$ each primer, $0.15 \mu \mathrm{l}$ Taq DNA polymerase (New England BioLabs) and $2 \mu 1$ DNA template. A general thermocycling profile was used for the amplification of all primer pairs and was optimised in some cases using the following PCR protocol with a temperature gradient for the annealing temperature (Table 4.3.2) The PCR protocol was carried out as follows: an initial 2 min at $95^{\circ} \mathrm{C}$, followed by 35 cycles of $1 \mathrm{~min}$ at $95^{\circ} \mathrm{C}, 1 \mathrm{~min}$ at $49^{\circ} \mathrm{C}$ and $1.5 \mathrm{~min}$ at $72^{\circ} \mathrm{C}$, ending with a final extension time of $5 \mathrm{~min}$ at $72^{\circ} \mathrm{C}$. Amplified lengths of all PCR products were viewed using a 100 base pair (bp) DNA ladder (Roche, Penzberg, Germany) on a 1.5\% 
agarose gel. Samples that resulted in single bands were cleaned with ExoSAP-IT (GE Life Sciences) and sequenced with an ABI3730 Genetic Analyzer by the Allan Wilson Centre Genome Service (Massey University, Palmerston North, New Zealand). Primer pairs that resulted in clean sequences were subsequently used in the phylogenetic analysis (Table 4.3.2) 
Table 4.3.2 primer pairs. $\mathrm{S}=$ single banded PCR product; $\mathrm{M}=$ multiple bands in PCR product; $-=$ no amplified product; $+=$ successful sequencing; $/=$ unsuccessful sequencing; - = no sequencing carried out. Markers used in the study are highlighted in BOLD.

\begin{tabular}{|c|c|c|c|c|c|c|c|c|c|}
\hline & region & genome & primer seq & nces & $\begin{array}{l}\text { PCR } \\
\text { results }\end{array}$ & sequence & $\begin{array}{l}\text { annealing } \\
\text { temp. }\end{array}$ & $\begin{array}{l}\text { base } \\
\text { pairs }\end{array}$ & literature \\
\hline 1 & ITS & nuclear & $\begin{array}{l}\text { ITS28cc } \\
\text { ITS5 }\end{array}$ & $\begin{array}{l}\text { CGC CGT TAC TAG GGG AAT CCT TGT AAG } \\
\text { GGA AGT AAA AGT CGT AAC AAG G }\end{array}$ & $\mathrm{S}$ & + & $50^{\circ} \mathrm{C}$ & $\sim 750$ & $\begin{array}{l}\text { Wagstaff and Garnock- } \\
\text { Jones, 1998; } \\
\text { White et al., } 1990\end{array}$ \\
\hline 2 & waxy & nuclear & $\begin{array}{l}\text { waxy } 7 \mathrm{~F} \\
\text { waxy13R }\end{array}$ & $\begin{array}{l}\text { GYY TTS TGC ATC CAC AAC ATT GC } \\
\text { GGA GTG GCR ACG TTT TCC TT }\end{array}$ & M & - & $49^{\circ} \mathrm{C}$ & & Olmstead et al., 1999) \\
\hline 3 & matK & chloroplast & $\begin{array}{l}934 \mathrm{~F} \\
1470 \mathrm{R}\end{array}$ & $\begin{array}{l}\text { ATT TTG GTT ATG ACA ATA A } \\
\text { AAG ATG TTG AT[T/C] GTA AAT GA }\end{array}$ & - & - & $50^{\circ} \mathrm{C}$ & & Johnson and Soltis, 1994 \\
\hline 4 & rps16 & chloroplast & $\begin{array}{l}\text { rpsl6F } \\
\text { rpsi6R }\end{array}$ & $\begin{array}{l}\text { AAA CGA TGT GGT ARA AAG CAA C } \\
\text { AAC ATC WAT TGC AAS GAT TCG ATA }\end{array}$ & $\mathrm{S}$ & + & $48^{\circ} \mathrm{C}$ & $\sim 920$ & Shaw et al., 2005 \\
\hline 5 & $\begin{array}{l}\operatorname{trn} \mathrm{Lc}- \\
\operatorname{trn} \mathrm{Lf}\end{array}$ & chloroplast & $\begin{array}{l}\mathrm{C} \\
\mathrm{f}\end{array}$ & $\begin{array}{l}\text { CGA AAT CGG TAG ACG CTA CG } \\
\text { ATT TGA ACT GGT GAC ACG AG }\end{array}$ & M & - & $50^{\circ} \mathrm{C}$ & & Taberlet et al., 1991 \\
\hline 6 & $\begin{array}{l}\text { trns-G } \\
\text { spacer }\end{array}$ & chloroplast & $\begin{array}{l}\operatorname{trn} S^{\mathrm{GCU}} \\
3^{\prime} \operatorname{trnG}{ }^{\mathrm{UUC}}\end{array}$ & $\begin{array}{l}\text { AGA TAG GGA TTC GAA CCC TCG GT } \\
\text { GTA GCG GGA ATC GAA CCC GCA TC }\end{array}$ & M & - & $49^{\circ} \mathrm{C}$ & & Shaw et al., 2005 \\
\hline 7 & $r b c L$ & chloroplast & $\begin{array}{l}\mathrm{aF} \\
\mathrm{cR}\end{array}$ & $\begin{array}{l}\text { ATG TCA CCA CAA ACA GAG ACT AAA GC } \\
\text { GCA GCA GCT AGT TCC GGG CTC CA }\end{array}$ & - & - & $49^{\circ} \mathrm{C}$ & & Hasebe et al., 1994 \\
\hline 8 & $\begin{array}{l}\text { trnT-trnE } \\
\text { spacer }\end{array}$ & chloroplast & $\begin{array}{l}\operatorname{trnE} \\
\operatorname{trnTr}\end{array}$ & $\begin{array}{l}\text { GCC TCC TTG AAA GAG AGA TG } \\
\text { TAC CAC TGA GTT AAA AGG GC }\end{array}$ & $\mathrm{S}$ & + & $52{ }^{\circ} \mathrm{C}$ & $\sim 650$ & Doyle et al., 1992 \\
\hline 9 & $p s b \mathrm{~A}-t r n \mathrm{~K}$ & chloroplast & $\begin{array}{l}\operatorname{trnK} 3 \mathrm{~F} \\
\text { PsbAR }\end{array}$ & $\begin{array}{l}\text { CCG ACT AGT TCC GGG TTC GAA TC } \\
\text { CGC GTC TCT CTA AAA TTG CAG TCA T }\end{array}$ & $\mathrm{S}$ & l & $49^{\circ} \mathrm{C}$ & & Winkworth et al., 2002a \\
\hline 10 & rpoB-trnC & chloroplast & $\begin{array}{l}\text { trnC-gcaR } \\
\text { rpoB }\end{array}$ & $\begin{array}{l}\text { CAC CCR GAT TYG AAC TGG GG } \\
\text { CKA CAA AAY CCY TCR AAT TG }\end{array}$ & M & - & $57^{\circ} \mathrm{C}$ & & Shaw et al., 2005 \\
\hline 11 & $\begin{array}{l}\text { psbA-trnH } \\
\text { spacer }\end{array}$ & chloroplast & $\begin{array}{l}\operatorname{trnH} \mathrm{H}^{\mathrm{GUG}} \\
\mathrm{psbA}\end{array}$ & $\begin{array}{l}\text { CGC GCA TGG TGG ATT CAC AAT CC } \\
\text { GTT ATG CAT GAA CGT AAT GCT C }\end{array}$ & $\mathrm{S}$ & l & $49^{\circ} \mathrm{C}$ & & $\begin{array}{l}\text { Tate and Simpson, 2003; } \\
\text { Sang, Crawford, and } \\
\text { Stuessy, } 1997\end{array}$ \\
\hline 12 & Atp1 & mitochondrial & $\begin{array}{l}\text { F83-atp1 } \\
\text { R725-atp1 }\end{array}$ & $\begin{array}{l}\text { ATG AGG TCG GTC GAG TGR T } \\
\text { GGA TCC GAA GCM GTG GCT GCT AC }\end{array}$ & - & - & $49^{\circ} \mathrm{C}$ & & $\begin{array}{l}\text { Wikstrom and Pryer, } \\
2005\end{array}$ \\
\hline 13 & NIA3 & mitochondrial & $\begin{array}{l}\text { NIA-i3F } \\
\text { NIA-i3R }\end{array}$ & $\begin{array}{l}\text { AAR TAY TGG TGY TGG TGY TTY TGG TC } \\
\text { GAA CCA RCA RTT GTT CAT CAT DCC }\end{array}$ & - & - & $49^{\circ} \mathrm{C}$ & & Howarth and Baum, 2005 \\
\hline
\end{tabular}




\subsubsection{Molecular techniques}

DNA extractions were performed following a modified cetyltrimethylammonium bromide (CTAB) protocol by Doyle and Doyle (1990), after tissue was finely ground with a pestle and mortar. For older herbarium specimen, a CTAB protocol by Loockerman and Jansen (1996) was used with some success. Primers used to amplify DNA regions were: ITS28CC (Wagstaff and Garnock-Jones, 1998) and ITS5 (White et al., 1990); $\operatorname{trn} \mathrm{E}$ and $\operatorname{trn} \operatorname{Tr}$ (Doyle et al., 1992); rps16F and rps16R (Shaw et al., 2005).

PCR amplification was performed similar to PCR amplification for the primer assays. The amplification for ITS28CC and ITS5 was carried out with a thermocycling profile of an initial $2 \mathrm{~min}$ at $95^{\circ} \mathrm{C}$, followed by 35 cycles of $1 \mathrm{~min}$ at $95^{\circ} \mathrm{C}, 1 \mathrm{~min}$ at $50^{\circ} \mathrm{C}$ and $1.5 \mathrm{~min}$ at $72^{\circ} \mathrm{C}$, ending with a final extension time of $5 \mathrm{~min}$ at $72^{\circ} \mathrm{C}$. The PCR protocol for rps16 differed from the ITS protocol only in the annealing temperature, which was $48^{\circ} \mathrm{C}$ instead of $50^{\circ} \mathrm{C}$ and the extension time in the cycle, which was 1.5 min at $72^{\circ} \mathrm{C}$. The PCR protocol for $\operatorname{trn} \mathrm{T}-\operatorname{trn} \mathrm{E}$ had the following thermocycling profile: initial $2 \mathrm{~min}$ at $92^{\circ} \mathrm{C}$, followed by 32 cycles of $30 \mathrm{sec}$ at $95^{\circ} \mathrm{C}, 30 \mathrm{sec}$ at $52^{\circ} \mathrm{C}$ and 1 min at $72^{\circ} \mathrm{C}$, ending with a final extension time of 5 min at $72^{\circ} \mathrm{C}$. PCR products were mixed with blue juice and viewed on $1.5 \%$ agarose gels and subsequently cleaned with ExoSAP-IT (GE Life Sciences).

The cleaned PCR products were sequenced in the forward direction by the Allan Wilson Centre Genome Service (Massey University, Palmerston North, New Zealand). 


\subsubsection{Dataset alignment and analysis}

The program Geneious (Drummond et al., 2009) was used to assemble and align sequences for each accession. Different individuals from the same location were removed if sequences were identical but included in the analysis if some differences were detected in the sequences. Sequences were aligned with the default Geneious align option with a cost matrix of $65 \%$ similarity, gap open penalty of 9.9 and gap extension penalty of 2.9. A global alignment with free end gaps was performed. Since sequencing was only done in the forward direction, sequences became difficult to read reliably towards the end. Ends were therefore cut off, which resulted in sequences of even lengths for samples sequenced for this study. Additional to those sequences, $C$. muscoides and $C$. brevisepalus and some outgroup species were added from GenBank (Table 4.3.1). The ITS dataset included 63 individuals of 25 species and three unidentified samples. Of these, two were undescribed New Zealand species, six outgroup species and four South American species. The rps 16 dataset included 60 individuals of 25 species and three unidentified samples. Of these species, seven were part of the outgroup, three were South American species and of the 15 New Zealand species two were undescribed. The $\operatorname{trn} \mathrm{T}-\operatorname{trn} \mathrm{E}$ dataset comprised 23 individuals of 12 species and one unidentified sample (Table 4.3.1) Of the 12 species, one was Sagina as part of the outgroup, one was South American and one was an undescribed species. Because both chloroplast datasets had a very low number of variable sites (tested in previous analysis, not presented here), they were concatenated to one chloroplast dataset. Additionally, the ITS dataset and the chloroplast dataset were combined into one concatenated set after a Hompart test was performed in PAUP*. 
Maximum parsimony (MP) analysis was conducted using PAUP* v4.b10 (Swofford, 2002). A heuristic search was conducted under a MP criterion using 10,000 replicates of random sequence addition and tree-bisection-reconnection (TBR) branch swapping and gaps were coded as missing. Bootstrap support was assessed using 1000 replicates and 10 random addition sequences.

Modeltest v3.7 (Posada and Crandall, 1998) was used to identify the appropriate models of evolution for the respective datasets. The program tests the best fit among a number of different models of different complexity using a hierarchical likelihood ratio test. Models were then selected using Akaike Information Weights criterion (AIC) (Posada and Buckley, 2004). Table 4.3.3 contains a summary of the statistics for all three datasets used in the study.

Table 4.3.3 Summary of statistics for the datasets used in this study.

\begin{tabular}{|c|c|c|c|}
\hline & ITS & chloroplast & $\begin{array}{l}\text { ITS and } \\
\text { choloroplast }\end{array}$ \\
\hline base frequencies of all sites $(\%)$ & $\begin{array}{l}A=0.2228 \\
C=0.2703 \\
G=0.2813 \\
T=0.2256\end{array}$ & $\begin{array}{l}A=0.3678 \\
C=0.1290 \\
G=0.1615 \\
T=0.3417\end{array}$ & $\begin{array}{l}A=0.3179 \\
C=0.1841 \\
G=0.2010 \\
T=0.2970\end{array}$ \\
\hline sequence length including outgroups (bp) & 986 & 1638 & 2624 \\
\hline $\begin{array}{l}\text { no. of variable parsimony informative sites including } \\
\text { outgroups (only ingroup) }\end{array}$ & $138(18)$ & $129(18)$ & $267(36)$ \\
\hline model of evolution (AIC) & $\mathrm{GTR}+\mathrm{G}$ & $\mathrm{K} 81 \mathrm{uf}+\mathrm{G}$ & $\mathrm{GTR}+\mathrm{I}+\mathrm{G}$ \\
\hline gamma shape estimate & 0.4098 & 0.6872 & 1.0713 \\
\hline pinvar & 0 & 0 & 0.3239 \\
\hline
\end{tabular}

MrBayes v3.1.1 (Huelsenbeck and Ronquist, 2001) was used to conduct heuristic searches, while implementing the AIC model that was chosen by Modeltest for the respective dataset (see Table 4.3.3). Each dataset was initially analysed with four chains and 4,000,000 generations. Additional generations were added if necessary to achieve a standard deviation of split frequencies of less than 0.01 . For ITS, 6,000,000 
generations were run and $30 \%$ of the trees were excluded as burn-in. The chloroplast DNA dataset was run for $14,000,000$ generations and $10 \%$ of the trees were excluded as burn-in. The combined ITS and chloroplast dataset was run for $6,000,000$ generations and $5 \%$ of trees were excluded as burn-in.

Phylogenetic trees from both analyses had congruent topology and it was therefore decided to only display one example. Trees obtained from MrBayes were visualized in Figtree v1.3.1 (Morariu et al., 2008) and posterior values were added as well as bootstrap support obtained from PAUP*. Branches with posterior probabilities of less than $50 \%$ were collapsed in the phylogeny.

SplitsTree vs 4.11.3 was used to visualise incompatible splits in each of the three datasets (Hudson, 1998; Hudson and Bryant, 2006). Because of long distances between the outgroups and Colobanthus and very short distances within Colobanthus, outgroups were removed from the datasets to concentrate on conflicting signals within Colobanthus. Datasets were then transformed to uncorrected p-distances with the MatchStates option. Split decomposition networks were constructed using the equalangle-splits transformation. If connections between species are shown as boxes, it indicates conflicting signals within the dataset, e.g. incompatible splits.

Pairwise genetic distances were calculated using uncorrected p-distances in PAUP*. These were used to assess species delimitation/discrimination by comparing interspecific and intraspecific distances. Species discrimination was considered when the minimum uncorrected interspecific p-distance involving one species was larger than the maximum uncorrected intraspecific p-distance of that species (CBOL Plant Working Group, 2009). For this analysis ITS, rps16 and trnT-trnE datasets were analysed separately and only species were used that had more than one sample per species. Unidentified specimens (e.g. blackbirch1, see Table 4.3.1) were excluded. 


\subsubsection{RESULTS}

\subsubsection{ITS dataset}

The ITS dataset contained 63 sequences, 55 of which were generated for this study and eight obtained from GenBank (Table 4.3.1). The alignment consisted of 986 characters, of which 138 were parsimony informative but only 18 of these are informative within the ingroup (Table 4.3.3). Gaps were treated as missing. Bayesian and parsimony analysis showed similar results and a phylogenetic tree for ITS in Colobanthus is shown in Fig. 4.3.1. All Colobanthus species form an unresolved crown clade with one backbone, which has weak (62\%) bootstrap support for monophyly. Two samples of Sagina apetala form the well-supported sister clade to the crown clade. There is a $99 \%$ bootstrap support for the Colobanthus/Sagina clade, indicating that the low support for the Colobanthus clade results from almost entirely alternative trees where Sagina apetala is not distinguished from the Colobanthus clade. Within Colobanthus, no support is given for a distinction between South American and New Zealand species or species with sessile fruits versus species with longer pedicels. Several smaller clades branch of the crown clade but these have low bootstrap support and posterior values and never contain all samples of one species.

The splits graph network shows a large number of incompatible splits within Colobanthus, visualized by boxes (Fig. 4.3.2). Longer branches represent longer genetic distances from the core of the network. However, all species at the end of longer branches are also represented in the boxy core of the network. Analysing the South American species and the species with longer pedicels separately (splits graphs not shown) resulted in graphs with boxes in the cores, indicating incompatible splits within these sample subsets. 


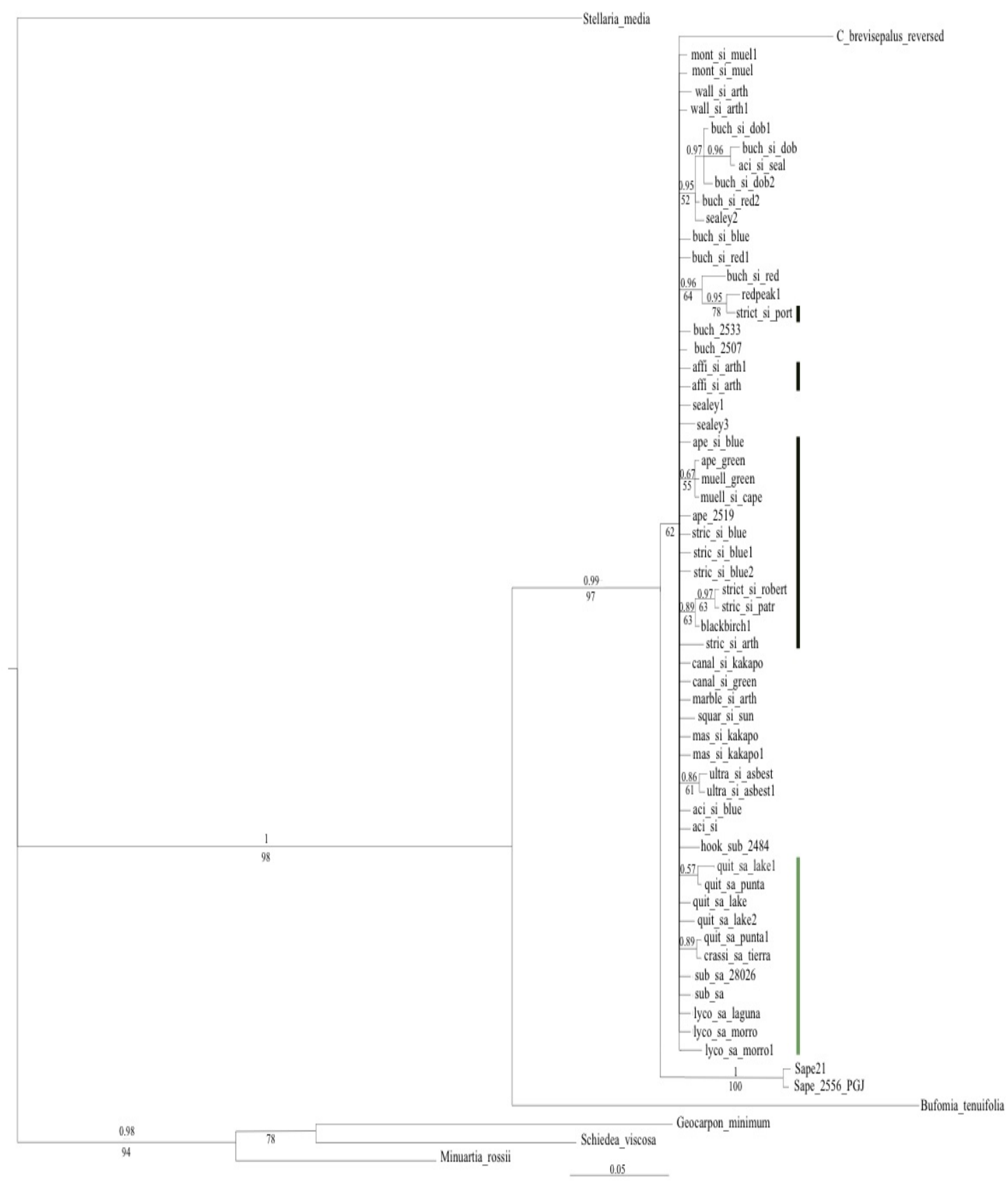

FIG 4.3.1 50\% consensus tree using Bayesian analysis of the ITS dataset. Branch lengths are proportional to the number of changes. Numbers above the branches are Bayesian posterior probabilities (numbers $<0.5$ not shown). Numbers below branches show parsimony bootstrap support (values $<50 \%$ not shown). Matching species names to species abbreviations can be found in Table 4.3.1. Numbers behind species abbreviations indicate different voucher specimen. The green bar highlights South American species, whereas the black bars signify species with longer pedicels. 
CHAPTER FOUR

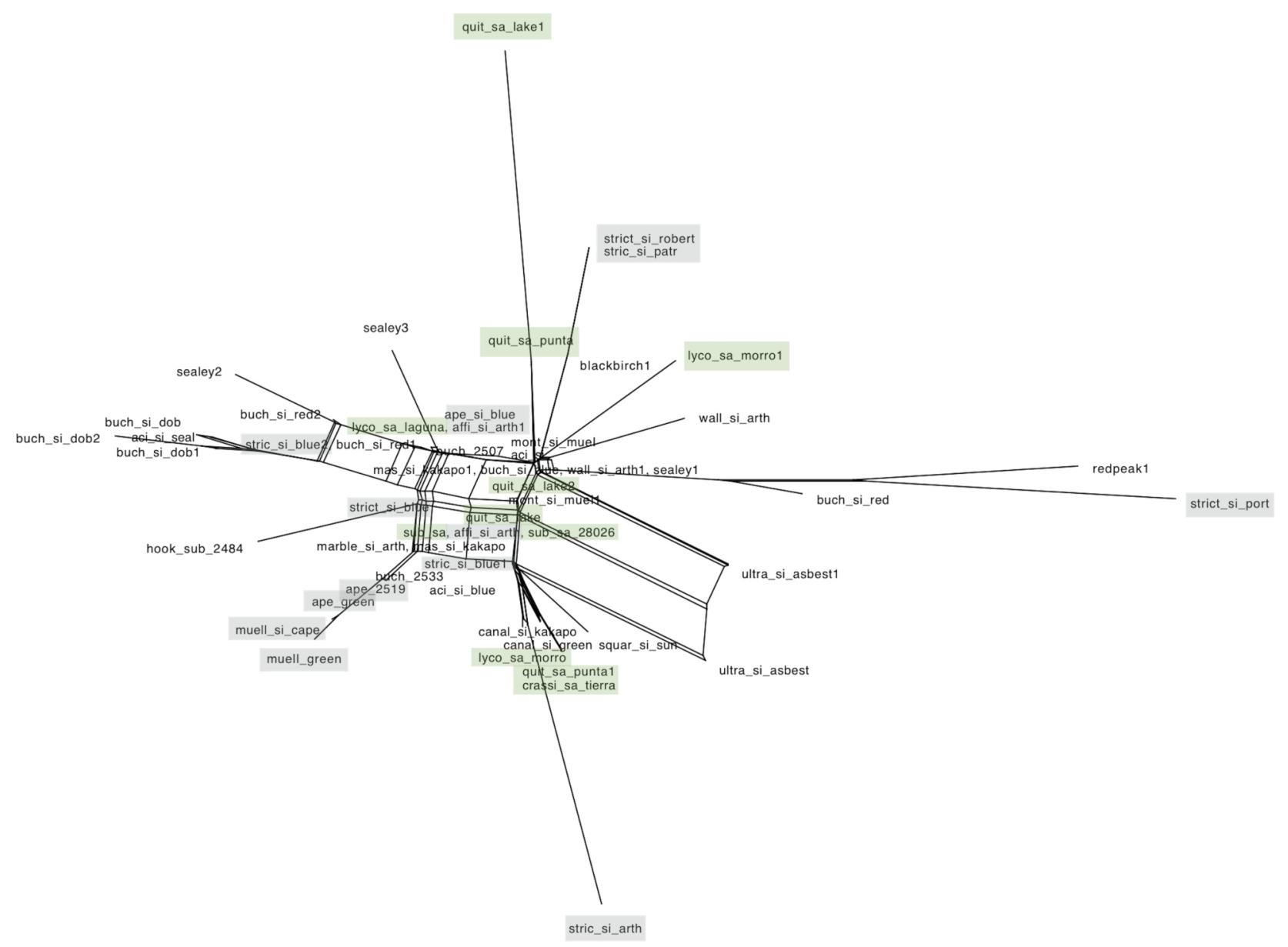

FIG 4.3.2 Splits graph network illustrating relationships among the ITS sequences of Colobanthus. Branch lengths are drawn proportionally to the genetic distances, a scale is provided at the top left corner. South American species are highlighted in green and species with longer pedicels are highlighted in grey. 
CHAPTER FOUR

\subsubsection{Chloroplast dataset}

The chloroplast dataset is a concatenated dataset of $r p s 16$ and $\operatorname{trn} \mathrm{T}-\operatorname{tnr} \mathrm{E}$ sequences. In total, 63 sequences are analysed; seven of these were obtained from GenBank and 55 were generated for this study (Table 4.3.1). The rps 16 dataset contained 60 sequences including all GenBank samples, whereas the $\operatorname{trn} \mathrm{T}-\operatorname{trn} \mathrm{E}$ dataset comprised 23 sequences, all generated for this study. The concatenated chloroplast alignment contained 1638 characters, 129 of which were parsimony informative (including outgroup). When the outgroup was excluded, 18 characters were parsimony informative (Table 4.3.3).

Parsimony and Bayesian analyses showed similar results and topography of inferred trees, therefore only the $50 \%$ consensus tree from the Bayesian analysis is presented with posterior values and bootstrap support from the MP analysis in PAUP* is added (Fig. 4.3.3). The tree shows an arrangement of outgroups similar to the phylogeny from a combined chloroplast dataset presented in Harbaugh et al. (2010). These clades show both high bootstrap support as well as high posterior values. A clade representing Sagina and Colobanthus is well supported by bootstrap (90\%) and posterior values (1). Within this clade, monophyly for Colobanthus is poorly supported by a bootstrap value of 57\%. All Colobanthus species form an unresolved and weakly supported crown clade with a well supported Sagina apetala clade (bootstrap 93\%, posterior value 1) as sister group. Within the crown clade there is very little resolution and neither South American species or species with longer pedicels are grouped with each other.

A splits graph network of all Colobanthus species (Fig. 4.3.4) shows a high number of incompatible splits within the core group, visualized by the high number of boxes between the species. South American species are concentrated on one side of the core 
network on two different clades, whereas species with longer pedicels are scattered throughout the network. Separate analyses of the South American species and species with longer pedicels (splits graphs not shown) show connections between species as boxes in each dataset. These indicate conflicting signals in the chloroplast dataset.

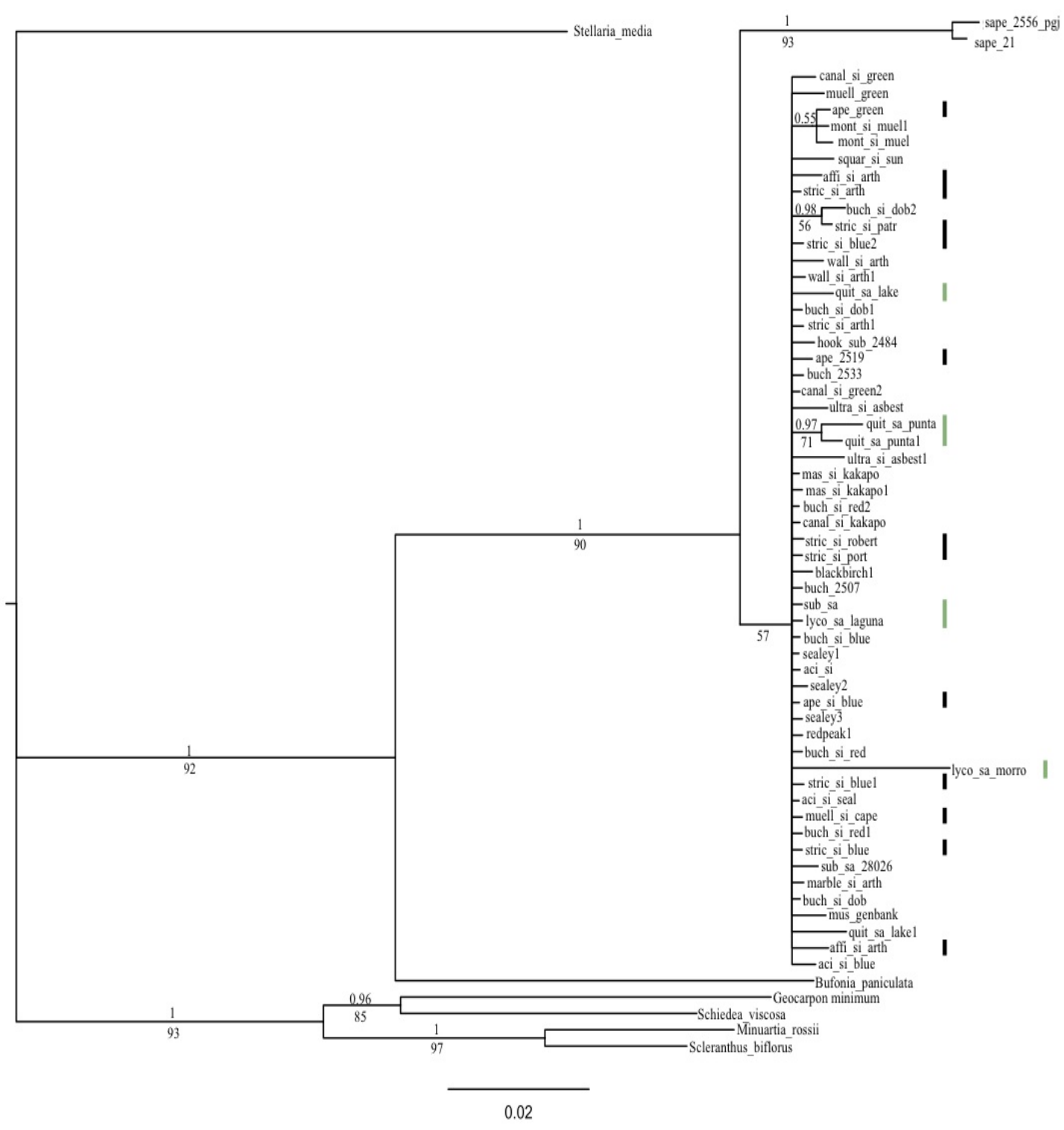

FIG 4.3.3 50\% consensus tree using Bayesian analysis of the combined chloroplast dataset (rps16 and trnT-trnE). Branch lengths are proportional to the number of changes. Numbers above the branches are Bayesian posterior probabilities (numbers $<0.5$ not shown). Numbers below branches show parsimony bootstrap support (values $<50 \%$ not shown). Matching species names to species abbreviations can be found in Table 4.3.1. Numbers behind species abbreviations indicate different voucher specimen. The green bars highlight South American species, whereas the black bars signify species with longer pedicels. 
CHAPTER FOUR

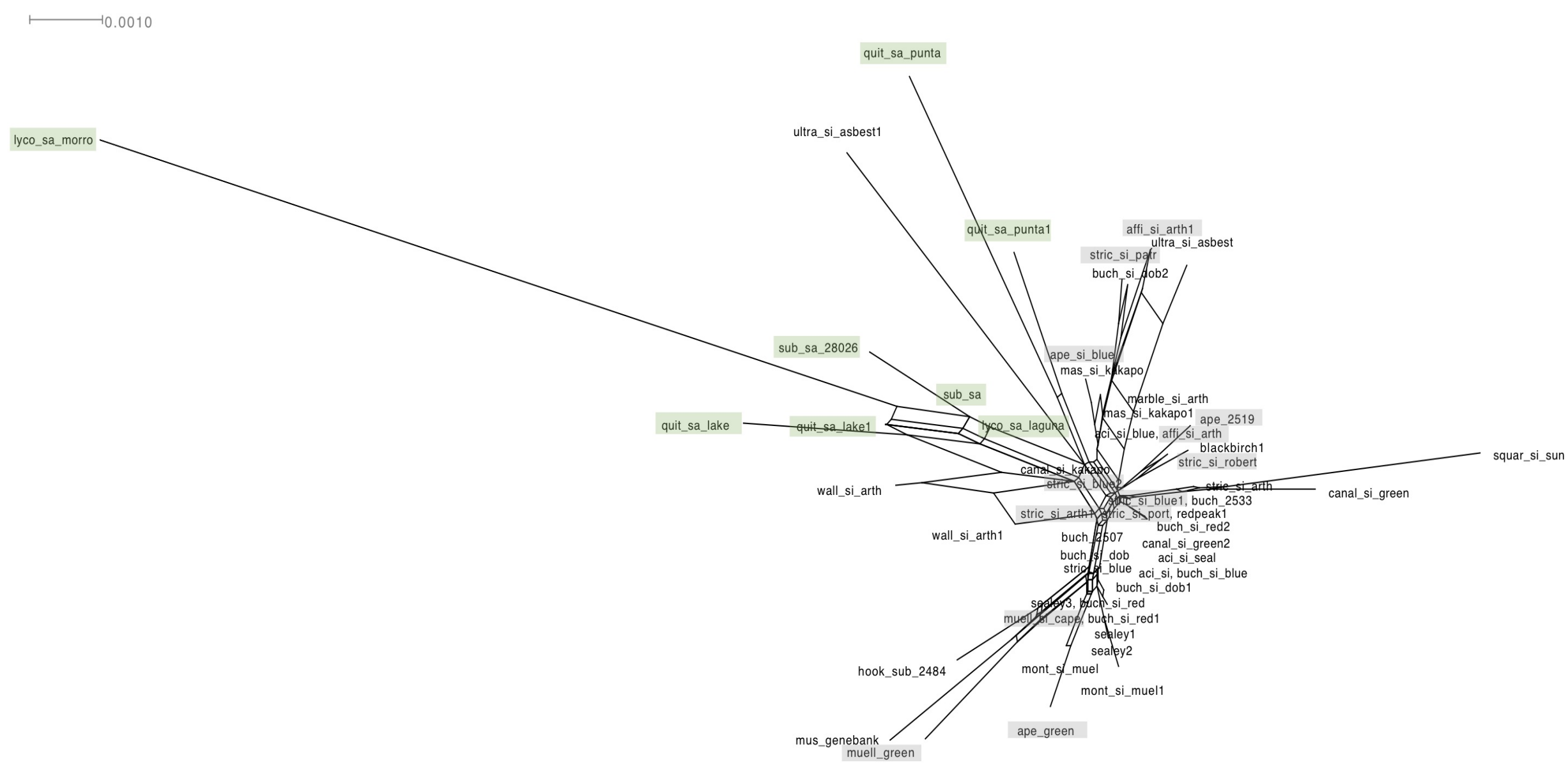

FIG 4.3.4 Splits graph network illustrating relationship among the chloroplast sequences of Colobanthus. Branch lengths are drawn proportionally to the genetic distances, a scale is provided in the upper left corner of the figure. South American species are highlighted in green and species with longer pedicels are highlighted in grey. 


\subsubsection{Combined ITS and chloroplast dataset}

The combined dataset includes all sequences from the ITS dataset as well as all sequences from the concatenated chloroplast dataset. The final alignment included 2624 characters with 267 parsimony informative sites (including outgroups). When restricted to Colobanthus sequences, the number of parsimonious sites was 36 .

Both parsimony analysis and Bayesian analysis resulted in similar phylogenetic trees and were therefore combined in the figure, which shows a 50\% majority-rule consensus tree with bootstrap support and posterior values (Fig. 4.3.5). The arrangement of the outgroups inferred from the combined dataset is similar to the arrangement of these genera in phylogenetic trees presented by Harbaugh et al. (2010). Colobanthus and Sagina are sister groups and together with Bufonia form a clearly separated clade from the other Caryophyllaceae with strong bootstrap support (98\%) and posterior values (1). Monophyly of Colobanthus is only weakly supported by a bootstrap value of $65 \%$. All Colobanthus species form an unresolved crown clade with one backbone. Within the crown clade, smaller clades branch off with weak support values. These include species that are also part of the backbone of the crown clade.

The splits graph of the combined Colobanthus sequences (excluding outgroups) shows a high number of boxes in the core and very short genetic distances (Fig. 4.3.6), indicating conflict in the dataset and very little variation among sequences. Subsets of only South American species and species with longer pedicels (splits graphs not shown) also indicate incompatible splits by forming boxes instead of branches. 


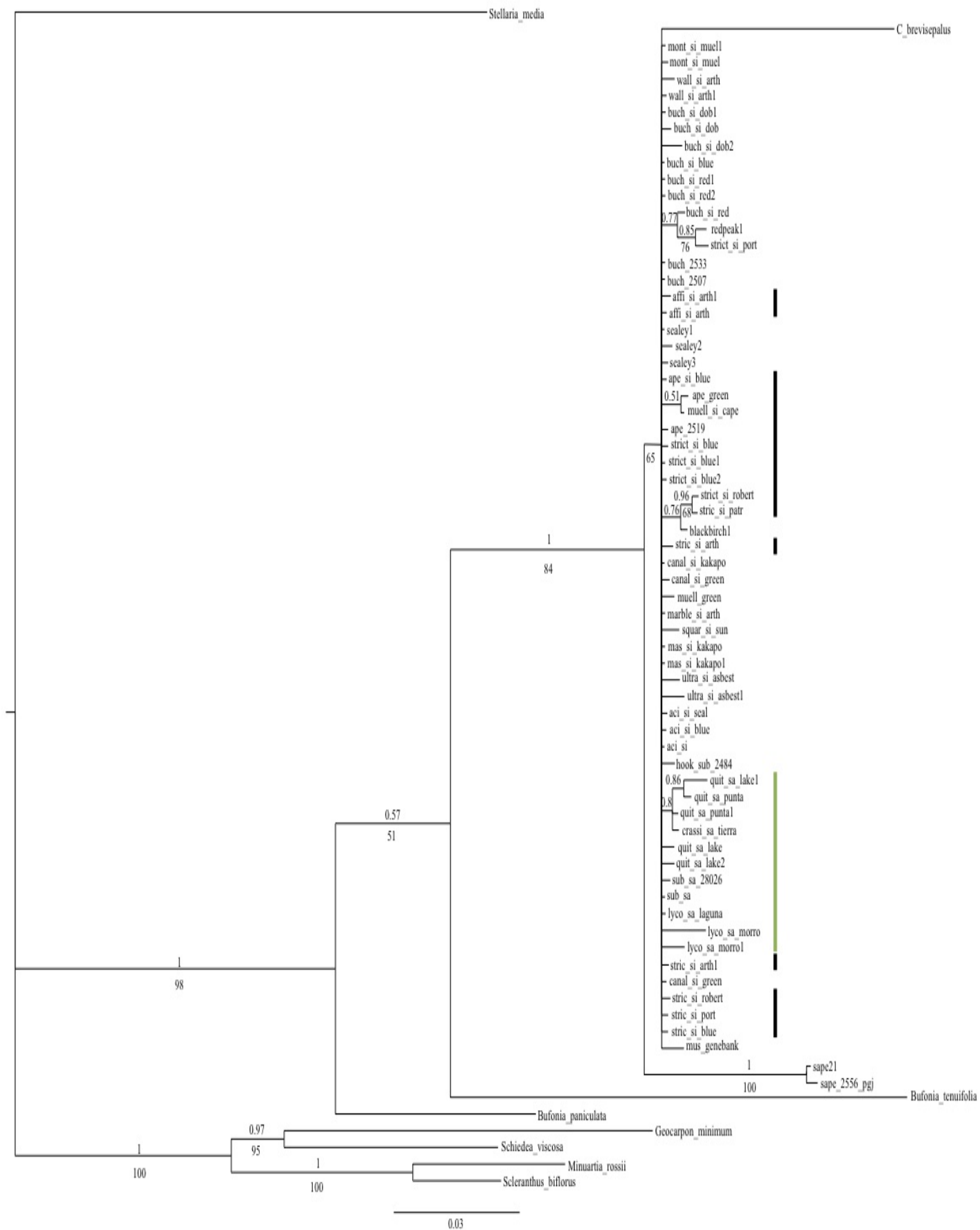

FIG 4.3.5 50\% consensus tree using Bayesian analysis of the combined dataset (ITS, rps 16 and $\operatorname{trn} \mathrm{T}-\operatorname{trn} \mathrm{E})$. Branch lengths are proportional to the number of changes. Numbers above the branches are Bayesian posterior probabilities (numbers $<0.5$ not shown). Numbers below branches show parsimony bootstrap support (values $<50 \%$ not shown). Matching species names to species abbreviations can be found in Table 4.3.1. Numbers behind species abbreviations indicate different voucher specimen. The green bars highlight South American species, whereas the black bars signify species with longer pedicels. 
CHAPTER FOUR

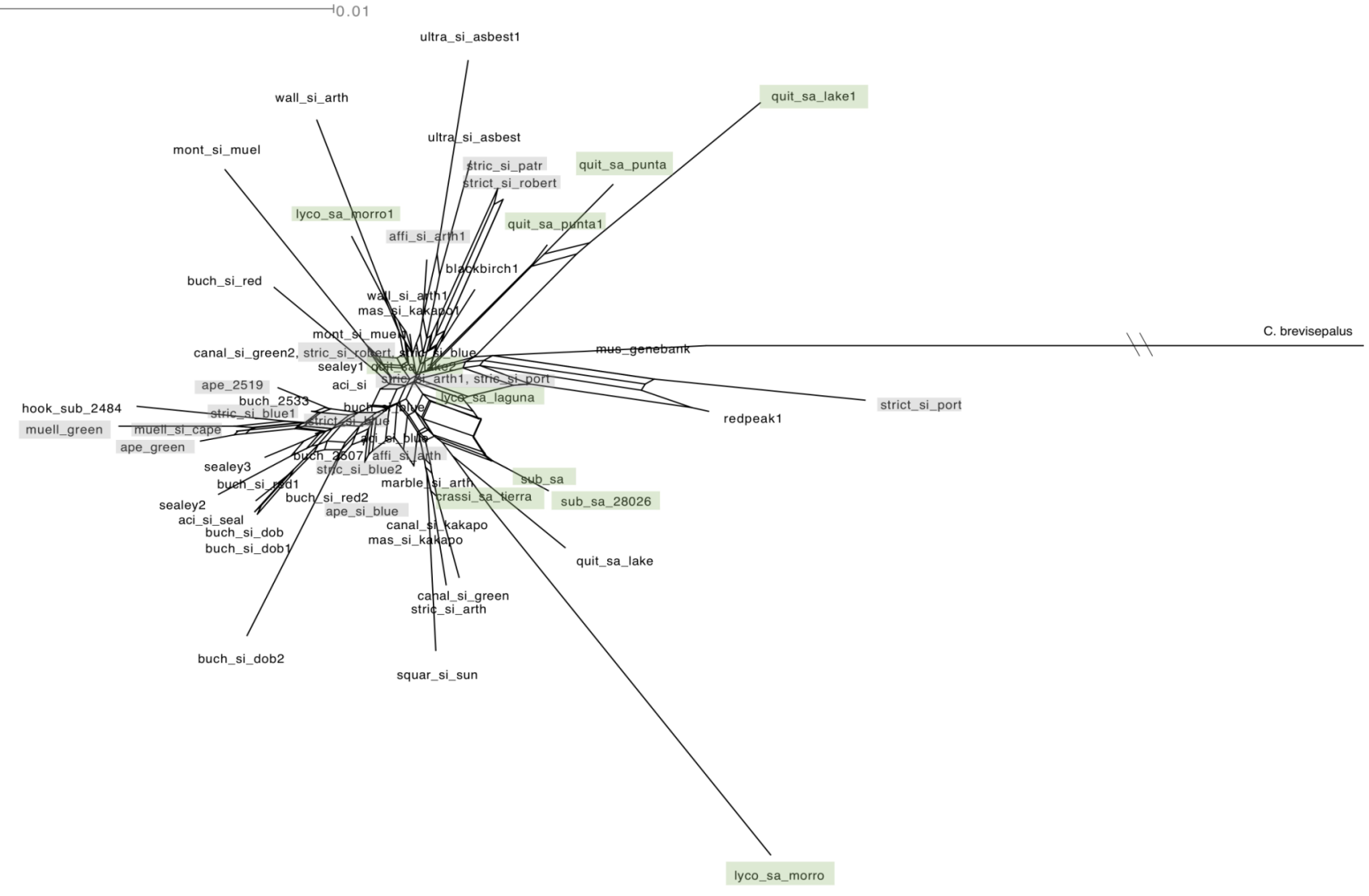

FIG 4.3.6 Splits graph network illustrating relationship among the combined nuclear and chloroplast dataset of Colobanthus. Branch lengths are drawn proportionally to the genetic distances, a scale is provided in the upper left corner of the figure. South American species are highlighted in green and species with longer pedicels are highlighted in grey. The branch of $C$. brevisepalus is cut in order to be included in the splits graph. 
CHAPTER FOUR

\subsubsection{Uncorrected p-distances}

Uncorrected p-distances were calculated separately for the ITS, $\operatorname{rps} 16$ and $\operatorname{trn} \mathrm{T}-\operatorname{trn} \mathrm{E}$ datasets. Species with multiple samples were included and unidentified specimens were excluded.

In the ITS dataset, uncorrected p-distances were high between Colobanthus and its outgroups $(13.5 \%-19.6 \%)$ as well as within the outgroup $(12.3 \%$. $-26.1 \%)$. Between Sagina and Colobanthus, uncorrected p-distances range from $2.9 \%$ to $10 \%$. Within Colobanthus, uncorrected p-distances are very low $(0 \%-6.8 \%)$. The same distances are also given for comparisons between New Zealand and South American species as well as species with sessile capsules and species with capsules on longer pedicels. Within the South American species, the highest distance is $0.7 \%$.

Table 4.3.4 contains uncorrected p-distances between ITS sequences of Colobanthus species to test for species delimitation. Overall, the p-distances are very low and mostly the minimum interspecific distances are smaller than the maximum intraspecific distances. Colobanthus 'ultramafic' is the only species that is discriminated from all other species by its uncorrected p-distances and C. muelleri is discriminated from all species except $C$. apetalus. South American species cannot be discriminated based on uncorrected p-distances.

In the rps 16 dataset, distances between Colobanthus and the outgroup ranged from $7.6 \%$ to $14.4 \%$, within the outgroup distances were $3.5 \%-12.9 \%$.

Between Colobanthus and Sagina uncorrected p-distances ranged from 2.7\% to $3.1 \%$. Within Colobanthus, distances were generally very low $(0 \%-1.4 \%)$, as were the distances between species with sessile fruits or capsules on longer pedicels $(0 \%-$ $0.6 \%)$, distances between New Zealand and South American species $(0.1 \%-2.5 \%)$ and within South American species $(0 \%-2.2 \%)$. 
The trnT-trnE dataset did not contain further outgroups, therefore uncorrected $\mathrm{p}$ distances could only be calculated within Colobanthus and between Colobanthus and Sagina. Within Colobanthus, distances ranged from $0 \%$ to $2.3 \%$. These distances include calculations between one South American and the New Zealand species $(0.7 \%$ $-1.9 \%)$ as well as species with sessile fruits and capsules on longer pedicels $(0 \%-$ 2.3\%). Between Colobanthus and Sagina, uncorrected p-distances of $2.3 \%$ to $3.4 \%$ were calculated.

Tables 4.3.5 and 4.3.6 contain uncorrected p-distances for rps16 sequences (Table 4.3.5) and trnT-E sequences (Table 4.3.6) to test for species discrimination. Both tables have lower numbers of samples since less species had more than one sample per species compared to the ITS dataset. No clear species delimitation can be detected with the very low uncorrected p-distances although $C$. masoniae is discriminated from all other species except C. apetalus in the rps16 dataset. In the trnT-E dataset (Table 4.3.6), only C. muelleri, $C$. quitensis and $C$. 'ultramafic' showed slightly higher values of uncorrected p-distances, all other species are similar. Since no intraspecific distances are given for these species, a conclusion about species discrimination cannot be drawn. 
Table 4.3.4 Uncorrected p-distances between ITS sequences of Colobanthus. Maximum intraspecific distances are in BOLD, minimum interspecific distances larger than the max. intraspecific distances are in ITALICS. The top row contains only species with more than one sample per species, therefore not all species have maximum intraspecific distances.

\begin{tabular}{|c|c|c|c|c|c|c|c|c|c|c|c|c|c|}
\hline & acicularis & affinis & apetalus & buchananii & canaliculatus & lycopodioides & masoniae & monticola & muelleri & quitensis & strictus & subulatus & ultra \\
\hline acicularis & 0.004 & 0 & 0 & 0 & 0 & 0 & 0 & 0 & 0.001 & 0 & 0 & 0 & 0.003 \\
\hline affinis & 0 & 0.001 & 0.001 & 0 & 0 & 0 & 0 & 0 & 0.003 & 0 & 0.001 & 0 & 0.003 \\
\hline apetalus & 0 & 0.001 & 0.001 & 0 & 0.001 & 0.001 & 0.001 & 0.001 & 0 & 0.001 & 0 & 0.001 & 0.004 \\
\hline brevisepalus & 0.051 & 0.056 & 0.057 & 0.051 & 0.061 & 0.051 & 0.056 & 0.051 & 0.068 & 0.051 & 0.051 & 0.057 & 0.056 \\
\hline buchananii & 0 & 0 & 0 & 0.01 & 0.001 & 0 & 0 & 0 & 0.001 & 0.001 & 0 & 0.001 & 0.003 \\
\hline canaliculatus & 0 & 0 & 0 & 0.001 & 0 & 0 & 0 & 0.003 & 0.003 & 0 & 0.001 & 0 & 0.003 \\
\hline crassifolius & 0.003 & 0.001 & 0.003 & 0.003 & 0.001 & 0.001 & 0.001 & 0.003 & 0.004 & 0 & 0.003 & 0.001 & 0.004 \\
\hline hookeri & 0.003 & 0.004 & 0.003 & 0.003 & 0.004 & 0.004 & 0.004 & 0.004 & 0.004 & 0.004 & 0.003 & 0.004 & 0.007 \\
\hline lycopodioides & 0 & 0 & 0.001 & 0 & 0 & 0.005 & 0 & 0 & 0.003 & 0.001 & 0.001 & 0 & 0.003 \\
\hline marble & 0 & 0 & 0.001 & 0.001 & 0 & 0 & 0 & 0.001 & 0.003 & 0 & 0.001 & 0 & 0.004 \\
\hline masoniae & 0 & 0 & 0.001 & 0 & 0 & 0 & 0.001 & 0 & 0.003 & 0 & 0.001 & 0 & 0.003 \\
\hline monticola & 0 & 0 & 0.003 & 0 & 0.003 & 0 & 0 & 0 & 0.004 & 0.001 & 0.001 & 0.001 & 0.004 \\
\hline muelleri & 0.003 & 0.003 & 0 & 0.001 & 0.003 & 0.003 & 0.003 & 0.004 & 0 & 0.003 & 0.001 & 0.003 & 0.006 \\
\hline quitensis & 0 & 0 & 0.001 & 0.001 & 0 & 0 & 0 & 0.001 & 0.003 & 0.007 & 0.001 & 0 & 0.004 \\
\hline squarrosus & 0.003 & 0.001 & 0.003 & 0.003 & 0.001 & 0.001 & 0.001 & 0.003 & 0.004 & 0.004 & 0.003 & 0.001 & 0.004 \\
\hline strictus & 0 & 0.001 & 0 & 0 & 0.001 & 0.001 & 0.001 & 0.001 & 0.001 & 0.001 & 0.012 & 0.001 & 0.004 \\
\hline subulatus & 0 & 0 & 0.001 & 0.001 & 0 & 0 & 0 & 0.001 & 0.003 & 0 & 0.001 & 0 & 0.004 \\
\hline ultra & 0.003 & 0.003 & 0.004 & 0.003 & 0.003 & 0.003 & 0.003 & 0.004 & 0.006 & 0.004 & 0.004 & 0.004 & 0.001 \\
\hline wallii & 0 & 0 & 0.001 & 0 & 0.004 & 0 & 0 & 0 & 0.004 & 0.001 & 0.001 & 0.001 & 0.003 \\
\hline
\end{tabular}


Table 4.3.5 Uncorrected p-distances between rps 16 sequences of Colobanthus. Maximum intraspecific distances are in BOLD, minimum interspecific distances larger than the max. intraspecific distances are in ITALICS. The top row contains only species with more than one sample per species, therefore not all species have maximum intraspecific distances.

\begin{tabular}{|c|c|c|c|c|c|c|c|c|c|c|c|}
\hline & acicularis & apetalus & buchananii & canaliculatus & lycopodioides & masoniae & monticola & muelleri & quitensis & strictus & ultra \\
\hline acicularis & 0 & 0.001 & 0 & 0 & 0.001 & 0.001 & 0.001 & 0.001 & 0.005 & 0 & 0.002 \\
\hline affinis & 0.003 & 0.002 & 0.003 & 0.003 & 0.006 & 0.001 & 0.006 & 0.005 & 0.006 & 0.003 & 0.002 \\
\hline apetalus & 0.001 & 0.004 & 0 & 0.001 & 0.001 & 0 & 0 & 0 & 0.005 & 0.001 & 0.004 \\
\hline buchananii & 0 & 0 & 0.007 & 0 & 0.001 & 0.001 & 0 & 0 & 0.005 & 0 & 0.003 \\
\hline canaliculatus & 0 & 0.001 & 0 & 0.004 & 0.001 & 0.001 & 0.001 & 0.001 & 0.005 & 0 & 0.003 \\
\hline hookeri & 0.003 & 0.004 & 0.002 & 0.003 & 0.006 & 0.005 & 0.005 & 0.002 & 0.007 & 0.002 & 0.006 \\
\hline lycopodioides & 0.001 & 0.001 & 0.001 & 0.001 & 0.015 & 0.004 & 0.004 & 0.009 & 0.004 & 0.001 & 0.009 \\
\hline marble & 0 & 0.001 & 0 & 0 & 0.001 & 0.001 & 0.001 & 0.001 & 0.003 & 0 & 0.003 \\
\hline masoniae & 0.001 & 0 & 0.001 & 0.001 & 0.004 & $\mathbf{0}$ & 0.002 & 0.002 & 0.005 & 0.001 & 0.002 \\
\hline monticola & 0.001 & 0 & 0 & 0.001 & 0.004 & 0.002 & 0.001 & 0 & 0.005 & 0.001 & 0.005 \\
\hline muelleri & 0.001 & 0 & 0 & 0.001 & 0.009 & 0.002 & 0 & 0.004 & 0.005 & 0.001 & 0.009 \\
\hline muscoides & 0.004 & 0.004 & 0.004 & 0.004 & 0.008 & 0.007 & 0.004 & 0.004 & 0.009 & 0.004 & 0.008 \\
\hline quitensis & 0.005 & 0.005 & 0.005 & 0.005 & 0.004 & 0.005 & 0.005 & 0.005 & 0.012 & 0.002 & 0.009 \\
\hline squarrosus & 0.006 & 0.007 & 0.004 & 0.004 & 0.009 & 0.007 & 0.009 & 0.007 & 0.009 & 0.004 & 0.009 \\
\hline strictus & 0 & 0.001 & 0 & 0 & 0.001 & 0.001 & 0.001 & 0.001 & 0.002 & 0.004 & 0.002 \\
\hline subulatus & 0.001 & 0.004 & 0.001 & 0.001 & 0 & 0.004 & 0.004 & 0.004 & 0.004 & 0.001 & 0.008 \\
\hline ultra & 0.002 & 0.004 & 0.003 & 0.003 & 0.009 & 0.002 & 0.005 & 0.004 & 0.009 & 0.002 & 0.007 \\
\hline wallii & 0.001 & 0.003 & 0.001 & 0.001 & 0.003 & 0.003 & 0.003 & 0.003 & 0.001 & 0.001 & 0.004 \\
\hline
\end{tabular}


Table 4.3.6 Uncorrected p-distances between trnT-E sequences of Colobanthus. Maximum intraspecific distances are in BOLD, minimum interspecific distances larger than the max. intraspecific distances are in ITALICS. The top row contains only species with more than one sample per species, therefore not all species have maximum intraspecific distances.

\begin{tabular}{|lrrrrr|}
\hline & acicularis & apetalus & buchananii & canaliculatus & strictus \\
\hline acicularis & $\mathbf{0}$ & 0 & 0 & 0 & 0 \\
affinis & 0 & 0 & 0 & 0 & 0 \\
apetalus & 0 & $\mathbf{0 . 0 0 3}$ & 0 & 0 & 0 \\
buchananii & 0 & 0 & $\mathbf{0}$ & 0 & 0 \\
canaliculatus & 0 & 0 & 0 & $\mathbf{0}$ & 0 \\
masoniae & 0 & 0 & 0 & 0 & 0 \\
muelleri & 0.003 & 0.003 & 0.003 & 0.003 & 0 \\
quitensis & 0.009 & 0.011 & 0.009 & 0.009 & 0.007 \\
squarrosus & 0 & 0 & 0 & 0 & 0 \\
strictus & 0 & 0 & 0 & 0 & $\mathbf{0 . 0 0 3}$ \\
ultra & 0.011 & 0.006 & 0.009 & 0.009 & 0.009 \\
wallii & 0 & 0 & 0 & 0 & 0 \\
\hline \hline
\end{tabular}

\subsubsection{DisCUSSION}

Both nuclear and chloroplast sequences show similar results, albeit very little variation. The phylogenies emerging from the ITS and chloroplast sequences as well as the combined dataset recognize Colobanthus as one weakly supported and unresolved crown clade with Sagina forming the sister group. The selected outgroups have been confirmed as outgroups consistent with Smissen et al. (2002) and Harbaugh et al. (2010). Especially the combined dataset shows very strong support for the outgroup topography in the phylogenetic tree.

All three datasets place all Colobanthus species in one clade separately from Sagina, potentially suggesting monophyly. However, bootstrap support is generally weak and no posterior values are given, even though the bootstrap values increased slightly in the combined dataset. Therefore the monophyly of Colobanthus cannot clearly be inferred from the three sequenced genes and further sampling of Sagina is warranted to resolve the relationship between these two related genera.

Colobanthus species are presented as a crown clade and splits graphs visualize a high number of conflicting signals among the sequences in the genus. To investigate 
species delimitation further, interspecific and intraspecific uncorrected p-distances have been calculated. Two questions were asked concerning species relationships within Colobanthus - (1) how many South American species are there and (2) are species delimitations in New Zealand Colobanthus appropriate?

In general, uncorrected p-distances are larger in the ITS dataset compared to the chloroplast datasets, which also contain fewer species. However, within Colobanthus distances are very low and therefore results have to be treated with caution. Often the maximum intraspecific distances equal $0 \%$, especially when two samples are from the same location. Maximum distances are usually larger when samples of the same species are compared between different locations.

South American species cannot be discriminated based on uncorrected p-distances, since the minimum interspecific distances are never larger than the maximum intraspecific distance (CBOL Plant Working Group, 2009) of any South American species in the ITS dataset. The use of five different names should therefore be abandoned. However, the names that are currently used $(C$. quitensis and $C$. subulatus) apply to two morphologically very different species (Moore, 1983; own obs.) and I propose to maintain the names based on the morphological differences.

Within New Zealand, very few differences could be found between the species. This suggests that speciation and morphological divergence have been achieved without corresponding divergence of ITS, rps16 and trnT-E sequences. Colobanthus brevisepalus has large uncorrected p-distances to all other species. The sample used in this analysis was taken from GenBank and mistakes might have been made in the alignment of this sample with the other specimens. Further sequencing is recommended to confirm the difference to other tested species. Colobanthus 'ultramafic' can be discriminated from all other species based on the p-distances in 
the ITS dataset and its position on phylogenetic trees inferred from ITS and chloroplast markers (but not the combined dataset) also indicate larger genetic differences to other Colobanthus species. This undescribed species can only be found on ultramafic rocks in two locations in the North of the South Island (B. Sneddon, pers. comm.; own obs.). Previously it was identified as C. strictus (Robinson et al., 1997) but results of the phylogenetic analysis might indicate that C. 'ultramafic' might be a different species.

Uncorrected p-distances between South American and New Zealand species do not show species discrimination between most species and species delimitation should be reconsidered. Comparing species with sessile capsules and species with capsules on longer pedicels, only C. muelleri stands out because it can be clearly discriminated from all other species except $C$. apetalus and this difference is constricted to the ITS dataset. This species is also the only coastal species and therefore ecologically separated from other New Zealand species (Allan, 1961). It is also morphologically very distinct as it is the only species that forms small rosettes. Phylogenetic analyses of the ITS and chloroplast dataset (but not the combined dataset) also indicate that $C$. muelleri is separate from other Colobanthus species.

Another potential aim of the molecular analysis of the phylogeny of Colobanthus was the identification of unidentified specimen (e.g. blackbirch, sealey). Some New Zealand Colobanthus species are very similar and occur conspecific (Allan, 1961) and species identification is difficult. However, due to the low resolution of all tested genetic markers, I have not been able to identify these unknown specimens.

Within Colobanthus, the lack of significant sequence divergence and the formation of an unresolved crown clade in all analysed sequence data support a closely related 
southern hemisphere genotype and suggest very recent and rapid dispersal and speciation.

The lack of resolution in molecular datasets for New Zealand plant species is not uncommon and well documented in Sophora (Mitchell and Heenan, 2002), Veronica (Wagstaff and Garnock-Jones, 2000; Meudt and Bayly, 2008), Hoheria (Wagstaff et al., 2010), Scleranthus (Smissen et al., 2003), Gnaphalieae (Smissen et al., 2004), Abrotanella (Wagstaff et al., 2006) and Plantago (Tay, 2008). These unresolved clades can be explained by the natural history of New Zealand. In recent years it became evident that a large part of the New Zealand flora was formed after recent long-distance dispersal events followed by rapid diversification after the tertiary uplift of the mountains and Quaternary climate change (Raven, 1973; Pole, 1994; Macphail, 1997; Swenson and Bremer, 1997; Winkworth et al., 1999; Winkworth et al., 2002b). Even though recent long-distance dispersal presents a possible explanation for the low variation between South American and New Zealand species, the dispersal mechanism and seed size (Allan, 1961; Bergstrom, 1986; Hennion and Walton, 1997; Webb and Simpson, 2001; Chapter 4.2) seem unlikely to support this hypothesis. Colobanthus kerguelensis seeds have been found to be able to float in freshwater for up to 24 hours but dispersal agents between islands have still not been identified (Hennion and Walton, 1997; Van der Putten et al., 2010). Nevertheless, long distance dispersal has been proposed in other plants with hygrochastic capsules (e.g. two Veronica species of the snow hebe clade occur in New Zealand and Australia (Meudt, 2008)).

However, the extremely low resolution in the tested nuclear and chloroplast sequences is exceptional since not even wide geographic separation, e.g. between South American and New Zealand species seem to have resulted in considerable 
sequence divergence. Although some species are morphologically distinct (e.g. species with longer pedicels and caespitose growth form compared to cushion plants with sessile capsules), these differences do not show in the phylogenetic analysis of nuclear and chloroplast sequences. This might suggest that morphological evolution is proceeding at a rate greater than the molecular evolution of the ITS, $\operatorname{rps} 16$ and $\operatorname{trnT}$ trnE regions (Hurr et al., 1999; Mitchell and Heenan, 2002).

Similar difficulties associated with establishing sound relationships among species using molecular phylogenies also occur in other genera within the Caryophyllaceae (Smissen et al., 2003; Fior and Karis, 2007; Kool et al., 2007). Likewise, morphological homoplasy is common in the Caryophyllaceae and makes species discrimination problematic (Endress, 1996; Hufford, 1996; Smissen et al., 2002; Fior et al., 2006).

The phylogenies presented here are based on one nuclear and two chloroplast sequences and are by no means sufficient to clearly resolve interspecific relationships in Colobanthus. Genetic variation in all three markers is extremely low and restricted to single point mutations to different bases in different specimens, which might also have contributed to the conflicting signals in the splits graph analysis. Reasons for the low resolution the molecular datasets could be very recent speciation and subsequent radiation into new habitats.

There are other, as of yet unexplored ways to solve the phylogeny of this genus. This could include the use of different markers with higher variation or the combination of molecular and morphological data, which has proved to be successful in other Caryophyllaceae (Fior and Karis, 2007) or other New Zealand taxa with otherwise low genetic variation ((Meudt, 2008). Chromosome counts are useful in assessing polyploidy, which might have an influence on incompatible splits in splits graphs 
(Tay, 2008; Wagstaff et al., 2010). Other appropriate molecular methods also include

AFLPs or microsatellites, which can reveal genetic variation not seen in DNA sequences from a small number of regions (Ellis et al., 2006; Selkoe and Toonen, 2006; Meudt and Bayly, 2008).

\subsubsection{REFERENCES}

AdAms, L. G., J. G. West, AND K. J. Cowley. 2008. Revision of Spergularia (Caryophyllaceae) in Australia. Australian Systematic Botany 21: 251-270.

AlBACH, D. C., AND M. W. CHASE. 2004. Incongruence in Veroniceae (Plantaginaceae): evidence from two plastid and a nuclear ribosomal DNA region. Molecular Phylogenetics and Evolution 32: 183-197.

Allan, H. H. 1961. Flora of New Zealand Volume 1 Indigenous Tracheophyta. Government Printer, Wellington, New Zealand.

Applequist, W. L., W. L. WAGNer, E. A. Zimmer, AND M. NePOKRoefF. 2006. Molecular evidence resolving the systematic position of Hectorella (Portulacaceae). Systematic Botany 31: 310-319.

Bacchetta, G., S. Brullo, M. Casti, AND G. P. G. Del Galdo. 2010. Taxonomic revision of the Dianthus sylvestris group (Caryophyllaceae) in central-southern Italy, Sicily and Sardinia. Nordic Journal of Botany 28: 137-173.

Baldwin, B. G., M. J. SAnderson, J. M. Porter, M. F. Wojciechowski, C. S. CAMPBell, AND M. J. Donoghue. 1995. The ITS region of nuclear ribosomal DNA: A valuable source of evidence on angiosperm phylogeny. Annals of the Missouri Botanical Garden 82: 247-277.

Bergstrom, D. 1986. An atlas of seeds and fruits from Macquarie Island. Proceedings of the Linnean Society of New South Wales 109: 69-90.

BitTRICH, V. 1993. Caryophyllaceae. In K. Kubitzki, V. Bittrich, and J. Rohwer [eds.], The families and genera of vascular plants, 206-230. Springer Verlag, Berlin

CBOL Plant Working Group, C. P. W. 2009. A DNA barcode for land plants. Proceedings of the National Scademy of Sciences of the United States of America 106: 12794-12797.

Cuenoud, P., V. Savolainen, L. W. Chatrou, M. Powell, R. J. Grayer, AND M. W. CHASE. 2002. Molecular phylogenetics of Caryophyllales based on nuclear $18 \mathrm{~S}$ rDNA and plastid $r b c \mathrm{~L}$, attpB, and matK DNA sequences. American Journal of Botany 89: 132-144.

Cummings, M. P., S. P. OtTo, AND J. Wakeley. 1995. Sampling properties of DNA seqeunec data in phylogenetic analysis. Molecular Biology and Evolution 12: 814822 .

Downie, S. R., AND J. D. PALMER. 1994. A chloroplast DNA phylogeny of the Caryophyllales based on structural and inverted repeat restriction site variation. Systematic Botany 19: 236-252.

Downie, S. R., S. KATZ-Downie, AND K. ChO. 1997. Relationships in the Caryophyllales as suggested by phylogenetic analysis of partial chloroplast DNA ORF2280 homolog sequences. American Journal of Botany 84: 252-273.

DoYle, J. J., AND J. D. DOYLE. 1990. Isolation of plant DNA from fresh tissue. Focus 12: $13-15$.

Doyle, J. J., J. I. Davis, R. J. Soreng, D. Garvin, AND M. J. Anderson. 1992. Chloroplast DNA inversions and the origin of the grass family (Poaceae). 
Proceedings of the National Scademy of Sciences of the United States of America 89: $7722-7726$.

Drummond, A. J., B. Ashton, M. Cheung, J. Heled, M. Kearse, R. Moir, S. StoneHavas, T. Thierer, AND A. Wilson. 2009. Geneious v4.8, Available from http://www.geneious.com/.

Ellis, A. G., A. E. WEIS, AND B. S. GAUT. 2006. Evolutionary radiation of "stone plants" in the genus Argyroderma (Aizoaceae): Unraveling the effects of landscape, habitat, and flowering. Evolution 60: 39-55.

ENDRESS, P. K. 1996. Homoplasy in angiospern flowers. In M. J. Sanderson and L. Hufford [eds.], Homoplasy: the recurrence of similarity in evolution, 303-325. Academic Press, San Diego, CA.

FIOR, S., AND P. O. KARIS. 2007. Phylogeny, evolution and systematics of Moehringia (Caryophyllaceae) as inferred from molecular and morphological data: a case of homology reassessment. Cladistics 23: 362-372.

FIOR, S., P. O. KARIS, G. CASAZZA, L. MinUTO, AND F. SALA. 2006. Molecular phylogeny of the Caryophyllaceae (Caryophyllales) inferred from chloroplast matK and nuclear rDNA ITS sequences. American Journal of Botany 93: 399-411.

FRAJMAN, B., AND B. OXELMAN. 2007. Reticulate phylogenetics and phytogeographical structure of Heliosperma (Sileneae, Caryophyllaceae) inferred from chloroplast and nuclear DNA sequences. Molecular Phylogenetics and Evolution 43: 140-155.

GILFEDDER, L., AND J. B. KIRKPATRICK. 1996. The distribution, ecology and conservation needs of Colobanthus curtisiae West. Papers and Proceedings of the Royal Society of Tasmania 130: 25-30.

Harbaugh, D. T., M. Nepokroeff, R. K. Rabeler, J. McNeill, E. A. Zimmer, AND W. L. WAGNER. A new lineage-based tribal classification of the family Caryophyllaceae. International Journal of Plant Sciences 171: 185-198.

Hasebe, M., T. OMORI, M. NAKAZAwa, T. SANO, M. Kato, AND K. IwatsuKi. 1994. Rbcl gene-sequences provide evidence for the evolutionary lineages of leptosporangiate ferns. Proceedings of the National Scademy of Sciences of the United States of America 91: 5730-5734.

Hennion, F., AND D. W. H. WALton. 1997. Seed germination of endemic species from Kerguelen phytogeographic zone. Polar Biology 17: 180-187.

HowarTh, D. G., AND D. A. BAUM. 2005. Genealogical evidence of homoploid hybrid speciation in an adaptive radiation of Scaevola (Goodeniaceae) in the Hawaiian Islands. Evolution 59: 948-961.

HuDSON, D. H. 1998. SplitsTree: analyzing and visualizing evolutionary data. Bioinformatics 14: 68-73.

Hudson, D. H., AND D. BRYANT. 2006. Application of phylogenetic networks in evolutionary studies. Molecular Biology and Evolution 23: 254-267.

HuelsenbeCK, J. P., AND F. RonQuist. 2001. MrBayes: Bayesian inference of phylogenetic trees. Bioinformatics 17: 754-755.

HufFORD, L. 1996. Ontogenetic evolution, clade diversification, and homoplasy. In M. J. Sanderson and L. Hufford [eds.], Homoplasy: the recurrence of similarity in evolution, 271-302. Academic Press, San Diego, CA.

Hurr, K. A., P. J. Lockhart, P. B. Heenan, AND D. Penny. 1999. Dispersal of the Edwardsia section of Sophora (Leguminosae) around the southern oceans: molecular evidence. Journal of Biogeography 26: 565-577.

JOHNSON, L. A., AND D. E. SOLTIS. 1994. matK DNA sequences and phylogenetic reconstruction in Saxifragaceae s.s. Systematic Botany 19: 143-156.

Kool, A., A. Bengtson, AND M. Thulin. 2007. Polyphyly of Polycarpon (Caryophyllaceae) inferred from DNA sequence data. Taxon 56: 775-782.

Lockhart, P. J., P. A. Mclenachan, D. Harell, D. Glenny, D. Huson, AND U. JENSEN. 2001. Phylogeny, radiation, and transoceanic dispersal of New Zealand alpine buttercups: Molecular evidence under split decomposition. Annals of the Missouri Botanical Garden 88: 458-477. 
LOOCKERMAN, D. J., AND R. K. JANSEN. 1996. The use of herbarium material for DNA studies. In T. F. Stuessy and S. Sohmer [eds.], Sampling of the green world, 205-220. Columbia University Press, New York.

MaCPhaIL, M. K. 1997. Comment on M. Pole (1994): 'The New Zealand flora - entirely long-distance dispersal?' journal of Biogeography 24: 113-117.

MEudT, H. M. 2008. Taxonomic revision of Australasian snow hebes (Veronica, Plantaginaceae). Australian Systematic Botany 21: 387-421.

MeUdT, H. M., AND M. J. BAYLY. 2008. Phylogeographic patterns in the Australasian genus Chionohebe (Veronica s.l., Plantaginaceae) based on AFLP and chloroplast DNA sequences. Molecular Phylogenetics and Evolution 47: 319-338.

Minuto, L., S. Fior, E. Roccotiello, AND G. CASAzZA. 2006. Seed morphology in Moehringia L. and its taxonomic significance in comparative studies within the Caryophyllaceae. Plant Systematics and Evolution 262: 189-208.

Mitchell, A. D., AND P. B. HEENAN. 2002. Sophora sect. Edwardsia (Fabaceae): further evidence from nrDNA sequence data of a recent and rapid radiation around the Southern Oceans. Botanical Journal of the Linnean Society 140: 435-441.

Moore, D. M. 1983. Flora of Tierra del Fuego. Anthony Nelson, Shropshire, England.

Morariu, V. I., B. V. SRinivasan, V. C. RAYKar, R. Duraiswami, AND L. S. Davis. 2008. Automatic online tuning for fast Gaussian summation. Advances in Neural Information Processing Systems.

Mort, M. E., J. K. Archibald, C. P. Randle, N. D. Levsen, T. R. O'Leary, K. Topalov, C. M. WIEGAND, AND D. J. CRAWFORD. 2007. Inferring phylogeny at low taxonomic levels: Utility of rapidly evolving cpDNA and nuclear ITS loci. American Journal of Botany 94: 173-183.

Olmstead, R. G., J. A. Sweere, R. E. Spangler, I. Bohs, AND J. D. Palmer. 1999. Phylogeny and provisional classification of the Solanaceae based on chloroplast DNA. In M. Nee, D. E. Symon, J. P. Jessup, and J. G. Hawkes [eds.], Solanaceae, Vol 4, Advances in biology and utilization, 111-137. Royal Botanical Gardens, Kew.

Oxelman, B., B. Ahlgren, AND M. Thulin. 2002. Circumscription and phylogenetic relationships of Gymnocarpos (Caryophyllaceae-Paronychioideae). Edinburgh Journal of Botany 59: 221-237.

Oxelman, B., M. Liden, R. K. Rabeler, AND M. Popp. 2000. A revised generic classification of the tribe Sileneae (Caryophyllaceae). Nordic Journal of Botany 20: 743-748.

Pole, M. 1994. The New Zealand flora - entirely long-distance dispersal? Journal of Biogeography 21: 625-635.

Popp, M., P. ERIXON, F. EgGens, AND B. OXelman. 2005. Origin and evolution of a circumpolar polyploid species complex in Silene (Caryophyllaceae) inferred from low copy nuclear RNA polymerase introns, rDNA, and chloroplast DNA. Systematic Botany 30: 302-313.

PosadA, D., AND K. A. CRANDAll. 1998. Modeltest: testing the model of DNA substitution. Bioinformatics 14: 817-818.

PosADA, D., AND T. R. BUCKLEY. 2004. Model selection and model averaging in phylogenetics: advantages of the AIC and Bayesian approaches over likelihood ratio tests. Systematic Biology 53: 793-808.

Rabeler, R. K., AND H. E. K. Hartmann. 2005. Caryophyllaceae. In F. o. N. A. E. Committee [ed.], Flora of North America North of Mexico, 3-8. Oxford University Press, New York.

RAVEN, P. H. 1973. Evolution of subalpine and alpine plant groups in New Zealand. New Zealand Journal of Botany 11: 177-200.

RetTig, J. H., H. D. WiLsOn, AND J. R. MANHART. 1992. Phylogeny of the Caryophyllales: gene sequence data. Taxon 41: 201-209.

Robinson, B. H., R. R. Brooks, J. H. Kirkman, P. E. H. GregG, AND H. V. Alvarez. 1997. Edaphic influences on a New Zealand ultramafic ("serpentine") flora: A statistical approach. Plant and Soil 188: 11-20. 
SAKai, A. K., S. G. Weller, W. L. Wagner, M. NepokroefF, AND T. M. Culley. 2006. Adaptive radiation and evolution of breeding systems in Schiedea (Caryophyllaceae), an endemic Hawaiian genus. Annals of the Missouri Botanical Garden 93: 49-63.

SANG, T., D. J. CraWford, AND T. F. StUeSsy. 1997. Chloroplast DNA phylogeny, reticulate evolution and biogeography of Paeonia (Paeoniaceae). American Journal of Botany 84: 1120-1136.

SCHAEFERHOFF, B., K. F. MUELleR, AND T. BORSCH. 2009. Caryophyllales phylogenetics: disentangling Phytolaccaceae and Molluginaceae and description of Microteaceae as a new isolated family. Willdenowia 39: 209-228.

Scheen, A.-C., C. Brochmann, A. K. Brysting, R. Elven, A. Morris, D. E. Soltis, P. S. Soltis, AND V. A. ALBERT. 2004. Northern hemisphere biogeography of Cerastium (Caryophyllaceae): Insights from phylogenetic analysis of noncoding plastid nucleotide sequences. American Journal of Botany 91: 943-952.

SElkoe, K. A., AND R. J. TOONEN. 2006. Microsatellites for ecologists: a practical guide to using and evaluatingmicrosatellite markers. Ecology Letters 9: 615-629.

Shaw, J., E. B. Lickey, J. T. Beck, S. B. Farmer, W. S. LiU, J. Miller, K. C. Siripun, C. T. Winder, E. E. SCHILling, AND R. L. SMALl. 2005. The tortoise and the hare II: Relative utility of 21 noncoding chloroplast DNA sequences for phylogenetic analysis. American Journal of Botany 92: 142-166.

SMissen, R. D., AND P. J. GARNOCK-JONES. 2002. Relationships, classification and evolution of Scleranthus (Caryophyllaceae) as inferred from analysis of morphological characters. Botanical Journal of the Linnean Society 140: 15-29.

Smissen, R. D., P. J. GARnOCK-Jones, AND G. K. Chambers. 2003. Phylogenetic analysis of ITS sequences suggests a Pliocene origin for the bipolar distribution of Scleranthus (Caryophyllaceae). Australian Systematic Botany 16: 301-315.

SMissen, R. D., I. BReITWIESER, AND J. M. WARD. 2004. Phylogenetic implications of trans-specific chloroplast DNA sequence polymorphism in New Zealand Gnaphalieae (Asteraceae). Plant Systematics and Evolution 249: 37-53.

Smissen, R. D., G. K. Chambers, AND P. J. GARnOCK-JoneS. 2005. Dating nodes on molecular phylogenies: older or younger than the earth itself? Cladistics 21: 403.

Smissen, R. D., J. C. Clement, P. J. Garnock-Jones, AND G. K. Chambers. 2002. Subfamilial relationships within Caryophyllaceae as inferred from 5' ndhF sequences. American Journal of Botany 89: 1336-1341.

SNEDdON, B. V. 1999. The taxonomy and breeding system of Colobanthus squarrosus (Caryophyllaceae). New Zealand Journal of Botany 37: 195-204.

SosA, V., H. OCHOTERENA, AND M. EsCAMILla. 2006. A revision of Cerdia (Caryophyllaceae). Botanical Journal of the Linnean Society 152: 1-13.

SWENSON, U., AND K. BREMER. 1997. Pacific biogeography of the Asteraceae genus Abrotanella (Senecioneae, Blennospermatinae). Systematic Botany 22: 493-508.

SWOFFORD, D. L. 2002. PAUP*. Phylogenetic analysis using parsimony (*and other methods). Sinauer Associates, Sunderland, Massachusetts.

TABerlet, P., L. Gielly, G. Pautou, AND J. Bouvet. 1991. Universal primers for amplification of 3 noncoding regions of chloroplast DNA. Plant Molecular Biology 17: 1105-1109.

TAte, J. A., AND B. B. Simpson. 2003. Paraphyly of Tarasa (Malvaceae) and diverse origins ofthe polyploid species. Systematic Botany 28: 723-737.

TAY, M.L. 2008. Evolution of Australasian Plantago (Plantaginaceae). MSc. thesis, Victoria University of Wellington, Wellington, New Zealand.

THIERS, B. [continuously updated]. Index Herbariorum: A global directory of public herbaria and associated staff. New York Botanical Garden's Virtual Herbarium. http://sweetgum.nybg.org/ih/

TZvelev, N. N. 2006. About the systematic position of the some Caryophyllaceae species from the far east. Byulleten' Moskovskogo Obshchestva Ispytatelei Prirody Otdel Biologicheskii 111: 37-40. 
VAn der Putten, N., C. Verbruggen, R. Ochyra, E. Verleyen, AND Y. Frenot. 2010. Subantarctic flowering plants: pre-glacial survivors or post-glacial immigrants? Journal of Biogeography 37: 582-592.

WAGSTAFF, S. J., AND P. GARNOCK-JONES. 1998. Evolution and biogeography of the Hebe complex (Scrophulariaceae) inferred from ITS sequences. New Zealand Journal of Botany 36: 425-437.

. 2000. patterns of diversification in Chionohebe and Parahebe (Scrophulariaceae) inferred from ITS sequences. New Zealand Journal of Botany 38: 389-407.

WAgstafF, S. J., I. BReITwIESER, AND U. SWENSON. 2006. Origin and relationships of the austral genus Abrotanella (Asteraceae) inferred from DNA sequences. Taxon 55: 95106.

WagstafF, S. J., B. P. J. Molloy, AND J. A. TATE. 2010. Evolutionary significance of long-distance dispersal and hybridisation in the New Zealand endemic genus Hoheria (Malvaceae). Australian Systematic Botany 23: 112-130.

WebB, C. J., AND M. J. A. SimPSON. 2001. seeds of New Zealand gymnosperms and dicotyledons. Manuka Press, Christchurch.

White, T. J., T. BRUNS, S. LEE, AND J. TAYLOR. 1990. Amplification and direct sequencing of fungal ribosomal RNA genes for phylogenetics. In M. Innis, C. Gelfand, J. Sninsky, and T. White [eds.], PCR protocols: a guide to methods and applications, 315-322. Academic Press, San Diego, CA.

WiKSTROM, N., AND K. M. PRYER. 2005. Incongruence between primary sequence data and the distribution of a mitochindrial atpl group II intron among ferns and horsetails. Molecular Phylogenetics and Evolution 36: 484-493.

Winkworth, R. C., A. W. Robertson, F. EHrendorfer, AND P. J. LOCKHART. 1999. The importance of dispersal and recent speciation in the flora of New Zealand. Journal of Biogeography 26: 1323-1325.

Winkworth, R. C., J. GraU, A. W. ROBERTSOn, AND P. J. LOCKHART. 2002a. The origins and evolution of the genus Myosotis L. (Boranginaceae). Molecular Phylogenetics and Evolution 24: 180-193.

Winkworth, R. C., S. J. Wagstaff, D. Glenny, AND P. J. Lockhart. 2002b. Plant dispersal N.E.W.S from New Zealand. Trends in Ecology and Evolution 17: 514-520.

Zimmer, E.A., E.H. RoAlson, L.E. SKOG, J.K. BogGan AND A. IDNURM. 2002. Phylogenetic relationships in the Gesnerioideae (Gesneriaceae) based on nrDNA ITS and cpDNA trnL-F and trnE-T spacer region sequences. American Journal of Botany 89: 296-311. 
CHAPTER FOUR

\section{Chapter 4.4}

\section{Summary}

Contrasting to earlier assumptions, only one dehiscence type can be found across all Colobanthus species. Slight differences from species to species are the size of cells and number of valves, but in general, all species are capable of opening upon wetting by using a combination of imbibition and cohesion mechanism in the capsule wall. Unlike most hygrochastic capsules, which are closed when dry, most Colobanthus species are partly open due to splits between the valves of the capsules.

Some species can be found in alpine habitats, along water currents and in coastal areas, where splash water as a dispersal agent is readily available. However, some South American species grow on the plains of Patagonia, where rain is scarce. Here, heavy winds can probably contribute to the dispersal of the seeds by shaking the entire plant and seeds escaping through the small slits between the valves.

A molecular approach was taken to investigate the phylogeny of Colobanthus. Due to very little variation in the tested genetic markers, the phylogeny remains unresolved. This is probably due to very recent speciation. Since no noticeable genetic differences could be found between South American, subantarctic and New Zealand species, long-distance dispersal between those locations might be a possible explanation for the close interspecific relationships. However, in Chapter 4.2 I established that all Colobanthus species are hygrochastic, which implies short distance dispersal as the primary dispersal strategy (see also Chapter Three). Although the occurrence of the same specific dehiscence mechanism in all species supports the recent speciation hypothesis, it appears to contradict the long-distance dispersal theory. However, most Colobanthus capsules stay slightly open once they are ripe, which might allow very strong winds to blow seeds out of the capsules and disperse them over wider 
distances. The capsules themselves are quite fragile since they do not contain any lignin and could be destroyed easily, which might also release seeds independently from water drops.

Further research is warranted to investigate the chance events that allow seeds of hygrochastic species to be dispersed over long-distances and colonize new habitats. Colobanthus might be an extreme example of possibly several recent long-distance dispersal events across the southern hemisphere.

Incidental to the main aims of this chapter, phylogenetic analysis suggests species limits in Colobanthus might be too narrowly delineated. Molecular methods that are more sensitive and a wider sampling of Sagina are recommended as approaches to taxonomic questions raised here. 


\section{CHAPTER FIVE}

\section{Capsule Dehiscence Types in Oenothera (Onagraceae)}

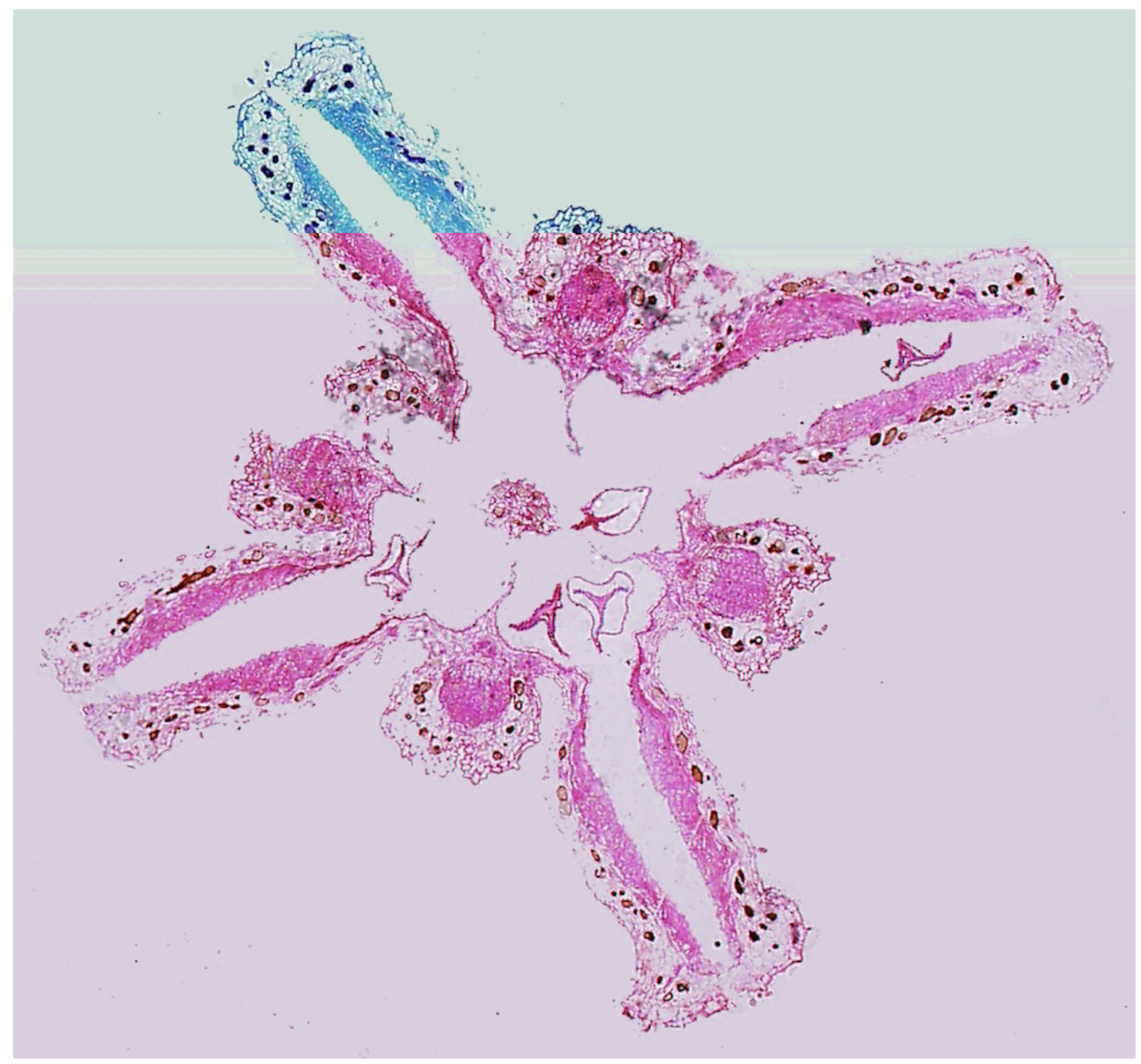

FIG 5.1 Micrograph of cross section through an Oneothera speciosa capsule, stained with Toluidine Blue at $4 \mathrm{x}$ magnification. 


\subsection{Abstract}

Oenothera is a species-rich genus and best known for its showy flowers that open in the evening, hence the common name evening primrose. However, fruits in this genus prove to be just as fascinating, with the capsule exhibiting a range of dehiscence mechanisms, such as xerochasy and hygrochasy. Hygrochastic capsules stay closed until they are moistened during rainfall and open in the form of a splashcup, whereas xerochastic opening occurs during drying out and is reversed when moistened. This phenomenon has been described in a small number of the 145 species of this genus, all of them in a subclade characterized by winged fruits. I investigate additional Oenothera species regarding their dehiscence type using observations of the opening and detailed anatomical study. Oenothera fruticosa, O. speciosa and O. perennis exhibit hygrochasy, whereas $O$. howardii is likely to have xerochastic capsules. Oenothera pallida, a 'ripening dehiscent' species, showed hygrochastic movement of the already dehisced fruit. In all investigated species, hygrochastic movement is achieved by directional swelling of the endocarp of the valves and the dorsal bundle together with the exocarp act as resistance tissue. This work extends the list of described hygrochastic and xerochastic Oenothera species to nine species and provides the base for further research on the connection between dispersal strategies, systematics and habitat type in several hygrochastic genera.

Keywords: capsule anatomy, hygrochasy, evening primrose, Oenothera, North America, rain dispersal 


\subsection{Introduction}

Oenothera is the second largest genus in the Onagraceae with 145 species in 18 sections (Wagner et al., 2007). The genus has a wide distribution across temperate and subtropical areas of North and South America with a few species in Central America. Habitats range from sea level up to $5000 \mathrm{~m}$ elevation. Plants can often be found in open or disturbed habitats. A number of species are invasive or naturalized in Europe, Asia, Australia and New Zealand (Webb et al., 1988; Thompson, 1990; Sun et al., 1992; Dhaliwal and Sharma, 1995; Deng et al., 2001; Hosking et al., 2003; Mihulka et al., 2006; Gfutte et al., 2007; Lambdon et al., 2008). The common name evening primrose alludes to the showy flowers opening mostly in the evening and rarely lasting for more than one day. The vespertine flowers are usually pollinated by hawkmoths, whereas diurnal flowers have various pollinators, such as bees, butterflies or hummingbirds (Wagner et al., 2007).

Seed anatomy and capsule morphology have been used with some success to divide the genus roughly into two lineages (Tobe et al., 1987) - lineage A is defined by radially enlarged endotestal cells and lineage B by angled or winged capsules. Molecular evidence more or less supports these two subclades with some differences (Levin et al., 2004). Poppendieck (1995) investigated dispersal strategies in some species of subclade B and found a shift to hygrochastic dispersal in some species and a shift to xerochastic dispersal in Oenothera macrocarpa, based on anatomical differences and capsule opening observations. Hygrochasy is a dehiscence mechanism where structures open when moistened and close again when they dry out (Fahn and Werker, 1972). Different plant structures such as bracts, sepals or even entire plants can be involved (Fahn and Werker, 1972; Gutterman, 1990, 1994; Hegazy et al., 2006) but hygrochasy is often restricted to the fruit itself, mostly a woody capsule 
(Garside and Lockyer, 1930; Ellner and Shmida, 1981; Van der Pijl, 1982; Ihlenfeldt, 1983; Thulin, 1987; Poppendieck, 1995; Parolin, 2006). Hygrochastic seed dispersal is generally known from plants in arid regions (Ellner and Shmida, 1981; Ihlenfeldt, 1983; Gutterman, 1990, 1994; Van Oudtshoorn and Van Rooyen, 1999) where it serves as a strategy to delay dispersal in time by restricting it to rainfalls. As part of ombrohydrochoric dispersal strategies, hygrochasy also results in atelechoric dispersal since raindrops transport the seeds only over a short distance (Ihlenfeldt, 1983; Hartmann, 1988; Gutterman, 1990; Parolin, 2001; Pufal and Garnock-Jones, 2010). Next to the well-known Aizoaceae, hygrochastic capsule dehiscence has also been reported in various other plant groups and habitats, such as herbs alongside streams in temperate climate (Nakanishi, 2002), Xylocalyx (Scrophulariaceae) in Somalia (Thulin, 1987) and alpine Veronica in New Zealand (Garnock-Jones, 1993; GarnockJones and Lloyd, 2004; Pufal et al., 2010).

Poppendieck's work on Oenothera is not the only report of hygrochasy in this genus. In a technical conservation assessment, Ladyman (2005) describes O. harringtonii as hygrochastic and Walck and Hidayati (2007) investigated the influence of the dehiscence type on seed dispersal in O. triloba (hygrochastic) and O. macrocarpa (xerochastic), both described by Poppendieck (1995). Of importance is also the discovery of hygrochasy in O. rosea by Brodie (1951). So far, capsule anatomy in hygrochastic Oenothera has only been described for three species in greater detail ( $O$. triloba, O. fruticosa ssp. glauca, O. rosea) and observations of hygrochasy have been made in two additional species (O. perennis, O. acaulis) (Poppendieck, 1995; Ladyman, 2005).

In this study I investigate the fruits of several species from subclade B as well as a comparative example belonging to sect. Anogra in subclade A regarding their 
dispersal mechanism. The aim is to identify and describe their opening mechanism using the methods successfully implemented by Poppendieck (1995). Poppendieck (1995) also proposed a sequence of increasing structural complexity in hygrochastic fruit of Oenothera and results from this work are compared with Poppendieck's findings. This study will provide the basis for further research on connections between dehiscence, dispersal mechanisms, distribution and systematics.

\subsection{Materials and methods}

Material for this study was collected at field sites in the northwestern USA and additional specimens were provided by K. N. Krakos and M. Johnson (St. Louis University) (Table 5.1). The state of the capsules (open/closed) was noted and capsules were then submerged in water. If opening or movement occurred, the time until completion of the movement was recorded. For some species only closed unripe capsule material was available, which was not suitable for this test. However, the opening mechanism of some of them has been described previously by Poppendieck (1995).

Dry capsules of all species were subjected to an ethanol series and embedded in epoxy resin (see Chapter 2.3 for details on this procedure). Capsules of $O$. howardii and O. macrocarpa were cut in half lengthwise due to their size and for O. pallida single valves were used instead of entire capsules. Sections of $2-4 \mu \mathrm{m}$ thickness were cut using a Leica Ultracut E ultratome and stained using toluidine blue (O'Brien et al., 1964), which stains cell walls. Micrographs were taken in order to describe the arrangement of swelling tissue and resistance tissue, both essential in the hygrochastic opening of capsules. Photographs of all ripe capsules were taken before and after wetting under a stereo microscope with a Panasonic G1 camera. 
Table 5.1 Origin of Oenothera capsules used in the study. The subclade according to Levin et al (2004) is indicated behind the species name.

\begin{tabular}{|c|c|c|c|c|}
\hline species & location & coordinates & collector & voucher \# \\
\hline O. flava (B) & $\begin{array}{l}\text { State Highway } 70 \text { near } \\
\text { Portola, California }\end{array}$ & $\begin{array}{l}\text { N 39³9'33.0" } \\
\text { W12921'29.5" }\end{array}$ & $\begin{array}{l}\text { Gesine Pufal, } \\
22 / 07 / 08\end{array}$ & WELTU20244 \\
\hline O. fruticosa (B) & $\begin{array}{l}\text { Durham Co, North } \\
\text { Carolina }\end{array}$ & & $\begin{array}{l}\text { Marc Johnson, } \\
27 / 06 / 07\end{array}$ & \\
\hline O. gaura (B) & $\begin{array}{l}\text { Belchertown, } \\
\text { Massachusetts }\end{array}$ & & $\begin{array}{l}\text { Kyra N. Krakos, } \\
09 / 09 / 07\end{array}$ & 07KK01 \\
\hline O. howardii (B) & $\begin{array}{l}\text { along State Highway } 12 \\
\text { near Red Canyon, Utah }\end{array}$ & $\begin{array}{l}\text { N } 37^{\circ} 44^{\prime} 29.7^{\prime \prime} \\
\text { W112 } 12^{\circ} 00.4^{\prime \prime}\end{array}$ & $\begin{array}{l}\text { Gesine Pufal, } \\
17 / 07 / 08\end{array}$ & WELTU20245 \\
\hline O. linifolia $(\mathrm{B})$ & $\begin{array}{l}\text { Nel's Homberg } \\
\text { property, Gray Summit, } \\
\text { MO }\end{array}$ & & $\begin{array}{l}\text { Kyra N. Krakos, } \\
25 / 06 / 08\end{array}$ & 08KK03 \\
\hline O. macrocarpa & $\begin{array}{l}\text { Shaw Nature Reserve, } \\
\text { Missouri }\end{array}$ & & $\begin{array}{l}\text { Kyra N. Krakos, } \\
20 / 06 / 08\end{array}$ & 08KK08 \\
\hline O. perennis (B) & $\begin{array}{l}\text { Great Meadows } \\
\text { National Forest, } \\
\text { Massachusetts }\end{array}$ & & $\begin{array}{l}\text { Kyra N. Krakos, } \\
07 / 07 / 08\end{array}$ & 08KK12 \\
\hline O. speciosa (B) & Payson, Arizona & $\begin{array}{l}\text { N 34 } 34^{\circ} 4^{\circ} 25.1^{\prime \prime} \\
\text { W } 111^{\circ} 19^{\prime} 05.4^{\prime \prime}\end{array}$ & $\begin{array}{l}\text { Gesine Pufal, } \\
14 / 07 / 08\end{array}$ & WELTU20246 \\
\hline O.pallida (A) & $\begin{array}{l}\text { Outside fence at north } \\
\text { entrance Petrified } \\
\text { Forest National Park, } \\
\text { Arizona }\end{array}$ & $\begin{array}{l}\text { N } 35^{\circ} 03^{\prime} 40.3^{\prime \prime} \\
\text { W 109 } 46 \text { '58.2" }\end{array}$ & $\begin{array}{l}\text { Gesine Pufal, } \\
15 / 07 / 08\end{array}$ & WELTU20247 \\
\hline
\end{tabular}

\subsection{Results}

Capsules were available for nine species, although five of them (O. howardii, $O$. gaura, O. macrocarpa, O. pallida and $O$. flava) were still unripe and tissues were partly not fully developed (e.g. dorsal bundle not differentiated). Oenothera macrocarpa has been described previously by Poppendieck (1995) and is here used as reference in comparison with $O$. howardii. In $O$. gaura and $O$. flava the development of tissues was not completed and they are therefore not used in the analysis of micrographs. In the remaining five Oenothera species opening was observed in $O$. fruticosa, O. linifolia and $O$. perennis and in some $O$. speciosa capsules, which were already slightly open when received (Table 5.2). Capsules of $O$. pallida were unripe 
when collected and split slightly during storage in silica gel. Here, valves moved outward further when submerged in water.

Table 5.2 State of Oenothera capsules before and after wetting. If opening occurred the time was noted. Given is the mean opening time for the number of capsules tested.

\begin{tabular}{||lllll||}
\hline species & before wetting & after wetting & time & \# caps. \\
\hline O. flava & unripe & NA & NA & 10 \\
O. fruticosa & top closed, splits between valves & splash cup & 3 min & 11 \\
O. gaura & unripe & NA & NA & 10 \\
O. howardii & unripe & NA & NA & 5 \\
O. linifolia & closed & splash cup & 2 min & 11 \\
O. macrocarpa & unripe & NA & NA & 7 \\
O. pallida & unripe, valves slightly split open & Further opening & 2 min & 6 \\
O. perennis & closed & splash cup & 4.5 min & 4 \\
O. speciosa & slightly open & splash cup & 5 min & 4 \\
\hline
\end{tabular}

Below, the arrangement of tissues in capsules is specified in six species and their role in the movement of the capsules is described.

\subsubsection{OENOTHERA LINIFOLIA (SECT. PENIOPHYLLUM)}

Plants of this species are slender erect herbs between 15 and $45 \mathrm{~cm}$ tall. The capsules are described as nearly obovoid, sessile, puberulent and sharply four-sided (Britton and Brown, 1970) (Fig. 5.2 A). The wings are the tips of valves folded backward and attached to each other. When dehiscing, the valves separated and the capsules split at the wings. Especially older fruit, which had been open before, opened quickly (Table 5.2) and displayed a very wide splash cup (Fig. 5.2 B). The swelling tissue is located at the inside of the capsule walls and consists of several cell layers (endoderm) (Fig. $5.3 \mathrm{~A})$. 


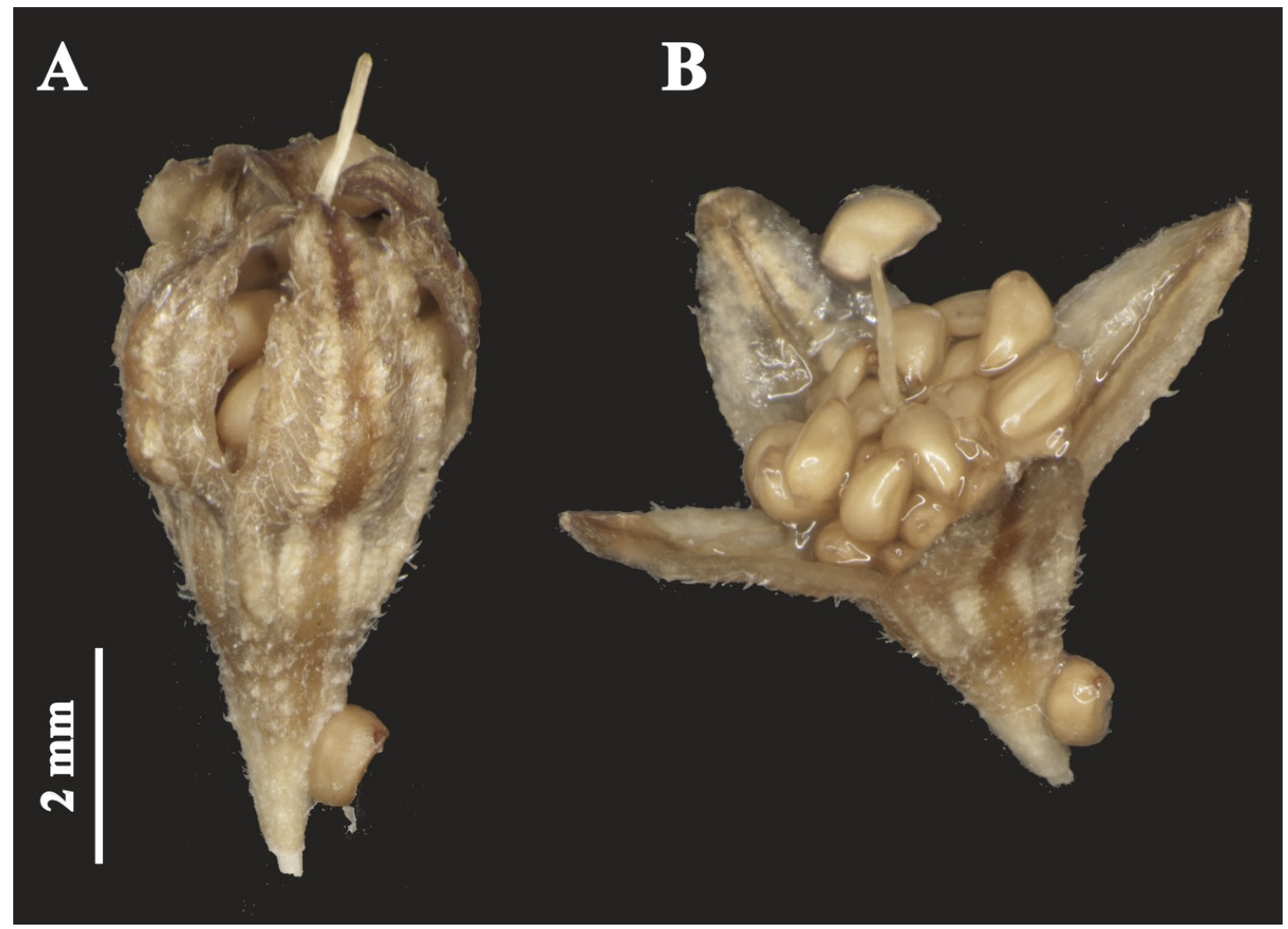

FIG 5.2 Dry (A) and wet (B) capsule of O. linifolia. Mucilage on the seeds exposed in the splash cup is visible.

The cells have considerably thickened cell walls compared to the cells in the dorsal bulge around the dorsal bundle (indicated by the strong staining with toluidine blue) (Fig. 5.3 A). After moistening the swelling tissue enlarges lengthwise leading to straightening of the valves and a subsequent split at the wings. Rigidity of the valve is given by the dorsal bulge, which, together with the outer capsule wall, acts as resistance tissue. This resistance forces the straightened valves to move backwards as a whole, resulting in a wide splash cup. Note that the dorsal bulge hardly 'bulges' at all, compared to other Oenothera species it is rather flat and the dorsal bundle is embedded in the valve. Another interesting feature is that the seeds develop mucilage immediately upon wetting. When dry, the mucilage acts like glue, keeping the seeds firmly in place. 


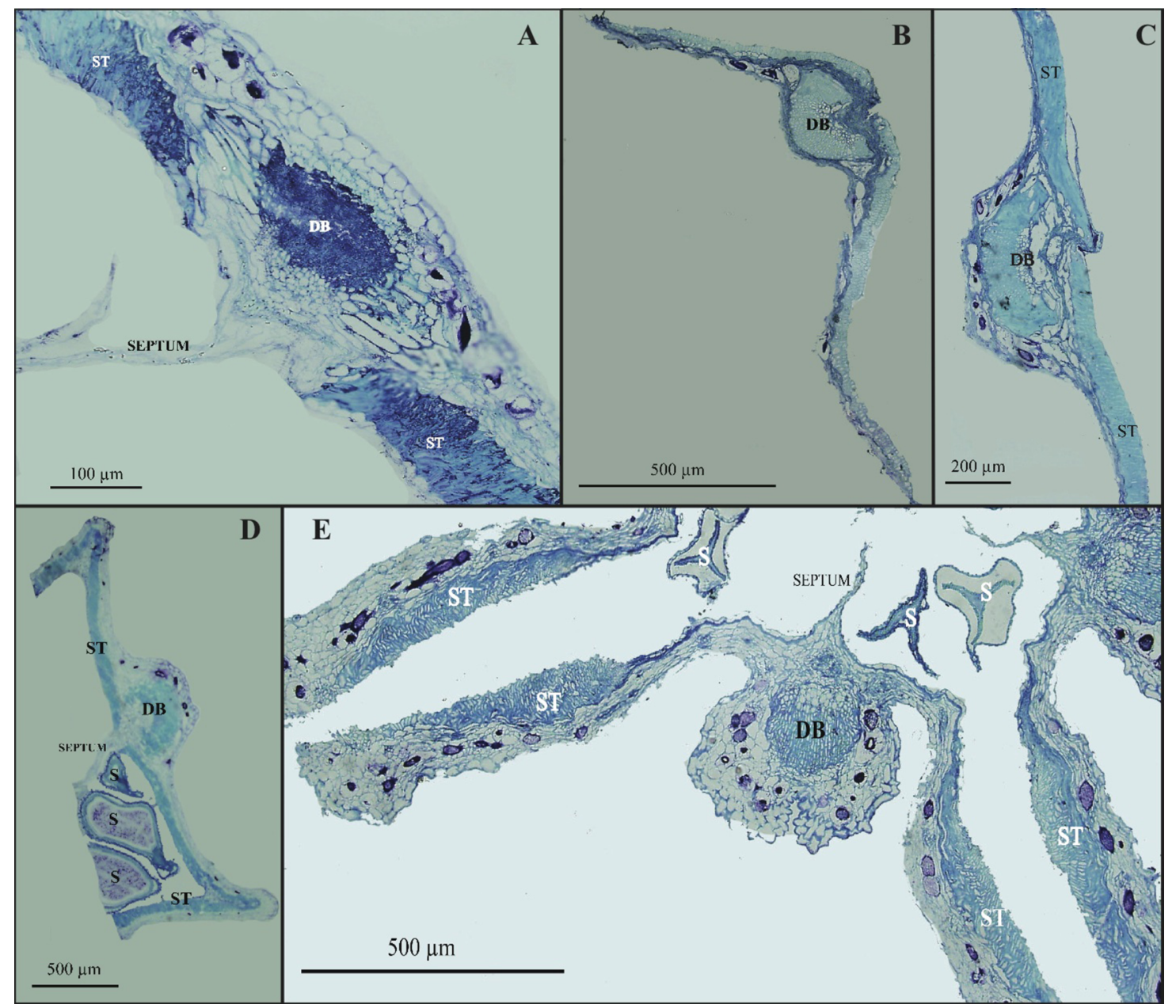

FIG 5.3 Micrographs cross-sections of Oenothera capsules, stained with toluidine blue. Species from subclade B are BOLD - (A) O. linifolia valve, (B) O. pallida valve, (C) $\boldsymbol{O}$. fruticosa valve, (D) O. perennis valve (still attached to neighbouring valves) and seeds, (E) O. speciosa two valves and seeds. DB - dorsal bundle, ST - swelling tissue, S - seed.

\subsubsection{OENOTHERA PERENNIS (SECT. KNEIFFIA)}

This perennial herb is 20 to $75 \mathrm{~cm}$ tall and only sparingly branched. Capsules are tetragonal or narrowly winged, approximately $5-10 \mathrm{~mm}$ long and $2-3 \mathrm{~mm}$ thick, tapering to a short stipe (Straley, 1977). In contrast to O. linifolia, the dorsal bulge is very dominant with a strongly developed dorsal bundle. The swelling tissue is located on the inside of the capsule wall and extends along the entire length of the valve. No swelling tissue can be found on the septum (Fig. 5.3 D). The hygrochastic mechanism in this species works similarly to what has been described in O. linifolia. The samples 
available were not fully ripe when processed (Fig. 5.4 A). The opening after wetting affects only the upper third of the capsules (Fig. 5.4 B) but might extend further in ripe capsules.

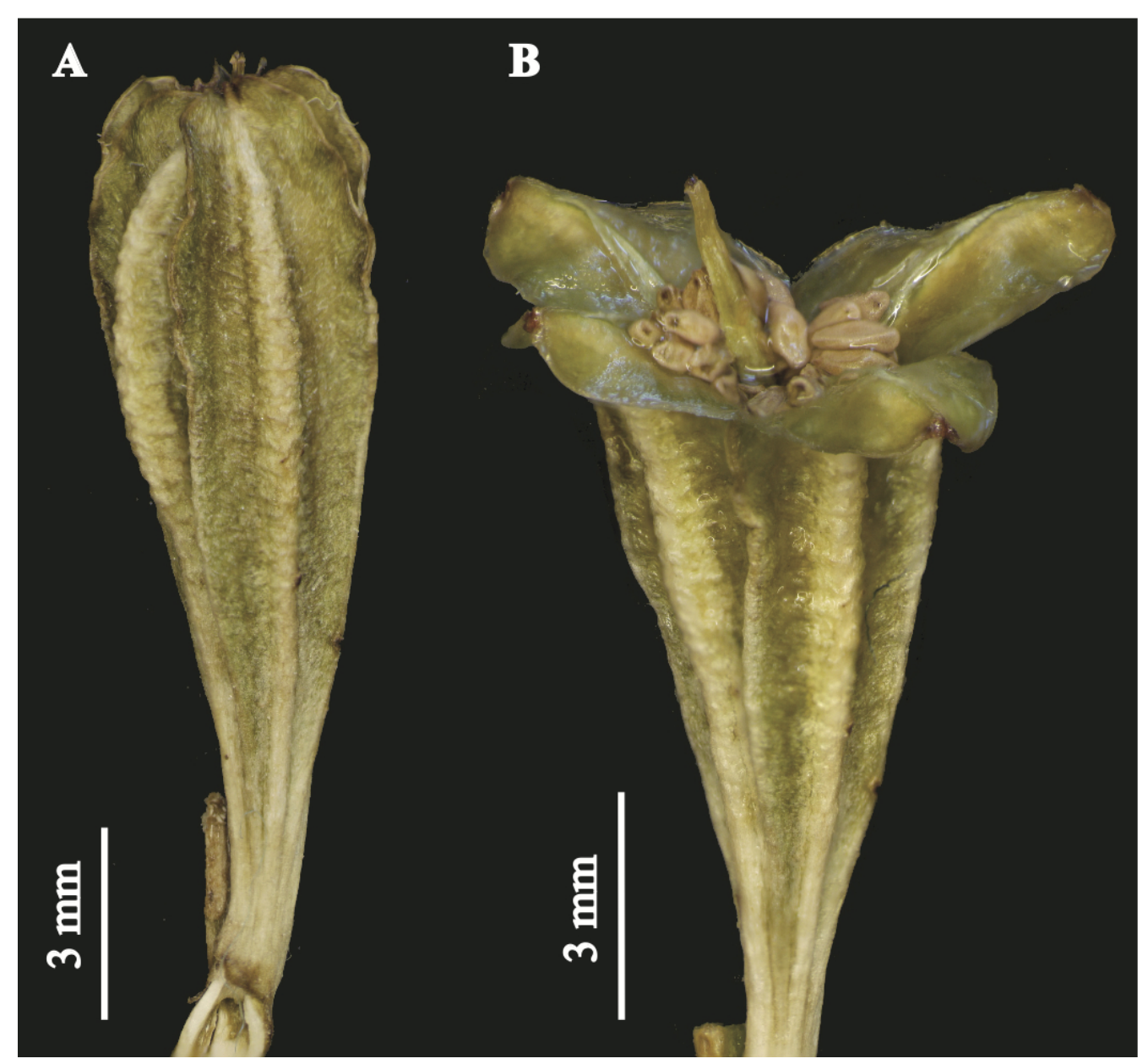

FIG 5.4 Dry capsule (A) of Oenothera perennis and same capsule after wetting (B) exposing seeds and placental column.

\subsubsection{OENOTHERA SPECIOSA (SECT. HARTMANNIA)}

Plants of this species are erect, ascending or decumbent perennials between 15 and 95 $\mathrm{cm}$ tall. The capsules are more or less clavate, strongly four-ribbed and four-winged and sit on a short pedicel (Britton and Brown, 1970). Here, the swelling tissue does not cover the entire inside of the valve; rather, when viewed in transverse sections, it is very prominent in the middle with several cell layers and disappears towards the 
end of the valve (Fig. 5.3 E). The dorsal bulge is extremely thick, which is additionally accentuated by the thinness of the valve around the dorsal bulge (Fig. 5.3 E). In dry conditions the valves are bent backwards, which causes the very prominent wings of the capsule. Of the material available the capsules closest to ripening did not open. However, some unripe capsules that dried in the silica gel opened slightly during the drying process (Fig. 5.5 A). After wetting, the four valves of those capsules opened in a splash cup in the upper third of the capsule (Fig. 5.5 B). Since the valves are bent back in dry conditions, the stretching of the swelling tissue after wetting leads to forward motion of the valves, basically unfolding the wings and straightening the valves. The dorsal bundle and the cells surrounding it act as resistance tissue and the valves stretch and open into a splash cup.

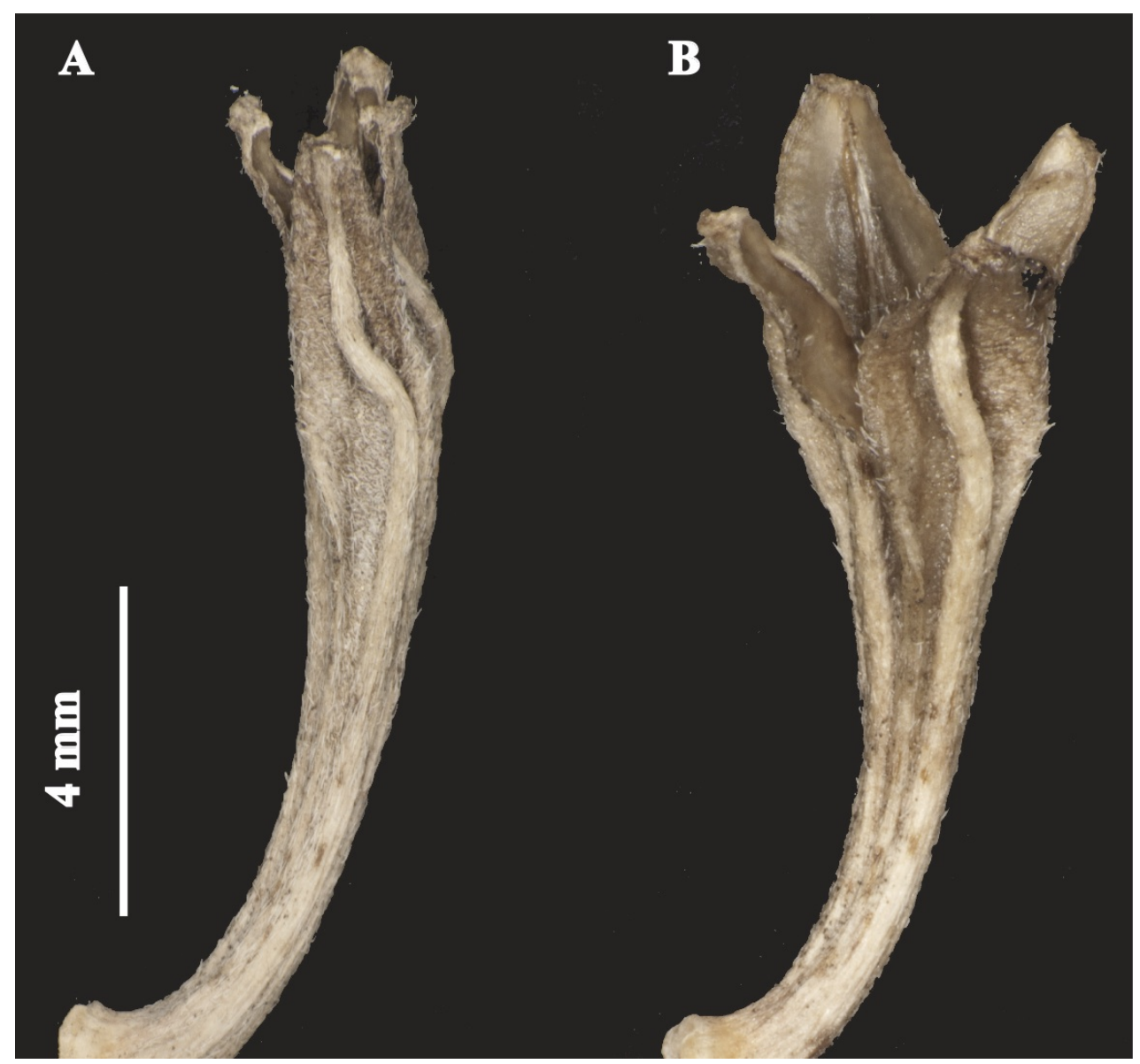

FIG 5.5 Dry capsule (A) of Oenothera speciosa and same capsule after wetting (B). 


\subsubsection{OENOTHERA FRUTICOSA (SECT. KNEIFFIA)}

This erect and branched herb is about 30 to $95 \mathrm{~cm}$ tall and pubescent. Capsules are sessile or sit on very short pedicels, oblong and prominently winged (Britton and Brown, 1970) (Fig. 5.6 A). Poppendieck (1995) sectioned O. fruticosa subsp. glauca 'Highlight" and found swelling tissue only at the inner wall of the capsule, which can also be confirmed for wild material of $O$. fruticosa. In contrast to O. speciosa but similar to O. linifolia and O. perennis, the swelling tissue occupies the entire length of the inner valve, resulting in a very wide stretch of the valve (Fig $5.3 \mathrm{C}$ ). The dorsal bulge is prominent but not as much as in O. speciosa. Poppendieck (1995) noted that the capsules did not open widely in O. fruticosa subsp. glauca 'Highlight' but in wild O. fruticosa a wide splash cup is formed with the valve splitting more than halfway down the capsule (Fig 5.6 B).

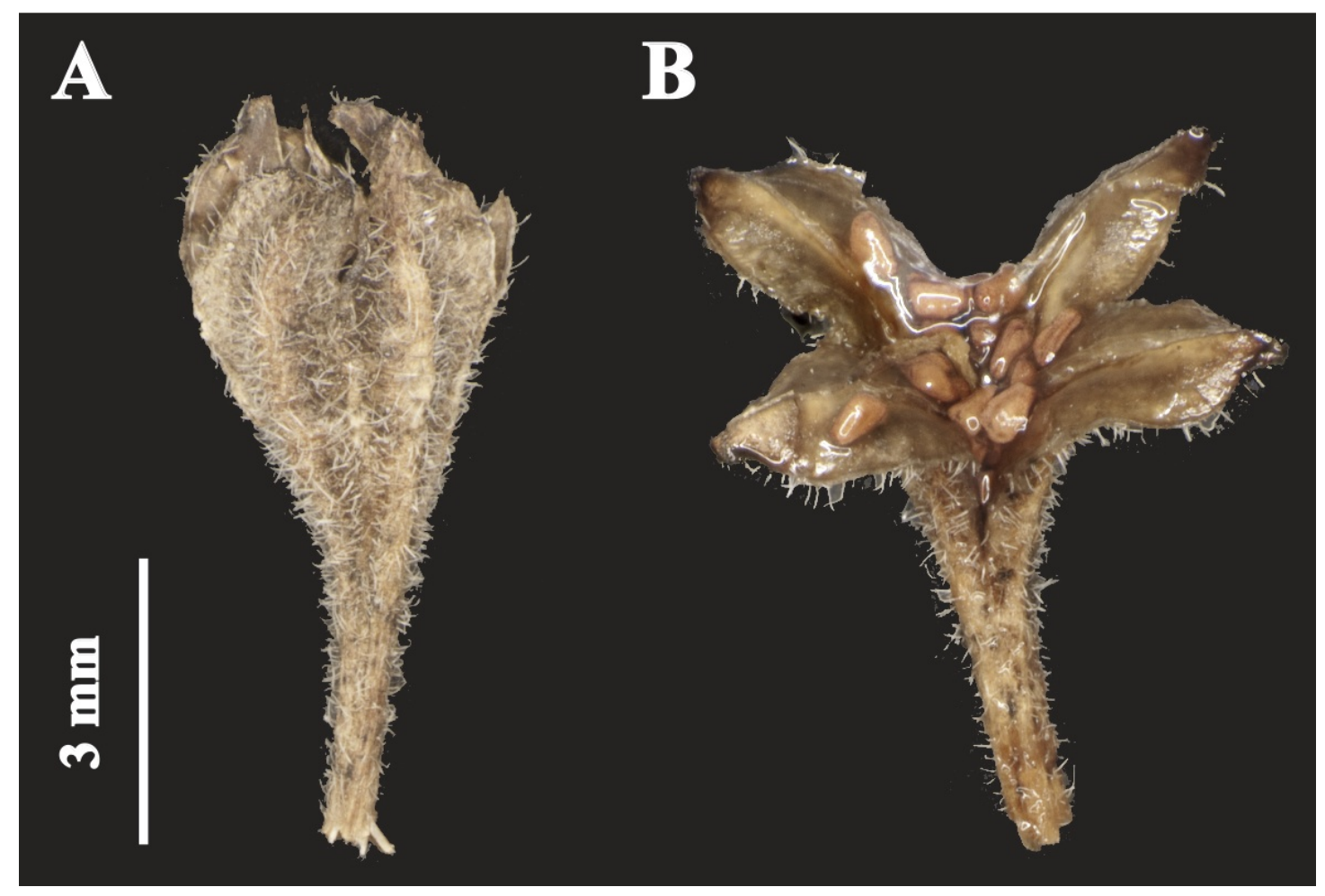

FIG 5.6 Dry capsule (A) of Oenothera fruticosa and same capsule after wetting (B), exposing seeds and the collapsed placental column. 


\section{CHAPTER FIVE}

\subsubsection{OENOTHERA PALLIDA (SECT. ANOGRA)}

This species represents the only sample from subclade A (Tobe et al., 1987; Levin et al., 2004). Plants are perennial herbs without basal rosettes of leaves and their fruits are sessile, linear capsules (Taylor, 1998; Wagner et al., 2007). Ripe fruits are pale brown in colour and dehisce during the ripening process about half the length of the capsule and seeds can fall out. Specimens in this study were still unripe but slight splits were visible after drying in silica gel (Fig. 5.7 A). However, an opening of the valves after wetting was observed (Fig. $5.7 \mathrm{~B}$ ). The micrograph shows a prominent dorsal bundle not unlike $O$. perennis (Fig. $5.3 \mathrm{~B}$ ) and the valves are bent back substantially in dry conditions, leading to the split of the capsule. The endocarp in the micrograph appears also very similar to the swelling tissue of species in the subclade $\mathrm{B}$ but the exocarp in the sample presented in Fig. 5.3 B is disintegrating. Oenothera pallida dehisces very similarly to $O$. biennis during ripening, which has been described by Ridley in great detail (1930). 


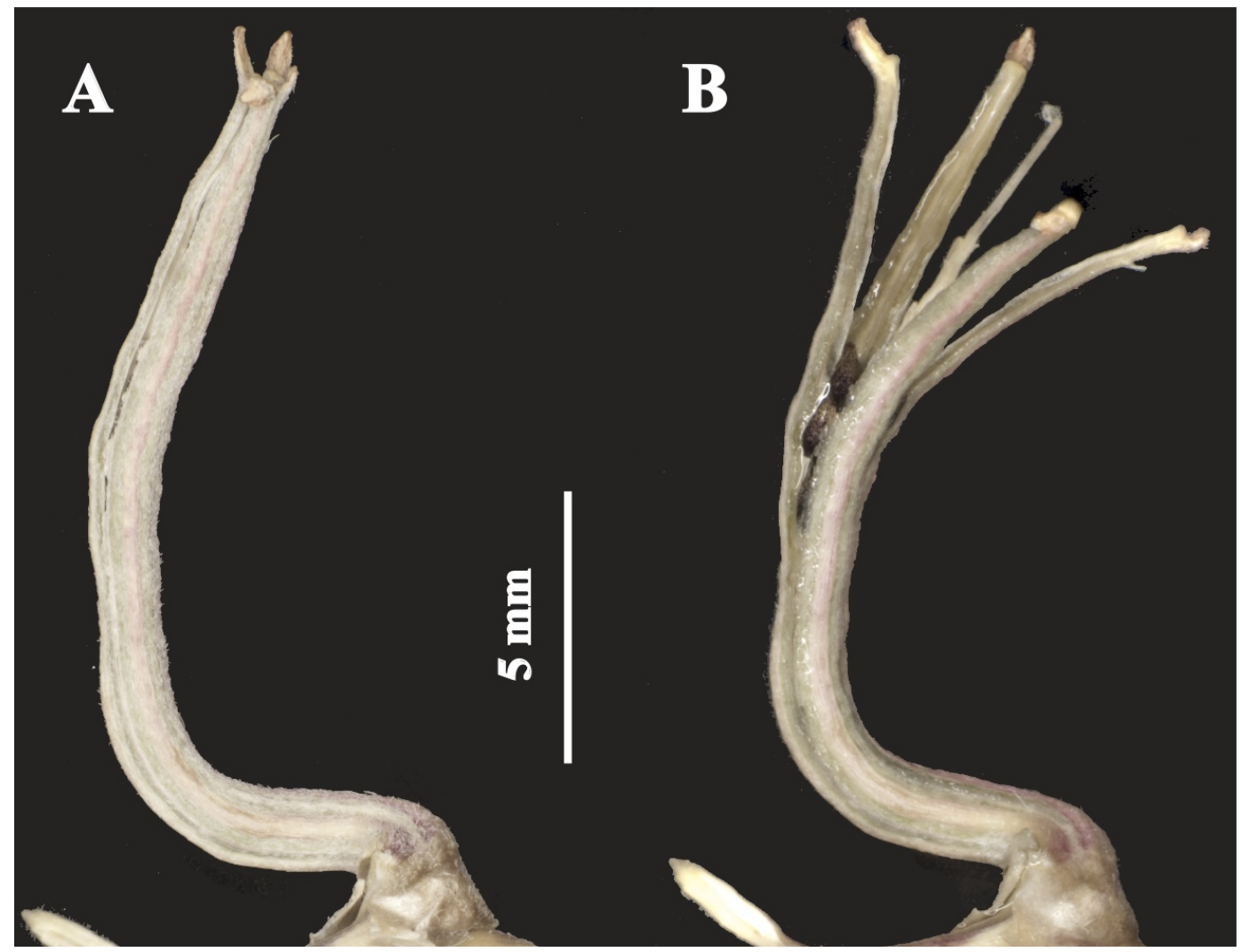

FIG 5.7 Unripe, dry capsule (A) of Oenothera pallida with splits between valves visible and same capsule after wetting (B), exposing seeds and placental column.

However, the valves curl back substantially when wetted but unlike the hygrochastic species from subclade $B$, the valves do not possess wings that bend back and form a splash cup. Rather, the bending of the valves away from the placental column leads to a deeper split of the capsule but due to the lanceolid shape of the capsule the deeper split does not result in a splash cup. This curling motion is probably due to the swelling capacity of the endocarp but since the exocarp disintegrates, a sufficient resistance tissue is absent. 


\section{CHAPTER FIVE}

\subsubsection{OENOTHERA HOWARDII (SECT. MEGAPTERIUM)}

This species is one of four species in sect. Megapterium and is described as a perennial herb with a branching caudex arising from a taproot (Wagner et al., 2007). Capsules are winged and appear quadrangular in cross-section.

Comparing cross-sections, Oenothera howardii is very similar to O. macrocarpa, which has been described as xerochastic (Poppendieck, 1995) (Fig. 5.8 A). It is therefore highly likely that $O$. howardii is xerochastic as well, given the systematic background.

According to Poppendieck (1995), O. macrocarpa opens when dry and closes when wet due to fibres at cross-angles in the wings (valves), which make the wings coil when dry. This leads to a widening of the capsule cavity. Additionally, the exocarp acts as swelling tissue and bulges outward when dry. The septum and the dorsal bulge have the function of resistance tissue. The collenchyma acting as swelling tissue can be seen in the micrograph of $O$. howardii (Fig. $5.8 \mathrm{~B}$ ), but in this section it has partly separated from the capsule wall. 


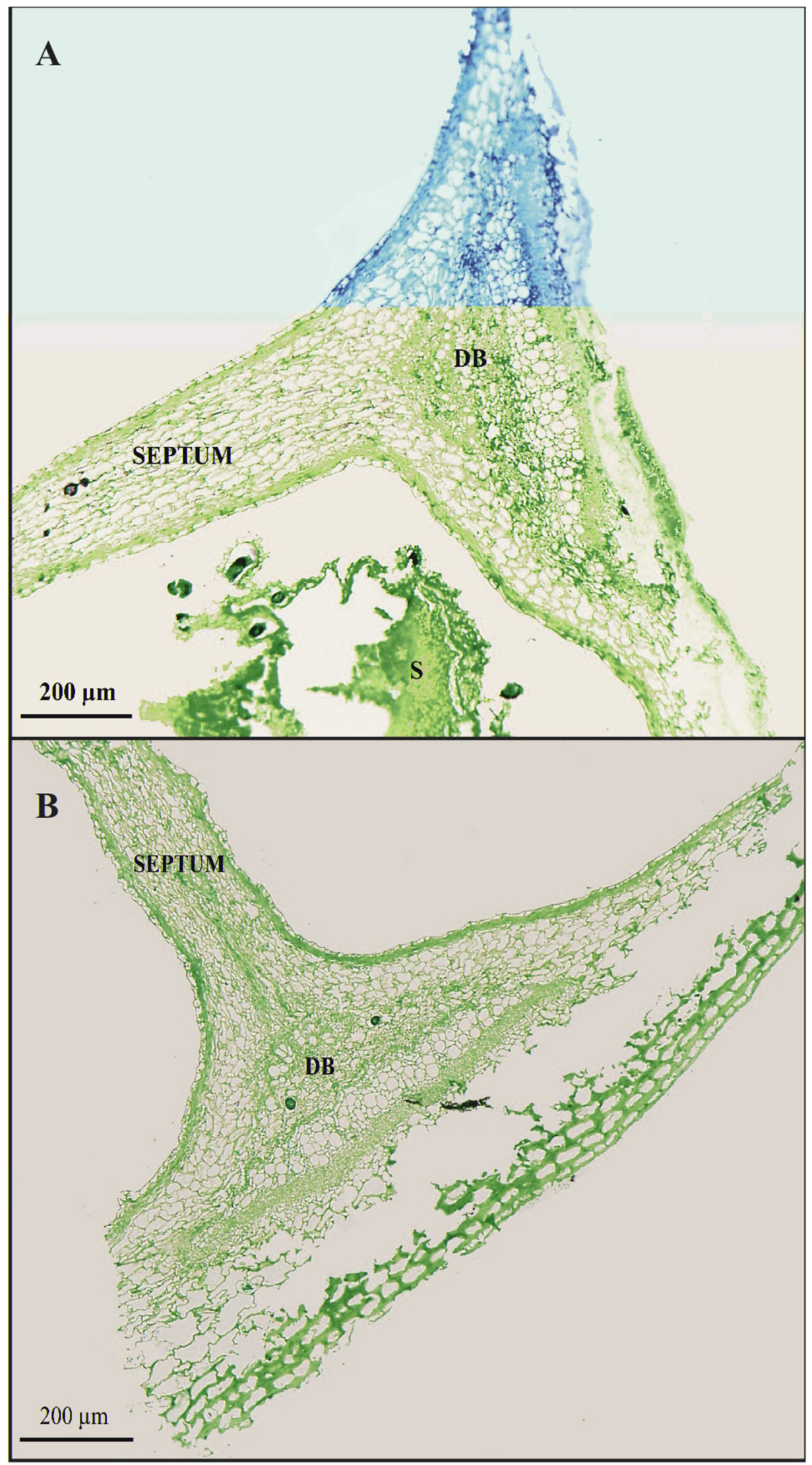

FIG 5.8 Micrographs of O. macrocarpa (A) and $O$. howardii (B) stained with Toluidine Blue. $\mathrm{S}=$ seed, $\mathrm{DB}=$ dorsal bundle. Magnification is $10 \mathrm{x}$. 
CHAPTER FIVE

\subsection{Discussion}

Additional to the observations on the dehiscence mechanisms in some Oenothera (Poppendieck, 1995), hygrochasy was observed and described in four more species and xerochasy in $O$. howardii is also strongly suspected. Previously, three sections within subclade B were known to include hygrochastic species (Poppendieck, 1995); with $O$. speciosa, the section Xylopleurom can also be recognized as including plants with hygrochastic capsules.

Like other hygrochastic woody capsules (Steinbrinck, 1883; Garside and Lockyer, 1930; Ihlenfeldt, 1978; Parolin, 2001; Pufal et al., 2010) the opening of hygrochastic Oenothera is caused by an imbibition mechanism depending on the interaction of swelling tissue and resistance tissue (Fahn and Werker, 1972). In every species tested, the dorsal bundle acts as resistance tissue whereas the endocarp of the valves (or wings) represents the swelling tissue, having thick cell walls capable of absorbing water. Xerochasy is also based on an imbibition mechanism, but in contrast to hygrochasy, the opening of the fruit occurs in dry conditions and closing commences with moistening (Fahn and Werker, 1972). Here, the swelling tissue is located in the exocarp of the capsule, resulting in an outward bulge as the exocarp shrinks in dry conditions and therefore a wider opening of the capsule (Poppendieck, 1995). Similar to hygrochastic Oenothera, the dorsal bulge fulfils the role of resistance tissue, but here, the septum is involved as well. Due to the position of the swelling tissue the movement occurs in the opposite direction compared to hygrochastic species.

Oenothera pallida represents the only species sampled from subclade A and has capsules that dehisce with ripening. Here, the exocarp disintegrates during ripening but the endocarp remains as capsule wall. As in hygrochastic species from subclade $\mathrm{B}$, the endocarp seems to be capable of absorbing water and during rainfall events this 
can lead to a further splitting of the already open capsule. However, this movement probably only occurs in capsules, that are already dehisced and therefore O. pallida is still classified as dehiscing during ripening ('ripening dehiscent').

Hygrochasy as part of ombrohydrochory is assumed to result in atelechoric dispersal strategies (Fahn and Werker, 1972; Ellner and Shmida, 1981; Ihlenfeldt, 1983; Gutterman, 1994; Poppendieck, 1995; Pufal and Garnock-Jones, 2010; Chapter 3.3), since raindrops transport the seeds only a short distance. On the other hand, xerochasy is viewed as a telechoric mechanism (Fahn and Werker, 1972) since a number of dispersal agents, such as wind and animals can carry the seeds over large distances. However, Walck and Hidayati (2007) describe the xerochastic capsules of $O$. macrocrapa as indirect ombrohydrochoric. Capsules close during rain but open fully when moisture decreases after rain whereas opening without previous rainfall was not as prominent.

As in Aizoaceae (Van Oudtshoorn and Van Rooyen, 1999), Poppendieck (1995) proposed a sequence of increasing structural complexity in Oenothera, but unlike in the Aizoaceae it is unclear whether this sequence adequately reflects the phylogeny of the genus. Nevertheless, the species investigated here can be arranged seamlessly within the proposed sequence. Thus, O. pallida represents terete capsules from subclade A, O. howardii is most likely a xerochastic species similar to O. macrocarpa and $O$. linifolia, $O$. perennis and $O$. fruticosa have simpler hygrochastic capsules with the swelling tissue covering the entire length of the valve. Lastly, O. speciosa has a more complex hygrochastic capsule with the swelling tissue only extending to parts of the valve.

Including the results of this study, Oenothera is now known to comprise at least eight hygrochastic species and two xerochastic species, all in subclade B (Wagner et al., 
2007). There is a high likelihood that more species in this subclade exhibit either of the investigated dehiscence types, especially species from the same section. Despite broadening the knowledge about hygrochastic Oenothera with this work, there are still many unresolved questions regarding this dispersal strategy. Poppendieck (1995) mentioned that interpreting hygrochasy as an atelechoric mechanism is justified in Oenothera but does not give an explanation for this statement. Based on previous studies (Ellner and Shmida, 1981; Ihlenfeldt, 1983; Gutterman, 1994; Pufal and Garnock-Jones, 2010; Chapter 3.3), I would predict that habitat characteristics of hygrochastic Oenothera play an important role in the evolution of hygrochasy. Additionally, the taxonomy of this genus will likely be of interest in investigating dehiscence mechanisms in greater detail, given the sequence of structural complexity (Poppendieck, 1995). The following chapter aims to address these questions by investigating whether the hypotheses developed for hygrochastic capsules in plants of arid and alpine regions also apply to Oenothera by using a multidisciplinary approach.

\subsection{References}

BRITTON, N. L., AND A. BROWN. 1970. An illustrated flora of the northern United States and Canada, Volume Two Amaranthaceae to Liganiaceae. Dover Publications, Inc., New York.

Brodie, H. J. 1951. The splash-cup dispersal mechanism in plants. Canadian Journal of Botany 29: 224-234.

DENG, Y.-C., H.-M. HUA, J. LI, AND P. LAPINSKAS. 2001. Studies on the cultivation and uses of evening primrose (Oenothera spp.) in China. Economic Botany 55: 83-92.

Dhaliwal, D. S., AND M. Sharma. 1995. Oenothera affinis Camb. (Onagraceae): A new record for India from Himalaya. Rheedea 5: 151-153.

ELLNER, S., AND A. SHMIDA. 1981. Why are adaptations for long-range seed dispersal rare in desert plants? Oecologia (Berlin) 51: 133-144.

FAHN, A., AND E. WERKER. 1972. Anatomical mechanisms of seed dispersal. In T. T. Kozlowski [ed.], Seed Biology. Academic Press, New York, USA.

GARNOCK-JONES, P. J. 1993. Phylogeny of the Hebe complex (Scrophulariaceae: Veroniceae). Australian Systematic Botany 6: 457-479.

GARNOCK-JONES, P. J., AND D. G. LlOYD. 2004. A taxonomic revision of Parahebe (Plantaginaceae) in New Zealand. New Zealand Journal of Botany 42: 181-232. 
GARSIDE, S., AND S. LOCKYER. 1930. Seed dispersal from the hygroscopic fruits of Mesembryanthemum carpanthea (Mesembryanthemum) pomeridiana, N. E. Br. Annals of Botany 44: 639-U636.

Gfutte, P., M. BReitfeld, AND H. D. HorBach. 2007. Oenothera deflexa Gates - A evening primrose new for Bavaria. Berichte der Bayerischen Botanischen Gesellschaft zur Erforschung der Heimischen Flora 77: 201-203.

GUTTERMAN, Y. 1990. Seed dispersal by rain (ombrohydrochory) in some of the flowering desert plants in the deserts of Israel and the Sinai Peninsula. Mitteilungen aus dem Institut fuer Allgemeine Botanik Hamburg 22b: 841-852.

. 1994. Strategies of seed dispersal and germination in plants inhabiting deserts. Botanical Review 60: 373-425.

HaRtmann, H. E. K. 1988. Fruit types in Mesembryanthema. Beitraege zur Biologie der Pflanzen 63: 313-349.

Hegazy, A. K., H. N. BARAKAT, AND H. F. KABIEL. 2006. Anatomical significance of the hygrochastic movement in Anastatica hierochuntica. Annals of Botany 97: 47-55.

Hosking, J. R., B. J. CONN, AND B. J. LEPSCHI. 2003. Plant species first recognised as naturalised for New South Wales over the period 2000-2001. Cunninghamia 8: 175187.

IHLENFELDT, H.-D. 1978. Morphologie und Taxonomie der Gattung Oophytum N. E. BR. (Mesembryanthemaceae) Botanische Jahrbuecher 99: 303-328.

1983. Dispersal of Mesembryanthemaceae in arid habitats. Sonderbaende des Naturwissenschaftlichen Vereins Hamburg 7: 381-390.

Ladyman, J. A. R. 2005. Oenothera harringtonii Wagner, Stockhouse \& Klein (Colorado Springs evening-primrose): A technical conservation assessment. In R. M. R. USDA Forest Service, Species Conservation Project [ed.], 1-43.

Lambdon, P. W., P. Pysek, C. Basnou, M. Hejda, M. Arianoutsou, F. Essl, V. Jarosik, J. Pergl, M. Winter, P. Anastasiu, P. Andriopoulos, I. Bazos, G. Brundu, L. Celesti-Grapow, P. Chassot, P. Delipetrou, M. Josefsson, S. Kark, S. Klotz, Y. Kokkoris, I. Kuehn, H. Marchante, I. Perglova, J. Pino, M. VILA, A. ZIKOS, D. ROY, AND P. E. HULME. 2008. Alien flora of Europe: species diversity, temporal trends, geographical patterns and research needs. Preslia (Prague) 80: 101-149.

Levin, R. A., W. L. Wagner, P. C. Hoch, W. J. Hahn, A. Rodriguez, D. A. Baum, L. KATINAS, E. A. ZIMMER, AND K. J. SYTSMA. 2004. Paraphyly in Tribe Onagreae: Insights into phylogenetic relationships of Onagraceae based on nuclear and chloroplast sequence data. Systematic Botany 29: 147-164.

MinulKa, S., P. PYSEK, J. MARTINKOVA, AND V. JAROSIK. 2006. Invasiveness of Oenothera congeners alien to Europe: Jack of all trades, master of invasion? Perspectives in Plant Ecology Evolution and Systematics 8: 83-96.

NAKANISHI, H. 2002. Splash seed dispersal by raindrops. Ecological Research 17: 663-671.

O'Brien, T. P. O., N. FEDER, AND M. E. MCCulLy. 1964. Polychromatic staining of plant cell walls by toluidine blue O. Protoplasma 59: 367-373.

PAROLIN, P. 2001. Seed expulsion in fruits of Mesembryanthema (Aizoaceae): A mechanistic approach to study the effect of fruit morphological structures on seed dispersal. Flora (Jena) 196: 313-322.

. 2006. Ombrohydrochory: Rain-operated seed dispersal in plants - With special regard to jet-action dispersal in Aizoaceae. Flora (Jena) 201: 511-518.

POPPENDIECK, H.-H. 1995. Hygrochastic capsules in Oenothera (Onagraceae). Mitteilungen aus dem Institut fuer Allgemeine Botanik Hamburg 25: 99-115.

PUFAL, G., K.G. RYAN AND P. GARNOCK-JONES. 2010. Hygrochastic capsule dehiscence in New Zealand alpine Veronica (Plantaginaceae). American Journal of Botany 97: 1413-1423

PUFAL AND P. GARNOCK-JONES. 2010. Hygrochastic capsule dehiscence supports safe site strategies in New Zealand alpine Veronica (Plantaginaceae). Annals of Botany 106: 405-412 
STEINBRINCK, C. 1883. Ueber einige Fruchtgehaeuse, die ihre Samen infolge von Benetzung freilegen. Berichte der Deutschen Botanischen Gesellschaft 1: 339-347.

StRALey, G.B. 1977. Systematics of Oenothera sect. Kneiffia (Onagraceae). Annals of the Missouri Botanical Garden 64: 381-424

Sun, B. Y., C. H. KIM, AND T. J. KIM. 1992. Naturalized weeds and new location of plants to Korean flora. Korean Journal of Plant Taxonomy 22: 235-240.

TAYlOR, R. J. 1998. Desert wildflowers of North America. Mountain Press Publishing Company, Missoula, Montana.

ThOMPSON, J. 1990. Onagraceae, Bureau of Flora and Fauna, Canberra. Flora of Australia, Vol. 18. Podostemaceae to Combretaceae. Xvi+349p. Australian Government Publishing Service: Canberra, Australian Capital Territory, Australia. Illus. Maps. Paper, 215-243.

Thulin, M. 1987. A new species of Xylocalyx (Scrophulariaceae) from Somalia. Nordic Journal of Botany 7: 267-269.

ToBe, H., W. L. WAGNER, AND H.-C. CHIN. 1987. A systematic and evolutionary study of Oenothera (Onagraceae): Seed coat anatomy. Botanical Gazette 148: 235-257.

VAN DER PIJL, L. 1982. Principles of dispersal in higher plants. Springer-Verlag, Berlin, Germany.

VAN OUdTSHOORn, R. K., AND M. W. VAN ROOYEN. 1999. Dispersal biology of desert plants. Springer-Verlag, Berlin, Germany.

Wagner, W. L., P. C. Hoch, AND P. H. Raven. 2007. Revised Classification of the Onagraceae. Systematic Botany Monographs 83: 1-240.

WALCK, J. L., AND S. N. HiDAYATI. 2007. Ombrohydrochory and its relationship to seed dispersal and germination strategies in two temperate North American Oenothera species (Onagraceae). International Journal of Plant Sciences 168: 1279-1290.

WebB, C.J., SYKeS, W.R. AND P. GARNOCK-JONES. 1988. Flora of New Zealand: Naturalized Pteridophytes, Gymnosperms, Dicotyledons. Government Printer, Wellington, New Zealand 


\section{CHAPTER SIX}

Are Hypotheses for Hygrochasy in Plants of Arid Regions

also Applicable for Unrelated Genera in Different Habitats?

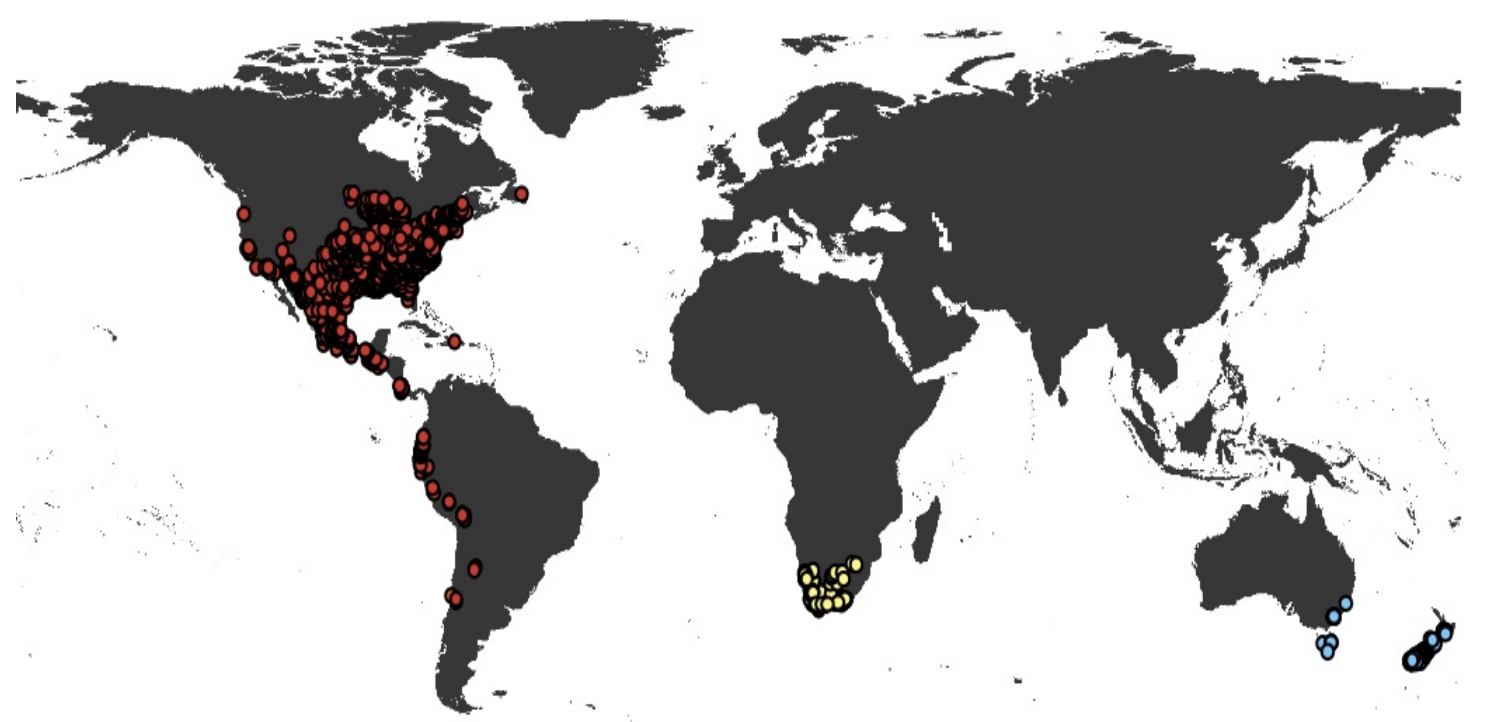

FIG 6.1 Worldwide distribution of hygrochastic Veronica (blue dots), Oenothera (red dots) and Aizoaceae (yellow dots). 


\subsection{Abstract}

Hygrochasy, the opening of capsules in response to moisture and the subsequent dispersal of seeds by raindrops from the open splash cup (ombrohydrochory) has evolved in several unrelated genera in very different habitats.

The main theories for this dispersal strategy commonly associated with plants in arid environments are that (1) hygrochasy restricts dispersal spatially to the suitable parent habitat in a harsh environment and (2) it also restricts dispersal temporally to times when rainfall is sufficient for seed germination and seedling establishment. In this study I investigate whether hypotheses postulated for hygrochasy in arid areas are also applicable for hygrochastic Oenothera in North America. At least seven species of Oenothera in one subclade of the genus are hygrochastic. They have different life and growth forms and occur in a wide range of habitats across North America, some of them extend into Central and South America.

I tested the application of known hypotheses for hygrochasy in Oenothera by using various methods such as laboratory dispersal experiments, cluster analysis of morphological data, analysis of environmental and distribution data as well as character evolution. Examples of hygrochastic Aizoaceae and Veronica are used in comparison, since the hypotheses have been successfully implemented for those species.

Analysis revealed that none of the proposed hypotheses applies for present day hygrochastic Oenothera. However, it is highly likely that hygrochasy evolved only once in the genus. The hygrochastic species possibly evolved as part of the MadroTertiary flora, when the temporal restriction hypothesis might have played an important role in response to dry, highly seasonal climate with unpredictable rainfall. The time since then to present date was sufficient for the species to spread across the 
continent, since they do not seem to have specialized ecological niches. Therefore, hygrochasy seems to be an ancient relict, that is still present in most species of one Oenothera subclade, but in others a shift to xerochasy or indehiscent capsules took place.

Key words: Aizoaceae, alpine, arid, character evolution, dispersal, hygrochasy, Madro-Tertiary flora, North America, Oenothera, splash cup, Veronica

\subsection{Introduction}

Hygrochasy is defined as the opening of a structure in response to moisture and its closing on drying (Fahn and Werker, 1972). It can be found in a variety of plant parts, such as parts of the inflorescence (Fahn and Werker, 1972; Gutterman, 1990, 1994; Gutterman and Ginott, 1994), or branches, leading to hygrochastic movement of the entire plant (Hegazy et al., 2006). Most commonly, hygrochasy can be found as a specialized dehiscence mechanism in woody dehiscent capsules (Garside and Lockyer, 1930; Ellner and Shmida, 1981; Van der Pij1, 1982; Ihlenfeldt, 1983; Thulin, 1987; Gutterman, 1994; Poppendieck, 1995; Parolin, 2006). In contrast to most capsular fruits that dehisce during the ripening process, hygrochastic capsules stay closed until they are wetted sufficiently. Opening results in a so-called splash cup, which exposes the seeds to falling raindrops. These subsequently disperse the seeds by splashing them out (ombrohydrochry) (Brodie, 1951; Van der Pijl, 1982; Nakanishi, 2002; Parolin, 2006).

The opening of hygrochastic capsules is usually based on an imbibition mechanism, where two antagonistic tissues interact with each other. A swelling tissue is capable of absorbing water and increasing considerably in size (usually in one direction), 
whereas the resistance tissue is unable to swell and instead directs the movement of the increase of the swelling tissue. In most fruits, two different tissues are involved but cases of swelling and resistance happening in opposite cell walls of the same cells are also known (Fahn and Werker, 1972). However, a combination of imbibition and cohesion mechanisms can also be found in hygrochastic capsules of Colobanthus (Caryophyllaceae) (see Chapter four).

In the Aizoaceae in southern Africa more than $98 \%$ of the species are hygrochastic with a multitude of different capsule morphologies (Garside and Lockyer, 1930; Ihlenfeldt, 1983; Van Rooyen, 1990; Van Oudtshoorn and Van Rooyen, 1999; Parolin, 2001, 2006). Hygrochastic capsules are generally woody and contain several locules, depending on the species. Species in the core Ruschioideae also exhibit special features such as covering membranes or closing bodies, which retain seeds in the capsule over several rainfalls and also allow for slightly further dispersal distances (Parolin, 2001; Klak et al., 2004). The specialisation and increasing complexity reflects the phylogeny of the family, with the species-poor Mesembryanthemeae having simpler capsules, whereas Ruschioideae show more complex structures (Van Oudtshoorn and Van Rooyen, 1999; Klak et al., 2004).

Other examples of plants in arid areas include some Xylocalyx species in Somalia (Thulin, 1987), and desert plants in the Middle Eastern flora (Zohary and Fahn, 1941; Ellner and Shmida, 1981; Gutterman, 1990, 1994).

Poppendieck (1995) investigated hygrochastic capsules in some Oenothera of North American origin and Ladyman (2005) reported an additional Oenothera species from the US as hygrochastic. Oenothera is a species rich genus and in recent years the phylogeny has been changed and updated several times (Tobe, et al., 1987; Levin et al., 2004; Wagner, 2005; Wagner et al., 2007). Hygrochastic species are placed in 
subclade B of Oenothera, which is characterized by angled or winged fruits (Tobe et al., 1987). They occur across North America well into South America in varying habitats.

In hygrochastic Oenothera, the swelling tissue consists of cells in the endocarp with thickened cell walls capable of swelling (Poppendieck, 1995; see also Chapter Five). Poppendieck (1995) also observed that in O. triloba the septum contributed to the swelling tissue as well. The role of resistance tissue is fulfilled by the lignified vascular bundle of the dorsal bulge and sometimes the outside of the valves. All Oenothera open to form a splash cup but seeds might be stacked differently, leading to seed retention in some species (Poppendieck, 1995).

Veronica in alpine New Zealand (Garnock-Jones, 1993; Garnock-Jones and Lloyd, 2004; Meudt, 2008) with a cushion or subshrub habit and solitary capsules exhibit hygrochasy, which I investigated in regards to their anatomy and biomechanics (Pufal et al., in press). Capsules vary in size, but they are all narrowly angustiseptate. In all investigated species, the endocarp in the septum acts as swelling tissue, having elongated cylindrical cells with an enlarged cell wall capable of absorbing water. The resistance tissue is the endocarp of the valves and has lignified, thickened cell walls (Pufal et al., 2010).

Not surprisingly, hypotheses for the evolution of hygrochastic capsule dehiscence stem from work with species in arid habitats Table 6.1. In the following paragraphs I will introduce these hypotheses; additionally, an overview can be found in Table 6.1.

\section{Temporal Restriction Hypothesis}

Hygrochastic capsules stay closed until they are sufficiently wetted. Therefore, dispersal is restricted to rain events, which is essentially a restriction in time and guarantees favourable germination conditions at time of dispersal (Fahn and Werker, 
1972; Ellner and Shmida, 1981; Van der Pijl, 1982; Ihlenfeldt, 1983; Van Oudtshoorn and Van Rooyen, 1999; Parolin, 2006), especially in regions where rainfall events are rare and unpredictable.

\section{Spreading Dispersal Hypothesis}

The 'temporal restriction hypothesis' can also be specified - most Aizoaceae (core Ruschioidae (Klak et al., 2004)) possess specialized structures that retain seeds in the capsules over several rainfall events and only release a small percentage of seeds with single rainfalls (Parolin, 2001). This enables seed release over time, therefore spreading the risk at germination over time as well (Van Rooyen et al., 1980; Van Oudtshoorn and Van Rooyen, 1999; Parolin, 2001; Klak et al., 2004; Burke, 2005).

\section{Spatial Restriction Hypothesis and Safe Site Hypothesis}

Hygrochastic capsules form a splash cup when wetted by rain and raindrops act as the predominant dispersal agent. Dispersal by raindrops results in very short dispersal distances for seed, which results in spatial restriction. This plays an important role in a highly heterogenous environment, where hygrochastic species only occupy a small, specialized niche (Ellner and Shmida, 1981; Ihlenfeldt, 1983; Gutterman, 1994; Van Oudtshoorn and Van Rooyen, 1999) or to support a safe site strategy to ensure higher survival rates for seedlings (Pufal and Garnock-Jones, 2010).

\section{Protection Hypothesis}

Hygrochastic capsules are only open during rainfall events, in between rainfalls they stay closed. Especially in arid regions, they can stay closed for very long times but since seeds are stored in the capsule, they are protected against seed predators and harsh environmental conditions. In case of a sufficient rainfall event, seeds are released and germinate quickly, therefore avoiding seed predators that use the soil 
seed bank (Steinbrinck, 1883; Ellner and Shmida, 1981; Ihlenfeldt, 1983; Van Oudtshoorn and Van Rooyen, 1999).

\section{Suitable Strategy Hypothesis}

The forming of a splash cup is also advantageous for small herbaceous species, where water drops from taller plants act as dispersal agents (Nakanishi, 2002). Here, hygrochasy is not essential but hygrochastic species were identified that comply with this hypothesis. Why those species are hygrochastic is not yet fully understood. It was also thought that splash cups are the only available form of dispersal, when capsules are sessile or sunken in a cushion (P. Garnock-Jones, pers. comm.), e.g. in hygrochastic alpine Veronica that have a cushion growth form. But again, hygrochasy is not necessary in forming a splash cup; other species (e.g. Sagina decumbens (Brodie, 1951) or Chrysosplenium species (Nakanishi, 2002)) dehisce to form a splash cup during the ripening process.

Hygrochastic capsule dehiscence evolved independently in a number of unrelated families and is therefore a homoplastic character. Convergent evolution of a character is due to adaptation to similar environments or similar functions. Therefore, the same hypotheses for the evolution of hygrochastic capsules should apply to all species, regardless of their origin. While most studies focussed on plants of arid zones (Ellner and Shmida, 1981; Van der Pijl, 1982; Ihlenfeldt, 1983; Van Oudtshoorn and Van Rooyen, 1999; Parolin, 2001, 2006), I have added anatomical and ecological information on temperate alpine plants (Veronica and Colobanthus) in previous chapters. 
Table 6.1 Traditional hypotheses for hygrochastic capsules.

\begin{tabular}{|c|c|c|}
\hline hypothesis & description & references \\
\hline $\begin{array}{l}\text { Temporal } \\
\text { restriction } \\
\text { (Bradyspory) }\end{array}$ & $\begin{array}{l}\text { restriction seed dispersal to favourable } \\
\text { germination conditions, e.g. sufficient rain }\end{array}$ & $\begin{array}{l}\text { Fahn and Werker (1972); Ellner } \\
\text { and Shmida (1981); Van der Pijl } \\
\text { (1982); Ihlenfeldt (1983); Van } \\
\text { Oudtshoorn and Van Rooyen } \\
\text { (1999); Parolin (2006) }\end{array}$ \\
\hline $\begin{array}{l}\text { Spreading } \\
\text { dispersal over } \\
\text { time }\end{array}$ & $\begin{array}{l}\text { Only a few seeds are released at one rainfall } \\
\text { event, more are saved in the capsule for future } \\
\text { rainfall events - this spreads the risk of } \\
\text { germination over time. }\end{array}$ & $\begin{array}{l}\text { Van Rooyen, Barkhuizen, and } \\
\text { Myburgh (1980); Van Oudtshoorn } \\
\text { and Van Rooyen (1999); Parolin } \\
\text { (2001); Klak, Reeves, and } \\
\text { Hedderson (2004); Burke (2005) }\end{array}$ \\
\hline $\begin{array}{l}\text { spatial } \\
\text { restriction } \\
\text { (atelechory) }\end{array}$ & $\begin{array}{l}\text { restricting dispersal to suitable habitat close to } \\
\text { the parent plant in an otherwise heterogenous } \\
\text { hostile environment }\end{array}$ & $\begin{array}{l}\text { Ellner and Shmida (1981); } \\
\text { Ihlenfeldt (1983); Gutterman } \\
\text { (1994); Van Oudtshoorn and Van } \\
\text { Rooyen (1999), Chapter } 3.3\end{array}$ \\
\hline $\begin{array}{l}\text { safe site } \\
\text { strategy }\end{array}$ & $\begin{array}{l}\text { ensuring dispersal to safe sites, such as nurse } \\
\text { plants, or creating safe sites by dispersing } \\
\text { seeds in clumps }\end{array}$ & Pufal and Garnock-Jones, 2010 \\
\hline protection & $\begin{array}{l}\text { When closed, capsules protect seeds against } \\
\text { predators and harsh environmental conditions. }\end{array}$ & $\begin{array}{l}\text { Steinbrinck (1883); Ellner and } \\
\text { Shmida (1981); Ihlenfeldt (1983); } \\
\text { Van Oudtshoorn and Van Rooyen } \\
\text { (1999) }\end{array}$ \\
\hline \multirow{2}{*}{$\begin{array}{l}\text { suitable } \\
\text { dispersal } \\
\text { strategy }\end{array}$} & $\begin{array}{l}\text { splash cup only effective dispersal mechanism } \\
\text { for plant morphology, hygrochasy not } \\
\text { essential }\end{array}$ & P. Garnock-Jones, pers. comm. \\
\hline & $\begin{array}{l}\text { splash cup effective along water streams, } \\
\text { hygrochasy not essential }\end{array}$ & Nakanishi (2002) \\
\hline
\end{tabular}

To test for a universal explanation of hygrochasy, the North American genus Oenothera (Onagraceae) is used as study group. At least seven species in the subclade B are hygrochastic (Poppendieck, 1995; Ladyman, 2005; Wagner et al., 2007; see also Chapter Five) and they occur in a wide range of habitats across northern America. Different approaches such as laboratory dispersal experiments, analysis of morphological data, analysis of environmental, climatic and distributional variables and the investigation of character evolution in combination with phylogenetic data are used to test to application of common hypotheses for hygrochasy. The well studied Aizoaceae (see references above) and Veronica (Pufal and Garnock-Jones, 2010; Pufal et al., 2010) are used as references for the compliance with the hypotheses. 


\subsection{Materials and methods}

To infer whether hypotheses that were developed for the evolution of hygrochasy in plants of arid region can also explain hygrochasy in unrelated genera in different habitat types, a multidisciplinary approach was chosen using laboratory experiments, occurrence data and climatic variables in arcGIS (gbif and worldclim), plant morphology and phylogenetic information. The global biodiversity information facility (gbif) (http://data.gbif.org) provides occurrence and distribution data for most plants, animals, fungi or micro-organisms as well as inventory lists for countries or entire datasets, which are based on records provided by organization such as museums, herbaria or societies. WorldClim is a dataset of global climate layers, which is also available online (www.worlclim.org) (Hijmans et al., 2005).

The main hypotheses tested are the delay of dispersal in time (temporal restriction hypothesis) and the restriction of dispersal in space (spatial restriction hypothesis). Each approach was conducted separately and explained in detail in the following sections.

\subsubsection{DiSPERSAL AND SEED RETENTION}

In arid conditions it is favourable to delay dispersal over time and only release a few seeds per rainfall to spread the risk of germination failure (Parolin, 2006). In Aizoaecae, structures such as funicles, closing membranes or closing bodies are present. These structures prevent all seeds dispersing at one time but their presence also increases the dispersal distances of seeds that are dispersed. In this part of the study dispersal distances of some Veronica, Oenothera and Aizoaceae are compared and the differences between seed retention in those species is investigated (Table 6.2). 
In order to achieve a relevant comparison with previously investigated Aizoaceae species, dispersal experiments were modelled on Parolin (2001). Different plant heights were taken into account to simulate natural conditions. Dispersal distances were measured and number of seeds retained after 100 drops were counted. In addition to Parolin's experiments (2001), we also timed the opening of capsules. Kruskal-Wallis and Mann-Whitney-U tests were used to compare all species with each other. Genera were grouped and compared with each other as well. Statistical analysis was carried out in R (R Development Core Team, 2005).

Table 6.2 Species used in various analyses for this study.

\begin{tabular}{|c|c|c|c|c|c|}
\hline species & dispersal & seed retention & opening time & morphology & habitat \\
\hline Acrodon subulatus & yes & yes & no & yes & yes \\
\hline Argyroderma fissum & yes & yes & no & yes & yes \\
\hline Bergeranthus scapiger & yes & yes & no & yes & yes \\
\hline Cephalophyllum spissum & yes & yes & no & yes & yes \\
\hline Dracophilus dealbatus & yes & yes & no & yes & yes \\
\hline Drosanthemum globosum & yes & yes & no & yes & yes \\
\hline Drosanthemum hispidum & yes & yes & no & yes & yes \\
\hline Drosanthemum schoenlandianum & yes & yes & no & yes & yes \\
\hline Ebracteola wilmaniae & yes & yes & no & yes & yes \\
\hline Phyllobolus spinuliferus & yes & yes & no & yes & yes \\
\hline Rhombophyllum dolabriforme & yes & yes & no & yes & yes \\
\hline Oenothera fruticosa & no & no & yes & yes & yes \\
\hline Oenothera harringtonii & no & no & no & yes & yes \\
\hline Oenothera linifolia & yes & yes & yes & yes & yes \\
\hline Oenothera perennis & yes & yes & yes & yes & yes \\
\hline Oenothera rosea & no & no & no & yes & yes \\
\hline Oenothera speciosa & no & no & yes & yes & yes \\
\hline Oenothera triloba & no & no & yes & yes & yes \\
\hline Veronica birleyi & no & no & no & yes & yes \\
\hline Veronica cheesemanii & yes & yes & yes & yes & yes \\
\hline Veronica ciliolata & no & no & yes & yes & yes \\
\hline Veronica densifolia & yes & yes & yes & yes & yes \\
\hline Veronica planopetiolata & yes & yes & yes & yes & yes \\
\hline Veronica pulvinaris & no & no & yes & yes & yes \\
\hline Veronica thomsonii & yes & yes & yes & yes & yes \\
\hline Veronica spathulata & yes & yes & yes & no & yes \\
\hline
\end{tabular}




\subsubsection{PLANT MORPHOLOGY}

In order to identify a syndrome or syndromes for hygrochasy in unrelated species, morphological characters deemed important for dispersal (e.g., plant height, length of pedicel) were assessed for all species. This analysis was carried out previously for Veronica (Pufal et al., 2010) but not all characters used there could be used in this analysis. Traits such as capsule shape are mostly genus-specific and were therefore not taken into consideration. Twelve traits were considered but only seven were used in statistical analysis. Seed size, seed shape, seed number per capsule and development of mucilage were omitted from analysis due to missing values in some species. Additionally, retention mechanisms could not be used since they were only found in the Aizoaceae. Characters were either coded as binary or multistate or left as continuous variables (e.g. max capsule height) (Table 6.3).

Table 6.3 Characters and character states used in the cluster analysis of morphological characters in hygrochastic plants.

\begin{tabular}{||lll||}
\hline & character & character states \\
\hline 1 & Pedicel length & sessile $(1),<1 \mathrm{~cm}(2),<2 \mathrm{~cm}(3), 2-4 \mathrm{~cm}(4),>$ \\
& & $4 \mathrm{~cm}(5)$ \\
2 & number of capsules & solitary (1), 1-3 (2), 3 and more (3) \\
3 & orientation of capsules & erect(1), hanging down (2), both (3) \\
4 & plant habit & cushion (1), tufted/caespitose (2), acaulescent \\
& & $(3)$, creeping susbshrub (4), subshrub (5), herb \\
& & $(6)$, shrub (7) \\
5 & max. capsule height above ground & max plant height in cm \\
6 & capsules at different heights on plant & no (0), yes (1) \\
7 & life form & perennial (1), annual (2), both (3) \\
\hline \hline
\end{tabular}

The final matrix was converted into a distance matrix using Gower's coefficient in the function 'daisy' in the R package 'cluster' (Gower, 1971; Kaufman and Rousseeuw, 1990). Gower's coefficient has the ability to convert mixed matrices into a distance 
matrix and was therefore chosen for this analysis. The resulting distance matrix was analysed with cluster analysis after Ward's method (Ward, 1963).

To interpret how well the dendrogram imposes on the Gower's distance matrix, the cophenetic correlation coefficient was calculated. All statistical analysis was carried out in R (R Development Core Team, 2005).

\subsubsection{HABITAT QUALITY, CLIMATE CONDITIONS AND SPECIES DISTRIBUTION}

Hypotheses for hygrochasy in plants state, that this dehiscence type delays dispersal until favourable germination conditions are present and/or restricts dispersal in space to safe sites and specific habitats (Table 6.1). In order to investigate if any of these hypotheses apply to Oenothera, species distribution and climatic conditions were assessed for hygrochastic Oenothera and compared with hygrochastic New Zealand Veronica and some Aizoaceae in South Africa.

The distribution of species was measured as the number of grid cells occupied by the respective species based on the gbif database (for citations on the origin of data see Appendix 6.1). Occurrences in habitats due to cultivation and spread by humans were not taken into consideration and only occurrences with coordinates were used. All known hygrochastic species in Oenothera and Veronica are used in this part of the study. Aizoaceae species investigated by Parolin (2001), for which sufficient information was available in the gbif database, were also included.

Precipitation data were used from the worldclim database (Hijmans et al., 2005) and the climatic layers annual precipitation, driest quarter as well as seasonality (Coefficient of Variation) were imported in arcGIS. Occurrences with geospatial information for all species were imported from the gbif database and precipitation 
values for the locations were recorded. If data points were very close together only one record was taken for those sites.

The number of grid cells occupied by species in the gbif database was used as a measure of distribution for the spatial hypothesis. All variables were standardized using the scale function in R (R Development Core Team, 2005) and converted into a distance matrix using Euclidean distances. Ward's hierarchical cluster analysis was performed. The cophenetic correlation coefficient was calculated to determine how well the dendrogram represents the original Euclidean distance matrix.

It was not possible to assess the habitat size and ecological niche breadth on location, hence literature was used to make a qualitative assessment of these variables. They were used as additional information for the hierarchical cluster analysis.

\subsubsection{SYSTEMATICS AND CHARACTER EVOLUTION}

Hygrochastic capsules in the Aizoaceae show an array of capsule structures from simple to complex, with modifications such closing bodies and covering membranes to retain seeds (Van Oudtshoorn and Van Rooyen, 1999; Parolin, 2001). It appears that, at least in the Aizoaceae, hygrochasy evolved once and varying complexity can be traced in the phylogeny of the family (Van Oudtshoorn and Van Rooyen, 1999; Klak et al., 2004).

In order to test if hygrochasy is a trait that evolved only once or if it is a rather labile trait, parts of published phylogenies of Oenothera (Levin et al., 2004; Wagner et al., 2007) and Veronica (Albach and Meudt, 2010) were used in MacClade 4.08 (Maddison and Maddison, 2001). In Oenothera, a consensus tree based on ITS and cpDNA sequences was used (Levin et al., 2004) with updated names according to Wagner et al. (2007). Here, only the genus Oenothera was used for the analysis. Only 
New Zealand Veronica were used from an ITS phylogeny (Albach and Meudt, 2010) in the analysis of character evolution. The dehiscence type of species (hygrochastic, xerochastic, 'ripening dehiscent', indehiscent, unknown) was traced on the phylogeny in MacClade 4.08 to investigate character evolution. It was traced as an unordered character and polytomies were interpreted as soft polytomies. In this interpretation, the character's evolution is traced and steps counted assuming that the polytomy is resolved in the most favourable way for the character. 


\subsection{Results}

\subsubsection{DISPERSAL AND SEED RETENTION}

Dispersal distances from laboratory experiments were available for five Veronica species, two Oenothera and 11 Aizoaceae (Parolin, 2001) (Table 6.4). Significant differences were detected amongst the Veronica species (Kruskal-Wallis-test: chisquared $=15.34, \mathrm{df}=4, \mathrm{p}=0.004)$, the Oenothera species (Mann-Whitney-U test: W $=1924.5, \mathrm{p}=0.008)$ but not among the Aizoaceae (Kruskal-Wallis-test: chi-squared $=$ 8.06, $\mathrm{df}=10, \mathrm{p}=0.623)$

Table 6.4 Opening times $(\mathrm{min})$, dispersal distances $(\mathrm{cm})$ and percentage of expelled seeds after 100 water drops from $175 \mathrm{~cm}$. Data for Aizoaceae were provided by P. Parolin (see also Parolin, 2001) and opening times for $O$. fruticosa ssp. glauca and O. triloba are taken from Poppendieck (1995). For full species names see Table 6.2.

\begin{tabular}{||lllllll||}
\hline species & opening time & min & max & mean & sd & \% expelled \\
\hline Ac. subulatus & NA & 8 & 45 & 26 & 18.71 & 14.3 \\
Ar. fissum & NA & 7 & 116 & 42.96 & 27.25 & 7.4 \\
B. scapiger & NA & 20 & 70 & 41 & 25.94 & 8.3 \\
C. spissum & NA & 6 & 116 & 42.15 & 22.7 & 13 \\
Dr. globosum & NA & 3 & 79 & 42 & 37.16 & 57.1 \\
Dr. hispidum & NA & 7 & 7 & 7 & 0 & 20 \\
Dr. schoenlandianum & NA & 13 & 117 & 58.83 & 36.47 & 15.8 \\
Draco. dealbatus & NA & 11 & 152 & 44.58 & 41.46 & 26 \\
E. wilmaniae & NA & 11 & 124 & 49.13 & 25.11 & 9.4 \\
Phy. spinuliferus & NA & 28 & 28 & 28 & 0 & 7.7 \\
Rh. dolabriforme & NA & 2 & 86 & 35.25 & 39.83 & 6.7 \\
O. fruticosa ssp. glauca & 285 & NA & NA & NA & NA & NA \\
O. linifolia & 112.8 & 0.1 & 59 & 16.01 & 12.57 & 94.5 \\
O. perennis & 277 & 1 & 66.7 & 24.64 & 18.28 & 62.1 \\
O. speciosa & 298 & NA & NA & NA & NA & NA \\
O. triloba & 300 & NA & NA & NA & NA & NA \\
O. fruticosa & 181.6 & NA & NA & NA & NA & NA \\
V. cheesemanii & 90 & 1 & 12 & 5.49 & 3.62 & 69.2 \\
V. ciliolata & 158.43 & NA & NA & NA & NA & NA \\
V. densifolia & 234.3 & 0.3 & 110.5 & 15.6 & 16.04 & 73.1 \\
V. planopetiolata & 107 & 1 & 23 & 15.81 & 7.59 & 100 \\
V. pulvinaris & 139.1 & NA & NA & NA & NA & NA \\
V. spathulata & 220.3 & 0.3 & 54.9 & 10.69 & 13.54 & 100 \\
V. thomsonii & 162 & 0.5 & 38.7 & 10.01 & 8.79 & 93.5 \\
\hline \hline
\end{tabular}




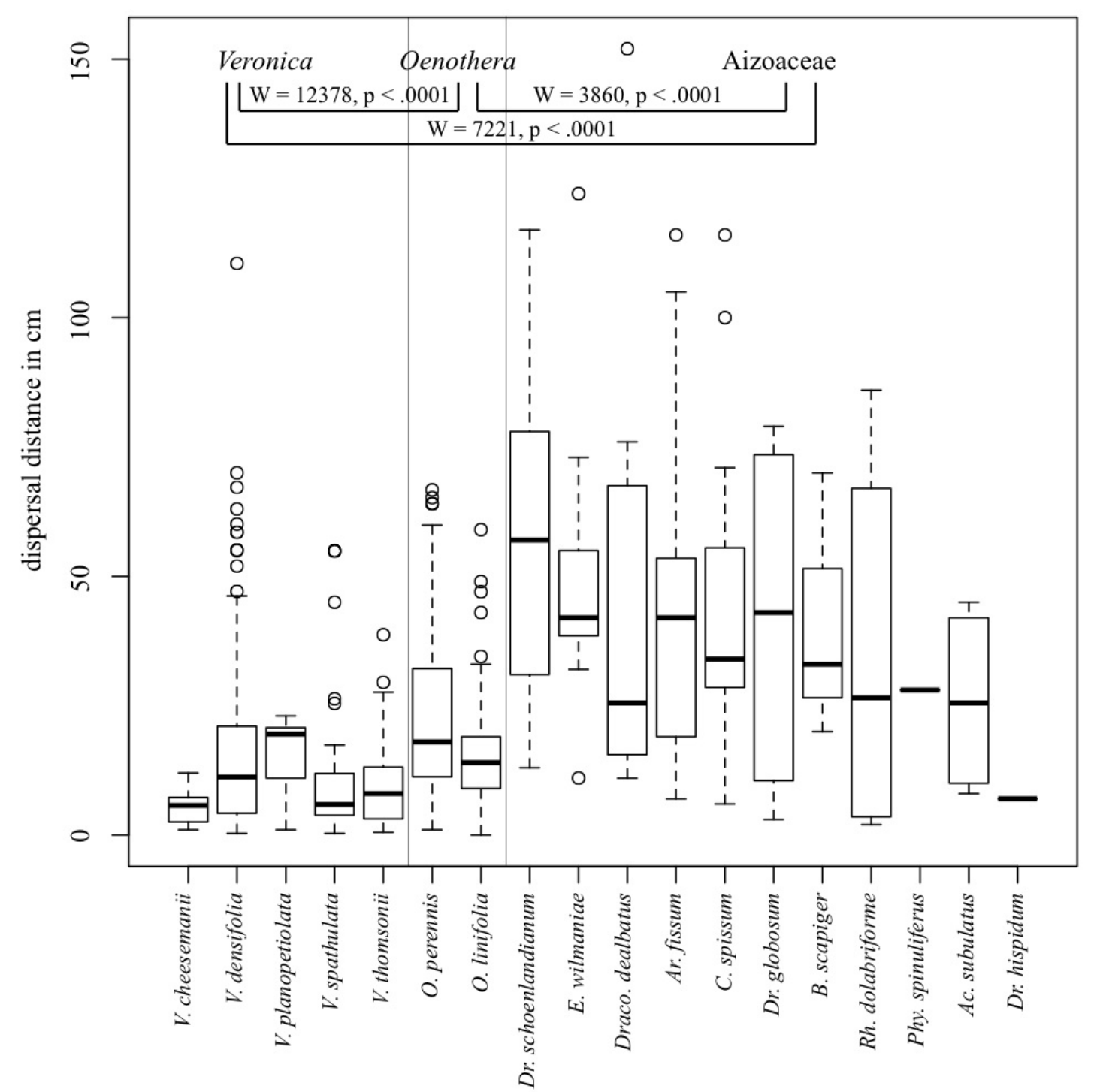

FIG 6.2 Dispersal distances of hygrochastic species. Significant differences between Veronica, Oenothera and Aizoaceae are given as results of Mann-Whitney-U tests.

Further statistical tests were carried out among the genera and families, respectively. Significant differences exist between all groups, with the Aizoaceae having the longest dispersal distances, followed by Oenothera and then Veronica with the shortest distances in comparison (Fig. 6.2).

Capsule opening times were only available for seven Veronica species and six Oenothera species. Of these, Oenothera fruticosa ssp. glauca and O. triloba were taken from Poppendieck (1995) (Table 6.4). Kruskal-Wallis tests showed significant 
differences among Veronica (chi-squared $=31.6, \mathrm{df}=6, \mathrm{p}<0.0001$ ) and Oenothera species ( chi-squared $=17.27, \mathrm{df}=3, \mathrm{p}=0.0006)$, respectively.

However, when both genera were compared with each other, no significant differences were found (Mann-Whitney-U test: $\mathrm{W}=969.5, \mathrm{p}=0.55$ ).

After 100 drops of water from a height of $175 \mathrm{~cm}$, the majority of Veronica seeds were dispersed, regardless of species (Table 6.3). Both Oenothera species tested showed similar high numbers of expelled seeds, whereas all Aizoaceae species (except Drosanthemum globosum) only dispersed a small proportion of their seeds.

\subsubsection{PLANT MORPHOLOGY}

The cluster analysis of morphological traits of hygrochastic species shows three distinct clusters with good support (cophenetic value $=0.723)($ Fig. 6.3).

The first cluster includes species with solitary, erect capsules on short plants with all capsules at the same height (Table 6.5). Except Oenothera triloba, all species are perennial plants.

The second cluster comprises species with solitary erect capsules on taller plants, where the capsules are located at different heights on the plant. The third cluster is distinguished from the other groups by species having between one and three flowers in the inflorescence. 


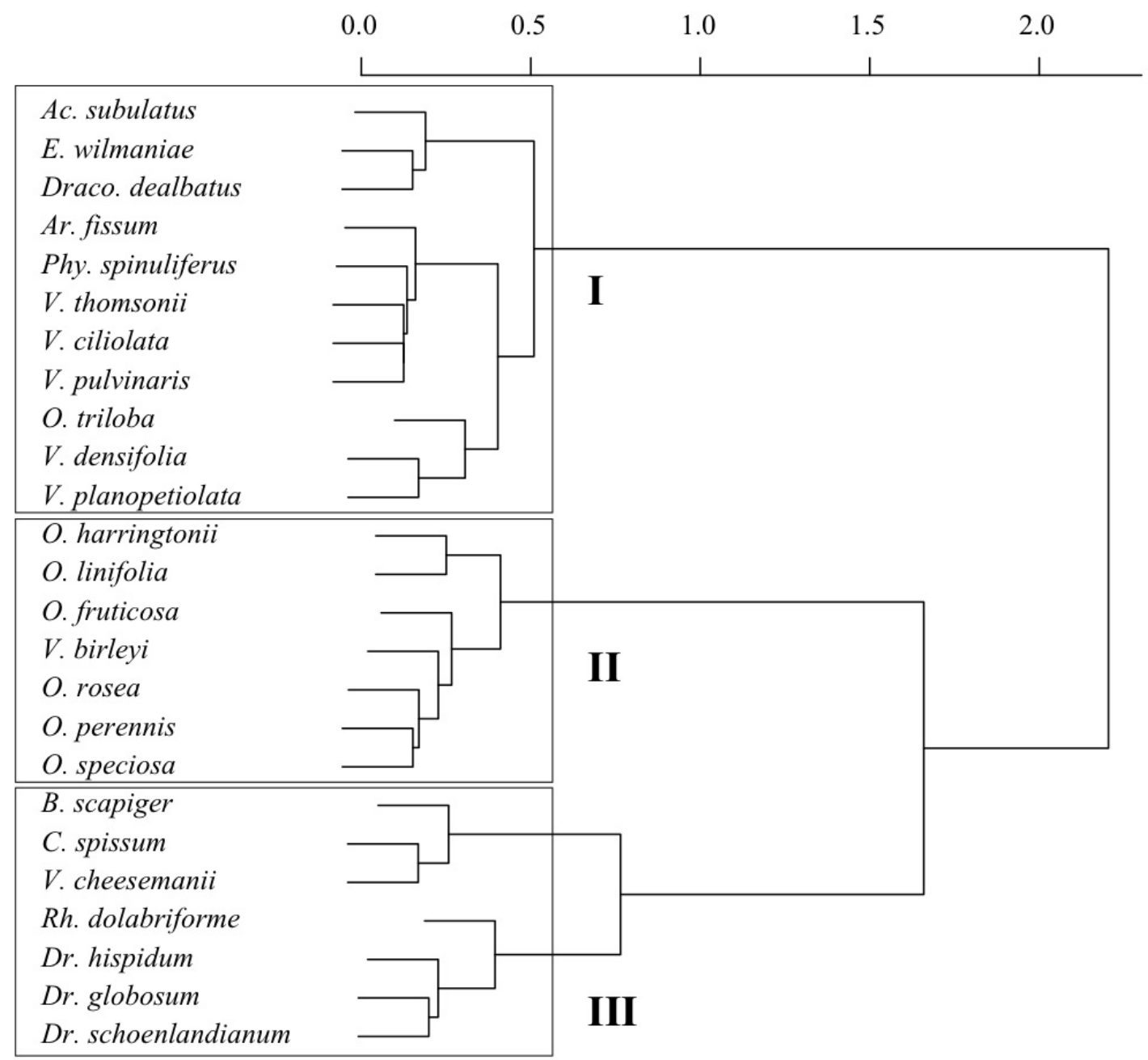

FIG 6.3 Ward's cluster analysis of morphological characters in hygrochastic species, based on a distance matrix between character states using Gowers' coefficient (Table 6.3 and Table $6.5)$. 
Table 6.5 Morphological traits of hygrochastic species coded as character states based on Table 6.2. References: (1) Jacobsen (1954), (2) Meudt (2008), (3) Walck and Hidayati (2007), (4) Wagner et al. (2007), (5) Garnock-Jones and Lloyd (2004), (6) Ladyman (2005), (7) Straley (1977), (8) Poppendieck (1995), (9) Britton and Brown (1970), (10) Wolin et al. (1984).

\begin{tabular}{|c|c|c|c|c|c|c|c|c|}
\hline & Cluster & 1 & 2 & 3 & 4 & 5 & 6 & 7 \\
\hline Acrodon subulatus ${ }^{\prime}$ & \multirow{11}{*}{$\mathrm{I}$} & 4 & 1 & 1 & 2 & 10 & 0 & 1 \\
\hline Ebracteola wilmaniae ${ }^{l}$ & & 3 & 1 & 1 & 2 & 10 & 0 & 1 \\
\hline Dracophilus dealbatus ${ }^{l}$ & & 3 & 1 & 1 & 1 & 5 & 0 & 1 \\
\hline Argyroderma fissum ${ }^{l}$ & & 1 & 1 & 1 & 2 & 5 & 0 & 1 \\
\hline Phyllobolus spinuliferus ${ }^{l}$ & & 1 & 1 & 1 & 1 & 10 & 0 & 1 \\
\hline Veronica thomsonii $^{2}$ & & 1 & 1 & 1 & 1 & 4 & 0 & 1 \\
\hline Veronica $_{\text {ciliolata }}{ }^{2}$ & & 1 & 1 & 1 & 1 & 4 & 0 & 1 \\
\hline Veronica pulvinaris $^{2}$ & & 1 & 1 & 1 & 1 & 4 & 0 & 1 \\
\hline Oenothera triloba ${ }^{3,4,9}$ & & 1 & 1 & 1 & 4 & 5 & 0 & 3 \\
\hline Veronica densifolia $^{2}$ & & 1 & 1 & 1 & 4 & 7 & 0 & 1 \\
\hline Veronica planopetiolata ${ }^{5}$ & & 2 & 1 & 1 & 4 & 5 & 0 & 1 \\
\hline Oenothera harringtonii ${ }^{6}$ & \multirow{7}{*}{ II } & 1 & 1 & 1 & 6 & 30 & 1 & 3 \\
\hline Oenothera linifolia ${ }^{7}$ & & 2 & 1 & 1 & 6 & 50 & 1 & 2 \\
\hline Oenothera fruticosa ${ }^{7}$ & & 2 & 1 & 1 & 6 & 120 & 1 & 1 \\
\hline Veronica birleyi ${ }^{5}$ & & 1 & 1 & 1 & 5 & 20 & 1 & 1 \\
\hline Oenothera rosea ${ }^{4,8}$ & & 1 & 1 & 1 & 6 & 100 & 1 & 1 \\
\hline Oenothera perennis ${ }^{7}$ & & 1 & 1 & 1 & 6 & 75 & 1 & 1 \\
\hline Oenothera speciosa ${ }^{4,9,10}$ & & 1 & 1 & 1 & 6 & 50 & 1 & 1 \\
\hline Bergeranthus scapiger $^{I}$ & \multirow{7}{*}{ III } & 4 & 2 & 1 & 2 & 10 & 0 & 1 \\
\hline Cephalophyllum spissum ${ }^{l}$ & & 3 & 2 & 1 & 4 & 5 & 0 & 1 \\
\hline Veronica cheesemanii $^{5}$ & & 2 & 2 & 1 & 4 & 4 & 0 & 1 \\
\hline Rhombophyllum dolabriforme ${ }^{l}$ & & 1 & 2 & 1 & 2 & 30 & 1 & 1 \\
\hline Drosanthemum hispidum ${ }^{l}$ & & 4 & 2 & 1 & 7 & 60 & 1 & 1 \\
\hline Drosanthemum globosum ${ }^{1}$ & & 2 & 2 & 1 & 7 & 45 & 1 & 1 \\
\hline Drosanthemum schoenlandianum ${ }^{l}$ & & 3 & 2 & 1 & 7 & 15 & 1 & 1 \\
\hline
\end{tabular}

\subsubsection{HABITAT QUALITY, CLIMATE CONDITIONS AND SPECIES DISTRIBUTION}

Precipitation, distribution and altitude information was obtained for a total of 26 species (Table 6.6). A hierarchical cluster analysis resulted in a dendrogram with three distinctive clusters, which is moderately supported with a cophenetic value of 0.638 (Fig. 6.4). The first cluster represents alpine species with high annual rainfall, no obvious seasonality and a small distribution. This cluster exclusively contains New Zealand Veronica. 
The second cluster contains all Aizoaceae and two Oenothera species. It represents species with a restricted distribution (except $O$. triloba), low annual rainfall and/or very dry seasons and/or high seasonality. Altitudinal ranges vary between species. Cluster three contains the remaining Oenothera species, which occur in a wide range of areas with high annual rainfall and little seasonality. Oenothera rosea shows a very high seasonality and has also the highest altitudinal range.

Table 6.6 Precipitation, altitudinal and distribution information for hygrochastic species based on the worldclim (mean annual rain, seasonality, altitude range, altitude mean) and gbif database (distribution). For full species names see Table 6.2.

\begin{tabular}{|c|c|c|c|c|c|c|}
\hline species & $\begin{array}{l}\text { Mean annual } \\
\text { rain }\end{array}$ & seasonality & $\begin{array}{l}\text { Min. driest } \\
\text { quarter }\end{array}$ & distribution & $\begin{array}{l}\text { Altitude } \\
\text { range }\end{array}$ & $\begin{array}{l}\text { Altitude } \\
\text { mean }\end{array}$ \\
\hline$V$. densifolia & 1602 & 13 & 191 & 7 & 791 & 1339 \\
\hline$V \cdot$ pulvinaris & 2318 & 15 & 205 & 10 & 1176 & 1400 \\
\hline V. ciliolata & 3033 & 12 & 318 & 12 & 897 & 1397 \\
\hline V. thomsonii & 1983 & 11 & 321 & 2 & 595 & 1440 \\
\hline$V$. cheesemanii & 2340 & 16 & 270 & 3 & 649 & 1306 \\
\hline V. birleyi & 3489 & 12 & 603 & 3 & 1017 & 1969 \\
\hline$V \cdot$ planopetiolata & 2948 & 11 & 497 & 2 & 686 & 1362 \\
\hline V. spathulata & 3030 & 19 & 480 & 6 & 901 & 1413 \\
\hline P. spinuliferus & 77 & 38 & 10 & 1 & 0 & 349 \\
\hline D. globosum & 352 & 19 & 56 & 1 & 279 & 482 \\
\hline R. dolabriformes & 611 & 21 & 107 & 1 & 0 & 940 \\
\hline A. subulatus & 618 & 33 & 65 & 5 & 868 & 465 \\
\hline D. dealbatus & 64 & 38 & 6 & 2 & 842 & 517 \\
\hline B. scapiger & 504 & 43 & 28 & 2 & 975 & 679 \\
\hline O. triloba & 913 & 36 & 17 & 93 & 1815 & 481 \\
\hline D. hispidum & 300 & 42 & 4 & 33 & 1571 & 668 \\
\hline E. wilmaniae & 453 & 78 & 4 & 5 & 343 & 1404 \\
\hline $\begin{array}{l}\text { O. harringtonii } \\
D .\end{array}$ & 351 & 57 & 21 & 4 & 698 & 1671 \\
\hline schoenlandianum & 210 & 65 & 11 & 2 & 811 & 540 \\
\hline A. fissum & 171 & 68 & 10 & 2 & 141 & 81 \\
\hline C. spissum & 165 & 66 & 11 & 1 & 0 & 146 \\
\hline O. rosea & 1092 & 82 & 6 & 150 & 4115 & 1584 \\
\hline O. speciosa & 1059 & 31 & 2 & 302 & 1910 & 433 \\
\hline O. linifolia & 1211 & 20 & 72 & 96 & 580 & 242 \\
\hline O. fruticosa & 1193 & 17 & 130 & 190 & 1218 & 367 \\
\hline O. perennis & 1023 & 19 & 46 & 162 & 1116 & 331 \\
\hline
\end{tabular}


squared euclidean distances

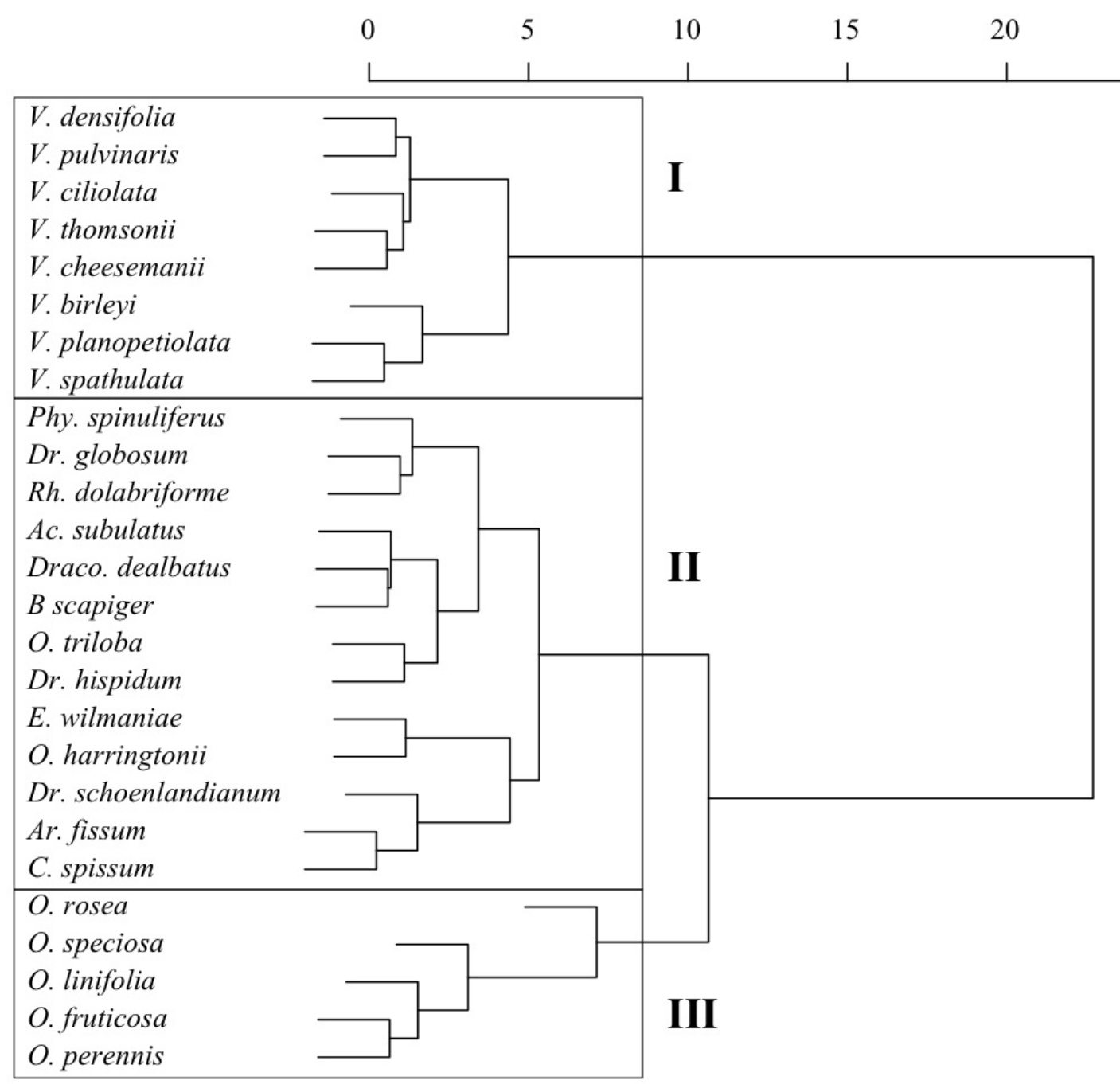

FIG 6.4 Ward's hierarchical cluster analysis of precipitation, distribution and altitude in hygrochastic species. 


\subsubsection{SYSTEMATICS AND CHARACTER EVOLUTION}

To investigate the evolution of hygrochasy in Oenothera, part of the phylogeny of Onagraceae published by Levin et al. (2004) and updated by Wagner et al. (2007) was used. The strict consensus is based on ITS (nuclear), trnL-trnF and rps16 (both chloroplast) data. Here, I present the Oenothera clade with the subclades A and B (Fig. 6.5). Some species used in this study were not presented in the phylogeny but have putative close relatives of the same section that were included. For these, the name of the species tested for capsule dehiscence is given in brackets behind the relative's name in the phylogenetic tree. Hygrochasy and xerochasy only occur in subclade B, whereas 'ripening dehiscent' fruits can be found in subclade A. Hygrochasy is also present in species of sect. Lavauxia (O. triloba and O. acaulis) and sect. Pachylophis (O. harringtonii), both outside the main subclade B. Sections Gaura and Gauropsis comprise species with indehiscent capsules (Wagner et al., 2007), marked by black branches in the dendrogram (Fig. 6.5). These form one clade within subsection B. 


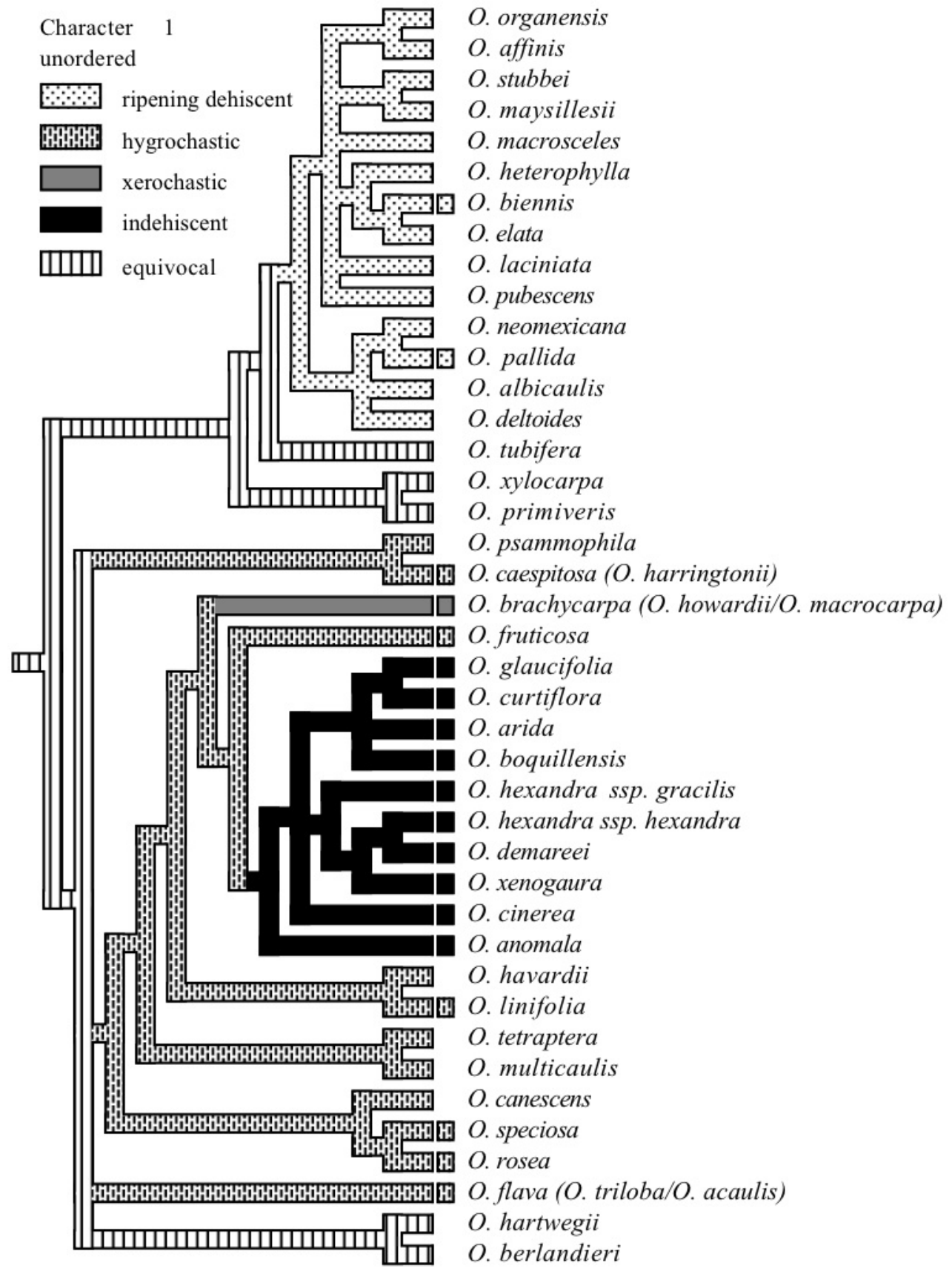

FIG 6.5 Updated strict consensus tree of combined ITS, trnL-trnF and rps16 data, reproduced from Wagner et al. (2007). The two main subclades of Oenothera are indicated as A and B. The character 'capsules dehiscence' is traced on the phylogeny using MacClade 4.08. Species for which concrete information was available are marked with a box at the branch end. 
For the investigation of hygrochastic capsule evolution in Veronica, only the New Zealand section of this genus was used (Albach and Meudt, 2010). The phylogenetic tree is based on the combined ITS and cpDNA data and is well supported (Albach and Meudt, 2010) (Fig. 6.6). This study focussed on the speedwell hebe and snow hebe clades which contain hygrochastic species. The shrubby hebe clade with ripening dehscent capsules is represented by 5 of its 85 species ( $V$. elliptica to $V$. salicornioides in Fig. 6.6). Except for Veronica tubata, the dehiscence mechanism is known in all presented species. Hygrochasy is present in the entire snow hebe group and as well as in some speedwell hebes and in $V$. planopetiolata. All other species have capsules that dehisce during the ripening process. 


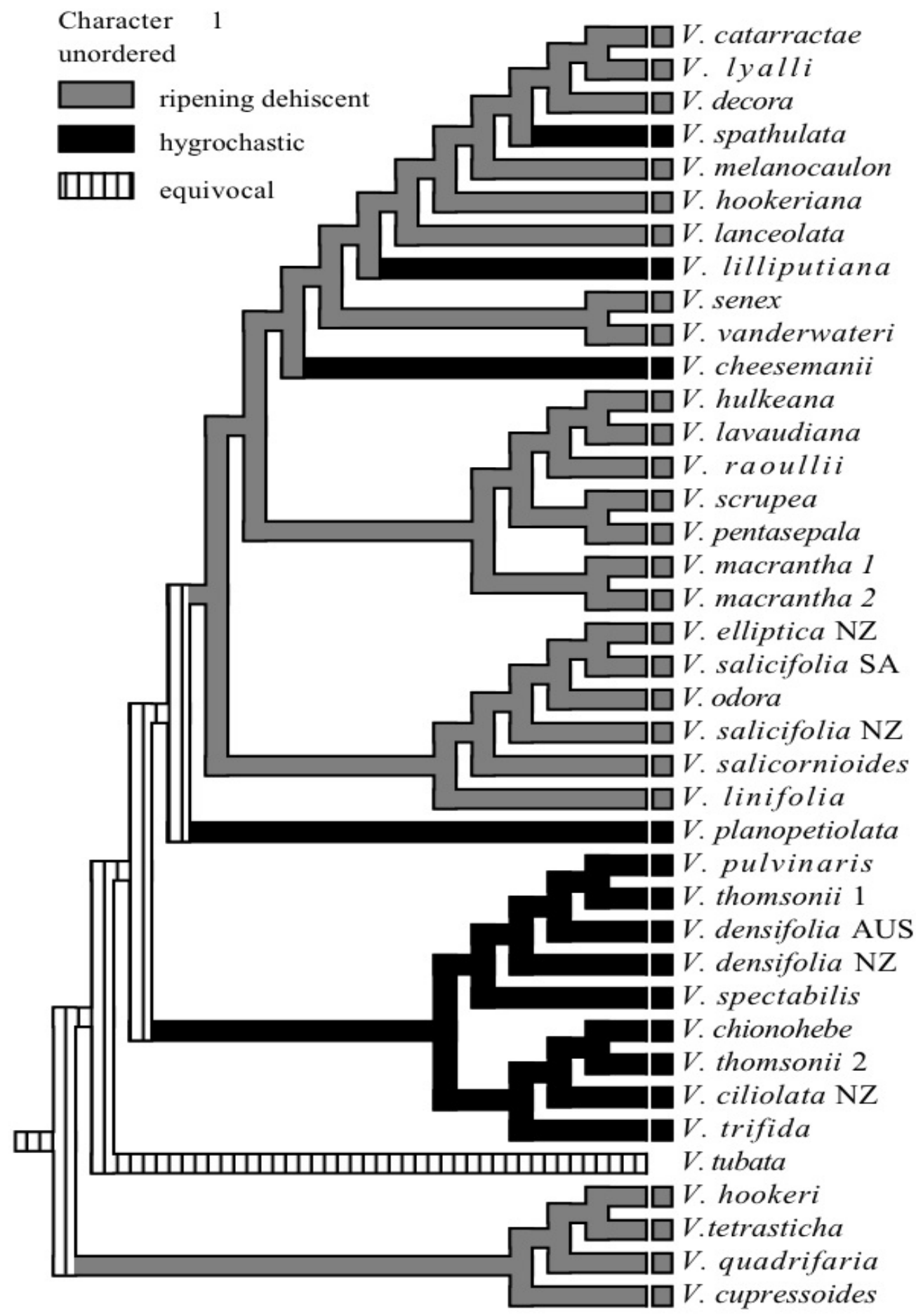

FIG 6.6 Combined phylogeny (ITS and cpDNA) of Veronica sect. Hebe, reproduced from Albach and Meudt (2010). The character capsule dehiscence is traced on the phylogeny, species with definite information are indicated with a box at the branch end. 


\subsection{Discussion}

There are several hypotheses for the evolution of hygrochastic capsule dehiscence, most of them developed for plant species in arid areas (Table 6.1). In this study I explore whether the two main hypotheses apply to genera outside arid areas as well. Both the temporal and spatial restriction hypotheses are discussed in hygrochastic North American Oenothera species and a possible explanation for hygrochasy in this genus is sought.

\subsubsection{DISPERSAL AND SEED RETENTION}

All species tested show short dispersal distances with the longest distances not further than $1.5 \mathrm{~m}$ (Dracophilus dealbatus). It is generally known that hygrochasy restricts dispersal to raindrops, which cannot transport seeds very far (Ihlenfeldt, 1983; Van Oudtshoorn and Van Rooyen, 1999; Parolin, 2001; Nakanishi, 2002) and this is certainly true for the tested Oenothera species as well. Overall, seeds of Aizoaceae species were dispersed furthest, followed by Oenothera; Veronica species had the shortest dispersal distances. Data for Aizoaceae species was provided by P. Parolin, who used the same data in a study of the influence of specialized capsule parts in dispersal distance and seed retention (Parolin, 2001). She showed that covering membranes and closing bodies successfully retain seeds in the capsule, so as not to disperse all of them in one rainfall, spreading the risk of germination over time. As a trade-off these appendages enhance the dispersal distance as well. Here, membranes transfer energy of falling drops, whereas closing bodies restrict the outlet, causing ejected water drops to be squirted further through a smaller aperture, taking single seeds with them. 
In the laboratory test of seed dispersal, the capsules of both tested Oenothera species were mounted $30 \mathrm{~cm}$ above the ground to simulate realistic conditions of capsules on the plants. This most likely resulted in the larger dispersal distances for those species (Parolin, 2001). Since all tested species are definitely short distance dispersed, the spatial restriction hypothesis is a possible explanation for hygrochasy in Oenothera. Habitat and distribution data are used to explore this idea further.

Restriction of dispersal in time has been explored extensively in Aizoaceae and also in other plants of arid regions (Fahn and Werker, 1972; Ellner and Shmida, 1981; Van der Pijl, 1982; Ihlenfeldt, 1983; Van Rooyen, 1990; Van Oudtshoorn and Van Rooyen, 1999; Parolin, 2006). It is very pronounced in Aizoaceae, at least for species in the core Ruschioideae (Klak et al., 2004), which have been tested in Parolin's work (2001). The risk of germination is spread over time, since only a few seeds are released at a rainfall event, preserving more seeds in the capsule for future rainfall (Van Oudtshoorn and Van Rooyen, 1999). In Oenothera, temporal restriction does not seem to be as important, with the majority of the seeds dispersed after only a small amount of rain (Table 6.3). However, Poppendieck (1995) observed that in Oenothera triloba only a few seeds at a time are dispersed, since seeds are arranged in vertical piles and not easily splashed out of the capsule. Hygrochasy certainly restricts dispersal to rainfall events, which is a form of temporal restriction but it is not evident in Oenothera if dispersal and henceforth the germination risk is spread over time.

\subsubsection{PLANT MORPHOLOGY}

Splash cup dispersal and henceforth also hygrochasy could potentially be associated with plant morphology. Nakanishi (2002) stated that small herbaceous plants profit from waterdrops, which act as dispersal agents when falling from taller plants; 
especially in vegetation where wind cannot reach all fruits. In alpine cushion plants, splash cups also seem to be an advantage for sessile fruits that are embedded in the cushion (P. Garnock-Jones, pers. comm.). Plant morphology of all hygrochastic species in this study was therefore investigated regarding traits that might be of importance for hygrochasy (suitable dispersal hypothesis). In a previous study (Pufal et al., 2010), a syndrome for hygrochastic Veronica was identified. Here, hygrochasy is associated with either solitary or few erect, narrowly angustiseptate capsules on short peduncles of creeping subshrubs or cushion plants.

Other than erect capsules and fewer than three capsules in one cluster, no common morphological traits were found for hygrochastic species of unrelated genera. Sessile fruits or fruits on short pedicels were predominantly found in Veronica and Oenothera, but Aizoaceae exhibit a range of pedicel lengths. Nakanishi's (2002) argument of splash cups in small herbaceous plants could also not be supported. Especially in Oenothera and Aizoaceae, hygrochastic species represent a range of life forms and can be quite tall. In prairies, which are a common habitat for Oenothera (Britton and Brown, 1970; Straley, 1977; Wolin et al., 1984; Wagner et al., 2007), individuals are mostly not overshadowed by other vegetation and capsules are easily exposed to wind. However, Cluster One in the analysis is associated with small plants (either cushion or rosettes) (Fig. 6.3), which complies with the suitable dispersal hypothesis. At least for Oenothera triloba, which is included in this cluster, this theory might be applicable. For all other hygrochastic Oenothera species, the suitable dispersal hypothesis of splash cups in small herbaceaous plants has to be rejected (Cluster 2 in Fig. 6.3). 


\subsubsection{HABITAT QUALITY AND SPECIES DISTRIBUTION}

Most hygrochastic Aizoaecae are found in arid and semi arid regions in Southern Africa and often have a small and patchy distribution (Ihlenfeldt, 1983) (spatial restriction hypothesis). The spatial restriction hypothesis also applies to hygrochastic New Zealand Veronica, which only occur in small habitat patches in the alpine zone. Here, the short-distance dispersal heightens the chances for seeds to land in safe sites within a suitable habitat (Pufal and Garnock-Jones, 2010; Chapter 3.2).

A hierarchical cluster analysis based on environmental and distribution data groups all species in three distinctive clusters (Fig. 6.4). Cluster One corresponds to the spatial restriction hypothesis - it includes all hygrochastic Veronica species, which receive abundant rainfall year round but have a small distribution and are restricted to the alpine zone. Cluster Two includes all Aizoaceae species and two species of Oenothera and represents species for which the temporal restriction hypothesis applies. Here, either low annual rainfall or dry seasons with very little rain are common, seasonality occurs for some species and altitude varies greatly. Except for Oenothera triloba, all species have a narrow distribution - for those, the spatial restriction hypothesis applies as well. Oenothera triloba can be found in this group since it receives very little rainfall in the dry season. It would therefore be favourable to only disperse seeds in the wet season, when germination conditions are favourable. Oenothera harringtonii can also be found in this group. It only occurs in Colorado (Ladyman, 2005) and is subjected to a dry climate and high seasonality.

The last cluster includes the remaining Oenothera species, which receive abundant rainfall and have a wide distribution with a range of different habitats at varying altitudes (Straley, 1977; Wolin et al., 1984; Wagner et al., 2007). Even though Oenothera rosea shows a very high seasonality and very little precipitation in the 
driest quarter, it clusters with the other Oenothera due to its great range and distribution. It also needs to be taken into account that the minimum driest quarter value only represents the minimum for some locations out of a pool of hundreds. This species is also the only alpine species in this cluster (according to average altitude) but specimens can also be found at sea level.

At least for two Oenothera species, the temporal restriction hypothesis seems to apply and $O$. harringtonii is also a good candidate for the spatial restriction hypothesis. However, for the other Oenothera species neither hypothesis seems to be applicable, at least not with the data analysed here.

Nakanishi (2002) also mentioned that species with splash cups can be found along streams or water torrents, where the splash water is an effective dispersal agent. The predominant habitat of Oenothera triloba (Wagner et al., 2007) is along streams and the suitable dispersal hypothesis could be relevant for this species in this regard.

\subsubsection{SYSTEMATICS AND CHARACTER EVOLUTION}

Recent phylogenetic trees of Oenothera and Veronica were used to trace the evolution of hygrochastic capsules in these genera and to find out whether the trait evolved once or several times. It appears that in the New Zealand Veronica, hygrochasy has evolved independently several times (Fig. 6.6). This might be due to homoplasy - the character hygrochasy is mostly restricted to cushion plants or low subshrubs in alpine habitat. In fact, homoplasy is relatively common in Veronica and has previously led to difficulties in resolving the phylogeny (Meudt, 2008; Albach and Meudt, 2010). Other reasons for previously poorly resolved trees might be a rapid species radiation in the New Zealand Veronica (Albach et al., 2004; Albach et al., 2004a; Albach et al., 2004b; Albach and Meudt, 2010). According to Wagstaff et al. (2002) rapid 
speciation of Veronica (as Hebe) in New Zealand occurred in the late Tertiary and plants radiated from alpine areas into the lowland. Hence, hygrochastic Veronica are relatively young and the rapid speciation in a highly heterogenous alpine environment combined with a short distance dispersal mechanism might be an explanation for the restricted distributions of those species. Exceptions are $V$. densifolia and $V$. ciliolata, which can also be found in Australia and Tasmania (Meudt, 2008; Meudt and Bayly, 2008). This is most likely due to unexplained long distance dispersal events (Meudt, 2008). However, Veronica densifolia possesses mucilaginous seeds (own obs.), which could easily stick to feathers of birds when wet and be dispersed over long distances. Aizoaceae, with more than $98 \%$ of their species being hygrochastic, also have a history of rapid speciation. The rapid radiation of the core Ruschioideae (approximately 1500 species) is unprecedented. They diversified over the last 3.8 to 8.7 Myr with a diversification rate per lineage of only 0.77 to $1.75 \mathrm{Myr}$ (Klak et al., 2004). The morphology of hygrochastic capsules in the core Ruschioideae is very specialized, which might have played an important role in the diversification. The capsules have retention features such as closing bodies or funicles, which are lacking in the species-poor Mesembryanthemoideae. These features allow the plants to spread dispersal over time, whereas the Mesembryanthemoideae disperse their seeds in only a few rainfall events. The spreading of dispersal over time is highly advantageous in regions with erratic rainfall. It reduces the chance of secondary dispersal, thereby reducing gene flow distances and potentially leading to isolation of populations in space (Parolin, 2001). Burke (2005) also suggested that hygrochasy might play an important role in the evolution of endemic species in Namibia.

In Oenothera, hygrochasy seems to have evolved only once in the subclade B and parallel in sect. Lavauxia and Pachylophus (Fig. 6.5). According to new findings, 
these sections can also be included in subclade B (K. N. Krakos, pers. comm.), leading effectively to one shift from 'ripening dehiscent' species to hygrochastic species. According to the analyses presented so far, none of the hypotheses proposed for hygrochastic plants in arid regions, alpine areas or the splash cup dispersal in herbaceous vegetation seems to apply to Oenothera, with a few exceptions $(O$. triloba, O. harringtonii).

For Oenothera, the centre of diversity lies in the semiarid to subhumid mountains and plains of interior North America (Tobe et al., 1987; Katinas et al., 2004). The genus Oenothera has diverged from Eremothera about 10 Myr ago (Sytsma et al., 2004). Raven and Axelrod (1978) postulate that the early diversification of Onagraceae tribe Onagreae took place in the Madrean vegetation of western North America as part of the Madro-Tertiary flora (Axelrod, 1958). This flora was derived mainly from subtropical to temperate groups, which evolved in response to the expansion of a new adaptive zone with much drier climate. Katinas et al. (2004) postulate that the current distribution of Onagrae can be partly attributed to either short distance dispersal into geographically contiguous but unrelated areas or Quaternary migrations into areas, where the previous flora had been eliminated by glacial or preglacial conditions (Grichuk, 1984).

A Madro-Tertiary origin might explain the evolution of hygrochasy in Oenothera in combination with the temporal restriction hypothesis. Compared to Aizoaceae and Veronica, Oenothera are comparatively old and might have had time to spread across the continent despite having restricted dispersal distances. Hygrochasy in Oenothera can be most parsimoniously interpreted as a single evolution in the ancestor of subclade B (Fig. 6.5). Hence, hygrochastic dehiscence does not necessarily relate to any living species. 


\subsection{Conclusion}

When analysing the dispersal distances, opening times, plant morphology and distribution and climatic conditions of hygrochastic Oenothera, no apparent link could be found to common hypotheses for hygrochasy in other genera. Exceptions are Oenothera triloba and $O$. harringtonii, for which the spatial restriction hypothesis, the suitable dispersal hypothesis as well as the temporal restriction hypothesis might apply. However, most hygrochastic Oenothera are widespread, occur in areas with sufficient rainfall and low seasonality and seem to have no specialized habitat preferences. However, the phylogeny revealed that hygrochastic capsule dehiscence most likely evolved once with a one-time shift to indehiscence and likewise to xerochasy. The evolutionary history of the tribe Onagreae suggests an origin as part of the Madro-Tertiary flora, where hygrochasy could have been an advantage by delaying the dispersal and germination of seeds to favourable conditions in a dry and seasonal climate. Given the approximate age of the genus Oenothera (10 Myr) and the distribution theories of Katinas et al (2004), short-distance dispersal by hygrochastic capsules does not negate the wide distribution of hygrochastic

\section{Oenothera.}

With the available dataset I was only able to explore four out of six potential hypotheses for hygrochasy in Oenothera. The safe site strategy might be a possibility, since seeds occasionally get dispersed in clumps of two or more (unpubl. data) and seedlings could shelter each other (Pufal and Garnock-Jones, 2010). However, I was only able to test seed dispersal in two species and more data are needed on the specific habitats and competition between seedlings for all hygrochastic Oenothera species. 
The protection hypothesis might also be possible explanation for hygrochasy in Oenothera. Seed predation can play an important role in herbaceous vegetation, such as deserts or grassland (Brown and Heske, 1990; Price and Joyner, 1997). Storing seeds in the canopy (e.g. hygrochastic capsules) would therefore be of advantage compared to a soil seedbank. Support for this hypothesis can be found in Oenothera triloba. The seeds are nondormant (Walck and Hidayati, 2007) and would therefore germinate quickly after dispersal (mostly within one week), decreasing the chance of being destroyed by seed predators. However, more information is needed on seed predators in the diverse habitats of hygrochastic Oenothera and dormancy of seeds.

In conclusion I propose that hygrochasy in Oenothera is probably an ancient relict from the mid- to late Miocene, when hygrochasy might have evolved in species of the subclade $\mathrm{B}$ according to the temporal restriction hypothesis. The spatial restriction hypothesis probably did not play a role, since most hygrochastic Oenothera occur in a wide range of habitats and do not seem to have a restricted ecological niche. However, both the protection hypothesis and safe site strategy might play a role in present day hygrochastic Oenothera, but more information is needed to investigate these hypotheses in more detail.

\subsection{References}

AlBaCh, D. C., AND H. M. MeudT. 2010. Phylogeny of Veronica in the Southern and Northern Hemispheres based on plastid, nuclear ribosomal and nuclear low-copy DNA. Molecular Phylogenetics and Evolution 54: 457-471.

Albach, D. C., M. M. Martinez-Ortega, AND M. W. Chase. 2004. Veronica: parallel morphological evolution and phylogeography in the Mediterranean. Plant Systematics and Evolution 246: 177-194.

Albach, D. C., M. M. Martinez-Otega, M. A. Fischer, AND M. W. Chase. 2004a. A new classification of the tribe Veroniceae - problems and a possible solution. Taxon 53: 429-452.

Albach, D. C., M. M. Martinez-Ortega, M. A. Fischer, AND M. W. Chase. 2004b. Evolution of Veroniceae: a phylogenetic perspective. Annals of the Missouri Botanical Garden 91: 275-302. 
AXELROD, D. I. 1958. Evolution of the Madro-Tertiary geoflora. Botanical Review 24: 433509.

BRITTON, N. L., AND A. BROWN. 1970. An illustrated flora of the northern United States and Canada, Volume Two Amaranthaceae to Liganiaceae. Dover Publications, Inc., New York.

Brodie, H. J. 1951. The splash-cup dispersal mechanism in plants. Canadian Journal of Botany 29: 224-234.

BROWN, J. H., AND E. J. HESKE. 1990. Control of a desert-grassland transition by keystone rodent guild. Science 250: 1705-1707.

BURKE, A. 2005. Endemic plants of the arid succulent karoo in Namibia: towards hypotheses for their evolution. Ecography 28: 171-180.

ELLNER, S., AND A. SHMIDA. 1981. Why are adaptations for long-range seed dispersal rare in desert plants? Oecologia (Berlin) 51: 133-144.

FAHN, A., AND E. WERKER. 1972. Anatomical mechanisms of seed dispersal. In T. T. Kozlowski [ed.], Seed Biology. Academic Press, New York, USA.

GARNOCK-Jones, P., D. ALBACH, AND B. G. BRIGGS. 2007. Botanical names in Southern Hemisphere Veronica (Plantaginaceae): sect. Detzneria, sect. Hebe, and sect. Labiatoides. Taxon 56: 571-582.

GARNOCK-JONES, P. J. 1993. Phylogeny of the Hebe complex (Scrophulariaceae: Veroniceae). Australian Systematic Botany 6: 457-479.

GARNOCK-JONES, P. J., AND D. G. LLOYD. 2004. A taxonomic revision of Parahebe (Plantaginaceae) in New Zealand. New Zealand Journal of Botany 42: 181-232.

GARSIDE, S., AND S. LOCKYER. 1930. Seed dispersal from the hygroscopic fruits of Mesembryanthemum carpanthea (Mesembryanthemum) pomeridiana, N. E. Br. Annals of Botany 44: 639-U636.

GOWER, J. C. 1971. A general coefficient of similarity and som eof its properties. Biometrics 27: 857-874.

GRICHUK, V. P. 1984. Late Pleistocene vegetation history. In A. A. Velichko, H. E. Wright, and C. W. Barnosky [eds.], Late Quaternary Environments of the Soviet Union. Univ. Minnesota Press, Minneapolis.

GUENSTER, A. 1992. Aerial seed banks in the central Namib: distribution of serotinous plants in relation to climate and habitat. Journal of Biogeography 19: 563-572.

GUTTERMAN, Y. 1990. Seed dispersal by rain (ombrohydrochory) in some of the flowering desert plants in the deserts of Israel and the Sinai Peninsula. Mitteilungen aus dem Institut fuer Allgemeine Botanik Hamburg 22b: 841-852.

1994. Strategies of seed dispersal and germination in plants inhabiting deserts. Botanical Review 60: 373-425.

GutTERMAN, Y., AND S. GiNOTT. 1994. Long-term protected 'seed bank' in dry inflorescences of Asteriscus pygmaeus achene dispersal mechanism and germination. Annals of Botany 97: 47-55.

HEgazy, A. K., H. N. BARAKAT, AND H. F. KABIEL. 2006. Anatomical significance of the hygrochastic movement in Anastatica hierochuntica. Annals of Botany 97: 47-55.

Hijmans, R. J., S. E. CAMERon, J. L. PARRA, P. G. Jones, AND A. JARVIS. 2005. Very high resolution interpolated climate surfaces for global land areas. International Journal of Climatology 25: 1965-1978.

IHLENFELDT, H.-D. 1978. Morphologie und Taxonomie der Gattung Oophytum N. E. BR. (Mesembryanthemaceae) Botanische Jahrbuecher 99: 303-328.

1983. Dispersal of Mesembryanthemaceae in arid habitats. Sonderbaende des Naturwissenschaftlichen Vereins Hamburg 7: 381-390.

JACOBSEN, H. 1954. A handbook of succulent plants - descriptions, synonyms and clutural details for succulents other than Cactaceae. Blandford Press, London.

Katinas, L., J. CRisci, W. L. Wagner, AND P. C. HoCh. 2004. Geographical diversification of tribes Epilobieae, Gongylocarpeae, and Onagreae (Onagraceae) in North America, based on parsimony analysis of endemicity and track compatibility analysis. Annals of the Missouri Botanical Garden 91: 159-185. 
KaufMan, L., AND P. J. Rousseeuw. 1990. Findings groups in data: An introduction to cluster analysis. Wiley, New York.

KlaK, C., G. ReEves, AND T. HedDERSON. 2004. Unmatched tempo of evolution in southern African semi-desert ice-plants. Nature 427: 63-65.

LADYMAN, J. A. R. 2005. Oenothera harringtonii Wagner, Stockhouse \& Klein (Colorado Springs evening-primrose): A technical conservation assessment. In R. M. R. USDA Forest Service, Species Conservation Project [ed.], 1-43.

Levin, R. A., W. L. Wagner, P. C. Hoch, W. J. Hahn, A. Rodriguez, D. A. Baum, L. KatinAS, E. A. ZimMer, AND K. J. SYTSMA. 2004. Paraphyly in Tribe Onagreae: Insights into phylogenetic relationships of Onagraceae based on nuclear and chloroplast sequence data. Systematic Botany 29: 147-164.

MAdDison, D. R., AND W. P. MAdDISON. 2001. MacClade 4: Analysis of phylogeny and character evolution. Version 4.03. Sinauer Associates, Sunderland, Massachusetts.

MeudT, H. M. 2008. Taxonomic revision of Australasian snow hebes (Veronica, Plantaginaceae). Australian Systematic Botany 21: 387-421.

MEUDT, H. M., AND M. J. BAYLY. 2008. Phylogeographic patterns in the Australasian genus Chionohebe (Veronica s.1., Plantaginaceae) based on AFLP and chloroplast DNA sequences. Molecular Phylogenetics and Evolution 47: 319-338.

NAKANISHI, H. 2002. Splash seed dispersal by raindrops. Ecological Research 17: 663-671.

PAROLIN, P. 2001. Seed expulsion in fruits of Mesembryanthema (Aizoaceae): A mechanistic approach to study the effect of fruit morphological structures on seed dispersal. Flora (Jena) 196: 313-322.

. 2006. Ombrohydrochory: Rain-operated seed dispersal in plants - With special regard to jet-action dispersal in Aizoaceae. Flora (Jena) 201: 511-518.

POPPENDIECK, H.-H. 1995. Hygrochastic capsules in Oenothera (Onagraceae). Mitteilungen aus dem Institut fuer Allgemeine Botanik Hamburg 25: 99-115.

PRICE, M. V., AND J. W. JOYNER. 1997. What resources are available to desert granivores: seed rain or soil seed bank. Ecology 78: 764-773.

PUFAL, G., K.G. RYAN AND P. GARNOCK-JONES. 2010. Hygrochastic capsule dehiscence in New Zealand alpine Veronica (Plantaginaceae). American Journal of Botany 97: $1413-1423$

PUFAL AND P. GARNOCK-JONES. 2010. Hygrochastic capsule dehiscence supports safe site strategies in New Zealand alpine Veronica (Plantaginaceae). Annals of Botany 106: 405-412

RAVEN, P. H., AND D. I. AXELROD. 1978. Origin and relationships of the California flora. University of California Publications in Botany 72: 1-134.

SteInBRINCK, C. 1883. Ueber einige Fruchtgehaeuse, die ihre Samen infolge von Benetzung freilegen. Berichte der Deutschen Botanischen Gesellschaft 1: 339-347.

Straley, G. B. 1977. Systematics of Oenothera sect. Kneiffia. Annals of the Missouri Botanical Garden 64: 381-424.

Sytsma, K. J., A. Litt, M. L. Zijhra, J. C. Pires, M. Nepokroeff, E. Conti, J. Walker, AND P. G. WILSON. 2004. Clades, clocks, and continents: Historical and biogeographical analysis of Myrtaceae, Vochysiaceae, and relatives in the southern hemisphere. International Journal of Plant Sciences 165 (4 suppl.): S85-S105.

TEAM, R. D. C. 2005. R: A language and environment for statistical computing. R Foundation for statistical computing, Vienna, Austria.

Thulin, M. 1987. A new species of Xylocalyx (Scrophulariaceae) from Somalia. Nordic Journal of Botany 7: 267-269.

TOBE, H., W. L. WAGNER, AND H.-C. ChIN. 1987. A systematic and evolutionary study of Oenothera (Onagraceae): Seed coat anatomy. Botanical Gazette 148: 235-257.

VAN DER PIJL, L. 1982. Principles of dispersal in higher plants. Springer-Verlag, Berlin, Germany.

VAn OUdTShoOrn, R. K., AND M. W. VAN RoOyen. 1999. Dispersal biology of desert plants. Springer-Verlag, Berlin, Germany. 
VAn Rooyen, M. W., Theron, G.K., AND N. GrobbelaAR. 1990. Life form and dispersal spectra of the flora of Namaqualand, South Africa. Journal of Arid Environments 19: 133-145.

Van Rooyen, M. W., A. Barkhuizen, AND S. E. Myburgh. 1980. Seed distribution of some representatives of the Mesembryanthemaceae. Journal of South African Botany 46: $173-192$.

WAgner, W. L. 2005. Systematics of Oenothera sections Contortae, Eremia, and Ravenia (Onagraceae). Systematic Botany 30: 332-356.

Wagner, W. L., P. C. Hoch, AND P. H. RAVEN. 2007. Revised Classification of the Onagraceae. Systematic Botany Monographs 83: 1-240.

WAGSTAFF, S. J., AND P. GARNOCK-JONES. 1998. Evolution and biogeography of the Hebe complex (Scrophulariaceae) inferred from ITS sequences. New Zealand Journal of Botany 36: 425-437. . 2000. patterns of diversification in Chionohebe and Parahebe (Scrophulariaceae) inferred from ITS sequences. New Zealand Journal of Botany 38: 389-407.

WAGSTAFF, S. J., M. J. BAYLY, P. GARnOCK-JONES, AND D. AlBACH. 2002. Classification, origin, and diversification of the New Zealand Hebes (Scrophulariaceae). Annals of the Missouri Botanical Garden 89: 38-63.

WALCK, J. L., AND S. N. HidAYATI. 2007. Ombrohydrochory and its relationship to seed dispersal and germination strategies in two temperate North American Oenothera species (Onagraceae). International Journal of Plant Sciences 168: 1279-1290.

WARD, J. H. 1963. Hierarchical grouping to optimize an objective function. Journal of the American Statistical Association 58: 236-244.

Wolin, C. L., C. GALEN, AND L. WATKINS. 1984. The breeding system and aspects of pollination effectiveness in Oenothera speciosa (Onagraceae). The Southwestern Naturalist 29: 15-20.

ZOHARY, M., AND A. FAHN. 1941. Anatomical-carpological observations in some hygrochastic plants of the oriental flora. Palestinian Journal of Botany: 125-135. 


\section{CHAPTER SEVEN}

\section{SUMMARY AND CONCLUSION}

\subsection{Summary of key findings}

In this dissertation, I report a series of multidisciplinary studies that answer key questions about the evolution and ecology of hygrochastic capsule dehiscence. Furthermore, the biomechanics and anatomy of hygrochastic capsules have been discovered and described in a number of species of three unrelated genera. The following sections re-introduces the key questions and presents key findings from associated chapters.

- How does hygrochasy operate in the investigated species and what are the differences regarding capsule anatomy in different hygrochastic species and between hygrochastic species and their non-hygrochastic relatives?

In Chapter Two, capsule anatomy of 17 New Zealand Veronica was desribed using different light microscopy techniques and subsequent analysis of cell properties. Additional vegetative and reproductive morphological data of a total of $23 \mathrm{New}$ Zealand Veronica were collected and analysed. With this dataset I identified 15 species of Veronica as hygrochastic in the speedwell hebe and snow hebe clades (for phylogeny see Albach and Meudt, 2010) whereas eight related species were shown not to be hygrochastic. The hygrochastic movement is based on an imbibition mechanism (Fahn and Werker, 1972). In hygrochastic Veronica, a swelling tissue in the septum, consisting of elongated cells with non-lignified, thickened cell walls, 
absorbs water and subsequently expands. The expansion of the swelling tissue is converted into an opening movement by a lignified resistance tissue in the capsule valve, which does not change its size or shape. The general biomechanics and involved tissues responsible for the movement are consistent with findings from other species (Steinbrinck, 1883; Garside and Lockyer, 1930; Zohary and Fahn, 1941; Fahn and Werker, 1972; Poppendieck, 1995) but the position of tissues is unique to Veronica.

Hygrochasy was previously suspected in some New Zealand Colobanthus species with sessile capsules. Capsule material was collected in the field and from herbarium specimen (Chapter Four) and analysed using similar methods to those used in Chapter Two. Phylogenetic relationships between sessile species were suspected and samples from herbaria and field sites were analysed using nuclear and chloroplast markers to construct a phylogeny of this genus.

Contrary to previous assumptions, hygrochasy was detected in all investigated Colobanthus species and is suspected to occur in every species of the genus. Compared to woody hygrochastic capsules, which function with an imbibition mechanism (Fahn and Werker, 1972), the non-lignified Colobanthus capsules open through a combination of imbibition and cohesion mechanism. Here, the outer cells of the capsule have thickened cell walls on the outside, which absorb water and expand. The inner cell walls of those cells are thin and act as resistance tissue. The cohesion mechanism takes place in the inner cells of the capsule, where the cell lumen takes up water and the entire cells expand in size.

The phylogenetic analysis remains inconclusive but shows that Colobanthus is probably monophyletic within the Caryophyllaceae. No significant genetic differences 
could be detected among Colobanthus species, which might be due to recent rapid speciation after long distance dispersal events. The occurrence of hygrochasy in all Colobanthus species might be further evidence that species are very closely related and species delimitation is discussed.

I studied capsule material of nine Oenothera species from North America using microscopic sections and observations of movement after water absorption (Chapter Five). Additionally to previously known hygrochastic Oenothera (Brodie, 1951; Poppendieck, 1995), I confirmed three more species from subclade B (Wagner et al., 2007) as hygrochastic (O. fruticosa, O. linifolia, O. speciosa) and one xerochastic species (O. howardii), also from subclade B. Interestingly, results show that Oenothera pallida, a "ripening dehiscent"' species of subclade A, has a similar water absorbent endocarp to hygrochastic species. The capsules exhibit post-dehiscence hygrochastic movement, when the exocarp has disintegrated and the endocarp swells due to water absorption.

- How does hygrochasy affect dispersal in New Zealand alpine plants?

This question has been addressed in Chapter Three. Population size measurements and dispersal distance data have been collected for a number of hygrochastic and nonhygrochastic New Zealand Veronica to explore explanations for hygrochasy in alpine areas in New Zealand. Additionally, environmental data (LENZ IV) for a sample of collection sites were used in arcGIS to identify the width of the ecological niche of those species. This study shows that seeds of hygrochastic Veronica are primarily dispersed by raindrops, which results in only short dispersal distances. Secondary dispersal is highly unlikely due to the microtopography of the ground cover (e.g. 
crevices, gravel or rocky substrate). Hygrochastic alpine Veronica can only be found in small habitat patches that are distinctly different from the surrounding environment. Environmental details from the LENZ IV database provide evidence that hygrochastic Veronica in New Zealand are specialists with a small ecological niche compared to related non-hygrochastic species which may be found in a wide variety of habitats. This study shows that hygrochasy is an advantageous strategy for alpine Veronica with a narrow ecological niche to restrict seed dispersal to safe sites within small parental habitat patches.

- What are the reasons for hygrochasy in plants of different habitats and what is the evolutionary history of hygrochasy?

To answer this question, a meta-dataset of dispersal distances, seed retention and capsule opening times was used together with distribution data, environmental data and character evolution analysis to test whether traditional hypotheses for hygrochasy apply to plants of varying habitats (Chapter Six). Hygrochastic North American Oenothera were used as study group in comparison with hygrochastic New Zealand alpine Veronica and some hygrochastic South African Aizoaceae. Capsule opening times were faster in Veronica and Oenothera than Aizoaceae and all three study groups show short-distance dispersal. There was no common syndrome for hygrochastic plants across different families other than three or fewer capsules in one infrutescence and with an erect posture. Both alpine Veronica in New Zealand as well as Aizoaceae occur in small, restricted habitats. However, Veronica occur in a very humid environment with frequent rainfalls all year round, whereas most Aizoaceae can be found in arid areas with often highly seasonal rainfall. In contrast, most Oenothera are very widespread and are present in a range of different habitats with 
varying rainfall. Neither of the traditional hypotheses for hygrochasy (restriction in time or space) applied to the widespread Oenothera species of present times. However, patterns of character evolution, ages of clades and geological and climate histories suggests that Oenothera might have evolved as part of the Madro-Tertiary flora (Raven and Axelrod, 1978; Tobe et al., 1987; Katinas et al., 2004; Sytsma et al., 2004), where hygrochasy could have posed an advantage to restrict dispersal to rare, seasonal rainfall events.

\subsection{Conclusion and future directions}

In this dissertation I have been able to answer a number of question regarding the evolution and ecology of hygrochastic capsule dehiscence in a range of species.

Hygrochasy is a specialised capsule opening mechanism that restricts seed dispersal by using raindrops as primary dispersal agents, resulting in short-distance dispersal (atelechory). Traditionally, hygrochasy has been mostly associated with plants of arid regions, especially Aizoaceae in Southern Africa (Ellner and Shmida, 1981; Ihlenfeldt, 1983; Van Oudtshoorn and Van Rheede, 1999; Parolin, 2001, 2006). Here, it was thought that it not only restricts dispersal in space but also in time, by limiting dispersal to times of rainfall, when germination conditions are favourable (Van Oudtshoorn and Van Rheede, 1999). The studies presented in my dissertation show that hygrochasy is not only a feature of desert plants but can also play an important role in alpine areas of New Zealand. Additionally, I was able to identify and describe hygrochasy in a number of species previously not known to be hygrochastic. The hypothesis of hygrochasy as an atelechoric strategy applies to hygrochastic Veronica in alpine areas but the wide distribution of hygrochastic Oenothera across Northern America and into South America defies traditional hypotheses associated with 
hygrochasy at first glance. However, they might have played a role when Oenothera first emerged as part of the Madro-Tertiary flora, when climatic circumstances were very different from the present day climate.

In a broader context my research shows that hygrochasy is not as rare and restricted as previously thought. It occurs in a wide range of habitats and in very different unrelated genera; some of them have never been associated with hygrochasy until now (e.g. Colobanthus).

I have shown that hygrochasy can play an important role for the dispersal of some alpine species and it is highly likely that other alpine cushion plants with sessile capsules might exhibit hygrochasy. For example, some Myosotis and Sagina in Japan were reported as hygrochastic (Nakanishi, 2002) and their alpine relatives might show this dehiscence type as well. Further research in alpine areas, not only in New Zealand but also elsewhere is warranted.

Occurrence data and associated GIS-based environmental data are increasingly being used in investigating ranges and distribution of plant species. In this study I take a novel approach by testing hypotheses about dispersal strategies with the use of these data. GIS-based information is increasingly updated and refined and often freely available online. These resources can provide tools to explore different theories and hypotheses about dispersal, distribution and analyse relationships between occurrence data, plant traits and habitats.

Larger data sets and more accurate location information of hygrochastic species would provide a clearer picture about the role of hygrochasy in plant dispersal and distribution. 
It appears that hygrochasy is a labile character and occurs in many unrelated genera. However, even within genera, the evolution of hygrochasy is diverse - it might have evolved only once in Oenothera and has then shifted to other mechanisms, whereas in Veronica it evolved several times independently but always shows the same structure. Further investigations especially in Colobanthus are worth persuing. The phylogeny is still unresolved and should be approached with different methods, such as AFLPs or microsatellites. It is important to explore the chance of long-distance dispersal between South America, Antarctica, the subantarctic Islands and New Zealand and Australia, especially since all species are hygrochastic and therefore predominantly short-distance dispersed.

I hope that the studies presented in this dissertation will inspire researchers to investigate not only hygrochasy but also other, little known dispersal strategies and their important role in plant distribution. Often the inconspicuous and overlooked details are very intriguing and evoke the desire to learn more about them. And sometimes these inconspicuous things, such as small capsules embedded in cushion plants on the top of mountains prove to be a lot more interesting than they appear to be at first glance. They mark the beginning of a study that spans continents and vastly different plants with very different capsules. Yet they are united by one small movement - they open when it rains. 


\subsection{References}

AlbaCh, D. C., AND H. M. Meudt 2010. Phylogeny of Veronica in the Southern and Northern Hemispheres based on plastid, nuclear ribosomal and nuclear low-copy DNA. Molecular Phylogenetics and Evolution 54: 457-471.

Brodie, H. J. 1951. The splash-cup dispersal mechanism in plants. Canadian Journal of Botany 29: 224-234.

ELLNER, S., AND A. SHMIDA. 1981. Why are adaptations for long-range seed dispersal rare in desert plants? . Oecologia (Berlin) 51: 133-144.

FAHN, A., AND E. WERKER. 1972. Anatomical mechanisms of seed dispersal. In T. T. Kozlowski [ed.], Seed Biology, 152-221. Academic Press, New York, USA.

GARSIDE, S., AND S. LOCKYER. 1930. Seed dispersal from the hygroscopic fruits of Mesembryanthemum carpanthea (Mesembryanthemum) pomeridiana, N. E. Br. Annals of Botany 44: 639-U636.

IHLENFELDT, H.-D. 1983. Dispersal of Mesembryanthemaceae in arid habitats. Sonderbaende des Naturwissenschaftlichen Vereins Hamburg 7: 381-390.

Katinas, L., J. CRisci, W. L. WAGNeR, AND P. C. Hoch. 2004. Geographical diversification of tribes Epilobieae, Gongylocarpeae, and Onagreae (Onagraceae) in North America, based on parsimony analysis of endemicity and track compatibility analysis. Annals of the Missouri Botanical Garden 91: 159-185.

NAKANISHI, H. 2002. Splash seed dispersal by raindrops. Ecological Research 17: 663-671.

PAROLIN, P. 2001. Seed expulsion in fruits of Mesembryanthema (Aizoaceae): A mechanistic approach to study the effect of fruit morphological structures on seed dispersal. Flora (Jena) 196: 313-322.

2006. Ombrohydrochory: Rain-operated seed dispersal in plants - With special regard to jet-action dispersal in Aizoaceae. Flora (Jena) 201: 511-518.

POPPENDIECK, H.-H. 1995. Hygrochastic capsules in Oenothera (Onagraceae). Mitteilungen aus dem Institut fuer Allgemeine Botanik Hamburg 25: 99-115.

RAVEN, P. H., AND D. I. AXELROD. 1978. Origin and relationships of the California flora. University of California Publications in Botany 72: 1-134.

STEINBRINCK, C. 1883. Ueber einige Fruchtgehaeuse, die ihre Samen infolge von Benetzung freilegen. Berichte der Deutschen Botanischen Gesellschaft 1: 339-347.

Sytsma, K. J., A. Litt, M. L. Zijhra, J. C. Pires, M. Nepokroeff, E. Conti, J. Walker, AND P. G. WILSON. 2004. Clades, clocks, and continents: Historical and biogeographical analysis of Myrtaceae, Vochysiaceae, and relatives in the southern hemisphere. International Journal of Plant Sciences 165 (4 suppl.): S85-S105.

ToBe, H., W. L. WAGNER, AND H.-C. CHIN. 1987. A systematic and evolutionary study of Oenothera (Onagraceae): Seed coat anatomy. Botanical Gazette 148: 235-257.

VAN OUdTSHOORN, R. K., AND M. W. VAN ROOYEN. 1999. Dispersal biology of desert plants. Springer-Verlag, Berlin, Germany.

Wagner, W. L., P. C. Hoch, AND P. H. RaVen. 2007. Revised Classification of the Onagraceae. Systematic Botany Monographs 83: 1-240.

ZOHARY, M., AND A. FAHN. 1941. Anatomical-carpological observations in some hygrochastic plants of the oriental flora. Palestinian Journal of Botany: 125-135. 


\section{APPENDIX}

\section{Appendix 2.1}

List of species used in the study. Given are origin of capsules (with voucher identification) and number of capsules used for different experiments. Species with a WELTU voucher number were collected for this study.

\begin{tabular}{|c|c|c|c|c|c|c|c|}
\hline species & location & altitude & coordinates & voucher & water test & cryostat & ultratome \\
\hline V. catarractae & Hawkes Bay, North Island & & & CHR535074 & 5 & 3 & 2 \\
\hline V. cheesemanii & $\begin{array}{c}\text { Mt Patriarch, Richmond Forest Park, South } \\
\text { Island }\end{array}$ & $1590 \mathrm{~m}$ & $\mathrm{~S} 41^{\circ} 36^{\prime} 34.8^{\prime \prime} \mathrm{E} 173^{\circ} 13^{\prime} 28.4^{\prime \prime}$ & WELTU20233 & 5 & 1 & 2 \\
\hline V. ciliolata & $\begin{array}{c}\text { Sealey Range, Mt Cook Aoraki National Park, } \\
\text { South Island }\end{array}$ & $1782 \mathrm{~m}$ & S 434’02.5”; E 17003'53.1” & WELTU20231 & 4 & 1 & 1 \\
\hline V. colostylis & Franz Joseph Glacier, South Island & & & CHR140140 & 2 & 1 & 1 \\
\hline V. decora & $\begin{array}{c}\text { Lakeside Track, Lake Rotoiti, Nelson, South } \\
\text { Island }\end{array}$ & $625 \mathrm{~m}$ & S 4152’06.8”; E 17249’18.2” & WELTU20231 & 5 & 2 & 3 \\
\hline$V$. densifolia & $\begin{array}{c}\text { Remarkables Skifield, Central Otago, South } \\
\text { Island }\end{array}$ & $1719 \mathrm{~m}$ & S 4503'32.1" E 16849'06.2” & WELTU20234 & 6 & 3 & 3 \\
\hline V. hookeriana & Mt Ruapehu Skifield, North Island & $1615 \mathrm{~m}$ & S 39¹8’20.4”; E 175³1'32.4”' & WELTU20238 & 6 & 3 & 3 \\
\hline$V$. lanceolata & $\begin{array}{c}\text { Waterfall track, granite cliff, Mt Ruapheu. } \\
\text { North Island }\end{array}$ & $1222 \mathrm{~m}$ & S 39¹9’51.8”; E 175²9’51.9” & WELTU20242 & 5 & 3 & 2 \\
\hline V. lilliputiana & Ashburton River, Lake Camp, South Island & $685 \mathrm{~m}$ & & CHR403927 & 4 & 1 & 1 \\
\hline V. lyallii & $\begin{array}{l}\text { Fox Glacier walking track, Fox Glacier, South } \\
\text { Island }\end{array}$ & $244 \mathrm{~m}$ & $\mathrm{~S} 43^{\circ} 29^{\prime} 50.5^{\prime \prime} \mathrm{E} 170^{\circ} 02^{\prime} 50.5^{\prime \prime}$ & WELTU20235 & 6 & 3 & 3 \\
\hline V. melanocaulon & $\begin{array}{c}\text { Blue Mountains Station, Waimara River, South } \\
\text { Island }\end{array}$ & $100 \mathrm{~m}$ & $\mathrm{~S} 41^{\circ} 52^{\prime} ; \mathrm{E} 173^{\circ} 49^{\prime}$ & CHR517481 & 2 & 1 & 1 \\
\hline$V \cdot$ planopetiolata & Mount Dick, Kingston, South Island & & & CHR512626 & 2 & 1 & 1 \\
\hline V.pulvinaris & $\begin{array}{c}\text { Mt Robert Ridgetrack, Nelson Lakes National } \\
\text { Park, South Island }\end{array}$ & $1649 \mathrm{~m}$ & $\mathrm{~S} 41^{\circ} 50^{\prime} 59.9^{\prime \prime} \mathrm{E} 172^{\circ} 47^{\prime} 14.5^{\prime \prime}$ & WELTU20241 & 6 & 2 & 2 \\
\hline$V$. senex & $\begin{array}{c}\text { Webb Stream, Anatori Valley, Nelson, South } \\
\text { Island }\end{array}$ & $6 \mathrm{~m}$ & S $40^{\circ} 42.76^{\prime} ;$ E $177^{\circ} 22^{\prime}$ & CHR547075B & 2 & 1 & 1 \\
\hline V. spathulata & Mt Ruapehu Skifield, North Island & $1620 \mathrm{~m}$ & S 39¹8'20.4”; E 175³1'32.4”' & WELTU20239 & 6 & 3 & 3 \\
\hline V. thomsonii & Mt Dobson Skifield, South Island & $1760 \mathrm{~m}$ & $\mathrm{~S} 43^{\circ} 56^{\prime} 36.1^{\prime \prime} ; \mathrm{E} 170^{\circ} 39^{\prime} 55.1^{\prime \prime}$ & WELTU20237 & 6 & 3 & 3 \\
\hline V. trifida & Blue Lake, Garvie Mountains, South Island & $1344 \mathrm{~m}$ & $\mathrm{~S} 45^{\circ} 28^{\prime} 33.4^{\prime \prime} ; \mathrm{E} 168^{\circ} 56^{\prime} 11.5^{\prime \prime}$ & WELTU20240 & 6 & 2 & 1 \\
\hline
\end{tabular}




\section{Appendix 2.2}

Measurements of cells in ultratome sections and change of ST length in cryostat sections.

Measuremenst are given in $\mu \mathrm{m}$, the change is measured in \%. STL - length of cells in swelling tissue (ST); STW - width of cells in the ST; STCW - thickness of cell walls in ST; RTDIA - diameter of cells in the resistance tissue (RT); RTCW - thickness of cell walls in the RT; change - percentage change of the length of ST after water absorption.

\begin{tabular}{|c|c|c|c|c|c|c|}
\hline species & STL & STW & STCW & RTDIA & RTCW & change \\
\hline V. cheesemanii & 105 & 30 & 12 & 27 & 6 & 30.43 \\
\hline$V$. cheesemanii & 117 & 33 & 12 & 30 & 6 & 41.33 \\
\hline$V$. cheesemanii & 105 & 27 & 12 & 27 & 6 & 28.40 \\
\hline$V$. cheesemanii & 117 & 36 & 15 & 18 & 3 & 26.19 \\
\hline V. cheesemanii & 120 & 33 & 12 & 21 & 3 & 51.20 \\
\hline V. cheesemanii & 120 & 30 & 12 & 27 & 6 & 61.25 \\
\hline$V$. cheesemanii & 120 & 27 & 12 & 24 & 6 & 28.69 \\
\hline$V$. cheesemanii & 114 & 30 & 12 & 30 & 6 & 32.20 \\
\hline$V$. cheesemanii & 120 & 30 & 15 & 21 & 4.5 & 59.40 \\
\hline V. cheesemanii & 108 & 27 & 12 & 24 & 4.5 & 54.80 \\
\hline$V$. ciliolata & 129 & 30 & 12 & 30 & 9 & 49.69 \\
\hline V. ciliolata & 111 & 24 & 9 & 18 & 6 & 56.03 \\
\hline V. ciliolata & 108 & 24 & 9 & 24 & 9 & 50.29 \\
\hline V. ciliolata & 120 & 21 & 6 & 18 & 9 & 53.12 \\
\hline V. ciliolata & 108 & 24 & 10.5 & 21 & 9 & 62.49 \\
\hline V. ciliolata & 120 & 27 & 10.5 & 24 & 9 & 85.55 \\
\hline V. ciliolata & 111 & 24 & 9 & 24 & 9 & 70.56 \\
\hline V. ciliolata & 99 & 27 & 7.5 & 30 & 9 & 62.93 \\
\hline V. ciliolata & 120 & 27 & 12 & 27 & 10.5 & 46.32 \\
\hline$V$. ciliolata & 105 & 24 & 9 & 18 & 6 & 40.00 \\
\hline V. colostylis & 105 & 24 & 9 & 36 & 12 & 67.03 \\
\hline V. colostylis & 90 & 24 & 9 & 36 & 9 & 85.86 \\
\hline V. colostylis & 84 & 18 & 6 & 36 & 12 & 97.40 \\
\hline V. colostylis & 105 & 24 & 6 & 42 & 9 & 99.94 \\
\hline V. colostylis & 90 & 15 & 6 & 30 & 7.5 & 79.61 \\
\hline V. colostylis & 99 & 24 & 6 & 18 & 9 & 67.99 \\
\hline V. colostylis & 102 & 21 & 6 & 24 & 9 & 58.23 \\
\hline V. colostylis & 90 & 21 & 6 & 24 & 6 & 65.99 \\
\hline V. colostylis & 96 & 21 & 6 & 21 & 7.5 & 93.06 \\
\hline V. colostylis & 90 & 21 & 7.5 & 15 & 6 & 72.71 \\
\hline V. densifolia & 240 & 36 & 18 & 30 & 9 & 11.63 \\
\hline V. densifolia & 249 & 36 & 18 & 30 & 9 & 12.11 \\
\hline V. densifolia & 240 & 42 & 18 & 27 & 6 & 18.86 \\
\hline V. densifolia & 210 & 48 & 24 & 30 & 9 & 20.51 \\
\hline V. densifolia & 285 & 36 & 15 & 30 & 9 & 20.60 \\
\hline V. densifolia & 300 & 33 & 15 & 30 & 12 & 36.77 \\
\hline V. densifolia & 300 & 36 & 15 & 33 & 9 & 38.10 \\
\hline V. densifolia & 255 & 30 & 15 & 24 & 9 & 30.25 \\
\hline V. densifolia & 255 & 30 & 12 & 33 & 12 & 29.02 \\
\hline V. densifolia & 240 & 30 & 12 & 27 & 9 & 40.74 \\
\hline V. lilliputiana & 60 & 21 & 9 & 36 & 9 & 26.83 \\
\hline
\end{tabular}




\begin{tabular}{|c|c|c|c|c|c|c|}
\hline V. lilliputiana & 75 & 24 & 7.5 & 30 & 4.5 & 22.40 \\
\hline$V$. lilliputiana & 75 & 42 & 10.5 & 36 & 9 & 22.67 \\
\hline V. lilliputiana & 90 & 27 & 9 & 24 & 4.5 & 40.39 \\
\hline$V$. lilliputiana & 60 & 33 & 9 & 36 & 9 & 33.34 \\
\hline V. lilliputiana & 72 & 27 & 6 & 33 & 6 & 55.43 \\
\hline V. lilliputiana & 60 & 27 & 6 & 27 & 6 & 36.64 \\
\hline$V$. lilliputiana & 54 & 27 & 6 & 36 & 6 & 27.85 \\
\hline$V$. lilliputiana & 75 & 30 & 9 & 30 & 4.5 & 26.25 \\
\hline$V$. lilliputiana & 60 & 36 & 9 & 36 & 3 & 24.48 \\
\hline$V \cdot$ planopetiolata & 180 & 36 & 18 & 33 & 9 & 39.48 \\
\hline$V$. planopetiolata & 147 & 39 & 18 & 24 & 6 & 42.33 \\
\hline$V \cdot$ planopetiolata & 168 & 42 & 15 & 27 & 6 & 55.93 \\
\hline$V \cdot$ planopetiolata & 156 & 36 & 15 & 27 & 9 & 33.92 \\
\hline$V$. planopetiolata & 168 & 36 & 15 & 30 & 6 & 41.57 \\
\hline$V$. planopetiolata & 165 & 30 & 12 & 24 & 6 & 51.21 \\
\hline$V \cdot$ planopetiolata & 168 & 30 & 12 & 24 & 6 & 70.55 \\
\hline$V$. planopetiolata & 150 & 36 & 15 & 27 & 6 & 63.99 \\
\hline$V \cdot$ planopetiolata & 132 & 30 & 15 & 24 & 6 & 67.73 \\
\hline$V \cdot$ planopetiolata & 171 & 42 & 18 & 24 & 4.5 & 68.20 \\
\hline$V \cdot$ pulvinaris & 138 & 36 & 15 & 30 & 9 & 42.26 \\
\hline V.pulvinaris & 144 & 36 & 15 & 24 & 9 & 33.93 \\
\hline$V \cdot$ pulvinaris & 135 & 27 & 12 & 27 & 9 & 35.95 \\
\hline$V \cdot$ pulvinaris & 135 & 30 & 12 & 27 & 9 & 67.19 \\
\hline V.pulvinaris & 129 & 30 & 9 & 27 & 9 & 30.36 \\
\hline$V \cdot$ pulvinaris & 114 & 36 & 16.5 & 27 & 6 & 42.57 \\
\hline$V \cdot$ pulvinaris & 210 & 30 & 15 & 24 & 6 & 41.46 \\
\hline$V \cdot$ pulvinaris & 195 & 36 & 18 & 27 & 9 & 30.68 \\
\hline$V \cdot$ pulvinaris & 150 & 27 & 12 & 30 & 6 & 31.99 \\
\hline V.pulvinaris & 150 & 27 & 13.5 & 30 & 7.5 & 66.59 \\
\hline V. spathulata & 120 & 36 & 15 & 30 & 9 & 21.95 \\
\hline V. spathulata & 105 & 30 & 12 & 39 & 9 & 49.45 \\
\hline V. spathulata & 165 & 30 & 12 & 36 & 9 & 56.30 \\
\hline V. spathulata & 150 & 27 & 9 & 30 & 9 & 45.63 \\
\hline V. spathulata & 120 & 24 & 12 & 42 & 12 & 53.97 \\
\hline V. spathulata & 165 & 39 & 12 & 33 & 9 & 23.66 \\
\hline V. spathulata & 135 & 27 & 9 & 39 & 9 & 65.15 \\
\hline V. spathulata & 150 & 30 & 12 & 48 & 12 & 35.14 \\
\hline V. spathulata & 135 & 30 & 12 & 36 & 12 & 22.57 \\
\hline V. spathulata & 114 & 27 & 9 & 30 & 9 & 51.42 \\
\hline V. thomsonii & 177 & 36 & 15 & 24 & 9 & 20.71 \\
\hline$V$. thomsonii & 174 & 30 & 12 & 18 & 6 & 24.47 \\
\hline$V$. thomsonii & 174 & 39 & 12 & 27 & 9 & 26.56 \\
\hline$V$. thomsonii & 180 & 36 & 12 & 30 & 9 & 35.88 \\
\hline V. thomsonii & 177 & 33 & 9 & 24 & 9 & 28.77 \\
\hline$V$. thomsonii & 120 & 24 & 12 & 27 & 6 & 25.72 \\
\hline$V$. thomsonii & 90 & 24 & 12 & 24 & 6 & 30.29 \\
\hline$V$. thomsonii & 126 & 24 & 10.5 & 21 & 6 & 23.18 \\
\hline$V$. thomsonii & 105 & 24 & 12 & 27 & 9 & 39.78 \\
\hline
\end{tabular}




\begin{tabular}{|c|c|c|c|c|c|c|}
\hline V. thomsonii & 120 & 21 & 9 & 30 & 9 & 43.98 \\
\hline V. trifida & 78 & 30 & 9 & 33 & 6 & 24.23 \\
\hline V. trifida & 69 & 30 & 10.5 & 27 & 4.5 & 22.69 \\
\hline V. trifida & 78 & 27 & 10.5 & 30 & 9 & 39.78 \\
\hline V. trifida & 84 & 30 & 9 & 30 & 9 & 18.98 \\
\hline V. trifida & 84 & 36 & 12 & 33 & 6 & 23.38 \\
\hline V. trifida & 87 & 24 & 9 & 30 & 6 & 11.45 \\
\hline V. trifida & 84 & 24 & 7.5 & 33 & 6 & 40.94 \\
\hline V. trifida & 90 & 24 & 9 & 27 & 6 & 20.92 \\
\hline V. trifida & 84 & 27 & 9 & 30 & 9 & 50.78 \\
\hline V. trifida & 75 & 24 & 12 & 30 & 6 & 19.07 \\
\hline V. catarractae & 36 & 36 & 9 & 30 & 12 & 2.35 \\
\hline V. catarractae & 30 & 30 & 12 & 30 & 9 & -11.51 \\
\hline V. catarractae & 45 & 27 & 12 & 24 & 6 & 4.35 \\
\hline V. catarractae & 45 & 45 & 12 & 33 & 12 & -1.03 \\
\hline V. catarractae & 42 & 42 & 9 & 30 & 9 & 3.15 \\
\hline V. catarractae & 51 & 30 & 15 & 36 & 12 & -1.32 \\
\hline V. catarractae & 33 & 33 & 12 & 33 & 9 & -2.80 \\
\hline V. catarractae & 36 & 36 & 9 & 30 & 9 & 1.39 \\
\hline V. catarractae & 30 & 30 & 9 & 39 & 13.5 & -4.35 \\
\hline V. catarractae & 42 & 42 & 12 & 21 & 9 & -8.13 \\
\hline$V$. decora & 33 & 33 & 9 & 24 & 6 & -3.64 \\
\hline V. decora & 24 & 24 & 6 & 24 & 6 & 5.79 \\
\hline V. decora & 24 & 24 & 6 & 24 & 4.5 & -3.92 \\
\hline V. decora & 27 & 27 & 6 & 30 & 6 & 3.19 \\
\hline V. decora & 30 & 30 & 9 & 27 & 6 & -1.88 \\
\hline V. decora & 21 & 36 & 7.5 & 36 & 9 & -3.59 \\
\hline V. decora & 21 & 30 & 6 & 27 & 9 & -1.44 \\
\hline V. decora & 18 & 45 & 6 & 24 & 6 & 2.46 \\
\hline V. decora & 21 & 36 & 6 & 30 & 7.5 & 0.81 \\
\hline$V$. decora & 21 & 36 & 7.5 & 36 & 10.5 & 0.28 \\
\hline V. hookeriana & 24 & 24 & 6 & 24 & 6 & -3.82 \\
\hline V. hookeriana & 33 & 33 & 6 & 33 & 6 & -5.22 \\
\hline V. hookeriana & 27 & 27 & 6 & 27 & 6 & 3.88 \\
\hline V. hookeriana & 33 & 33 & 6 & 33 & 6 & 1.75 \\
\hline V. hookeriana & 30 & 30 & 7.5 & 30 & 7.5 & 9.87 \\
\hline V. hookeriana & 24 & 24 & 7.5 & 24 & 7.5 & -8.78 \\
\hline V. hookeriana & 30 & 30 & 6 & 30 & 6 & -5.23 \\
\hline V. hookeriana & 30 & 30 & 9 & 30 & 9 & -2.43 \\
\hline V. hookeriana & 36 & 36 & 7.5 & 36 & 7.5 & 5.65 \\
\hline V. hookeriana & 27 & 27 & 6 & 27 & 6 & 2.70 \\
\hline V. lanceolata & 24 & 30 & 6 & 21 & 6 & 2.03 \\
\hline V. lanceolata & 30 & 30 & 9 & 30 & 12 & 3.13 \\
\hline$V$. lanceolata & 36 & 27 & 9 & 33 & 12 & -2.93 \\
\hline V. lanceolata & 21 & 39 & 9 & 27 & 9 & -0.03 \\
\hline$V$. lanceolata & 33 & 30 & 12 & 27 & 9 & 3.40 \\
\hline V. lanceolata & 18 & 30 & 9 & 36 & 12 & -5.64 \\
\hline$V$. lanceolata & 24 & 30 & 9 & 36 & 15 & -4.55 \\
\hline
\end{tabular}




\begin{tabular}{|c|c|c|c|c|c|c|}
\hline V. lanceolata & 30 & 30 & 7.5 & 30 & 10.5 & -4.14 \\
\hline$V$. lanceolata & 33 & 33 & 12 & 42 & 15 & -1.63 \\
\hline$V$. lanceolata & 30 & 42 & 9 & 36 & 15 & 1.93 \\
\hline V. lyallii & 18 & 33 & 6 & 24 & 6 & -6.59 \\
\hline V. lyallii & 21 & 42 & 9 & 27 & 7.5 & -2.05 \\
\hline V. lyallii & 24 & 24 & 7.5 & 24 & 6 & -6.02 \\
\hline V. lyallii & 18 & 36 & 6 & 30 & 9 & 5.46 \\
\hline V. lyallii & 15 & 39 & 6 & 30 & 7.5 & -4.21 \\
\hline V. lyallii & 33 & 33 & 9 & 18 & 6 & -2.46 \\
\hline V. lyallii & 15 & 39 & 6 & 21 & 7.5 & 3.35 \\
\hline V. lyallii & 21 & 30 & 7.5 & 36 & 6 & -0.33 \\
\hline V. lyallii & 24 & 42 & 9 & 24 & 4.5 & 0.56 \\
\hline V. lyallii & 24 & 39 & 7.5 & 27 & 6 & 3.01 \\
\hline$V$. melanocaulon & 27 & 27 & 6 & 18 & 6 & -13.21 \\
\hline$V$. melanocaulon & 24 & 24 & 6 & 15 & 6 & -3.56 \\
\hline V. melanocaulon & 24 & 24 & 6 & 15 & 6 & -11.33 \\
\hline V. melanocaulon & 30 & 27 & 7.5 & 18 & 6 & -6.42 \\
\hline$V$. melanocaulon & 27 & 27 & 6 & 21 & 7.5 & -4.49 \\
\hline$V$. melanocaulon & 30 & 30 & 9 & 21 & 6 & -7.04 \\
\hline$V$. melanocaulon & 28.5 & 27 & 7.5 & 18 & 6 & -5.00 \\
\hline$V$. melanocaulon & 21 & 18 & 4.5 & 15 & 6 & 1.71 \\
\hline$V$. melanocaulon & 24 & 24 & 6 & 18 & 6 & -4.00 \\
\hline V. melanocaulon & 24 & 24 & 4.5 & 18 & 6 & -3.23 \\
\hline$V$. senex & 24 & 51 & 9 & 30 & 9 & 0.98 \\
\hline$V$. senex & 33 & 54 & 12 & 30 & 9 & -16.82 \\
\hline$V$. senex & 36 & 36 & 12 & 27 & 9 & -10.75 \\
\hline$V$. senex & 42 & 42 & 12 & 27 & 6 & -0.39 \\
\hline$V$. senex & 30 & 30 & 9 & 21 & 6 & -8.19 \\
\hline$V$. senex & 18 & 33 & 6 & 33 & 9 & -5.77 \\
\hline$V$. senex & 27 & 27 & 9 & 30 & 9 & -0.65 \\
\hline$V$. senex & 36 & 36 & 9 & 27 & 9 & 1.40 \\
\hline$V$. senex & 30 & 42 & 9 & 33 & 9 & 1.48 \\
\hline$V$. senex & 24 & 33 & 6 & 30 & 7.5 & 0.56 \\
\hline
\end{tabular}




\section{Appendix 3.2.1}

Coordinates and associated elevation of locations used for experiments in habitat patches (transect and quadrats) and t-square index (TS). Hygrochastic species are shown in bold.

\begin{tabular}{|c|c|c|c|c|c|}
\hline \# & species & location & coordinates & Elevation (m) & experiment \\
\hline 1 & V. cheesemanii & Mt Robert Skifield & S 41 ${ }^{\circ} 50^{\prime} 42.1^{\prime \prime} \mathrm{E} 172^{\circ} 47^{\prime} 59.6^{\prime \prime}$ & 1507 & transect/quadrats/TS \\
\hline 2 & V. cheesemanii & Mt Robert Ridgetrack & S 41 ${ }^{\circ} 50^{\prime} 49.4^{\prime \prime}$ E $172^{\circ} 47^{\prime} 30.7 "$ & 1601 & transect/quadrats \\
\hline 3 & V. cheesemanii & Mole Tops scree & $\mathrm{S} 41^{\circ} 57^{\prime} 59.5^{\prime \prime} \mathrm{E} 172^{\circ} 34^{\prime} 51.2^{\prime \prime}$ & 1556 & transect/quadrats \\
\hline 4 & V. cheesemanii & Mole Tops & S 41 ${ }^{\circ} 58^{\prime} 05.4^{\prime \prime}$ E $172^{\circ} 34^{\prime} 54.4^{\prime \prime}$ & 1644 & transect/quadrats \\
\hline 5 & V. cheesemanii & Mt. Patriarch & $\mathrm{S} 41^{\circ} 36^{\prime} 34.8^{\prime \prime} \mathrm{E} 173^{\circ} 13^{\prime} 28.4^{\prime \prime}$ & 1590 & TS \\
\hline 6 & $V$. densifolia & Waiorau Snow Farm & 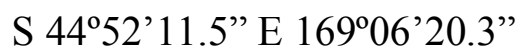 & 1560 & transect/quadrats \\
\hline 7 & $V$. densifolia & Coronet Peak & 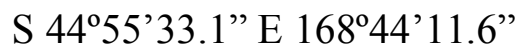 & 1237 & transect/quadrats \\
\hline 8 & $V$. densifolia & Remarkables Skifield & S 4503'32.1" E $168^{\circ} 49^{\prime} 06.2^{\prime \prime}$ & 1719 & transect/quadrats/TS \\
\hline 9 & $V$. densifolia & Blue Lake & S 4529'05.3" E $168^{\circ} 55^{\prime} 45.1^{\prime \prime}$ & 1412 & TS \\
\hline 10 & $V \cdot$ pulvinaris & Mt Robert Skifield & $\mathrm{S} 41^{\circ} 50^{\prime} 38.1^{\prime \prime} \mathrm{E} 172^{\circ} 48^{\prime} 04.5^{\prime \prime}$ & 1565 & transect/quadrats/TS \\
\hline 11 & $V \cdot$ pulvinaris & Mole Tops & S 41 ${ }^{\circ} 58^{\prime} 05.4^{\prime \prime}$ E $172^{\circ} 34^{\prime} 54.4^{\prime \prime}$ & 1644 & transect/quadrats \\
\hline 12 & $V \cdot$ pulvinaris & Mt Robert Ridgetrack & $\mathrm{S} 41^{\circ} 50^{\prime} 59.9^{\prime \prime} \mathrm{E} 172^{\circ} 47^{\prime} 14.5^{\prime \prime}$ & 1649 & transect/quadrats \\
\hline 13 & V.thomsonii & Remarkables Skifield & $\mathrm{S} 45^{\circ} 03^{\prime} 32.1^{\prime \prime} \mathrm{E} 168^{\circ} 49^{\prime} 06.2^{\prime \prime}$ & 1719 & transect/quadrats \\
\hline 14 & V.thomsonii & Remarkables Skifield & $\mathrm{S} 45^{\circ} 03^{\prime} 40.1^{\prime \prime} \mathrm{E} 168^{\circ} 49^{\prime} 00.0^{\prime \prime}$ & 1737 & transect/quadrats \\
\hline 15 & V.thomsonii & Remarkables track & S 4503'26.4” E $168^{\circ} 49^{\prime} 04.8^{\prime \prime}$ & 1667 & transect/quadrats \\
\hline 16 & $V$. decora & Arthurs Pass village & $\mathrm{S} 42^{\circ} 56^{\prime} 03.6^{\prime \prime} \mathrm{E} 171^{\circ} 33^{\prime} 34.8^{\prime \prime}$ & 771 & transect/quadrats \\
\hline 17 & $V$. decora & Kea Point, Mount Cook Village & $\mathrm{S} 43^{\circ} 42^{\prime} 55.1^{\prime \prime} \mathrm{E} 170^{\circ} 05^{\prime} 09.2^{\prime \prime}$ & 309 & transect/quadrats \\
\hline 18 & V. lyallii & Klondyke corner, Arthurs pass & S 4300'01.9” E $171^{\circ} 35^{\prime} 26.2^{\prime \prime}$ & 722 & transect/quadrats \\
\hline 19 & V. lyallii & Otira valley & S 42053'43.4" E $171^{\circ} 32^{\prime} 29.9 "$ & 991 & transect/quadrats \\
\hline 20 & V. lyallii & Fox Glacier walking track & $\mathrm{S} 43^{\circ} 29^{\prime} 50.5^{\prime \prime} \mathrm{E} 170^{\circ} 02^{\prime} 50.5^{\prime \prime}$ & 244 & transect/quadrats \\
\hline
\end{tabular}




\section{Appendix 4.2.1}

Location details and experiment information for species used in this study. Shown is the number of capsules that were used for cell measurements and SEM microgrpahs.

\begin{tabular}{|c|c|c|c|c|}
\hline species & location & voucher number & measurements & SEM \\
\hline C. acicularis & $\begin{array}{l}\text { Mt Kaweka, Kaweka Range, New } \\
\text { Zealand }\end{array}$ & CHR358804 & 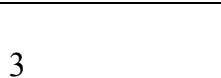 & 1 \\
\hline C. affinis & $\begin{array}{l}\text { Egmont, New Zealand } \\
\text { Blue Lake, Garvie Mountains, New }\end{array}$ & CHR86723 & 4 & 0 \\
\hline C. apetalus & Zealand & WELTU20257 & 3 & 1 \\
\hline C. brevisepalus & $\begin{array}{l}\text { Lake Tekapo, New Zealand } \\
\text { Mt Dobson Skifield, Canterbury, }\end{array}$ & WELTU17486 & 0 & 1 \\
\hline C. buchananii & $\begin{array}{l}\text { New Zealand } \\
\text { Mt Peel, Tasman Range, New }\end{array}$ & WELTU20248 & 6 & 2 \\
\hline C. canaliculatus & Zealand & CHR75580 & 5 & 1 \\
\hline C. kerguelensis & Marion and Prince Edward Islands & CHR2042 & 0 & 1 \\
\hline C. lycopodioides & $\begin{array}{l}\text { Morro Chico, Patagonia, Chile } \\
\text { Kakapo Peak, Kahurangi National }\end{array}$ & WELTU20249 & 0 & 1 \\
\hline C. masonae & $\begin{array}{l}\text { Park, New Zealand } \\
\text { Mt Gow, Landsborough Valley, New }\end{array}$ & WELTU20250 & 0 & 1 \\
\hline C. monticola & Zealand & CHR223853 & 0 & 1 \\
\hline C. muelleri & Cape Palliser, New Zealand & CHR146055 & 3 & 1 \\
\hline C. quitensis & $\begin{array}{l}\text { Punta Arenas, Patagonia, Chile } \\
\text { Mt Arthur, Kahurangi National Park, }\end{array}$ & WELTU20251 & 0 & 1 \\
\hline C. strictus & $\begin{array}{l}\text { New Zealand } \\
\text { Isla Capitan Aracena, Tierra del }\end{array}$ & WELTU20252 & 4 & 1 \\
\hline C. subulatus & $\begin{array}{l}\text { Fuego, Chile } \\
\text { Mt Arthur, Kahurangi National Park, }\end{array}$ & CHR259749 & 4 & 0 \\
\hline C. wallii & New Zealand & WELTU20253 & 4 & 1 \\
\hline
\end{tabular}

\section{Appendix 4.2.2}

Measurements of cells in paraffin sections and change of ST length in hand sectioned valves. Measuremenst are given in $\mu \mathrm{m}$, the change is measured in $\%$.

lin - length of inner cells; win - width of inner cells; cwin - thickness of cell walls of inner cells; lout - length of cells of outer capsule wall; wout - width of cells of outer capsule wall; cwout - cell wall thickness of cells of outer capsule wall; capswall - thickness of capsule wall; change - percentage change width of valve piece after water absorption.

\begin{tabular}{||lllllllll||}
\hline species & lin & win & cwin & lout & wout & cwout & capswall & change \\
\hline C. acicularis & 11.65 & 5.60 & 1.76 & 6.21 & 5.28 & 2.32 & 72.54 & 28.84 \\
C. acicularis & 7.33 & 4.80 & 1.34 & 6.21 & 4.96 & 2.49 & 50.10 & 22.01 \\
C. acicularis & 14.45 & 6.81 & 0.77 & 5.28 & 5.92 & 1.87 & 50.03 & 32.24 \\
C. acicularis & 8.96 & 7.14 & 0.88 & 7.22 & 6.19 & 2.26 & 59.99 & 10.14 \\
C. acicularis & 11.80 & 4.35 & 1.73 & 6.83 & 6.36 & 2.35 & 60.56 & 49.25 \\
C. acicularis & 8.84 & 5.99 & 0.77 & 6.06 & 4.62 & 2.01 & 43.04 & 20.36 \\
C. acicularis & 9.74 & 6.21 & 1.33 & 4.63 & 4.88 & 2.09 & 73.83 & 31.83 \\
C. acicularis & 11.80 & 6.52 & 1.14 & 7.39 & 5.10 & 2.14 & 56.47 & 28.37 \\
C. acicularis & 8.88 & 4.35 & 1.32 & 6.85 & 4.01 & 1.94 & 51.82 & 24.02 \\
C. acicularis & 9.70 & 7.09 & 0.92 & 7.41 & 3.76 & 1.95 & 64.91 & 14.86 \\
\hline C. affinis & 19.19 & 10.35 & 1.88 & 19.42 & 10.94 & 2.19 & 38.16 & 19.63 \\
C. affinis & 10.08 & 7.63 & 1.25 & 10.35 & 8.84 & 2.81 & 51.43 & 52.17 \\
C. affinis & 10.83 & 9.76 & 1.56 & 12.17 & 12.17 & 2.60 & 42.21 & 42.20 \\
\hline
\end{tabular}




\begin{tabular}{|c|c|c|c|c|c|c|c|c|}
\hline C. affinis & 12.89 & 11.96 & 1.56 & 12.87 & 11.75 & 3.44 & 52.82 & 13.22 \\
\hline C. affinis & 11.10 & 9.37 & 0.63 & 9.40 & 10.98 & 2.94 & 40.30 & 15.45 \\
\hline C. affinis & 7.41 & 6.50 & 0.94 & 11.22 & 15.73 & 2.83 & 43.08 & 13.39 \\
\hline C. affinis & 8.01 & 10.21 & 1.36 & 12.00 & 9.37 & 2.65 & 41.32 & 16.15 \\
\hline C. affinis & 8.81 & 8.68 & 0.66 & 15.70 & 9.02 & 4.00 & 39.13 & 15.68 \\
\hline C. affinis & 12.15 & 7.18 & 2.10 & 10.00 & 11.59 & 3.29 & 41.67 & 6.78 \\
\hline C. affinis & 12.75 & 12.66 & 1.25 & 11.12 & 8.95 & 3.52 & 43.78 & 8.99 \\
\hline C. apetalus & 16.21 & 7.09 & 0.49 & 7.84 & 5.47 & 1.49 & 65.92 & 39.72 \\
\hline C. apetalus & 13.87 & 14.90 & 0.49 & 6.87 & 4.68 & 1.71 & 51.44 & 7.05 \\
\hline C. apetalus & 20.46 & 17.70 & 0.94 & 4.75 & 5.55 & 1.72 & 58.51 & 20.37 \\
\hline C. apetalus & 9.56 & 8.75 & 0.89 & 6.71 & 8.88 & 2.74 & 61.59 & 12.47 \\
\hline C. apetalus & 9.81 & 10.25 & 1.72 & 9.66 & 9.69 & 2.03 & 66.74 & 16.88 \\
\hline C. apetalus & 13.67 & 11.96 & 0.95 & 7.36 & 8.75 & 2.18 & 54.07 & 13.77 \\
\hline C. apetalus & 16.00 & 8.49 & 1.00 & 6.64 & 9.89 & 2.27 & 52.21 & 12.55 \\
\hline C. apetalus & 10.31 & 9.41 & 1.34 & 5.78 & 8.33 & 2.03 & 63.54 & 16.94 \\
\hline C. apetalus & 10.47 & 7.65 & 0.78 & 6.56 & 8.31 & 2.06 & 35.19 & 17.18 \\
\hline C. apetalus & 13.98 & 10.05 & 0.49 & 8.52 & 5.99 & 1.44 & 51.63 & 14.58 \\
\hline C. buchananii & 22.02 & 13.56 & 1.27 & 12.74 & 10.42 & 3.55 & 64.64 & 24.18 \\
\hline C. buchananii & 18.84 & 8.55 & 1.30 & 8.35 & 10.49 & 4.38 & 58.71 & 43.97 \\
\hline C. buchananii & 9.56 & 9.00 & 0.42 & 6.67 & 7.92 & 3.96 & 59.40 & 21.03 \\
\hline C. buchananii & 13.83 & 5.81 & 2.08 & 8.33 & 7.88 & 3.03 & 72.37 & 25.20 \\
\hline C. buchananii & 8.20 & 4.16 & 1.51 & 10.46 & 9.42 & 3.44 & 68.06 & 33.15 \\
\hline C. buchananii & 16.80 & 11.88 & 1.47 & 13.08 & 10.09 & 3.33 & 77.41 & 45.32 \\
\hline C. buchananii & 13.21 & 9.59 & 1.56 & 12.92 & 13.14 & 4.15 & 79.69 & 13.79 \\
\hline C. buchananii & 19.40 & 20.02 & 2.21 & 10.71 & 8.77 & 3.43 & 65.95 & 20.01 \\
\hline C. buchananii & 15.37 & 7.71 & 1.46 & 10.02 & 9.67 & 4.25 & 64.85 & 39.78 \\
\hline C. buchananii & 9.43 & 9.87 & 1.47 & 8.40 & 7.19 & 4.35 & 63.57 & 16.06 \\
\hline C. canaliculatus & 16.96 & 14.72 & 1.10 & 12.02 & 10.92 & 3.79 & 75.15 & 11.83 \\
\hline C. canaliculatus & 9.87 & 13.16 & 0.34 & 8.31 & 10.75 & 2.96 & 47.79 & 16.41 \\
\hline C. canaliculatus & 7.69 & 10.69 & 0.94 & 9.95 & 10.59 & 2.89 & 38.90 & 35.90 \\
\hline C. canaliculatus & 8.89 & 7.89 & 0.47 & 7.48 & 11.06 & 2.96 & 44.34 & 20.41 \\
\hline C. canaliculatus & 15.11 & 12.93 & 1.71 & 8.45 & 10.53 & 3.76 & 61.05 & 23.91 \\
\hline C. canaliculatus & 9.19 & 9.11 & 0.47 & 6.99 & 11.37 & 3.29 & 59.71 & 20.66 \\
\hline C. canaliculatus & 7.96 & 9.52 & 0.64 & 7.44 & 10.87 & 3.24 & 68.76 & 24.83 \\
\hline C. canaliculatus & 9.03 & 15.22 & 1.25 & 16.19 & 11.18 & 3.02 & 60.68 & 15.39 \\
\hline C. canaliculatus & 6.08 & 17.33 & 0.47 & 9.89 & 10.31 & 3.29 & 66.28 & 10.89 \\
\hline C. canaliculatus & 4.89 & 8.75 & 0.47 & 4.49 & 9.03 & 2.71 & 49.45 & 13.29 \\
\hline C. muelleri & 12.77 & 8.86 & 2.68 & 12.09 & 15.50 & 5.62 & 77.71 & 30.42 \\
\hline C. muelleri & 11.13 & 11.46 & 1.25 & 15.09 & 14.67 & 4.62 & 45.16 & 14.83 \\
\hline C. muelleri & 22.02 & 6.59 & 2.10 & 10.94 & 10.15 & 4.55 & 63.71 & 19.91 \\
\hline C. muelleri & 14.14 & 12.53 & 0.81 & 13.00 & 13.38 & 5.73 & 59.87 & 35.58 \\
\hline C. muelleri & 22.34 & 14.19 & 1.47 & 9.30 & 17.07 & 6.70 & 52.69 & 39.78 \\
\hline C. muelleri & 19.12 & 7.97 & 1.33 & 8.40 & 14.88 & 6.15 & 63.71 & 21.65 \\
\hline C. muelleri & 12.24 & 8.25 & 0.83 & 14.13 & 13.54 & 4.81 & 43.02 & 6.03 \\
\hline C. muelleri & 16.20 & 10.87 & 1.79 & 13.32 & 11.14 & 5.31 & 91.35 & 24.97 \\
\hline C. muelleri & 17.27 & 13.15 & 1.40 & 13.76 & 14.03 & 4.31 & 58.40 & 131.10 \\
\hline C. muelleri & 12.09 & 9.05 & 1.63 & 19.66 & 13.58 & 5.73 & 56.40 & 13.74 \\
\hline C. strictus & 27.60 & 18.08 & 1.97 & 13.76 & 10.13 & 3.17 & 48.73 & 37.29 \\
\hline C. strictus & 21.15 & 9.79 & 2.37 & 16.33 & 9.67 & 3.94 & 45.82 & 11.15 \\
\hline C. strictus & 24.79 & 13.52 & 2.29 & 24.38 & 12.50 & 4.62 & 40.87 & 9.28 \\
\hline C. strictus & 27.22 & 25.92 & 2.33 & 18.83 & 11.62 & 4.05 & 48.57 & 41.97 \\
\hline C. strictus & 16.77 & 20.60 & 1.84 & 20.96 & 10.25 & 3.77 & 39.88 & 35.45 \\
\hline C. strictus & 12.53 & 6.45 & 1.77 & 20.01 & 12.12 & 3.26 & 52.47 & 10.93 \\
\hline C. strictus & 12.04 & 19.42 & 1.04 & 19.42 & 9.47 & 2.52 & 43.08 & 29.08 \\
\hline
\end{tabular}




\section{APPENDIX}

\begin{tabular}{|lllllllll||}
\hline C. strictus & 16.88 & 7.56 & 1.25 & 13.07 & 12.31 & 4.83 & 61.75 & 16.69 \\
C. strictus & 19.72 & 18.25 & 1.32 & 12.89 & 11.14 & 4.24 & 40.38 & 29.13 \\
C. strictus & 21.83 & 24.11 & 1.33 & 9.19 & 6.77 & 2.92 & 48.82 & 6.42 \\
\hline C. subulatus & 26.76 & 11.40 & 0.96 & 14.60 & 7.29 & 3.09 & 37.97 & 23.81 \\
C. subulatus & 23.00 & 12.35 & 1.67 & 13.98 & 6.83 & 2.92 & 49.33 & 19.13 \\
C. subulatus & 18.15 & 6.64 & 0.93 & 11.46 & 9.29 & 2.88 & 34.78 & 5.08 \\
C. subulatus & 7.77 & 6.18 & 1.26 & 11.65 & 8.10 & 2.81 & 50.31 & 14.19 \\
C. subulatus & 18.17 & 7.80 & 0.83 & 7.41 & 8.62 & 2.38 & 29.94 & 25.70 \\
C. subulatus & 9.59 & 12.97 & 1.04 & 11.38 & 6.04 & 2.37 & 37.93 & 14.23 \\
C. subulatus & 19.05 & 12.91 & 1.12 & 9.25 & 7.23 & 2.43 & 22.44 & 27.74 \\
C. subulatus & 6.67 & 8.63 & 1.25 & 9.14 & 6.36 & 2.29 & 41.19 & 11.63 \\
C. subulatus & 12.18 & 6.68 & 1.27 & 13.78 & 6.46 & 2.33 & 37.51 & 14.32 \\
C. subulatus & 21.90 & 15.84 & 0.86 & 13.05 & 6.43 & 2.40 & 38.43 & 34.03 \\
\hline C. wallii & 7.35 & 14.85 & 0.67 & 5.53 & 11.31 & 2.45 & 61.88 & 54.89 \\
C. wallii & 13.86 & 11.75 & 0.30 & 6.26 & 11.08 & 2.86 & 68.18 & 20.40 \\
C. wallii & 10.00 & 11.71 & 0.88 & 6.38 & 9.07 & 2.00 & 47.08 & 28.93 \\
C. wallii & 5.27 & 13.91 & 0.95 & 8.95 & 9.33 & 3.09 & 41.88 & 22.09 \\
C. wallii & 13.86 & 15.86 & 0.64 & 7.54 & 12.37 & 3.19 & 43.54 & 6.72 \\
C. wallii & 6.72 & 6.39 & 0.64 & 9.22 & 12.66 & 3.63 & 43.45 & 23.30 \\
C. wallii & 11.37 & 13.42 & 0.43 & 10.94 & 12.56 & 3.30 & 50.63 & 29.17 \\
C. wallii & 7.08 & 7.14 & 1.28 & 6.65 & 10.90 & 2.89 & 59.42 & 29.67 \\
C. wallii & 14.83 & 7.67 & 1.85 & 8.13 & 8.02 & 2.02 & 56.63 & 7.81 \\
C. wallii & 9.06 & 4.13 & 0.53 & 6.77 & 10.01 & 1.95 & 58.00 & 29.95 \\
\hline
\end{tabular}




\section{Appendix 4.2.3}

Kruskal-Wallis test for cell measurements of nine Colobanthus species and subsequent Mann-Whitney-U tests for measurements between species. Given are chi-squared, df and p-values for the Kruskal-Wallis test and W and p-values for mann-Whitney-U test. Significant results are highlighted in

\section{BOLD.}

LIN - length of inner cells; WIN - width of inner cells; CWIN - thickness of cell walls of inner cells; LOUT - length of cells of outer capsule wall; WOUT - width of cells of outer capsule wall; CWOUT - cell wall thickness of cells of outer capsule wall; CHANGE - percentage change of the width of valve pieces after water absorption; CAPSWALL - thickness of capsule wall.

\begin{tabular}{|c|c|c|c|c|c|c|c|c|c|c|c|c|c|c|c|c|}
\hline \multirow[t]{3}{*}{ 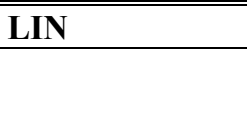 } & \multicolumn{4}{|c|}{ "Chi-squared $=52.99$} & \multirow{2}{*}{\multicolumn{2}{|c|}{$\begin{array}{l}\mathbf{D f}=\mathbf{9} \\
\text { C. buchananii }\end{array}$}} & \multicolumn{10}{|c|}{ p-value $<0.0001$} \\
\hline & \multicolumn{2}{|c|}{ C. acicularis } & \multicolumn{2}{|c|}{ C. affinis } & & & \multicolumn{2}{|c|}{ C. canaliculatus } & \multicolumn{2}{|c|}{ C. wallii } & \multicolumn{2}{|c|}{ C. apetalus } & \multicolumn{2}{|c|}{ C. subulatus } & \multicolumn{2}{|c|}{ C. strictus } \\
\hline & $\mathrm{W}$ & $\mathrm{p}$ & $\mathrm{W}$ & $\mathrm{p}$ & $\mathrm{W}$ & $\mathrm{p}$ & $\mathrm{W}$ & $\mathrm{P}$ & $\mathrm{W}$ & $\mathrm{p}$ & $\mathrm{W}$ & $\mathrm{p}$ & $\mathrm{W}$ & $\mathrm{p}$ & $\mathrm{W}$ & $\mathrm{p}$ \\
\hline C. affinis & 42 & 0.57 & & & & & & & & & & & & & & \\
\hline C. buchananii & 23 & 0.05 & 27 & 0.089 & & & & & & & & & & & & \\
\hline C. canaliculatus & 61 & 0.43 & 68 & 0.19 & 82 & 0.015 & & & & & & & & & & \\
\hline C. wallii & 55 & 0.73 & 61 & 0.43 & 78 & 0.038 & 47 & 0.85 & & & & & & & & \\
\hline C. apetalus & 21 & 0.03 & 31 & 0.17 & 54 & 0.796 & 18 & 0.015 & 23 & 0.05 & & & & & & \\
\hline C. subulatus & 26 & 0.08 & 32 & 0.19 & 43 & 0.63 & 20 & 0.023 & 23 & 0.05 & 38 & 0.39 & & & & \\
\hline C. strictus & 2 & 0.0003 & 9 & 0.0011 & 24 & 0.052 & 6 & 0.0003 & 6 & 0.001 & 15 & 0.007 & 35 & 0.28 & & \\
\hline C. muelleri & 8 & 0.002 & 17 & 0.012 & 43 & 0.63 & 11 & 0.002 & 14 & $\mathbf{0 . 0 0 7}$ & 31 & 0.166 & 51 & 0.97 & 70 & 0.14 \\
\hline \multirow[t]{3}{*}{ WIN } & \multicolumn{4}{|c|}{ Chi-squared = 39.03 } & \multicolumn{2}{|c|}{ Df $=9$} & \multicolumn{10}{|c|}{ p-value $<0.0001$} \\
\hline & \multicolumn{2}{|c|}{ C. acicularis } & \multicolumn{2}{|c|}{ C. affinis } & \multicolumn{2}{|c|}{ C. buchananii } & \multicolumn{2}{|c|}{ C. canaliculatus } & \multicolumn{2}{|c|}{ C. wallii } & \multicolumn{2}{|c|}{ C. apetalus } & \multicolumn{2}{|c|}{ C. subulatus } & \multicolumn{2}{|c|}{ C. strictus } \\
\hline & W & $\mathrm{p}$ & $\mathrm{W}$ & $\mathrm{p}$ & W & $\mathrm{p}$ & $\mathrm{W}$ & $\mathrm{p}$ & $\mathrm{W}$ & $\mathrm{p}$ & W & $\mathrm{p}$ & $\mathrm{W}$ & $\mathrm{p}$ & $\mathrm{W}$ & $\mathrm{p}$ \\
\hline C. affinis & 4 & 0.0006 & & & & & & & & & & & & & & \\
\hline C. buchananii & 16 & 0.0113 & 51 & 0.97 & & & & & & & & & & & & \\
\hline C. canaliculatus & $\mathbf{0}$ & 0.0002 & 26 & 0.075 & 33 & 0.22 & & & & & & & & & & \\
\hline C. wallii & 15 & 0.009 & 40 & 0.48 & 45 & 0.74 & 59 & 0.53 & & & & & & & & \\
\hline C. apetalus & 1 & 0.0002 & 43 & 0.63 & 44 & 0.68 & 63 & 0.35 & 50 & 1 & & & & & & \\
\hline C. subulatus & 11 & 0.004 & 45 & 0.74 & 47 & 0.85 & 69 & 0.17 & 56 & 0.68 & 55 & 0.74 & & & & \\
\hline C. strictus & 4 & 0.0006 & 22 & 0.035 & 25 & 0.06 & 29 & 0.12 & 24 & 0.052 & 26 & 0.075 & 22 & 0.035 & & \\
\hline C. muelleri & 3 & 0.0004 & 40 & 0.48 & 44 & 0.68 & 66 & 0.25 & 54 & 0.796 & 50 & 1 & 45 & 0.74 & 75 & 0.063 \\
\hline
\end{tabular}

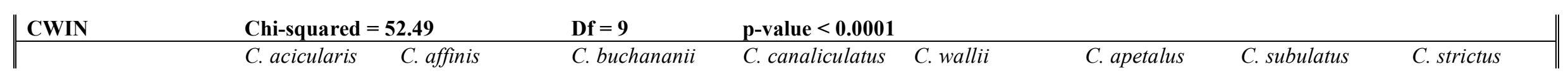


APPENDIX

\begin{tabular}{|c|c|c|c|c|c|c|c|c|c|c|c|c|c|c|c|c|}
\hline & W & $\mathrm{p}$ & $\mathrm{W}$ & $\mathrm{p}$ & W & $\mathrm{p}$ & W & $\mathrm{p}$ & W & $\mathrm{p}$ & W & $\mathrm{p}$ & W & $\mathrm{p}$ & W & $\mathrm{p}$ \\
\hline C. affinis & 42 & 0.57 & & & & & & & & & & & & & & \\
\hline C. buchananii & 30 & 0.14 & 40 & 0.47 & & & & & & & & & & & & \\
\hline C. canaliculatus & 79 & 0.03 & 82 & 0.017 & 84 & 0.01 & & & & & & & & & & \\
\hline C. wallii & 79 & 0.03 & 78 & 0.037 & 83 & 0.014 & 46 & 0.79 & & & & & & & & \\
\hline C. apetalus & 68 & 0.185 & 75 & 0.063 & 81 & 0.03 & 34 & 0.24 & 41 & 0.52 & & & & & & \\
\hline C. subulatus & 57 & 0.623 & 62 & 0.3843 & 82 & 0.017 & 24 & 0.053 & 24 & 0.054 & 31 & 0.16 & & & & \\
\hline C. strictus & 20 & 0.026 & 27 & 0.089 & 38 & 0.38 & 6 & 0.001 & 8 & 0.002 & 8 & 0.002 & 11 & 0.0036 & & \\
\hline C. muelleri & 30 & 0.14 & 39 & 0.43 & 52 & 0.91 & 13 & 0.006 & 15 & 0.009 & 19 & 0.02 & 26.5 & 0.082 & 60.5 & 0.45 \\
\hline LOUT & \multicolumn{4}{|c|}{ "Chi-squared $=70.25$} & $\overline{\text { Df }}$ & & \multicolumn{10}{|c|}{ p-value $<0.0001$} \\
\hline & \multicolumn{2}{|c|}{ C. acicularis } & \multicolumn{2}{|c|}{ C. affinis } & \multicolumn{2}{|c|}{ C. buchananii } & \multicolumn{2}{|c|}{ C. canaliculatus } & \multicolumn{2}{|c|}{ C. wallii } & \multicolumn{2}{|c|}{ C. apetalus } & \multicolumn{2}{|c|}{ C. subulatus } & \multicolumn{2}{|c|}{ C. strictus } \\
\hline & $\mathrm{W}$ & $\mathrm{p}$ & W & $\mathrm{p}$ & W & $\mathrm{p}$ & $\mathrm{W}$ & $\mathrm{p}$ & $\mathrm{W}$ & $\mathrm{p}$ & $\mathrm{W}$ & $\mathrm{p}$ & $\mathrm{W}$ & $\mathrm{p}$ & W & $\mathrm{p}$ \\
\hline C. affinis & $\mathbf{0}$ & 0.0002 & & & & & & & & & & & & & & \\
\hline C. buchananii & 5 & 0.0008 & 69 & 0.17 & & & & & & & & & & & & \\
\hline C. canaliculatus & 13 & 0.0058 & 83 & 0.012 & 67 & 0.22 & & & & & & & & & & \\
\hline C. wallii & 28 & 0.104 & 97 & $<0.0001$ & 82 & 0.015 & 67 & 0.22 & & & & & & & & \\
\hline C. apetalus & 37 & 0.34 & 99 & $<0.0001$ & 88 & 0.003 & 76 & 0.052 & 57 & 0.63 & & & & & & \\
\hline C. subulatus & 1 & 0.0002 & 53 & 0.85 & 31 & 0.17 & 26 & 0.075 & 8 & 0.0007 & 5 & 0.0002 & & & & \\
\hline C. strictus & $\mathbf{0}$ & 0.0002 & 18 & 0.015 & 9 & 0.001 & 7 & 0.0005 & 2 & $<0.0001$ & 1 & $<0.0001$ & 18 & 0.015 & & \\
\hline C. muelleri & $\mathbf{0}$ & 0.0002 & 41 & 0.53 & 20 & 0.023 & 17 & 0.0115 & 5 & 0.0002 & 3 & $<0.0001$ & 38 & 0.39 & 73.5 & 0.082 \\
\hline \multirow[t]{3}{*}{ WOUT } & \multicolumn{4}{|c|}{ Chi-squared $=71.88$} & \multicolumn{2}{|c|}{ Df $=9$} & \multicolumn{4}{|c|}{ p-value $<0.0001$} & & & & & & \\
\hline & \multirow{2}{*}{\multicolumn{2}{|c|}{$\begin{array}{l}\text { C. acicularis } \\
\mathrm{W}\end{array}$}} & \multicolumn{2}{|c|}{ C. affinis } & \multicolumn{2}{|c|}{ C. buchananii } & \multicolumn{2}{|c|}{ C. canaliculatus } & \multirow{2}{*}{\multicolumn{2}{|c|}{$\begin{array}{l}\text { C. wallii } \\
\mathrm{W} \mathfrak{\mathrm { p }}\end{array}$}} & \multicolumn{2}{|c|}{ C. apetalus } & \multicolumn{2}{|c|}{ C. subulatus } & \multicolumn{2}{|c|}{ C. strictus } \\
\hline & & & $\mathrm{W}$ & $\mathrm{p}$ & W & $\mathrm{p}$ & $\mathrm{W}$ & $\mathrm{p}$ & & & $\mathrm{W}$ & $\mathrm{p}$ & $\mathrm{W}$ & $\mathrm{p}$ & $\mathrm{W}$ & $\mathrm{p}$ \\
\hline C. affinis & $\mathbf{0}$ & $<0.0001$ & & & & & & & & & & & & & & \\
\hline C. buchananii & $\mathbf{0}$ & $<0.0001$ & 71 & 0.12 & & & & & & & & & & & & \\
\hline C. canaliculatus & $\mathbf{0}$ & $<0.0001$ & 55 & 0.74 & 17 & 0.012 & & & & & & & & & & \\
\hline C. wallii & $\mathbf{0}$ & $<0.0001$ & 47 & 0.85 & 29 & 0.12 & 44 & 0.68 & & & & & & & & \\
\hline C. apetalus & 15 & 0.0068 & 91 & 0.001 & 75 & 0.063 & 98 & $<0.0001$ & 90 & 0.0015 & & & & & & \\
\hline C. subulatus & 3 & $<0.0001$ & 97 & $<0.0001$ & 88 & 0.0023 & 99 & $<0.0001$ & 96 & 0.0001 & 54 & 0.80 & & & & \\
\hline C. strictus & $\mathbf{0}$ & $<0.0001$ & 45 & 0.74 & 30 & 0.14 & 48 & 0.91 & 51 & 0.97 & 10 & 0.0015 & 6 & 0.0003 & & \\
\hline C. muelleri & $\mathbf{0}$ & $<0.0001$ & 17 & 0.012 & 4 & 0.0001 & 11 & 0.002 & 10 & 0.0015 & $\mathbf{0}$ & $<0.0001$ & $\mathbf{0}$ & $<0.0001$ & 10.5 & 0.003 \\
\hline \multirow[t]{3}{*}{ CWOUT } & $\mathrm{Ch}$ & $=$ squared $=$ & 78.56 & & Df & & p-v & le $<0.0001$ & & & & & & & & \\
\hline & C. & cicularis & C. a & inis & $C$. & ananii & C. . & aliculatus & $C$. & allii & C. & petalus & C. st & ulatus & C. st & ictus \\
\hline & $\mathrm{W}$ & $\mathrm{p}$ & $\mathrm{W}$ & $\mathrm{p}$ & W & $p$ & W & $\mathrm{p}$ & W & $\mathrm{p}$ & W & $\mathrm{p}$ & $\mathrm{W}$ & $\mathrm{p}$ & W & $\mathrm{p}$ \\
\hline C. affinis & 4 & 0.0001 & & & & & & & & & & & & & & \\
\hline C. buchananii & $\mathbf{0}$ & $<0.0001$ & 14.5 & 0.008 & & & & & & & & & & & & \\
\hline
\end{tabular}


APPENDIX

\begin{tabular}{|c|c|c|c|c|c|c|c|c|c|c|c|c|c|c|c|c|}
\hline C. canaliculatus & $\mathbf{0}$ & $<0.0001$ & 38 & 0.38 & 87 & 0.0058 & & & & & & & & & & \\
\hline C. wallii & 21 & 0.029 & 61 & 0.44 & 92 & 0.0007 & 71 & 0.12 & & & & & & & & \\
\hline C. apetalus & 65 & 0.27 & 96 & 0.0006 & 100 & 0.0002 & 99 & 0.0002 & 81 & 0.021 & & & & & & \\
\hline C. subulatus & 9 & 0.001 & 75 & 0.063 & 99 & $<0.0001$ & 91 & 0.0022 & 60 & 0.48 & 6 & 0.001 & & & & \\
\hline C. strictus & $\mathbf{0}$ & $<0.0001$ & 24 & 0.05 & 55 & 0.74 & 28 & 0.104 & 15 & 0.007 & 1 & 0.0002 & 5.5 & 0.0009 & & \\
\hline C. muelleri & $\mathbf{0}$ & 0.0002 & $\mathbf{0}$ & 0.0002 & 2 & 0.0003 & $\mathbf{0}$ & 0.0002 & $\mathbf{0}$ & 0.0002 & $\mathbf{0}$ & 0.0002 & $\mathbf{0}$ & 0.0002 & 6.5 & 0.001 \\
\hline CHANGE & \multicolumn{4}{|c|}{ Chi-squared $=35.17$} & \multicolumn{2}{|c|}{ Df $=9$} & \multicolumn{10}{|c|}{ p-value $<0.0001$} \\
\hline & \multicolumn{2}{|c|}{ C. acicularis } & \multicolumn{2}{|c|}{ C. affinis } & \multicolumn{2}{|c|}{ C. buchananii } & \multicolumn{2}{|c|}{ C. canaliculatus } & \multicolumn{2}{|c|}{ C. wallii } & \multicolumn{2}{|c|}{ C. apetalus } & \multicolumn{2}{|c|}{ C. subulatus } & \multicolumn{2}{|c|}{ C. strictus } \\
\hline & $\mathrm{W}$ & $\mathrm{p}$ & W & $\mathrm{p}$ & W & $\mathrm{p}$ & W & $\mathrm{p}$ & & & $\mathrm{W}$ & $\mathrm{p}$ & W & $\mathrm{p}$ & $\mathrm{W}$ & $\mathrm{p}$ \\
\hline C. affinis & 71 & 0.123 & & & & & & & & & & & & & & \\
\hline C. buchananii & 46 & 0.80 & 24 & 0.052 & & & & & & & & & & & & \\
\hline C. canaliculatus & 69 & 0.17 & 42 & 0.59 & 75 & 0.06 & & & & & & & & & & \\
\hline C. wallii & 51 & 0.97 & 33 & 0.22 & 55 & 0.74 & 35 & 0.28 & & & & & & & & \\
\hline C. apetalus & 78 & 0.035 & 50 & 1 & 83 & 0.01 & 60 & 0.48 & 74 & 0.08 & & & & & & \\
\hline C. subulatus & 71 & 0.123 & 47 & 0.85 & 72 & 0.10 & 51 & 0.97 & 66 & 0.25 & 43 & 0.63 & & & & \\
\hline C. strictus & 55 & 0.74 & 47 & 0.85 & 64 & 0.32 & 46 & 0.80 & 53 & 0.85 & 46 & 0.80 & 43 & 0.63 & & \\
\hline C. muelleri & 53 & 0.85 & 34 & 0.25 & 58 & 0.58 & 35 & 0.28 & 49 & 0.97 & 28 & 0.10 & 34 & 0.25 & 43 & 0.63 \\
\hline \multirow[t]{3}{*}{ CAPSWALL } & \multicolumn{4}{|c|}{ Chi-squared $=63.62$} & \multicolumn{2}{|c|}{ df $=9$} & \multicolumn{4}{|c|}{ p-value $<0.0001$} & & & & & & \\
\hline & \multicolumn{2}{|c|}{ C. acicularis } & \multicolumn{2}{|c|}{ C. affinis } & \multicolumn{2}{|c|}{ C. buchananii } & \multicolumn{2}{|c|}{ C. canaliculatus } & \multicolumn{2}{|c|}{ C. wallii } & \multicolumn{2}{|c|}{ C. apetalus } & \multicolumn{2}{|c|}{ C. subulatus } & \multicolumn{2}{|c|}{ C. strictus } \\
\hline & $\mathrm{W}$ & $\mathrm{p}$ & W & $\mathrm{p}$ & $\mathrm{W}$ & $\mathrm{p}$ & $\mathrm{W}$ & $\mathrm{p}$ & $\mathrm{W}$ & $\mathrm{p}$ & $\mathrm{W}$ & $\mathrm{p}$ & $\mathrm{W}$ & $\mathrm{p}$ & $\mathrm{W}$ & $\mathrm{p}$ \\
\hline C. affinis & 91 & 0.001 & & & & & & & & & & & & & & \\
\hline C. buchananii & 25 & 0.063 & $\mathbf{0}$ & $<0.0001$ & & & & & & & & & & & & \\
\hline C. canaliculatus & 52 & 0.91 & 15 & 0.0068 & 73 & 0.089 & & & & & & & & & & \\
\hline C. wallii & 64 & 0.32 & 15 & 0.0068 & 89 & 0.002 & 64 & 0.315 & & & & & & & & \\
\hline C. apetalus & 51 & 0.97 & 13 & 0.0039 & 85 & 0.007 & 41 & 0.97 & 38 & 0.39 & & & & & & \\
\hline C. subulatus & 96 & 0.0001 & 80 & 0.023 & 100 & $<0.0001$ & 92 & 0.0007 & 92 & 0.0007 & 93 & 0.0005 & & & & \\
\hline C. strictus & 84 & 0.009 & 34 & 0.25 & 98 & $<0.0001$ & 74 & 0.075 & 71 & 0.12 & 81 & 0.019 & 19 & 0.019 & & \\
\hline C. muelleri & 47 & 0.85 & 7 & 0.001 & 73 & 0.0889 & 46 & 0.79 & 33 & 0.21 & 42 & 0.57 & 4 & 0.0006 & 17 & 0.014 \\
\hline
\end{tabular}




\section{Appendix 6.1}

Citation records for data used from the gbif database.

\begin{tabular}{|c|c|c|}
\hline species & accessed through gbif portal & occurences \\
\hline Acrodon subulatus & $\begin{array}{l}\text { HBGSpermatophyta - Herbarium Hamburgense, http://data.gbif.org/datasets/resource/1604 } \\
\text { SABIF Resource, http://data.gbif.org/datasets/resource/8051 }\end{array}$ & $9(14)$ \\
\hline Argyroderma fissum & $\begin{array}{l}\text { EURISCO, The European Genetic Resources Search Catalogue, } \text { http://data.gbif.org/datasets/resource/1905 } \\
\text { HBGSpermatophyta - Herbarium Hamburgense, http://data.gbif.org/datasets/resource/1604) } \\
\text { University of California Botanical Garden DiGIR provider, http://data.gbif.org/datasets/resource/1412 } \\
\text { SysTax, http://data.gbif.org/datasets/resource/1875 } \\
\text { Royal Botanic Gardens, Kew, http://data.gbif.org/datasets/resource/629 } \\
\text { SABIF Resource, http://data.gbif.org/datasets/resource/8051 }\end{array}$ & $10(91)$ \\
\hline $\begin{array}{l}\text { Bergeranthus } \\
\text { scapiger }\end{array}$ & 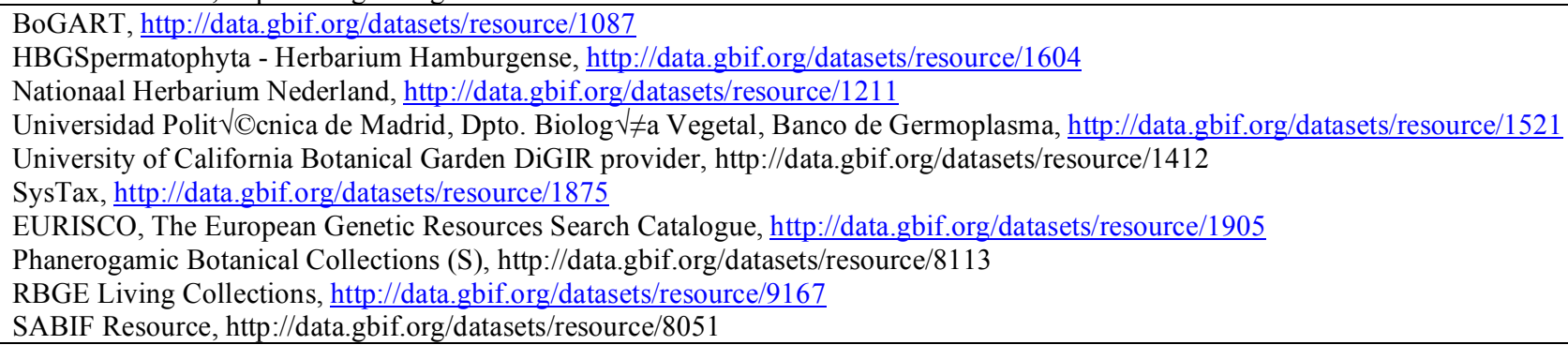 & $3(34)$ \\
\hline $\begin{array}{l}\text { Cephalophyllum } \\
\text { spissum }\end{array}$ & $\begin{array}{l}\text { HBGSpermatophyta - Herbarium Hamburgense, http://data.gbif.org/datasets/resource/1604 } \\
\text { Phanerogamic Botanical Collections (S), http://data.gbif.org/datasets/resource/8113 } \\
\text { SABIF Resource, http://data.gbif.org/datasets/resource/8051 }\end{array}$ & $4(16)$ \\
\hline $\begin{array}{l}\text { Dracophilus } \\
\text { dealbatus }\end{array}$ & $\begin{array}{l}\text { HBGSpermatophyta - Herbarium Hamburgense, http://data.gbif.org/datasets/resource/1604 } \\
\text { Herbarium Berolinense, http://data.gbif.org/datasets/resource/1095 } \\
\text { SysTax, http://data.gbif.org/datasets/resource/1875 } \\
\text { SABIF Resource, http://data.gbif.org/datasets/resource/8051 } \\
\text { Phanerogamic Botanical Collections (S), http://data.gbif.org/datasets/resource/8113 }\end{array}$ & $10(93)$ \\
\hline $\begin{array}{l}\text { Drosanthemum } \\
\text { globosum }\end{array}$ & $\begin{array}{l}\text { Royal Botanic Gardens, Kew, http://data.gbif.org/datasets/resource/629 } \\
\text { SABIF Resource, http://data.gbif.org/datasets/resource/8051 }\end{array}$ & $5(8)$ \\
\hline
\end{tabular}


HBGSpermatophyta - Herbarium Hamburgense, http://data.gbif.org/datasets/resource/1604

Nationaal Herbarium Nederland - Leiden Branch, http://data.gbif.org/datasets/resource/1085

University and Jepson Herbaria DiGIR provider, http://data.gbif.org/datasets/resource/1413

USDA PLANTS Database, http://data.gbif.org/datasets/resource/1066

Real Jardin Botanico (Madrid), Vascular Plant Herbarium (MA), http://data.gbif.org/datasets/resource/240

Phanerogamic Botanical Collections (S), http://data.gbif.org/datasets/resource/8113

EURISCO, The European Genetic Resources Search Catalogue, http://data.gbif.org/datasets/resource/1905

Drosanthemum SABIF Resource, http://data.gbif.org/datasets/resource/8051

hispidum

Consortium of California Herbaria, http://data.gbif.org/datasets/resource/9153

HBGSpermatophyta - Herbarium Hamburgense, http://data.gbif.org/datasets/resource/1604

Royal Botanic Gardens, Kew, http://data.gbif.org/datasets/resource/629

Drosanthemum Phanerogamic Botanical Collections (S), http://data.gbif.org/datasets/resource/8113

schoenlandianum SABIF Resource, $\mathrm{http}$ //data.gbiforg/datasets/resource/805

HBGSpermatophyta - Herbarium Hamburgense, http://data.gbif.org/datasets/resource/1604

SysTax, http://data.gbif.org/datasets/resource/1875

Ebracteola wilmaniae SABIF Resource, http://data.gbif.org/datasets/resource/8051)

Phanerogamic Botanical Collections (S), http://data.gbif.org/datasets/resource/8113

Phyllobolus

SysTax, http://data.gbif.org/datasets/resource/1875

HBGSpermatophyta - Herbarium Hamburgense, http://data.gbif.org/datasets/resource/1604

Nationaal Herbarium Nederland, http://data.gbif.org/datasets/resource/1211

Herbarium Berolinense, http://data.gbif.org/datasets/resource/1095

Universidad Polit $\sqrt{ }$ Ccnica de Madrid, Dpto. Biolog $\sqrt{\neq a}$ Vegetal, Banco de Germoplasma, http://data.gbif.org/datasets/resource/1521

Phanerogamie, http://data.gbif.org/datasets/resource/1506

Phanerogamic Botanical Collections (S), http://data gbiforg/datasets/resource/8113

RBGE Living Collections, http://data.gbif.org/datasets/resource/9167

Rhombophyllum EURISCO, The European Genetic Resources Search Catalogue, http://data.gbif.org/datasets/resource/1905

dolabriforme

Real Jardin Botanico (Madrid), Vascular Plant Herbarium (MA), http://data.gbif.org/datasets/resource/240

SBT-Living, http://data.gbif.org/datasets/resource/7962 
California State University, Chico, http://data.gbif.org/datasets/resource/737

NatureServe Network Species Occurrence Data, http://data.gbif.org/datasets/resource/607

SysTax, http://data.gbif.org/datasets/resource/1875

Herbarium of Oskarshamn (OHN), http://data.gbif.org/datasets/resource/1024

Missouri Botanical Garden, http://data.gbif.org/datasets/resource/621

Nationaal Herbarium Nederland, http://data.gbif.org/datasets/resource/1211

Nationaal Herbarium Nederland - Leiden Branch, http://data.gbif.org/datasets/resource/1085

United States National Plant Germplasm System Collection, http://data.gbif.org/datasets/resource/1429

USDA PLANTS Database, http://data.gbif.org/datasets/resource/1066

Botanic Garden of Finnish Museum of Natural History, http://data.gbif.org/datasets/resource/2406

Botany (UPS), http://data.gbif.org/datasets/resource/1045

CSU Herbarium, http://data.gbif.org/datasets/resource/7892

Harvard University Herbaria, http://data.gbif.org/datasets/resource/1827

E.C. Smith Herbarium, http://data.gbif.org/datasets/resource/1829

Botanical garden, University of Hohenheim, Germany, http://data.gbif.org/datasets/resource/1855

IPK Genebank, http://data.gbif.org/datasets/resource/1851

Plants of Papua New Guinea, http://data.gbif.org/datasets/resource/969

USU-UTC Specimen Database, http://data.gbif.org/datasets/resource/1508

Fairchild Tropical Botanic Garden Virtual Herbarium Darwin Core format, http://data.gbif.org/datasets/resource/202

EURISCO, The European Genetic Resources Search Catalogue, http://data.gbif.org/datasets/resource/1905

NMNH Botany Collections, http://data.gbif.org/datasets/resource/1874

CONN GBIF data, http://data.gbif.org/datasets/resource/7857

Oklahoma Vascular Plants Database Provider, http://data.gbif.org/datasets/resource/2558

EKY_Darwincore, $h$ ttp://data.gbif.org/datasets/resource/7894

MISS_DC_01MAR2006, http://data.gbif.org/datasets/resource/7895

Herbarium Berolinense, http://data.gbif.org/datasets/resource/1095

Herbarium, http://data.gbif.org/datasets/resource/7984

Phanerogamic Botanical Collections (S), http://data.gbif.org/datasets/resource/8113

Peabody Paleobotany DiGIR Service, http://data.gbif.org/datasets/resource/8141

Peabody Paleoportal DiGIR Service (PB), http://data.gbif.org/datasets/resource/8176

Herbarium of The New York Botanical Garden, http://data.gbif.org/datasets/resource/8967

RBGE Living Collections, http://data.gbif.org/datasets/resource/9167

Herbarium (UNA), http://data.gbif.org/datasets/resource/775

Oenothera fruticosa

Botany Vascular Plant Collection, http://data.gbif.org/datasets/resource/7915

SBT-Living, http://data.gbif.org/datasets/resource/7962 
APPENDIX

NatureServe Network Species Occurrence Data, http://data.gbif.org/datasets/resource/607

USDA PLANTS Database, http://data.gbif.org/datasets/resource/1066

Botany (UPS), http://data.gbif.org/datasets/resource/1045

CSU Herbarium, http://data.gbif.org/datasets/resource/7892

USU-UTC Specimen Database, http://data.gbif.org/datasets/resource/1508

Specimen Database of Colorado Vascular Plants, http://data.gbif.org/datasets/resource/1832

NMNH Botany Collections, http://data.gbif.org/datasets/resource/1874,

UA Herbarium, http://data.gbif.org/datasets/resource/7900

Botany Vascular Plant Collection, http://data.gbif.org/datasets/resource/7915

$\begin{array}{ll}\begin{array}{l}\text { Oenothera } \\ \text { harringtonii }\end{array} & \text { Phanerogamic Botanical Collections (S), http://data.gbif.org/datasets/resource/8113 } \\ \text { Herbarium of The New York Botanical Garden, http://data.gbif.org/datasets/resource/8967 }\end{array}$

Missouri Botanical Garden, http://data.gbif.org/datasets/resource/621,

USDA PLANTS Database, http://data.gbif.org/datasets/resource/1066

Harvard University Herbaria, http://data.gbif.org/datasets/resource/1827

NMNH Botany Collections, http://data.gbif.org/datasets/resource/1874

Oklahoma Vascular Plants Database Provider, http://data.gbif.org/datasets/resource/2558

MISS DC 01MAR2006, http://data.gbif.org/datasets/resource/7895

Botany Vascular Plant Collection, http://data.gbif.org/datasets/resource/7915

Herbarium, http://data.gbif.org/datasets/resource/7984

Phanerogamic Botanical Collections (S), http://data.gbif.org/datasets/resource/8113

RBGE Herbarium (E), http://data.gbif.org/datasets/resource/8402

Herbarium (UNA), httn://data obiforg/datasets/resource/775

Oenothera linifolia

Herbarium of The New York Botanical Garden, http://data.gbif.org/datasets/resource/8967 
Royal Botanical Gardens Herbarium, http://data.gbif.org/datasets/resource/512

herbario, http://data.gbif.org/datasets/resource/566

Database Schema for UC Davis [Herbarium Labels], http://data.gbif.org/datasets/resource/734

California State University, Chico, http://data.gbif.org/datasets/resource/737

NatureServe Network Species Occurrence Data, http://data.gbif.org/datasets/resource/607

SysTax, http://data obif.org/datasets/resource/1875

Missouri Botanical Garden, http://data.gbif.org/datasets/resource/621

Lund Botanical Museum (LD), http://data.gbif.org/datasets/resource/1028

USDA PLANTS Database, http://data.gbif.org/datasets/resource/1066

United States National Plant Germplasm System Collection, http://data.gbif.org/datasets/resource/1429

Plant Specimens of Kurashiki Museum of Natural History, http://data.gbif.org/datasets/resource/599

NMNH Botany Collections, http://data.gbif.org/datasets/resource/1874

MISS_DC_01MAR2006, http://data.gbif.org/datasets/resource/7895

Phanerogamic Botanical Collections (S), http://data.gbif.org/datasets/resource/8113

Herbarium (UNA), http://data.gbif.org/datasets/resource/775

Vascular Plant Specimen Database of Kanagawa Prefectural Museum of Natural History, http://data.gbif.org/datasets/resource/8011

Ibaraki Nature Museum, Vascular Plants collection (1), http://data.gbif.org/datasets/resource/8030

Gunma Museum of Natural History, Vascular Plant Specimen, http://data.gbif.org/datasets/resource/8018

Botany Vascular Plant Collection, http://data.gbif.org/datasets/resource/7915

CONN GBIF data, http://data.gbif.org/datasets/resource/7857 
Plant Specimens of Kurashiki Museum of Natural History, http://data.gbif.org/datasets/resource/599

herbario, http://data.gbif.org/datasets/resource/566

MEXU/Plantas Vasculares, http://data.gbif.org/datasets/resource/780

SysTax, http://data.gbif.org/datasets/resource/1875

Herbarium of Oskarshamn (OHN), http://data.gbif.org/datasets/resource/1024

Missouri Botanical Garden, http://data.gbif.org/datasets/resource/621

Lund Botanical Museum (LD), http://data.gbif.org/datasets/resource/1028

Herbario de la Universidad de Sevilla, SEV, http://data.gbif.org/datasets/resource/283

Herbarium WU, http://data.gbif.org/datasets/resource/1496

Herbario de la Universidad de Arizona, EUA, http://data.gbif.org/datasets/resource/2479

United States National Plant Germplasm System Collection, http://data.gbif.org/datasets/resource/1429

USDA PLANTS Database, http://data.gbif.org/datasets/resource/1066

Herbario de la Universidad de Sevilla, SEV-Historico, http://data.gbif.org/datasets/resource/284

Direcci $\sqrt[n]{ }$ General de Investigaci $\sqrt{ }$ n, Desarrollo Tecnol $\sqrt{ } \geq$ gico e Innovaci $\sqrt{ } \geq$ de la Junta de Extremadura(DGIDTI): HSS,

http://data.gbif.org/datasets/resource/291

Hortus Botanicus Sollerensis Herbarium (FBonaf $\sqrt{ }$ ( ), http://data.gbif.org/datasets/resource/300

Botany (UPS), http://data.gbif.org/datasets/resource/1045

Universidad de $\mathrm{M} \sqrt{\mathrm{E}} \neg^{\circ}$ laga: MGC-Cormof, http://data.gbif.org/datasets/resource/8105

Herbarium Specimens of Museum of Nature and Human Activities, Hyogo Pref., Japan, http://data.gbif.org/datasets/resource/589

SANT herbarium vascular plants collection, http://data.gbif.org/datasets/resource/222

Phanerogamie, http://data.gbif.org/datasets/resource/1506

Botanical specimens database of Mr. Jiro Ito collection, Shizuoka Prefecture Museum of Natural History,

http://data.gbif.org/datasets/resource/1811

USU-UTC Specimen Database, http://data.gbif.org/datasets/resource/1508

Universidad de Oviedo. Departamento de Biolog $\sqrt{E} \neg \neq$ a de Organismos y Sistemas: FCO, http://data.gbif.org/datasets/resource/245

Herbario del Instituto de Ecolog $\sqrt{\text { fa, A.C., }}$ M $\sqrt{ }$ Cxico (IE-BAJIO), http://data.gbif.org/datasets/resource/1595

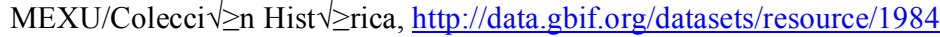

Herbario de la Universidad de Salamanca: SALA, http://data.gbif.org/datasets/resource/239

Real Jardin Botanico (Madrid), Vascular Plant Herbarium (MA), http://data.gbif.org/datasets/resource/240

Herbarium of Kitakyushu Museum of Natural History and Human History, http://data.gbif.org/datasets/resource/606

NMNH Botany Collections, http://data.gbif.org/datasets/resource/1874

UA Herbarium, http://data.gbif.org/datasets/resource/7900

Herbarium Specimens of Museum of Nature and Human Activities, Hyogo Prefecture, Japan, http://data.gbif.org/datasets/resource/1958

Herbarium Berolinense, http://data.gbif.org/datasets/resource/1095

EURISCO, The European Genetic Resources Search Catalogue, http://data.gbif.org/datasets/resource/1905

Phanerogamic Botanical Collections (S), http://data.gbif.org/datasets/resource/8113

Vascular Plants Collection of Sagamihara City Museum, http://data.gbif.org/datasets/resource/1809

RBGE Herbarium (E), http://data.gbif.org/datasets/resource/8402

Universidad de Oviedo. Departamento de Biolog $\sqrt{E} \rightarrow \neq$ a de Organismos y Sistemas: FCO-Briof, http://data.gbif.org/datasets/resource/8404

Herbarium of The New York Botanical Garden, http://data.gbif.org/datasets/resource/8967

Fundaci $\sqrt{E} \neg \geq \mathrm{n}$ Biodiversidad, Real Jard $\sqrt{\mathrm{E}} \neg \neq \mathrm{n}$ Bot $\sqrt{\mathrm{E}} \neg^{\circ}$ nico (CSIC): Anthos. Sistema de Informaci $\sqrt{\mathrm{E}} \neg \geq \mathrm{n}$ de las plantas de Espa $\sqrt{\mathrm{E}} \neg \pm \mathrm{a}$,

http://data.gbif.org/datasets/resource/9090

Consortium of California Herbaria, http://data.gbif.org/datasets/resource/9153

Royal Botanic Gardens, Kew, http://data.gbif.org/datasets/resource/629

Gunma Museum of Natural History, Vascular Plant Specimen, http://data.gbif.org/datasets/resource/8018

Herbario XAL del Instituto de Ecolog $\sqrt{\mathrm{E}} \neg \neq \mathrm{a}, \mathrm{A} . \mathrm{C} . \mathrm{M} \sqrt{\mathrm{E}} \neg$ Cxico (IE-XAL), http://data.gbif.org/datasets/resource/10980

Herbarium de Geo. B. Hinton, M $\sqrt{ }$ Cxico, http://data.gbif.org/datasets/resource/1594

Un 
herbario, http://data.gbif.org/datasets/resource/566

Database Schema for UC Davis [Herbarium Labels], http://data.gbif.org/datasets/resource/734

California State University, Chico, http://data.gbif.org/datasets/resource/737

Herbarium (UNA), http://data.gbif.org/datasets/resource/775

MEXU/Plantas Vasculares, http://data.gbif.org/datasets/resource/780

SysTax, http://data.gbif.org/datasets/resource/1875

Utah Valley State College Herbarium, http://data.gbif.org/datasets/resource/1013

Missouri Botanical Garden, http://data.gbif.org/datasets/resource/621

Nationaal Herbarium Nederland, http://data.gbif.org/datasets/resource/1211

Bishop Museum Natural History Specimen Data, http://data.gbif.org/datasets/resource/54

USDA PLANTS Database, http://data.gbif.org/datasets/resource/1066

Botany (UPS), http://data.gbif.org/datasets/resource/1045

Herbarium Specimens of Museum of Nature and Human Activities, Hyogo Pref., Japan, http://data.gbif.org/datasets/resource/589

University and Jepson Herbaria DiGIR provider, http://data.gbif.org/datasets/resource/1413

Botanical specimens database of Mr. Jiro Ito collection, Shizuoka Prefecture Museum of Natural History,

http://data.gbif.org/datasets/resource/1811

USU-UTC Specimen Database, http://data.gbif.org/datasets/resource/1508

Fairchild Tropical Botanic Garden Virtual Herbarium Darwin Core format, http://data.gbif.org/datasets/resource/202

Herbario del Instituto de Ecolog $\sqrt{ } \neq$ a, A.C., M $\sqrt{ }$ Cxico (IE-BAJIO), http://data.gbif.org/datasets/resource/1595

Plant Specimens of Kurashiki Museum of Natural History, http://data.gbif.org/datasets/resource/599

Herbarium Specimens of Tokushima Prefectural Museum, Japan, http://data.gbif.org/datasets/resource/600

NSW herbarium collection, http://data.gbif.org/datasets/resource/968

Phanerogamie, http://data.gbif.org/datasets/resource/1506

NMNH Botany Collections, http://data.gbif.org/datasets/resource/1874

Oklahoma Vascular Plants Database Provider, http://data.gbif.org/datasets/resource/2558

MISS DC 01MAR2006, http://data.gbif.org/datasets/resource/7895

New Mexico Biodiversity Collections Consortium database, http///data gbiforg/datasets/resource/7856

UA Herbarium, http://data.gbif.org/datasets/resource/7900

Botany Vascular Plant Collection, http://data.gbif.org/datasets/resource/7915

Herbarium Specimens of Museum of Nature and Human Activities, Hyogo Prefecture, Japan, http://data.gbif.org/datasets/resource/1958

Herbarium, http://data.gbif.org/datasets/resource/7984

Phanerogamic Botanical Collections (S), http://data.gbif.org/datasets/resource/8113

Peabody Paleobotany DiGIR Service, http://data.gbif.org/datasets/resource/8141

Peabody Paleoportal DiGIR Service (PB), http://data.gbif.org/datasets/resource/8176

Vascular Plants Collection of Sagamihara City Museum, http://data.gbif.org/datasets/resource/1809

Real Jardin Botanico (Madrid), Vascular Plant Herbarium (MA), http://data.gbif.org/datasets/resource/240

Herbarium of The New York Botanical Garden, http://data.gbif.org/datasets/resource/8967

Consortium of California Herbaria, http://data.gbif.org/datasets/resource/9153

EURISCO, The European Genetic Resources Search Catalogue, http://data.gbif.org/datasets/resource/1905

Royal Botanic Gardens, Kew, http://data.gbif.org/datasets/resource/629

Gunma Museum of Natural History, Vascular Plant Specimen, http://data.gbif.org/datasets/resource/8018

Herbario IEB del Instituto de Ecolog $\sqrt{E} \neg \neq$ a, A.C., M $\sqrt{E} \neg$ Cxico (IE-BAJ $\sqrt{E} \neg \neq O$ ), http://data.gbif.org/datasets/resource/11106

New Zealand National Plant Herbarium (CHR), http://data.gbif.org/datasets/resource/474

Australian National Herbarium (CANB), http://data.gbif.org/datasets/resource/47

CSU Herbarium, http://data.gbif.org/datasets/resource/7892

Herbarium de Geo. B. Hinton, MV Cxico, http://data.gbif.org/datasets/resource/1594

Arizona State University Vascular Plant Herbarium, http://data.gbif.org/datasets/resource/676 


\begin{tabular}{|c|c|c|}
\hline Oenothera triloba & 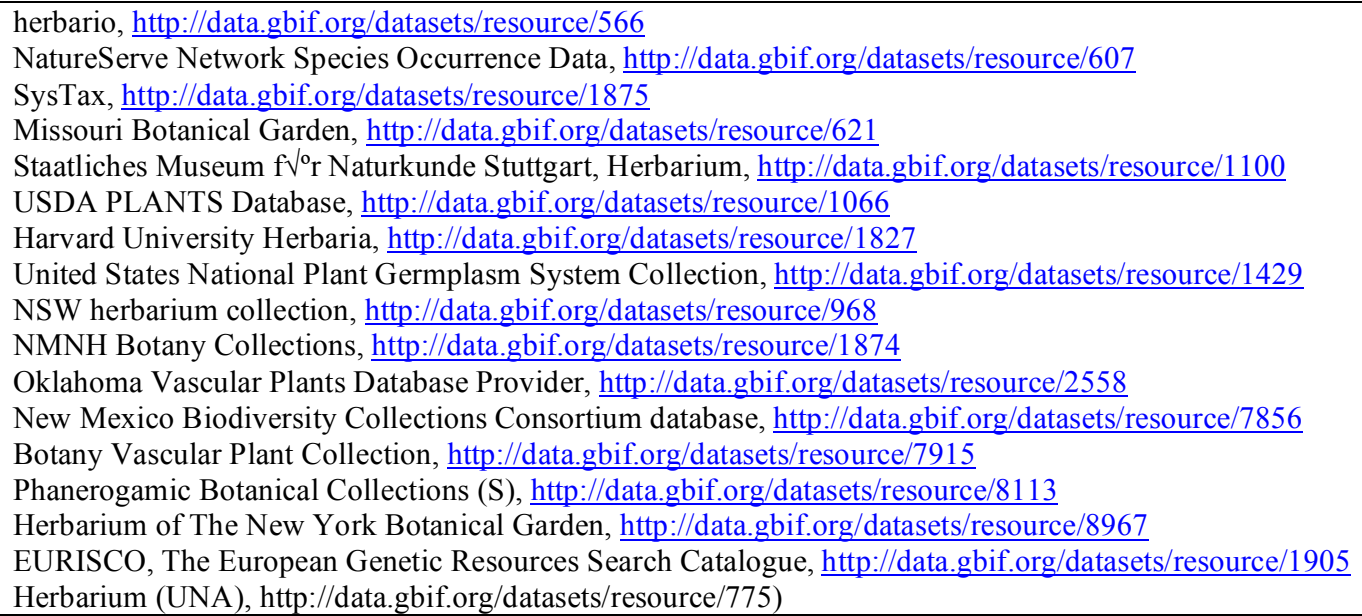 & $209(479)$ \\
\hline Veronica birleyi & $\begin{array}{l}\text { Nationaal Herbarium Nederland - Leiden Branch, http://data.gbif.org/datasets/resource/1085 } \\
\text { New Zealand National Plant Herbarium (CHR), http://data.gbif.org/datasets/resource/474 }\end{array}$ & $16(18)$ \\
\hline Veronica cheesemanii & New Zealand National Plant Herbarium (CHR), http://data.gbif.org/datasets/resource/474 & $34(41)$ \\
\hline Veronica ciliolata & $\begin{array}{l}\text { NSW herbarium collection, http://data.gbif.org/datasets/resource/968 } \\
\text { New Zealand National Plant Herbarium (CHR), http://data.gbif.org/datasets/resource/474 } \\
\text { RBGE Living Collections, http://data.gbif.org/datasets/resource/9167 } \\
\text { Royal Botanic Gardens, Kew, http://data.gbif.org/datasets/resource/629 } \\
\text { New Zealand Biodiversity Recording Network, http://data.gbif.org/datasets/resource/7910 } \\
\text { Australian National Herbarium (CANB), http://data.gbif.org/datasets/resource/47 }\end{array}$ & $39(54)$ \\
\hline Veronica densifolia & $\begin{array}{l}\text { NSW herbarium collection, http://data.gbif.org/datasets/resource/968 } \\
\text { New Zealand National Plant Herbarium (CHR), http://data.gbif.org/datasets/resource/474 } \\
\text { SysTax, http://data.gbif.org/datasets/resource/1875 } \\
\text { RBGE Living Collections, http://data.gbif.org/datasets/resource/9167 } \\
\text { Australian National Herbarium (CANB), http://data.gbif.org/datasets/resource/47 }\end{array}$ & $58(85)$ \\
\hline $\begin{array}{l}\text { Veronica } \\
\text { planopetiolata }\end{array}$ & New Zealand National Plant Herbarium (CHR), http://data.gbif.org/datasets/resource/474 & $4(5)$ \\
\hline
\end{tabular}


APPENDIX

NSW herbarium collection, http://data.gbif.org/datasets/resource/968

New Zealand National Vegetation Survey Databank, http://data.gbif.org/datasets/resource/473

New Zealand National Plant Herbarium (CHR), http://data.gbif.org/datasets/resource/474

RBGE Living Collections, http://data.gbif.org/datasets/resource/9167

EURISCO, The European Genetic Resources Search Catalogue, http://data.gbif.org/datasets/resource/1905

Royal Botanic Gardens, Kew, http://data.gbif.org/datasets/resource/629

NSW herbarium collection, http://data.gbif.org/datasets/resource/968

New Zealand National Plant Herbarium (CHR), http//data gbif.org/datasets/resource/474

RBGE Living Collections, http://data.gbif.org/datasets/resource/9167

Veronica thomsonii $\quad$ Royal Botanic Gardens, Kew, http://data.gbif.org/datasets/resource/629

SysTax, http://data.gbif.org/datasets/resource/1875

New Zealand National Plant Herbarium (CHR), http///data.gbif.org/datasets/resource/474

Veronica spathulata

RBGE Herbarium (E), http://data.gbif.org/datasets/resource/8402 